\title{
HEREDITY AND ENVIRONMENT
}

EDWIN G. CONKLIN 

Cātherine C. Atubbard 1915. 



\section{Ãnrthumegtern Ilniueraity}

\section{THE N. W. HARRIS LECTURES FOR 1914}






were founded in 1906 through the generosity of Mr. Norman Wait Harris of Chicago, and are to be given annually. The purpose of the lecture foundation is, as expressed by the donor, "to stimulate scientific research of the highest type and to bring the results of such research before the students and friends of Northwestern University, and through them to the world. By the term 'scientific research' is meant scholarly investigation into any department of human thought or effort without limitation to research in the socalled natural sciences, but with a desire that such investigation should be extended to cover the whole field of human knowledge."



1907 Personalism. Borden P. Bowne

1908 University Administration. Charles W. Eliot

1910 The Age of Mammals. Henry F. Osborn

1911 Democracy and Poetry. Francis B. Gummere

1912 The Milk Question. Milton J. Rosenau

1913 The Constitution of Matter. Joseph S. Ames 


\section{HEREDITY AND ENVIRONMENT}

IN THE

\section{DEVELOPMENT OF MEN}

BY

\section{EDWIN GRANT CONKLIN}

PROFESSOR OF BIOLOGY IN

PRINCETON UNIVERSITY



PRINCETON UNIVERSITY PRESS

PRINCETON

LONDON : HUMPHREY MILFORD

OXFORD UNIVERSITY PRESS 
Copyright, 1915, by

Princeton University Press

Published February, 1915

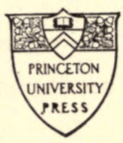




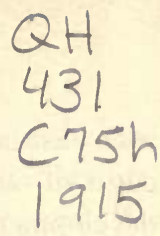

\section{PREFACE}

The origin of species was probably the greatest biological problem of the past century; the origin of individuals is the greatest biological subject of the present one. The many inconclusive attempts to determine just how species arose led naturally to a renewed study of the processes by which individuals come into existence, for it seems probable that the principles and causes of the development of individuals will be found to apply also to the evolution of races. As the doctrine of evolution wrought great change in prevalent beliefs regarding the origin and past history of man, so present studies of development are changing opinions as to the personality of man and the possibilities of improving the race. The doctrine of evolution was largely of theoretical significance, the phenomena of development are of the greatest practical importance; indeed there is probably no other subject of 


\section{PREFACE}

such vast importance to mankind as the knowledge of and the control over heredity and development. Within recent years the experimental study of heredity and development has led to a new epoch in our knowledge of these subjects, and it does not seem unreasonable to suppose that in time it will produce a better breed of men.

The lectures which compose this volume were given at Northwestern University in February, 1914, on the Norman W. Harris Foundation and were afterward repeated at Princeton University. I gladly take this opportunity of expressing to the faculties, students and friends of both institutions my deep appreciation of their interest and courtesy. In attempting to present to a general audience the results of recent studies on heredity and development, with special reference to their application to man, the author has had to choose between simplicity and sufficiency of statement, between apparent dogmatism and scientific caution, between a popular and a scientific presentation. These are hard alternatives, but the first duty of a lecturer is to address his audience and to make 
his subject plain and interesting, if he can, rather than to talk to the scientific gallery over the heads of the audience. In preparing the lectures for publication it has not been possible to avoid the technical treatment of certain subjects, but in the main the lectures are still addressed to the audience rather than to the scientific gallery. Unfortunately biology is still a strange subject to many intelligent people and its terminology is rather terrifying to the uninitiated; but it is hoped that the glossary at the end of the volume may rob these unfamiliar terms of many of their terrors.

I take this opportunity of thanking Dr. W. E. Castle and Dr. J. H. McGregor for the use of photographs which are reproduced in Figures 81, 82 and 99; and I wish especially to thank my assistant, Marguerite Ruddiman, for her aid in preparing figures and manuscript for publication.

Princeton, December, 1914 



\section{CON'TENTS}

CHAPTER I. FACTS AND FACTORS OF DEVELOPMENT

INTRODUCTION

A. PHENOMENA OF DEVELOPMENT

I. Development of the Body

1. The Germ Cells

2. Fertilization

3. Cleavage

4. Embryogeny

5. Organogeny

6. Oviparity and Viviparity

7. Development of Functions

II. Development of the Mind

1. Sensitivity

2. Tropisms, Reflexes, Instincts

3. Memory

4. Intellect, Reason

5. Will

6. Consciousness

B. FACTORS OF DEVELOPMENT

1. Preformation

2. Epigenesis

3. Preformation and Epigenesis

4. Heredity and Environment ix. 


\section{CONTENTS}

Othèr Mendelian Ratios

2. Results of Crossing Individuals with more than one pair of contrasting characters

Dihybrids and Trihybrids

3. Inheritance Formulæ

4. Presence and Absence Hypothesis

5. Summary of Mendelian Principles

a. The Principle of Unit Characters

b. The Principle of Dominance

c. The Principle of Segregation

II. Modifications and Extensions of Mendelian Principles

1. The Principle of Unit Characters and Inheritance Factors

Inheritance Factors and Germinal Units

2. Modifications of the Principle of Dominance

Sex and Sex Limited Inheritance

Sex Linked Inheritance

3. The Principle of Segregation

"Blending" Inheritance

III. Mendelian Inheritance in Man

CHAPTER IV. INFLUENCE OF ENVIRONMENT

A. RELATIVE IMPORTANCE OF HEREDITY AND ENVIRONMENT

1. Former Emphasis on Environment

2. Present Emphasis on Heredity

3. Both Indispensable to Development 


\section{CONTENTS}

B. EXPERIMENTAL MODIFICATIONS OF DEVELOPMENT

I. Developmental Stimuli

1. Physical Stimuli

2. Chemical Stimuli

II. Developmental Responses

Dependent upon (a) Nature of Organism, (b) Nature of Stimulus, (c) Stage of Development

1. Modifications of Germ Cells before Fertilization

2. During Fertilization

3. After Fertilization

C. FUNCTIONAL ACTIVITY AS A FACTOR OF DEVELOPMENT

D. INHERITANCE OR NON-INHERITANCE OF ACQUIRED CHARACTERS

E. APPLICATIONS TO HUMAN DEVELOPMENT: EUTHENICS

CHAPTER V. CONTROL OF HEREDITY: EUGENICS

A. DOMESTICATED ANIMALS AND CULTIVATED PLANTS

I. Influence of Environment in Producing New Races

II. Artificial Selection

1. The Methods of Breeders

2. How has Selection acted?

III. Methods of Modern Genetics

1. Mendelian Association and Dissociation of Characters

2. Origin of Mutations xiii 
CONTENTS

\section{B. CONTROL OF HUMAN HEREDITY}

I. Past Evolution of Man

II. Can Human Evolution be Controlled?

1. Selective Breeding the only Method of Improving the Race.

2. No Improvement in Human Heredity within Historic Times

3. Why the Race has not Improved

III. Eugenics

1. Possible and Impossible Ideals

2. Negative Eugenical Measures

3. Positive Eugenical Measures

4. Contributory Eugenical Measures

5. The Declining Birthrate

CHAPTER VI. GENETICS AND ETHICS

I. The Voluntaristic Conception of NaTURE ANd of HUMAN RESPONSIBILITY

II. The Mechanistic Conception of Nature and of Personality

1. The Determinism of Heredity

2. The Determinism of Environment

III. Determinism and Responsibility

1. Determinism not Fatalism

2. Control of Phenomena and of Self

3. Birth and Growth of Freedom

4. Responsibility and Will

5. Our Unused Talents

IV. The Individual and the Race

1. The Conflict between the Freedom of the Individual and the Good of Society

2. Perpetuation and Improvement of the Race the Highest Ethical Obligation References, Glossary, Index xiv 


\section{CHAPTER I}

\section{FACTS AND FACTORS OF DEVELOPMENT}


K 


\section{CHAP'TER I}

FACTS AND FACTORS OF DEVELOPMENT

\section{INTRODUCTION}

One of the greatest results of the doctrine of organic evolution has been the determination of man's place in nature. For many centuries it has been known that in bodily structure man is an animal; that he is born, nourished and developed, that he matures, reproduces and dies just as does the humblest animal or plant. For centuries it has been known that man belongs to that group of animals which have backbones, the vertebrates; to that class which have hair and suckle their young, the mammals, and to that order which have grasping hands, flat nails, and thoracic mammæ, the primates, a group which includes also the monkeys and apes. But as long as it was supposed that every species was distinct in its origin from every other one, and that each arose by a 
special divine fiat, it was possible to maintain that man was absolutely distinct from the rest of the animal world and that he had no kinship to the beasts, though undoubtedly he was made in their bodily image. But with the establishment of the doctrine of organic evolution this resemblance between man and the lower animals has come to have a new significance. The almost universal acceptance of this doctrine by scientific men, the many undoubted resemblances between man and the lower animals, and the discovery of the remains of lower types of man, real "missing links," have inevitably led to the conclusion that man also is a product of evolution, that he is a part of the great world of living things and not a being who stands apart in solitary grandeur in some isolated sphere.

But wholly aside from the doctrine of evolution, the fact that essential and fundamental resemblances exist among all kinds of organisms can not fail to impress thoughtful men. Life processès are everywhere the same in principle, though varying greatly in detail. All the general laws of life which apply to animals and plants apply also to man. This 
is no mere logical inference from the doctrine of evolution, but a fact which has been established by countless observations and experiments. The essential oneness of all life gives a direct human interest to all living things. If "the proper study of mankind is man," the proper study of man is the lower organisms in which life processes are reduced to their simplest terms, and where alone they may be subjected to conditions of rigid experimentation. Upon this fundamental likeness in the life processes of man and other animals are based the wonderful advances in experimental medicine, which may be counted among the greatest of all the achievements of science.

The experimental study of heredity, development and evolution in forms of life below man must certainly increase our knowledge of and our control over these processes in the human race. If human heredity, development and evolution may be controlled to even a slight extent, we may expect that sooner or later the human race will be changed for the better. At least no other scheme of social betterment and 
race improvement can compare for thoroughness, permanence of effect, and certainty of results, with that which attempts to change the natures of men and to establish in the blood the qualities which are desired. We hear much nowadays about man's control over nature, though in no single instance has man ever changed any law or principle of nature. What man can do is to put himself into such relations to natural phenomena that he may profit by them, and all that can be done toward the improvement of the human race is to apply consciously to man those great principles of development and evolution which have been operating unknown to man through all the ages.

\section{A. PHENOMENA OF DEVELOPMENT}

One of the greatest and most far-reaching themes which have ever occupied the minds of men is the problem of development. Whether it be the development of an animal from an egg, of a race or species from a pre-existing one, or of the body, mind and institutions of man, this problem is everywhere much the 
same in fundamental principles, and knowledge gained in one of these fields must be of value in each of the others. Ontogeny and phylogeny are not wholly distinct phenomena, but are only two aspects of the one general process of organic development. The evolution of races and of species is sufficiently rare and unfamiliar to attract much attention and serious thought; while the development of an individual is a phenomenon of such universal occurrence that it is taken as a matter of course by most people, something so evident that it seems to require no explanation; but familiarity with the fact of development does not remove the mystery which lies back of it, though it may make plain many of the processes concerned. The development of a human being, of a personality, from a germ cell is the climax of all wonders, greater even than that involved in the evolution of a species or in the making of a world.

The fact of development is everywhere apparent; its principal steps or stages are known for thousands of animals and plants; even the precise manner of development and its factors 
or causes are being successfully explored. Let us briefly review some of the principal events in the development of animals, and particularly of man, and then consider some of the chief factors and processes of development. Most of our knowledge in this field is based upon a study of the development of animals below man, but enough is now known of human development to show that in all essential respects it resembles that of other animals, and that the problems of heredity and differentiation are fundamentally the same in man as in other animals.

\section{Development of the Body}

The entire individual structure and functions, body and mind develops as a single indivisible unity, but for the sake of clarity it is desirable to deal with one aspect of the individual at a time. For this reason we shall consider first the development of the body, and then the development of the mind.

1. The Germ Cells.-In practically all animals and plants individual development begins with the fertilization of a female sex cell, or 
egg, by a male sex cell, or spermatozoon. The epigram of Harvey, "Omne vivum ex ovo," has found abundant confirmation in all later studies. Both egg and spermatozoon are alive and manifest all the general properties of living things. How little this fact is appreciated by the public is shown by the repeated announcements by the newspapers that "Professor So-and-so has created life because he has made an egg develop without fertilization." An egg or a spermatozoon is as much alive as is any other cell; as characteristically alive as is the adult animal into which it develops.

It is difficult to define life, as it is also to define matter, energy, electricity, or any other fundamental phenomenon, but it is possible to describe in general terms what living things are and what they do. Every living thing whatever, from the smallest and simplest micro-organism to the largest and most complex animal, from the microscopic egg or spermatozoon to the adult man, manifests the following distinctive properties:

(a) It contains protoplasm, "the material basis of life," which is composed of the most 
complex substances known to chemistry. Protoplasm is not a homogeneous substance, but it always exists in the form of cells, which are minute masses of protoplasm composed of many distinct parts, the most important of these being the nucleus and the cytoplasm (Fig. 1). Protoplasm is therefore organized, that is, composed of many parts all of which are integrated into a single system, the cell. Higher animals and plants are composed of multitudes of cells, differing more or less from one another, which are bound together and integrated into a single organism. Living cells and organisms are not static structures which are fixed and stable in character, but they are systems which are undergoing continual change. 'They are like the river, or the whirlpool, or the flame, which are never at two consecutive moments composed of the same particles but which nevertheless maintain a constant general appearance; in short they are complex systems in dynamic equilibrium.

The principal physiological processes by which all living things maintain this equilibrium are: 


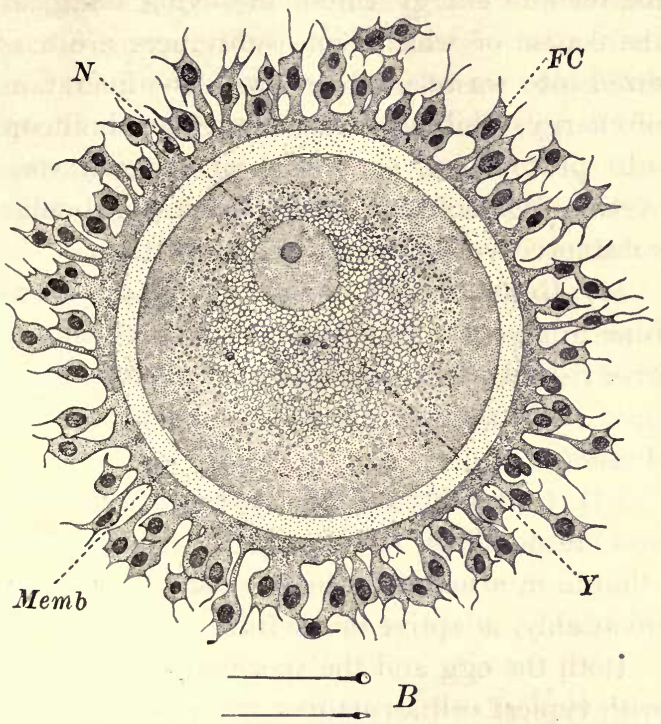

Fig. 1. A nearly ripe human ovum in the living condition. The ovum is surrounded by a series of follicle cells $(F C)$ inside of which is the clear membrane (Memb.) and within this is the ovum proper containing yolk granules $(Y)$ and a nucleus $(N)$ embedded in a clear mass of protoplasm. Magnified 500 diameters (x 500). (From O. Hertwig.) $B$, two human spermatozoa drawn to about the same scale of magnification. (After G. Retzius.) 
(b) Metabolism, or the transformation of matter and energy within the living thing, in the course of which some substances are oxidized into waste products, with the liberation of energy, while other substances are built up into protoplasm, each part of the cell converting food substances into its own particular substance by the process of assimilation.

(c) Reproduction, or the capacity of organisms to give rise to new organisms, of cells to give rise to other cells, and of parts of cells to give rise to similar parts by the process of division.

(d) Irritability, or the capacity of receiving and responding to impinging energies, or stimuli, in a manner which is usually, but not invariably, adaptive or useful.

Both the egg and the sperm are living cells with typical cell structures and functions, but with none of the parts of the mature organism into which they may develop. But although they do not contain any of the differentiated structures and functions of the developed organism, they differ from other cells in that they are capable under suitable conditions of 
producing these structures and functions by the process of development or differentiation, in the course of which the general structures and functions of the germ cells are converted into the specific structures and functions of the mature animal or plant.

In both plants and animals the sex cells are fundamentally alike, though they differ greatly in appearance. The female sex cells of flowering plants are called ovules, the male cells pollen. The corresponding cells of animals are known as ova and spermatozoa. Collectively all kinds of sex cells are called gametes, and the individual formed by the union of a male and female gamete is known as a zygote, while the cell formed by the union of egg and sperm is frequently called the oosperm.

The egg cell of animals is usually spherical in form and contains more or less food substance in the form of yolk; it varies greatly in size, depending chiefly upon the quantity of yolk, from the great egg of a bird, in which the yolk or egg proper may be hundreds of millimeters in diameter, to the miscroscopic 
eggs of oysters and worms, which may be no more than a few thousandths of a millimeter in diameter. The human ovum (Fig. 1) is microscopic in size (about $0.2 \mathrm{~mm}$. in diameter) but it is not smaller than is found in many other animals. It has all the characteristic parts of any egg cell, and can not be distinguished microscopically from the eggs of several other mammals, yet there is no doubt that the ova of each species differ from those of every other species, and later we shall see reasons for concluding that the ova produced by each individual are different from those produced by any other individual.

The sperm, or male gamete, is among the smallest of all cells and is usually many thou-



$B$

Fig. 2. Two Human Spermatozoa. $A$, showing the surface of the flattened head; $B$, its edge; $H$, head; $M$, middle-piece; $T$, tail. (After G. Retzius.) 
sands of times smaller than the egg. In most animals, and in all vertebrates, it is an elongated, thread-like cell with an enlarged head which contains the nucleus, a smaller middle-piece, and a very long and slender tail or flagellum, by the lashing of which the spermatozoon swims forward in the jerking fashion characteristic of many monads or flagellated protozoa. In different species of animals the spermatozoa often differ in size and appearance, and there is every reason to believe that the spermatozoa of each species are peculiar in certain respects even though we may not be able to distinguish any structural differences under the microscope. The human spermatozoa (Fig. 2) closely resemble those of other primates but are still slightly different, and the conclusion is logically inevitable, as we shall see later, that the spermatozoa as well as the ova of each individual differ slightly from those of every other individual.

2. Fertilization.-If a spermatozoon in its swimming comes into contact with a ripe but unfertilized egg, the head and middle-piece of the sperm sink into the egg while the tail is 
usually broken off and left outside. The nucleus in the head of the sperm then begins to absorb material from the egg and to grow in size and at the same time a minute granule, the centrosome, appears, either from the middle-piece or from the head of the sperm, and radiating lines run out from the centrosome into the substance of the egg. The sperm nucleus and centrosome then approach the egg nucleus and ultimately the two nuclei come to lie side by side (Figs. 4-7). Usually when one spermatozoon has entered an egg all others are barred from entering, probably by some change in the chemical substances given out by the egg.

This union of a single spermatozoon with an egg is known as fertilization. Whereas egg cells are usually, but not invariably, incapable of development without fertilization, there begins, immediately after fertilization, a long series of transformations and differentiations of the fertilized egg which leads to the development of a complex animal-of a person. In the fusion of the egg and sperm a new individual, the oosperm, comes into being. The 



Figs. 4-5. Two Stages in the Entrance of the Spermatozoon into the Egg of Nereis. Some of the protoplasm of the egg has gathered at the point of entrance to form the entrance cone $(E C)$ which, together with the sperm head, moves into the interior of the egg in later stages. The black spheres represent yolk. (From F. R. Lillie.)

Fig. 3. Entire Spermatozoon of the Annelid Nereis, showing perforatorium $(P)$; head $(H)$; middle-piece $(M)$, and tail $(T)$. (From F, R. Lillie.) 
oosperm, formed by the union of the two sex cells, is really a double cell, since parts of the egg and sperm never lose their identity, and the individual which develops from this oosperm is a double being; even in the adult man this double nature, caused by the union of egg and sperm, is never lost.

In by far the larger number of animal species the oosperm, either just before or shortly after fertilization, is set free to begin its own individual existence, and in such cases it is perfectly clear that the fertilization of the egg marks the beginning of the new individual. But in practically every class of animals there are some species in which the fertilized egg is retained within the body of the mother for a varying period during which development is proceeding. In such cases it is not quite so evident that the new individual comes into being with the fertilization of the egg; rather the moment of birth or the separation from the mother is generally looked upon as the beginning of the individual existence. And yet in all cases the egg or embryo is always distinguishable from the body of the mother and 
there is no protoplasmic connection between the two. In mammals generally, including also the human species, not a strand of protoplasm, not a nerve fiber, not a blood vessel passes over from the mother to the embryo; the latter is from the moment of fertilization of the egg a distinct individual with particular individual characteristics, and this is just as true of viviparous animals in which the egg undergoes a part of its development within the body of the mother as it is of oviparous forms in which the eggs are laid before development begins.

The fertilized egg of a star-fish, or frog, or man is not a different individual from the adults of these forms, rather it is a star-fish, a frog, or a human being in the one-celled stage, and thereafter this new being maintains its own individuality. This fertilized egg fuses with no other cells, it takes into itself no living substance, but manufactures its own protoplasm from food substances; it receives food and oxygen from without and it gives out carbonic acid and other waste products; it is sensitive to certain alterations in the environ- 

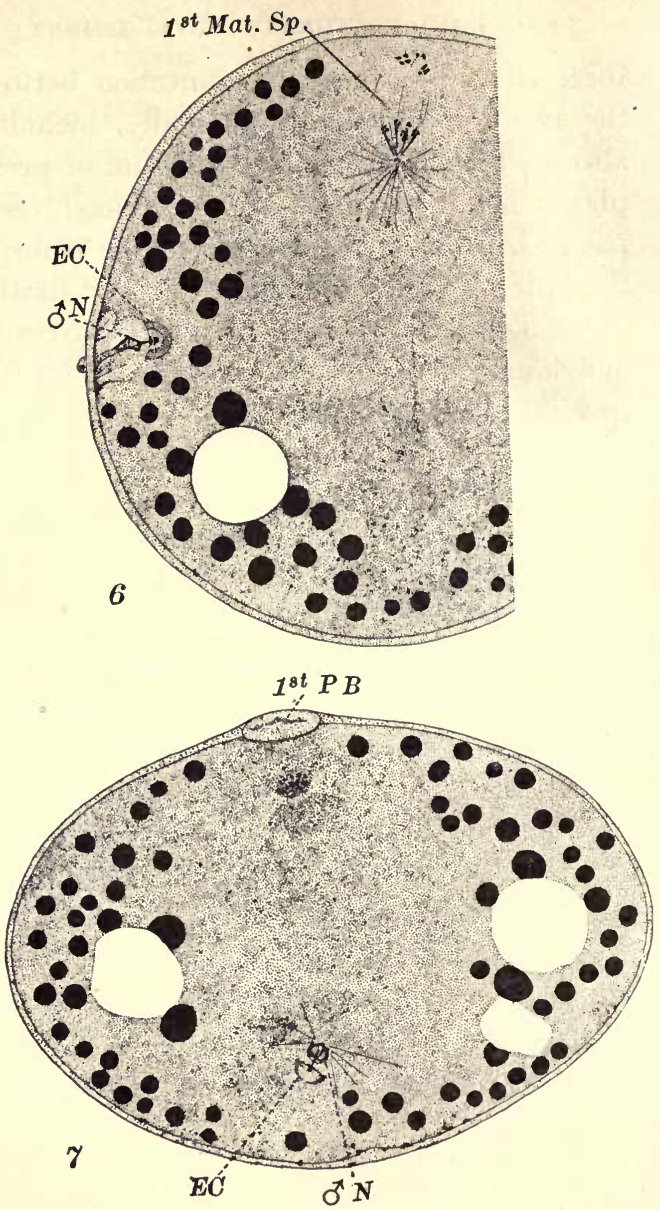

For description see opposite page. 



9

Figs. 6-9. Successive Stages in the Maturation and FertiLization of The Egg of Nereis, less highly magnified than Figs. 6 and 7, showing the progress of the entrance cone $(E C)$ and sperm nucleus $(\delta N)$ into the egg. Fig. 6 shows the first maturation spindle of the egg (1st Mat. Sp.); Fig. 7, the first polar body (1st PB) formed by this division; Fig. 8, the second maturation spindle ( $2 d$ Mat. $S p$.) and the sperm nucleus and spindle $\left(\sigma^{N} N\right)$; Fig. 9, the division of the male and female nuclei in the first cleavage spindle (1st Cl. Sp.). (From F. R. Lillie.) 
ment such as thermal, chemical and electrical changes - it is, in short, a distinct living thing, an individuality. Under proper environmental conditions this fertilized egg cell develops, step by step, without the addition of anything from the outside except food, water, oxygen, and such other raw materials as are necessary to the life of any adult animal, into the immensely complex body of a star-fish, a frog, or a man. At the same time, from the relatively simple reactions and activities of the fertilized egg there develop, step by step, without the addition of anything from without except raw materials and environmental stimuli, the multifarious activities, reactions, instincts, habits, and intelligence of the mature animal.

Is not this miracle of development more wonderful than any possible miracle of creation? And yet as one watches this marvellous process by which the fertilized egg grows into the embryo, and this into the adult, each step appears relatively simple, each perceptible change is minute; but the changes are innumerable and unceasing and in the end they 
accomplish this miracle of transforming the fertilized egg cell into the fish, or frog, or man - a thing which would be incredible were it not for the fact that it has been seen by hundreds of observers and can be verified at any time by those who will take the trouble to study the process for themselves.


Fig. 10. Four Stages in the Cleavage of the Egg of the SHeEP; $p b$, polar bodies. (After Assheton.) 
3. Cleavage.-When the two germ nuclei, egg nucleus and sperm nucleus, have come into contact after the fertilization of the egg they divide by a complicated process known as mitosis, or indirect nuclear division (Fig. 9). The centrosome, which usually accompanies the sperm nucleus in its passage through the egg, divides and forms a spindle-shaped figure with astral radiations at its two poles (Figs. $7,8)$. The chromatin, or stainable substance of the nucleus, takes the form of threads, the chromosomes (Fig. 9), of which there is a constant number for each species of animal and plant. Each chromosome then splits lengthwise, its two halves moving to opposite ends of the spindle, in which position the daughter chromosomes fuse together to form the daughter nuclei. In this way the chromatin of the egg and sperm nuclei is exactly halved.

After the germ nuclei have divided in this manner the entire egg divides by a process of constriction into two cells (Figs. 10, 11). This is the beginning of a long series of cell divisions, each of them essentially like the first, by which the egg is subdivided successively into 




D



G



$J$





E


K



C



E



I



L

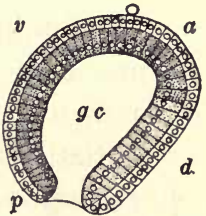

Fig. 11. Successive Stages in the Cleavage and GastrulaTion of Amphioxus. $A$, one cell; $B$, two cells; $C$ and $D$, four cells; $E$, eight cells; $F$, sixteen cells; $G$, blastula stage of about ninety-six cells; $H$, section through the same showing the cleavage cavity; $I$, blastula seen from the left side showing three zones of cells, viz., an upper clear zone of ectoderm, a middle (faintly shaded) zone of mesoderm and a lower (deeply shaded) zone of endoderm cells; $J$, section through the same showing these three types of cells; $K$ and $L$, successive stages in the infolding of the endoderm; cells indicated as in the preceding figure. In all figures except $D$ the polar body is shown at the upper pole. Figs. $A-H$ after Hatschek. $a$, anterior; $p$, posterior; $v$, ventral; $d$, dorsal; $b c$, blastocœl; $g c$, gastrocœl. 
a constantly increasing number of cells. During the earlier divisions there is little or no increase in the volume of the egg, consequently successive generations of cells continually grow smaller (Figs. 10, 11). This process is known as the cleavage of the egg, and by it the egg is not only split up into a considerable number of small cells, but a much more important result is that the different kinds of protoplasm in the egg become isolated in different cleavage cells, so that these substances can no longer freely commingle. The cleavage cells, in short, come to contain different kinds of substance, and thus to differ from one another. The differentiations of the cleavage cells appear much earlier in some forms than in others, but in all cases such differentiations appear during cleavage.

4. Embryogeny.-From this stage onward the course of development differs in different classes of animals to such an extent that it is difficult to formulate any general description which will apply to all of them. Usually the many cleavage cells form a hollow sphere, the blastula (Fig. 11, $\boldsymbol{H}$ ), and this in turn be- 
comes a gastrula (Fig. 11, K, L), in which at first two, and later three, groups or layers of cells may be recognized; the outer layer, which is formed from cells nearest the upper pole of the egg, is the ectoderm; the inner layer, or endoderm, is formed from cells nearest the lower pole; a middle layer, or group of cells, the mesoderm, is formed from cleavage cells which in vertebrates lie between the upper and lower poles.


Fig. 12, $A$ and $B$. Two Later Stages in the Development of Amphioxus, showing the elongation of the embryo in the antero-posterior axis $(a p)$, and formation of the somites $(80 \mathrm{~m})$; neural groove $(\mathrm{ng})$ and neural tube $(n t)$; ect, ectoderm; mes, mesoderm; ac, alimentary canal. (After Hatschek.) 
5. Organogeny.-By further differentiation of the cells of these layers and by dissimilar growth and folding of the layers themselves the various organs of the embryo begin to appear. From the ectoderm is formed the outer layer of the skin and the nervous system; from the endoderm arise the lining of the alimentary canal and its outgrowths; from the mesoderm come, in whole or in part, the skeletal, muscular, vascular, excretory, and reproductive systems. In vertebrates the nervous system appears as a plate of rather large ectoderm cells (Fig. $13 n p$ ); this plate rolls up at its sides to form a groove (Fig. $13 C$ ) and then a tube (Fig. $13 D$ ); and by enlargement of certain portions of this tube and by foldings and thickenings of its walls the brain and spinal cord are formed (Fig. 15, $C$, $D)$. The retina or sensory portion of the eye is formed as an outgrowth from the fore part of the brain (Fig. 15, D) ; the sensory portion of the ear comes from a cup-shaped depression of the superficial ectoderm which covers the hinder portion of the head (Fig. 15, $\boldsymbol{E}$ and $F^{\prime}$ ). The back-bone begins to appear as a deli- 
cate cellular rod (Fig. 13, ch), which then in higher vertebrates becomes surrounded successively by a fibrous, a cartilaginous, and a bony sheath. And so one might go on with a description of all the organs of the body, each of which begins as a relatively simple group or layer of cells, which gradually become more complicated by a process of growth and dif-


Fig. 13. Cross Section of Amphioxus Larvae in Successive Stages of Development. $A$, through a larva similar to $11 A$; $B$ and $C$, of a larva similar to $11 B ; D$, of a still older larva; ect, ectoderm; ent, endoderm; mes, mesoderm; ch, notochord; $n p$, neural plate; $g c$, gastrocœl; $a c$, alimentary canal; coel, cœlom. 
ferentiation, until these embryonic organs assume more and more the mature form.

6. Oviparity and Viviparity.-This very brief and general statement of the manner of embryonic development applies to all vertebrates, man included. 'There are many special features of human development which are treated at length in works on embryology, but which need not detain us here since they do not affect the general principles of development already outlined. In one regard the development of the human being or of any mammal is apparently very different from that of a bird or frog or fish, viz., in the fact that in the former the embryonic development takes place within the body of the mother whereas in the latter the eggs are laid before or soon after fertilization. In man, after the cleavage of the egg, a hollow vesicle is formed, which becomes attached to the uterine walls by means of processes or villi which grow out from it (Fig. 14, D, $\boldsymbol{E}, \boldsymbol{F}$ ) while only a small portion of the vesicle becomes transformed into the embryo. There is thus established a connection between the embryo and the uterine 



Fig. 14. Diagrams Showing the Early Development of the Human Oosperm. $A$, cleavage stage which has just come into the uterus; $B$ and $C$, blastodermic vesicles embedded in the mucous membrane of the uterus; $D, E$ and $F$, longitudinal sections of later stages, the anterior and posterior poles being marked by the axis $a p$. In $C$ cavities have appeared in the ectoderm, entoderm and mesoderm. $D$, villi forming from the trophoblast (nutritive layer, $t r$ ); black indicates ectoderm (ect); oblique lines, entoderm; few stipples, mesoderm; $\boldsymbol{V}$, villi; am, amnion; $y s$, yolk sac; $n$, neurenteric canal; x 25. (After Keibel.) 
walls through which nutriment is absorbed by the embryo. And yet this difference is not a fundamental one for in different animals there are all stages of transition between these two modes of development. While in most fishes, amphibians and reptiles the eggs are laid at the beginning of development and are free and independent during the whole course of ontogeny, there are certain species in each of these classes in which the development takes place within the body of the mother. Even in birds a portion of the development takes place within the body of the female before the eggs are laid, and there are mammals (monotremes) which lay eggs, while in others (marsupials) the young are born in a very imperfect condition. These facts indicate that there is no fundamental difference between oviparity and viviparity. In the latter the union between the embryo and the mother is a nutritive but not a protoplasmic one. Blood plasma passes from one to the other by a process of soakage, and the only material influences which can affect the developing embryo are such as may be conveyed through the blood plasma and are 




C

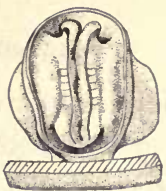

$D$



E


$H$

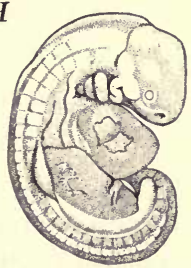

Fig. 15. $A-H$, successive stages in the early development of the human embryo. $A$, blastodermic vesicle showing primitive axis in embryonic area; age unknown. $B$, blastodermic vesicle attached to uterine wall at the posterior pole, showing neural groove; age unknown. $C$, later stage in which the neural folds are closing and five pairs of somites have appeared; age, ten to fourteen days. $D$, stage of fourteen somites showing enlargements of the neural folds at the anterior end which will form the brain; age, fourteen to sixteen days. $E$ and $F$ later stages, the latter with twenty-three somites and three visceral clefts. The ear shows as a depression at the dorsal angle of the second cleft. $G$, embryo of thirty-five somites showing eye, branchial arches and limb buds. $H$, embryo of thirty-six somites showing nasal pit, eye, branchial arches and clefts, limb buds and heart. (After Keibel.) 
chiefly nutritive in character. Careful studies have shown that supposed "maternal impressions" of the physical, mental, or emotional conditions of the mother upon the unborn child have no existence in fact, except in so far as the quality of the mother's blood may be changed and may affect the child. At no time, whether before or after birth, is the mother more than nurse to the child. Hereditary influences are transmitted only through the egg cell and the sperm cell and these influences are not affected by intra-uterine development. The principles of heredity and development are the same in oviparous and in viviparous animals - in fishes, frogs, birds and men.

Summary. - This is a very brief and incomplete statement of some of the important stages or phases of the development of the body of man or of any other vertebrate. In all cases development begins with the fertilized egg which contains none of the structures of the developed animal, though it may exhibit the polarity and symmetry of the adult and may also contain specific kinds of protoplasm which will give rise to specific tissues or organs of 

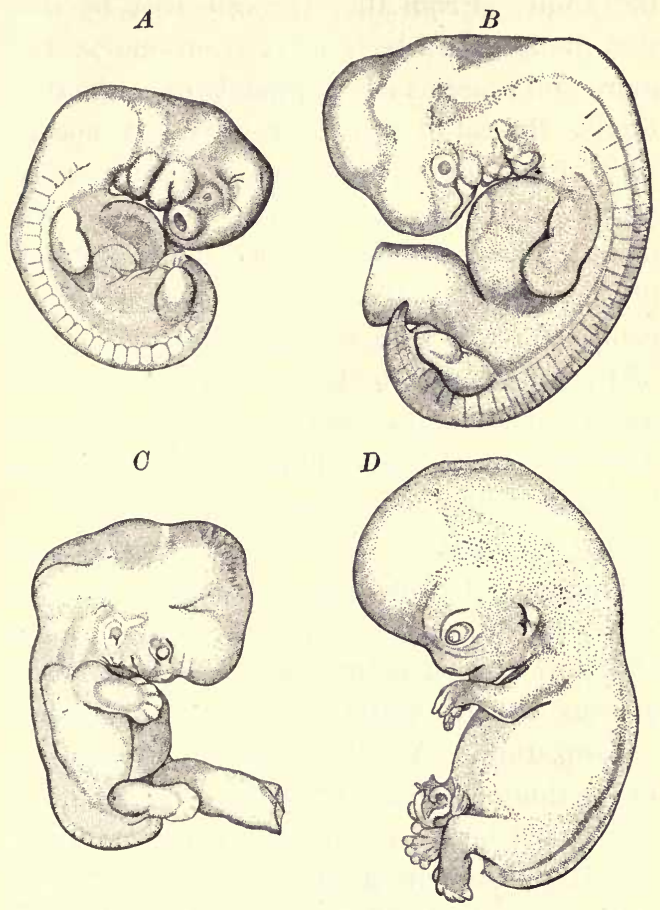

Fig. 16. $A$, human embryo of forty-two somites; age about twenty-one days. $B$, embryo of about four weeks. $C$, still older embryo showing the beginnings of the formation of digits. D, embryo of about two months. (After Keibel.) 
the adult. From this egg cell arise by division many cells which differ from one another more and more as development proceeds, until finally the adult animal results. A specific type of development is due to a specific organization of the germ cells with which development begins, but the earlier differentiations of the egg are relatively few and simple as compared with the bewildering complexities of the adult, and the best way of understanding adult structures is to trace them back in development to their simpler beginnings and to study them in the process of becoming.

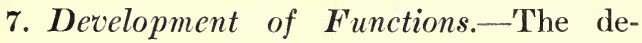
velopment of functions goes hand in hand with the development of structures; indeed function and structure are merely different aspects of one and the same thing, namely organization. All the general functions of living things are present in the germ cells, viz., (1) Constructive and destructive metabolism, (2) Reproduction, as shown in the division of cells and cell constituents, (3) Irritability, or the capacity of receiving and responding to stimuli. All these general functions of living 
things are manifested by germ cells, but as development advances each of these functions becomes more specialized, more complicated and more perfect. A cell which at an early stage was protective, locomotor and sensory in function may give rise to daughter cells in which these functions are distributed to different cells; cells which at an early stage were sensitive to many kinds of stimuli give rise to daughter cells which are especially sensitive to one particular kind of stimulus, such as vibration, light, or chemicals.

Functions develop from a generalized to a specialized condition by the process of "physiological division of labor" which accompanies morphological division of substance. But just as in the development of structures new parts, which were not present in the germ, appear by a process of "creative synthesis," so new functions appear in the course of development, which are not merely sorted out of the general functions present at the beginning, but which are created by the interaction and synthesis of parts and functions previously present.

Much less attention has been paid to the de- 
velopment of functions than to the development of structures, and consequently it is not possible to describe the former with the same degree of detail as the latter. But in spite of the lack of detailed knowledge regarding the development of particular functions the general fact of such development is well established. To what extent structures may modify functions or functions structures, in the course of development, is a problem which has been much discussed, and upon the answer to it depends the fate of certain important theories, for example Lamarckism; but this problem can be solved only by thoroughgoing experimental and analytical work. In the meantime it seems safe to conclude that living structures and functions are inseparable and that anything which modifies one of these must of necessity modify the other also; they are merely different aspects of organization, and are dealt with separately by the morphologists and physiologists only as a matter of convenience. At the same time there can be no doubt that minute changes of function can frequently be detected where no corresponding change of 
structure can be seen, but this shows only that physiological tests may be more delicate than morphological ones. In certain lines of modern biological work, such as bacteriology, cytology, and genetics, many functional distinctions are recognizable between organisnis which are morphologically indistinguishable. But this does not signify that functional changes precede structural ones, but only that the latter are more difficult to see than the former. For every change of function it is probable that an "unlimited microscopist" could discover a corresponding change of structure.

\section{Development of the Mind}

The development of the mind parallels that of the body: whatever the ultimate relations of the mind and body may be, there can be no reasonable doubt that the two develop together from the germ. It is a curious fact that many people who are seriously disturbed by scientific teachings as to the evolution or gradual development of the human race accept with equanimity the universal observation as to the 
development of the human individual,-mind as well as body. The animal ancestry of the race is surely no more disturbing to philosophical and religious beliefs than the germinal origin of the individual, and yet the latter is a fact of universal observation which can not be relegated to the domain of hypothesis or theory, and which can not be successfully denied. If we admit the fact of the development of the entire individual, surely it matters little to our philosophical or religious beliefs to admit the development or evolution of the race.

'The origin of the mind, or rather of the soul, is a topic upon which there has been much speculation by philosophers and theologians. One of the earliest hypotheses was that which is known as transmigration or metempsychosis. 'This doctrine probably reached its greatest development in ancient India, where it formed an important part of Buddhistic belief; it was also a part of the religion of ancient Egypt; it was embodied in the philosophies of Pythagoras and Plato. According to these teachings, the number of souls is a constant one; 
souls are neither made nor destroyed, but at birth a soul which had once tenanted another body enters into the new body. 'This doctrine was generally repudiated by the Fathers of the Christian Church. Jerome and others adopted the view that God creates a new soul for each body that is generated, and that every soul is thus a special divine creation. 'This has become the prevailing view of the Christian Church and is known as creationism. On the other hand 'Tertullian taught that souls of children are generated from the souls of parents as bodies are from bodies. This doctrine, which is known as traducianism, has been defended by certain modern theologians, but has been formally condemned by the Roman Catholic Church.

Traducianism undoubtedly comes nearer the scientific teachings as to the development of the mind than does either of the other doctrines named, but it is based upon the prevalent but erroneous belief that the bodies of the parents generate the body of the child, and that correspondingly the souls of the parents generate the soul of the child. Now we know 
that the child comes from germ cells which are not made by the bodies of the parents but have arisen by the division of antecedent germ cells. Every cell comes from a preexisting cell by a process of division, and every germ cell comes from a pre-existing germ cell. Consequently it is not possible to hold that the body generates germ cells, nor that the soul generates souls. The only possible scientific position is that the mind (or soul) as well as the body develops from the germ.

No fact in human experience is more certain than that the mind develops by gradual and natural processes from a simple condition which can scarcely be called mind at all; no fact in human experience is fraught with greater practical and philosophical significance than this, and yet no fact is more generally disregarded. We know that the greatest men of the race were once babies, embryos, germ cells, and that the greatest minds in human history were once the minds of babies, embryos and germ cells, and yet this stupendous fact has had but little influence on our beliefs as to the nature of man and of mind. We 
rarely think of Plato and Aristotle, of Shakespeare and Newton, of Pasteur and Darwin, except in their full epiphany, and yet we know that when each of these was a child he "thought as a child and spake as a child," and when he was a germ cell he behaved as a germ cell.

'The development of the mind from the activities of the germ cells is certainly most wonderful and mysterious, but probably no more so than the development of the complicated body of the adult animal from the structures of the germ. Both belong to the same order of phenomena and there is no more reason for supposing that the mind is supernaturally created than that the body is. Indeed, we know that the mind is formed by a process of development, and the stages of this development are fairly well known. There is nowhere in the entire course of mental development a sudden appearance of psychical processes, but rather a gradual development of these from simpler and simpler beginnings. No detailed study has been made of the reactions of human germ cells and embryos, but there is every reason to believe that these reactions are 
simpler in the embryo and germ cell than in the infant, and that they are generally similar to the reactions of the germ cells and embryos of other animals, and to the behavior of many lower organisms.

A few years ago such a statement would have been branded as "materialism" and promptly rejected without examination by those who are frightened by names. But the general spread of the scientific spirit is shown not only by the growing regard for evidence but also by the decreasing power of epithets. "Materialism," like many another ghost, fades away into thin air or at least loses many of its terrors, when closely scrutinized. But the statement that mind develops from the germ cells is not an affirmation of materialism, for while it identifies the origin of the entire individual, mind and body, with the development of the germ, it does not assert that "matter" is the cause of "mind" either in the germ or in the adult. It must not be forgotten that germ cells are living things and that we go no further in associating the beginnings of mind with the beginnings of body in the germ than 
we do in associating mind and body in the adult. It is just as materialistic to hold that the mind of the mature man is associated with his body as it is to hold that the beginnings of mind in the germ are associated with the beginnings of the body, and both of these tenets are incontrovertible.

It seems to me that the mind is related to the body as function is to structure; there are those who maintain that structure is the cause of function, that the real problem in evolution or development is the transformation of one structure into another, and that the functions which go with certain structures are merely incidental results; on the other hand are those who maintain that function is the cause of structure and that the problem of evolution or development is the change which takes place in functions and habits, these changes causing corresponding transformations of structure. Among adherents of the former view may be classed many morphologists and Neo-Darwinians; among proponents of the latter, many physiologists and Neo-Lamarckians. It seems to me that the defenders of each of these views 
fail to recognize the essential unity of the entire organism, structure as well as function; that neither of these is the cause of the other, though each may modify or condition the other, but that they are two aspects of one common thing, viz., organization. In the same way I think that the body or brain is not the cause of mind, nor mind the cause of body or brain, but that both are inherent in one common organization or individuality.

In asserting that the mind develops from the germ as the body does, no attempt is made to explain the fundamental properties of body or mind. As the structures of the body may be traced back to certain fundamental structures of the germ cell, so the characteristics of the mind may be traced back to certain fundamental properties and activities of the germ. Many of the psychical processes may be traced back in their development to properties of sensitivity, reflex motions, and persistence of the effects of stimuli. All organisms manifest these properties and for aught we know to the contrary they may be original and necessary characteristics of living things. In the 
simplest protoplasm we find organization, that is, structure and function, and in germinal protoplasm we find the elements of the mind as well as of the body, and the problem of the ultimate relation of the two is the same whether we consider the organism in its germinal or in its adult stage.

In some way the mind as well as the body develops out of the germ. What are the germinal bases of mind? What are the psychical Anlagen in embryos and how do they develop? In this case, even more than in the development of the body, we are compelled to rely upon the comparison of human development with that of other animals, but the great principle of the oneness of life, as respects its fundamental processes, has never yet failed to hold true and will not fail us here. In the study of the psychical processes of organisms other than ourselves we are compelled to rely upon a study of their activities, their reactions to stimuli, since we can not approach the subject in any other way. The reactions and behavior of organisms under normal and experimental conditions give the only insight which 
we can get into their psychical processes; and this applies to men no less than to protozoa.

1. Sensitivity.-The most fundamental phenomenon in the behavior of organisms is irritability or sensitivity, which is the capacity of receiving and responding to stimuli: this is one of the fundamental properties of all protoplasm. But living matter is not equally sensitive to all stimuli, nor to all strengths of the same stimulus. Many of the simplest unicellular plants and animals show that they are differentially sensitive; they often move toward weak light and away from strong light, away from extremes of heat and cold, into certain chemical substances and away from others; in short, all organisms, even the simplest, may respond differently to different kinds of stimuli or to different degrees of the same stimulus. 'This is what is known as differential sensitivity (Figs. 17, 18, 19). On the other hand, many organisms respond in the same way to different stimuli, and this may be taken to indicate generally that they are not differentially sensitive to such stimuli; it is 


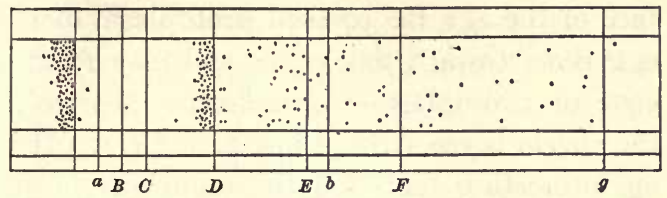

Fig, 17. Distribution of Bacteria in the Spectrum. The largest group is in the ultra-red at the left; the next largest group is in the yellow-orange close to the line $D$. (From Jennings, after Engelmann.)

not to be concluded because organisms respond differently to certain stimuli that they are therefore capable of distinguishing between all kinds of stimuli, for this is certainly not true. Even in adult men the capacity of distinguishing between different kinds of stimuli is far from perfect.

Egg cells and spermatozoa show this property of sensitivity. The egg is generally incapable of locomotion, and since the results of stimulation must usually be detected by movements it is not easy to determine to what extent the egg is sensitive; but though the egg lacks the power of locomotion, it possesses in a marked degree the power of intra-cellular movement of the cell contents. When a spermatozoon comes into contact with the sur- 
face of the egg the cortical protoplasm of the egg flows toward that point and may form a cone or protoplasmic prominence into which the sperm is received (Figs. 4, 5, EC). It is an interesting fact that the same sort of response follows when a frog's egg is pricked by a needle, thus showing that in this case the egg does not distinguish between the prick of the needle and that of the spermatozoon. The spermatozoon is usually a locomotor cell and it responds differently to certain stimuli, just as many bacteria and protozoa do; spermatozoa are strongly stimulated by weak alkali and alcohol, they gather in certain chemical substances and not in others, they collect in great numbers around fertilizable egg cells, etc.

The movements of fertilized egg cells, cleavage cells, and early embryonic cells are usually limited to flowing movements within the individual cells. These movements, which are of a complicated nature, are of the greatest significance in the differentiation of the egg into the embryo; they are caused chiefly by internal stimuli and by non-localized external 

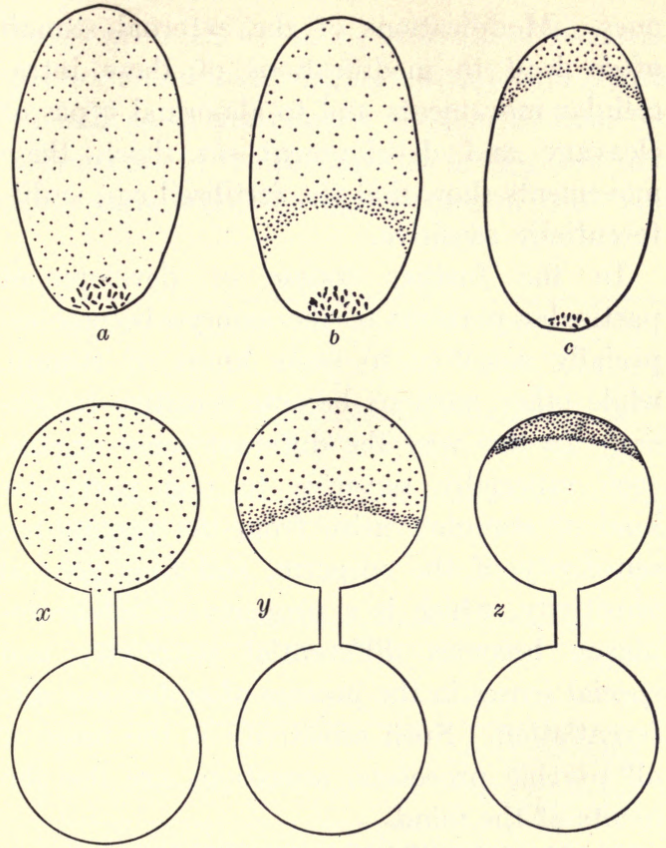

Fig. 18, $a, b, c$. Repulsion of Spirilla by Common Salt. $a$, condition immediately after adding crystals; $b$ and $c$, later stages in the reaction.

$x, y, z$, repulsion of Spirilla by distilled water. The upper drop consists of sea-water containing Spirilla, the lower drop, of distilled water. At $x$ these have just been united by a narrow neck; at $y$ and $z$, the bacteria have retreated before the distilled water. (From Jennings, after Massart.) 
ones. Modifications of the external stimuli often lead to modifications of these intracellular movements and to abnormal types of cleavage and development-in short, these movements show that the fertilized egg is differentially sensitive.

In the further course of development particular portions of the embryo become especially sensitive to some kinds of stimuli, while other portions become sensitive to others. In this way the different sense organs, each especially sensitive to one particular kind of stimulus, arise from the generalized sensitivity of the oosperm, and thus general sensitivity, which is a property of all protoplasm, becomes differential sensitivity and special senses in the process of embryonic differentiation. Such sensitivity is the basis of all psychic processes; sensations are the elements of the mind.

2. Tropisms, Reflexes, Instincts.-All the responses of germ cells, and of the simplest organisms, to stimuli are in the nature of tropisms or reflexes, that is, relatively simple, automatic responses. Such tropisms or re- 
flexes are seen in the movements of bacteria, protozoa and many higher animals and plants as well as in movements of spermatozoa, the movements of the protoplasm in egg cells and embryonic cells, the movements of cells and
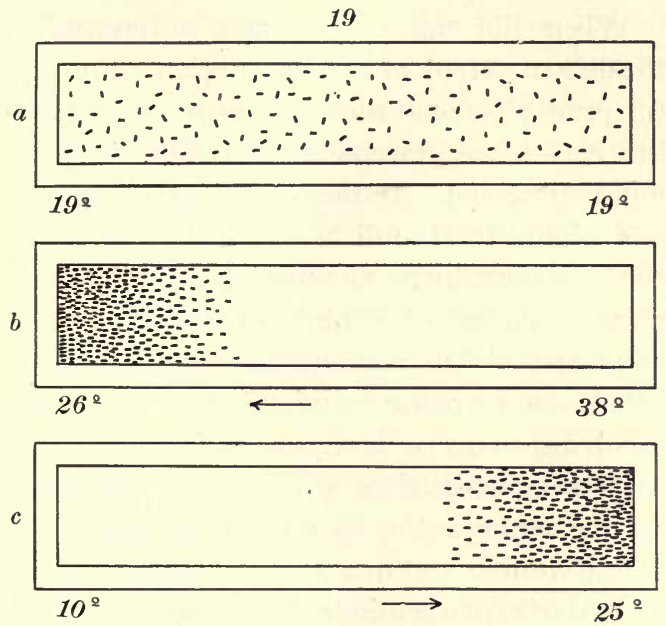

Fig. 19. Reactions of Paramecium to Heat and Cold. At $a$ the infusoria are uniformly distributed in a trough, both ends of which have a temperature of $19^{\circ}$; at $b$ the infusoria are shown collected at the cooler end of the trough; at $c$ they have collected at the warmer end of the trough. (From Jennings, after Mendelssohn.) 
cell masses in the formation of the gastrula, alimentary canal, nervous system and other organs. Indeed the entire process of development, whether accompanied by visible movements or not, may be regarded as a series of automatic responses to stimuli.

When the embryo becomes differentiated to such an extent as to have specialized organs for producing movement its capacity for making responsive movements to stimuli becomes much increased. If the responses of animals and plants to stimuli are of such a sort that the organism turns or moves toward or away from a source of stimulus they are termed tropisms; if the responses are very complicated, one response calling forth another and involving many reflexes, as is frequently the case in animals, they are known as instincts. In the embryo the rhythmic contractions of heart, amnion and intestine are early manifestations of reflex motions. These appear chiefly in the involuntary muscles before nervous connections are formed, the protoplasm of the muscle cells probably responding directly to the chemical stimulus of certain salts in the 
body fluids, as Loeb has shown in other cases. Reflexes which appear later are the random movements of the voluntary muscles of limbs and body, which are called forth by nerve impulses. 'Tropisms are manifested only by organisms capable of considerable free movement and hence are absent in the fotus though present in many free living larvæ. Some instincts are present immediately after birth, such as the instinct of sucking or crying, though these are so simple when compared with some instincts which develop later that they might be classed as reflexes; it is doubtful whether any of the activities before birth could properly be designated as instincts. Reflexes, tropisms and instincts have had a phylogenetic as well as an ontogenetic origin, and consequently we might expect that they would in general make for the preservation of the species, and as a matter of fact we usually find that they are remarkably adapted to this end. For instance the instincts of the human infant to grasp objects, to suck things which it can get into its mouth, to cry when in pain, are complicated reflexes which have survived in 
the course of evolution probably because they serve a useful purpose.

Very much has been written on the nature and origin of instincts, but the best available evidence strongly favors the view that instincts are complex reflexes, which, like the structures of an organism, have been built up, both ontogenetically and phylogenetically, under the stress of the elimination of the unfit, so that they are usually adaptive.

3. Memory.-Another general characteristic of protoplasm is the capacity of storing up or registering the effects of previous stimuli. A single stimulus may produce changes in an organism which persist for a longer or shorter time, and if a second stimulus occurs while the effect of a previous one still persists, the response to the second stimulus may be very different from that to the first. Macfarlane found that if the sensitive hairs on the leaf of Dionaea, the Venus fly-trap (Fig. 20, $S H$ ), be stroked once no visible response is called forth, but if they be stroked a second time within three minutes the leaf instantly closes. If a longer period than three minutes 
elapses after the first stimulus and before the second no visible response follows, $i$. $e$., two successive stimuli are necessary to cause the leaves to close, and the two must not be more than three minutes apart; the effects of the first stimulus are in some way stored or registered in the leaf for this brief time. This kind of phenomenon is widespread among living things and is known as "summation of stimuli." In all such cases the effects of a former stimulus are in some way stored up for a longer or shorter time in the protoplasm. It is possible that this is the result of the formation of some chemical substance which remains in the protoplasm for a certain time, during which time the effects of the stimulus are said to persist, or it may be due to some physical change in the protoplasm analogous to the "set" in metals which have been subjected to mechanical strain.

Probably of a similar character is the persistence of the effects of repeated stimuli and responses on any organ of a higher animal. A muscle which has contracted many times in a definite way ultimately becomes "trained" so 
that it responds more rapidly and more accurately than an untrained muscle; and the nervous mechanism through which the stimulus is transmitted also becomes trained in the same way. Indeed such training is probably chiefly a training of the nervous mechanism. The skill of the pianist, of the tennis player, of the person who has learned the difficult art

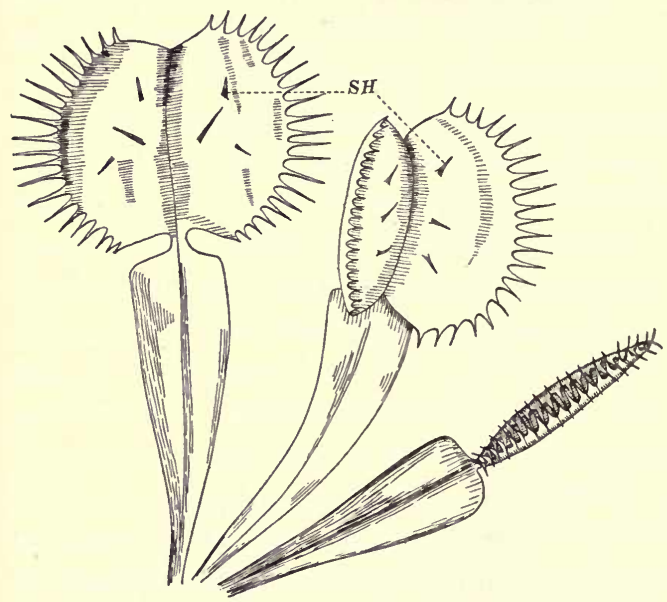

Fig. 20. Dionaea muscipula (Venus' Fly-trap). Three leaves showing marginal teeth and sensitive hairs $(S H)$. The leaf at the left is fully expanded, the one at the right is closed. 
of standing and walking, or the still more difficult art of talking, is probably due to the persistence in muscles and nerves of the effects of many previous activities. All such phenomena were called by Hering "organic memory," to indicate that this persistence of the effects of previous activities in muscles and other organs is akin to that persistence of the effects of previous experiences in the nervous mechanism which we commonly call memory. It seems probable that this ability of protoplasm in general to preserve for a time the effects of former stimuli is fundamentally of the same nature as the much greater power of nerve cells to preserve such effects for much longer periods and in complex associations, a faculty which is known as associative memory. The embryos, and indeed even the germ cells of higher animals, may safely be assumed to be endowed with protoplasmic and organic memory, out of which, in all probability, develop associative and conscious memory in the mature organism.

4. Intellect, Reason.-Even the intellect and reason which so strongly characterize man 
have had a development from relatively simple beginnings. All children come gradually to an age of intelligence and reason. In its simpler forms at least reason may be defined as the power of predicting future events and of reaching conclusions regarding unexperienced phenomena under the influence of past experience. In the absence of individual experience young children have none of this power, but it comes gradually as a result of remembering past experiences and of fitting such experiences into new conditions. Young infants and many lower animals lack the power of reason, though their behavior is frequently of such a sort as to suggest that they are reasoning. Even the lowest animals avoid injurious substances and conditions and find beneficial ones; more complex animals learn to move objects, solve problems, and find their way through labyrinths in the shortest and most economical way; but this apparently intelligent and purposive behavior has been shown to be due to the general elimination of all sorts of useless activities, and to the persistence of the useful ones. 
The ciliated infusorian, Paramecium, moves by the beating of cilia which are arranged in such a way that they drive the animal forward in a spiral course. However, when it is strongly irritated, the normal forward movement is reversed; the cilia beat forward instead of backward and the animal is driven backward for some distance (Fig. 21, 1, 2, 3) ; it then stands nearly still, merely rolling over and swerving toward the aboral side, and finally it goes ahead again, usually on a new course (Fig. 21, 3, 4, 5, 6). These movements seem to be conditioned rather rigidly by the organization of the animal: they are more or less fixed and mechanical in character, though to a certain extent they may be modified by experience or physiological states. Paramecium behaves as it does in virtue of its constitution, just as an egg develops in a particular way because of its particular organization.

But although limited in its behavior to these relatively simple motor reactions, Paramecium does many things which seem to show intelligence and purpose. It avoids many injurious 
substances, such as strong salts or acids, and it collects in non-injurious or beneficial substances, such as weak acids, masses of bacteria upon which it feeds, etc. It avoids extremes of heat and cold and if one end of a dish containing Paramecia is heated and the other end is cooled by ice, the Paramecia collect in the region somewhere between these two extremes (Fig. 19). Jennings, by studying carefully the behavior of single individuals, established the fact that this apparently intelligent action is due to differential sensitivity and to the single motor reaction of the animal. If in the
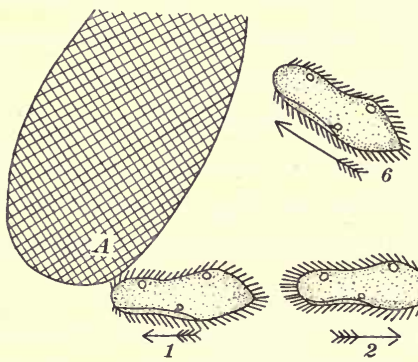

Fig. 21. Diagram of the Avoiding Reaction of Paramecium. $A$ is a solid object or other source of stimulation. 1-6, successive positions occupied by the animal. The rotation on the long axis is not shown. (After Jennings.) 
course of its swimming a Paramecium comes into contact with an irritating substance or condition, it backs a short distance, swerves toward its aboral side, and goes ahead in a new path; if it again comes in contact with the irritating conditions this reaction is repeated, and so on indefinitely until finally a path is found in which the source of irritation is avoided altogether. In short, Paramecium continually tries its environment, and backs away from irritating substances or conditions. Its apparently intelligent reactions are thus explained as due to a process of "trial and error." 1

The behavior of worms, star-fishes, crustaceans, mollusks, as well as of fishes, frogs,

${ }^{1}$ In Paramecium, there is certainly no consciousness of trial and error, and probably no unconscious attempt on the part of the animal to attain certain ends. Its responses are reflexes or tropisms, which are determined by the nature of the animal and the character of the stimulus. The fact that these responses are in the main self-preservative is due to the teleological organization of Paramecium which has been evolved, according to current opinion, as the result of long ages of the elimination of the unfit. If, in the opinion of any one, the expression "trial and error" necessarily involves a striving after ends, it would be advisable to replace it in this case by some such term as "useful or adaptive reactions." 
reptiles, birds and mammals, has been studied and in all cases it is found that their method of responding to stimuli is not at first really purposive and intelligent but by the gradual elimination of useless responses and the preservation (or remembering) of useful ones the behavior may come to be purposive and intelligent.

Thorndike found that when dogs, cats and monkeys were confined in cages which could be opened from the inside by turning a button, or pressing upon a lever, or pulling a cord, they at first clawed around all sides of the cage until by chance they happened to operate the mechanism which opened the door. Thereafter they gradually learned by experience, that is, by trial and error, and finally by trial and success, just where and how to claw in order to get out at once. When a dog has learned to turn a button at once and open a door we say he is intelligent, and if he can learn to apply his knowledge of any particular cage to other and different cages, a thing which Thorndike denies, we should be justified in saying that he reasons, though in this case 
intelligence and reason are founded upon memory of many past experiences, of many trials and errors and of a few trials and successes.

There is every evidence that human beings arrive at intelligence and reason by the same process, a process of many trials and errors and a few trials and successes, a remembering of these past experiences and an application of them to new conditions. A baby grasps for things which are out of its reach, until it has learned by experience to appreciate distances; it tests all sorts of pleasant and unpleasant things until it has learned to avoid the latter and seek the former; it experiments with its own body until it has learned what it can do and what it can not do. Is not this learning by experience akin to the same process in the dog and more remotely to the trial and error of the earthworm or the adaptive reflexes of Paramecium? Is not intelligence and reason in all of us, and upon all subjects, based upon the same processes of trial and error, memory of past experiences and application of this to new conditions? Surely this is true in all ex- 
perimental and scientific work. Indeed the scientific method is the method of trial and error, and finally trial and success-the method recommended by St. Paul to prove all things and hold fast that which is good.

In Paramecium the reflex type of behavior is relatively complete; there is no associative memory and no ability to learn by experience. In the earthworm associative memory is but slightly developed and the animal learns but little by experience and can make no application of past experiences to new conditions. In the dog associative memory is well developed; the animal learns by experience and can, to a limited extent, apply such memory of past experiences to new conditions. In adult man all of these processes are fully developed and particularly the last, viz., the ability to reason. But in his development the human individual passes through the more primitive stages of intelligence, represented by the lower animals named; the germ cells and embryo represent only the stages of reflex behavior, to these trial and error and associative memory are added in the infant and young child, and to these the 
application of past experience to new conditions, or reason, is added in later years.

5. Will.-Another characteristic, which many persons regard as the supreme psychical faculty, is the will. This faculty also undergoes development and from relatively simple beginnings. The will of the child has developed out of something which is far less perfect in the infant and embryo than in the child. Observations and experiments on lower animals and on human beings, as well as introspective study of our own activities, appear to justify the following conclusions:

(1.) Every activity of an organism is a response to one or more stimuli, external or internal in origin. These stimuli are in the main, if not entirely, energy changes outside or inside the organism. In lower organisms as well as in the germ cells and embryos of higher animals the possible number of responses are few and prescribed owing to their relative simplicity, and the response follows the stimulus directly. In more complex organisms the number of possible responses to a stimulus is greatly increased, and the visible 
response may be the end of a long series of internal changes which are started by the original stimulus.

(2.) The response to a stimulus may be modified or inhibited in the following ways:

(a) Through conflicting stimuli and changed physiological states, due to fatigue, hunger, etc. Many stimuli may reach the organism at the same time and if they conflict they may nullify one another or the organism may respond to the strongest stimulus and disregard the weaker ones. When an organism has begun to respond to one stimulus it is not easily diverted to another. Jennings found that the attached infusorian, Stentor, which usually responds to strong stimuli by closing up, may, when repeatedly stimulated, loosen its attachment and swim away, thus responding in a wholly new manner when its physiological state has been changed by repeated stimuli and responses. Whitman found that leeches of the genus Clepsine prefer shade to bright light, and other things being equal they always seek the under sides of stones and shaded places; but if a turtle from which they 
normally suck blood is put into an aquarium with the leeches, they at once leave the shade and attach themselves to the turtle. They prefer shade to bright light but they prefer their food to the shade. The tendency to remain concealed is inhibited by the stronger stimulus of hunger. On the other hand he found that the salamander, Necturus, is so timid that it will not take food, even though starving, until by gradual stages and gentle treatment its timidity can be overcome to a certain extent. Here fear is at first a stronger stimulus than hunger and unless the stimulus of fear can be reduced the animal will starve to death in the presence of the most tempting food.

(b) Responses may also be modified through compulsory limitation of many possible responses to a particular one, and the consequent formation of a habit. This is the method of education employed in training all sorts of animals. Thus Jennings found that a star-fish could be trained to turn itself over, when placed on its back, by means of one particular arm simply by persistently preventing 
the use of the other arms. Many responses of organisms are modified in a similar way, not only by artificial limitations but also by natural ones.

(c) Responses which have become fixed and constant through natural selection or other means of limitation may become more varied and general when the compulsory limitation is relaxed. Behavior in the former case is fixed and instinctive, in the latter more varied and plastic. Thus Whitman found that the behavior of domesticated pigeons is more variable and their instincts less rigidly fixed than in wild species. If the eggs are removed to a little distance from the nest the wild passenger pigeon returns to the nest and sits down as if nothing had happened. She soon finds out, not by sight but by feeling, that something is missing, and she leaves the nest after a few minutes without heeding the eggs. The ringneck pigeon also misses the eggs and sometimes rolls one of them back into the nest, but never attempts to recover more than one. The dove-cote pigeon generally tries to recover both eggs. According to Whitman: 
In these three grades the advance is from extreme blind uniformity of action, with little or no choice, to a stage of less rigid uniformity. ... Under conditions of domestication the action of natural selection has been relaxed, with the result that the rigor of instinctive co-ordination, which bars alternative action, is more or less reduced. Not only is the door to choice thus unlocked, but more varied opportunities and provocations arise, and thus the internal mechanism and the external conditions and stimuli work both in the same direction to favor greater freedom of action. When choice thus enters no new factor is introduced. There is greater plasticity within and more provocation without, and hence the same bird, without the addition or loss of a single nerve cell, becomes capable of higher action and is encouraged and even constrained by circumstances to learn to use its privileges of choice. Choice, as I conceive it, is not introduced as a little deity encapsuled in the brain. . . But increased plasticity invites greater interaction of stimuli and gives more even chances for conflicting impulses.

(d) Finally in all animals behavior is modified through previous experience, just as structure is also. Where several responses to a stimulus are possible and where experience has taught that one response is more satisfactory than another, action may be limited to tins particular response, not by external compul- 
sion but by the internal impulse of experience and intelligence. This is what we know as conscious choice or will. Whitman says:

Choice runs on blindly at first and ceases to be blind only in proportion as the animal learns through nature's system of compulsory education. The teleological alternatives are organically provided; one is taken and fails to give satisfaction, another is tried and gives contentment. This little freedom is the dawning grace of a new dispensation, in which education by experience comes in as an amelioration of the law of elimination. . . Intelligence implies varying degrees of freedom of choice, but never complete emancipation from automatism.

Freedom of action does not mean action without stimuli, but rather the introduction of the results of experience and intelligence as additional stimuli. 'The activities which in lower animals are "cabined, cribbed, confined," reach in man their fullest and freest expression; but the enormous difference between the relatively fixed behavior of a protozoan or a germ cell and the relatively free activities of a mature man is bridged not only in the process of evolution, but also in the course of individual development. 
6. Consciousness.-'The most complex of all psychic phenomena, indeed the one which includes many if not all of the others, is consciousness. Like every other psychic process this has undergone development in each of us; we not only came out of a state of unconsciousness, but through several years we were gradually acquiring consciousness by a process of development. Whether consciousness is the sum of all the psychic faculties, or is a new product dependent upon the interaction of the other faculties, it must pass through many stages in the course of its development, stages which would commonly be counted as unconscious or subconscious states, and complete consciousness must depend upon the complete development and activity of the other faculties, particularly associative memory and intelligence. The question is sometimes asked whether germ cells, and indeed all living things, may not be conscious in some vague manner. One might as well ask whether water is present in hydrogen and oxygen. Doubtless the elements out of which consciousness develops are present in the germ cells, in the 
same sense that the elements of the other psychic processes or of the organs of the body are there present; not as a miniature of the adult condition, but rather in the form of elements or factors, which by a long series of combinations and transformations, due to interactions with one another and with the environment, give rise to the fully developed condition.

Finally there seems good reason for believing that the continuity of consciousness, the continuing sense of identity, is associated with the continuity of material substance, for in spite of frequent changes of the materials of which we are composed our sense of identity remains undisturbed. However, the continuity of protoplasmic and cellular organization generally remains undisturbed throughout life, and the continuity of consciousness is associated with this continuity of organization, especially in certain parts of the brain. It is an interesting fact that in man, and in several other animals which may be assumed to have a sense of identity, the nerve cells, especially those of the brain, cease dividing at an early 
age, and these identical cells persist throughout the remainder of life. If nerve cells continued to divide throughout life, as epithelial cells do, there would be no such persistence of identical cells, and one is free to speculate that in such cases there would be no persistence of the sense of identity.

Organization includes both. structure and function, and continuity of organization implies not only persistence of protoplasmic and cellular structures but also persistence of the functions of sensitivity, reflexes, memory, instincts, intelligence, and will; the continuity of consciousness is associated with the continuity of these activities, as well as with the structures of the body in general and of the brain in particular. It is well known that things which interrupt or destroy these functions or structures interrupt or destroy consciousness. Lack of oxygen, anesthetics, normal sleep cause in some way a temporary interruption of these functions and consequently temporary loss of consciousness; while certain injuries or diseases of the brain which bring about the destruction of certain centers or as- 
sociation tracts may cause permanent loss of consciousness.

'The development of all of these psychical faculties runs parallel with the development of bodily structures and apparently the method of development in the two cases is similar, viz., progressive differentiation of complex and specialized structures and functions from relatively simple and generalized leginnings. Indeed the entire organism, structure and function, body and mind, is a unity, and the only justification for dealing with these constituents of the organism as if they were separate entities, whether they be regarded in their adult condition or in the course of their development, is to be found in the increased convenience and effectiveness of such separate treatment.

Development, like many other vital phenomena, may be considered from several different points of view, such as (1) physicochemical events involved, (2) physiological processes, (3) morphological characters, (4) ecological correlations and adaptations, (5) psychological phenomena, (6) social and 
moral developments. All of these phases of development are correlated, indeed they are parts of one general process, and a complete account of this process must include them all. General considerations may lead us to the belief that each of the succeeding aspects of development named above may be causally explained in terms of the preceding ones, and hence all be reducible to physics and chemistry. But this is not now demonstrable and may not be true. Function and structure may be related causally, or they may be two aspects of one substance. The same is true of body and mind or of matter and energy. But even if each of these different phases in the development of personality may not be causally explained by the preceding ones, at least the principle of explanation employed for any aspect of development ought to be consistent and harmonious with that employed for any other aspect.

The phenomena of mental development in man and other animals may be summarized as follows : 
DEVELOPMENT OF PSYCHICAL PROCESSES IN ON'TOGENY AND PHYLOGENY

All Living Things, Including Germ Cells and Embryos, Show:

1. Differential Sensitivity $=$ Different Responses to Stimuli differing in Kind or Quantity.

2. Reflex Motions $=$

Relatively Simple, Automatic Responses.

3. Organic Memory $=$ Results of Previous Experience registered in General Protoplasm.

4. Adaptive Responses $=$ Results of Elimination of U s e l e s s Responses through Trial and Error.

5. Varied Responses

Dependent upon Conflicting Stimuli and Physiological States.

6. Identity $=$

Continuity of Individual Organization.
Mature Forms of Higher Animals Show:

1. Special Senses and Sensations $=$

Sensations are the Elements of Mind.

2. Instincts

(Inherited), Habits (Acquired) $=$ Complex Reflexes, involving Nerve Centers.

3. Associative Memory $=$ Results of Experience registered in Nerve Centers and Association Tracts.

4. Intelligence, Reason $=$ Results of Trial and Error plus Associative Memory, i. e. Experience.

5. Inhibition, Choice, Will

Dependent upon Associative Memory, Intelligence, Reason.

6. Consciousness =

Continuity of Memory, Intelligence, Reason, Will. 


\section{B. FACTORS OF DEVELOPMENT}

These are some of the facts of development, - a very incomplete résumé of some of the stages through which a human being passes in the course of his development from the germ. What are the factors of development? $\mathrm{By}$ what processes is it possible to derive from a relatively simple germ cell the complexities of an adult animal? How can mind and consciousness develop out of the relatively simple psychical elements of the germ? These are some of the great problems of developmentthe greatest and most far-reaching theme which has ever occupied the minds of men.

1. Preformation.-When the mind is once lost in the mystery of this ever-recurring miracle it is not surprising to find that there have been those who have refused to believe it possible and who have practically denied development altogether. The old doctrine of "evolution," as it was called by the scientists of the eighteenth century, or of preformation as we know it to-day, held that all the organs or 
parts of the adult were present in the germ in a minute and transparent condition as the leaves and stem are present in a bud, or as the shoot and root of the little plant are present in the seed. ${ }^{2}$ In the case of animals it was generally impossible to see the parts of the future animal in the germ, but this was supposed to be due to the smaller size of the parts and to their greater transparency, and with poor microscopes and good imagination some observers thought they could see the little animals in the egg or sperm, and even the little man, or "homunculus," was described and figured as folded up in one or the other of the sex cells.

This doctrine of preformation was not only an attempt to solve the mystery of development, but it was also an attempt to avoid the theological difficulties supposed to be involved in the view that individuals are produced by a process of gradual development rather than

${ }^{2}$ The little plant in the seed is itself the product of the development of a single cell, the ovule, in which no trace of a plant is present, but of course this fact was not known until after careful microscopical studies had been made of the earliest stages of development. 
by supernatural creation. If every individual of the race existed within the germ cells of the first parents, then in the creation of the first parents the entire race with its millions of individuals was created at once. Thus arose the theory of "emboitement," or infinite encasement, the absurdities of which contributed to the downfall of the entire doctrine of preformation, which, in the form given it by many naturalists of the eighteenth century, is now only a curiosity of biological literature.

2. Epigenesis.-As opposed to this doctrine of preformation, which was founded largely on speculation, arose the theory of epigenesis, which was in its main features founded upon the direct observation of development, and which maintained that the germ contains none of the adult parts, but that it is absolutely simple and undifferentiated, and that from these simple beginnings the individual gradually becomes complex by a process of differentiation. We owe the theory of epigenesis, at least so far as its main features are concerned, to William Harvey, the discoverer of the circulation of the blood, and to Caspar 
Friederich Wolff, whose doctoral thesis, published in 1759 and entitled "Theoria Generationis," marked the beginning of a great epoch in the study of development. Wolff demonstrated that adult parts are not present in the germ, either in animals or in plants, but that these parts gradually appear in the process of development. He held, erroneously, that the germ is absolutely simple, homogeneous and undifferentiated, and that differentiation and organization gradually appear in this undifferentiated substance. How to get differentiations out of non-differentiated material, heterogeneity out of homogeneity, was the great problem which confronted Wolff and his followers, and they were compelled to assume some extrinsic or environmental force, some vis formativia or spiritus rector, which could set in motion and direct the process of development.

The doctrine of preformation, by locating in the germ all the parts which would ever arise from it, practically denied development altogether; epigenesis recognized the fact of development, but attributed it to mysterious 
and purely hypothetical external forces; the one placed all emphasis upon the germ and its structures, the other upon outside forces and conditions.

3. Preformation and Epigenesis.-Modern students of development recognize that neither of these extreme views is true-adult parts are not present in the germ, nor is the latter homogeneous-but there are in germ cells many different structures and functions which are, however, very unlike those of the adult, and by the transformation and differentiation of this germinal organization the complicated organization of the adult arises. Development is not the unfolding of an infolded organism, nor the mere sorting of materials already present in the germ cells, though this does take place, but rather it consists in the formation of new materials and qualities, of new structures and functions-by the combination and interaction of the germinal elements present in the oosperm. In similar manner the combination and interaction of chemical elements yield new substances and qualities which are not to be observed in the elements themselves. Such 
new substances and qualities, whether in the organic or in the inorganic world, do not arise by the gradual unfolding of what was present from the beginning, but they are produced by a process of "creative synthesis."

Modern studies of germ cells have shown that they are much more complex than was formerly believed to be the case; they may even contain different "organ-forming substances" which in the course of development give rise to particular organs; these substances may be so placed in the egg as to foreshadow the polarity, symmetry and pattern of the embryo, but even the most highly organized egg is relatively simple as compared with the animal into which it ultimately develops. Increasing complexity, which is the essence of development, is caused by the combination and interaction of germinal substances under the influence of the environment. The organization of the oosperm may be compared to the arrangement of tubes and flasks in a complicated chemical operation; they stand in a definite relation to one another and each contains specific substances. The final result of the 
operation depends not merely upon the substances used, nor merely upon the way in which the apparatus is set up, but upon both of these things, as well as upon the environmental conditions represented by temperature, pressure, moisture or other extrinsic factors.

4. Heredity and Environment.-Unquestionably the factors or causes of development are to be found not merely in the germ but also in the environment, not. only in intrinsic but also in extrinsic forces; but it is equally certain that the directing and guiding factors of development are in the main intrinsic, and are present in the organization of the germ cells, while the environmental factors exercise chiefly a stimulating, inhibiting or modifying influence on development. In the same dish and under similar environmental conditions, one egg will develop into a worm, another into a sea urchin, another into a fish, and it is certain that the different fate of each egg is determined by conditions intrinsic in the egg itself, rather than by environmental conditions. We should look upon the germ as a living thing, and upon development as one of its 
functions. Just as the character of any function is determined by the organism, though it may be modified by environment, so the character of development is determined by heredity, $i$. e., by the organization of the germ cells, though the course and results of development may be modified by environmental conditions.

\section{Summary}

In conclusion, we have briefly reviewed in this lecture the well known fact that every living thing in the world has come into existence by a process of development; that the entire human personality, mind as well as body, has thus arisen; and that the factors of development may be classified as intrinsic in the organization of the germ cells, and extrinsic as represented in environmental forces and conditions. The intrinsic factors are those which are commonly called heredity, and they direct and guide development in the main; the extrinsic or environmental factors furnish the conditions in which development takes place and modify, more or less, its course. 
CHAP'TER II

THE CELLULAR BASIS OF HEREDITY AND DEVELOPMENT 



\section{CHAP'TER II}

THE CELLULAR BASIS OF HEREDITY AND DEVELOPMENT

\section{A. INTRODUCTORY}

Heredity is to-day the central problem of biology. 'This problem may be approached from many sides, that of the observer, the statistician, the practical breeder, the experimenter, the embryologist, the cytologist; but these different aspects of the subject may be reduced to three general methods of study, (1) the observational and statistical, (2) the experimental, (3) the cytological and embryological. Before taking up these different aspects of heredity it is important that we should have clear definitions of the terms employed and a fairly accurate conception of the processes involved.

1. Definitions.-Heredity originally meant 
heirship, or the transmission of property from parents to children, and in the field of biology it has been defined erroneously as "the transmission of qualities or characteristics, mental or physical, from parents to offspring" (Century Dictionary). The colloquial meaning of the word has led to much confusion in biology, for it carries with it the idea of the transmission from one generation to the next of ownership in property. A son may inherit a house from his father and a farm from his mother, the house and farm remaining the same though the ownership has passed from parents to son. And when it is said that a son inherits his stature from his father and his complexion from his mother, the stature and complexion are usually thought of only in their developed condition, while the great fact of development is temporarily forgotten. Of course there are no "qualities" or "characteristics" which are "transmitted" as such from one generation to the next. Such terms are not without fault when used merely as figures of speech, but when interpreted literally, as they frequently are, they are altogether misleading; they are 
the result of reasoning about names rather than facts, of getting far from phenomena and philosophizing about them. The comparison of heredity to the transmission of property from parents to children has produced confusion in the scientific as well as in the popular mind. It is only necessary to recall the most elementary facts about development to recognize that in a literal sense developed characteristics of parents are never transmitted to children.

2. The Transmission Hypothesis.-And yet the idea that the characteristics of adult persons are transmitted from one generation to the next is a very ancient one and was universally held until the most recent times. Before the details of development were known it was natural to suppose, as Hippocrates did, that white-flowered plants gave rise to whiteflowered seeds and that blue-eyed parents produced blue-eyed germs, without attempting to define what was meant by white-flowered seed or blue-eyed germs. And even after the facts of development were fairly well known it was generally held that the germ cells were pro- 
duced by the adult animal or plant and that the characteristics of the adult were in some way carried over to the germ cells; but the manner in which this supposed transmission took place remained undefined until Darwin attempted to explain it by his "provisional hypothesis of pangenesis." Darwin assumed that minute particles or "gemmules" were given off by every cell of the body, at every stage of development, and that these gemmules then collected in the germ cells which thus became storehouses of little germs from all parts of the body. Afterward, in the development of the germ cells, the gemmules, or little germs, developed into cells and organs similar to those from which they came.

3. Germinal Continuity and Somatic Discontinuity.-Many ingenious hypotheses have been devised to explain beliefs which are not correct, and this is one of them. The doctrine that adult organisms manufacture germ cells and transmit their characters to them is known to be erroneous. Neither germ cells nor any other kind of cells are formed by the body as a whole, but every cell in the body 
comes from a preceding cell by a process of division, and germ cells are formed, not by contributions from all parts of the body, but by division of preceding cells which are derived ultimately from the fertilized egg (Fig. 22). The hen does not produce the egg, but the egg produces the hen and also other eggs. Individual traits are not transmitted from the hen to the egg, but they develop out of germinal factors which are carried along from cell to cell, and from generation to generation.

'There is a continuity of germinal substance, and usually of germinal cells, from one generation to the next. In some animals the germ cells are set apart at a very early stage of development, sometimes in the early cleavage stages of the egg. In other cases the germ cells are first recognizable at later stages, but in practically every case they arise from germinal or embryonic cells which have not differentiated into somatic tissues. Germinal continuity and somatic discontinuity of successive generations in sexually produced organisms is not a theory but an established fact. In general, germ cells do not come from dif- 
ferentiated somatic cells, but only from undifferentiated germinal cells, and if in a few doubtful cases differentiated cells may reverse

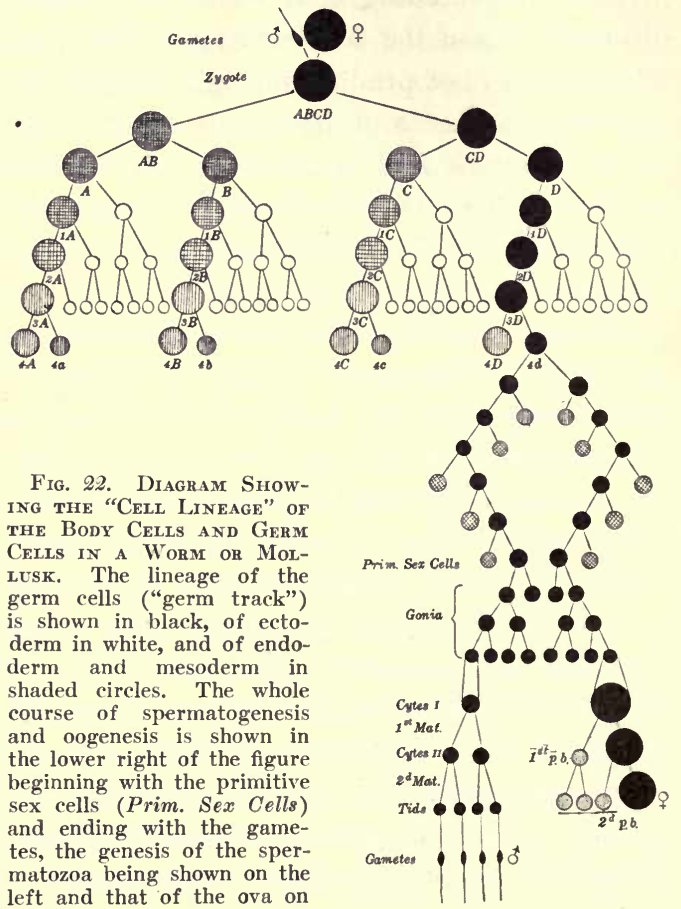
the right. 
the process of development and become embryonic cells and even germ cells it does not destroy this general principle of germinal continuity and somatic discontinuity.

Thus the problem which faces the student of heredity and development has been cut in two; he no longer inquires how the body produces the germ cells, for this does not happen, but merely how the latter produce the body and other germ cells. The germ is the undeveloped organism which forms the bond between successive generations; the person is the developed organism which arises from the germ under the influence of environmental conditions. The person develops and dies in each generation; the germ-plasm is the continuous stream of living substance which connects all generations. The person nourishes and protects the germ, and in this sense the person is merely the carrier of the germ-plasm, the mortal trustee of an immortal substance.

This contrast of the germ and the person, of the undeveloped and the developed organism, is fundamental in all modern studies of heredity. It was especially emphasized by 
Weismann in his germ-plasm theory and recently it has been made prominent by Johannsen under the terms "genotype" and "phenotype"; the genotype is the fundamental hereditary constitution of an organism, it is the germinal type; the phenotype is the developed organism with all of its visible characters, it is the somatic type.

But important as this distinction is between germ and soma it has sometimes been overemphasized. This is one of the chief faults of Weismann's theory. The germ and the soma are generically alike, but specifically different. Both germ cells and somatic cells have come from the same oosperm, but have differentiated in different ways; the tissue cells have lost certain things which the germ cells retain and have developed other things which remain undeveloped in the germ cells. But the germ cells do not remain undifferentiated; both egg and sperm are differentiated, the former for receiving the sperm and for the nourishment of the embryo, the latter for locomotion and for penetration into the egg. But while the differentiations of tissue cells are usually irre- 
versible, so that they do not again become germinal cells, the differentiations of the sex cells are reversible, so that these cells, after their union, again become germinal cells.

In many theories of heredity it is assumed that there is a specific "inheritance material," distinct from the general protoplasm, of which the function is the "transmission" of hereditary properties from generation to generation, and of which the characteristics are independence of the general protoplasm, continuity from generation to generation and extreme stability in organization. This is the idioplasm of Nageli, the germ-plasm of Weismann. But there is no reason to suppose that "germplasm" is anything other than germinal protoplasm, which is found in all cells in the earliest stages of development but which becomes limited in quantity or altered in quality in tissue cells. A "germ-plasm" which is absolutely distinct from and independent of the general protoplasm is a mere fiction which finds no justification in reality.

4. The Units of Living Matter.-The entire cell, nucleus and cytoplasm, is the ulti- 
mate unit of living matter which is capable of independent existence. Neither the nucleus nor the cytoplasm can for long live independently of each other, but the entire cell can perform all the fundamental vital processes. It transforms food into its own living material, it grows and divides, it is capable of responding to many kinds of stimuli. But while the parts of a cell are not capable of independent existence they may perform certain of these vital processes.

Not only is the cell as a whole capable of assimilation, growth and division, but every living part of the cell has this power. The nucleus builds foreign substances into its own substance, and after it has grown to a certain size it divides into two; the cytoplasm does the same, and this process of assimilation, growth and division occurs in many parts of the nucleus and cytoplasm, such as the chromosomes, chromomeres, centrosomes, etc. In all cases cells come from cells, nuclei from nuclei, chromosomes from chromosomes, centrosomes from centrosomes, etc.

Indeed, the manner in which all living mat- 
ter grows indicates that every minute particle of protoplasm has this power of taking in food substance and of dividing into two particles when it has, grown to maximum size. Presumably this power of assimilation, growth and division is possessed by particles of protoplasm which are invisible with the highest powers of our microscopes, though it is probable that these particles are much larger than the largest molecules known to chemistry. The smallest particle which can be seen with the most powerful microscope in ordinary light is about $250 \mu \mu$ (millionths of a millimeter) in diameter. The largest molecules are probably about $10 \mu \mu$ in diameter. Between these invisible molecules and the just visible particles of protoplasm there may be other units of organization. These hypothetical particles of protoplasm have been supposed by many authors to be the ultimate units of assimilation, growth and division, and in so far as these units are supposed to be different in different species, or with respect to different hereditary characters, they are known as inheritance units.

It is assumed in practically all theories of 
heredity that the "inheritance material," or more correctly the germinal protoplasm, is composed of ultra-microscopical units which have the power of individual growth and division and which are capable of undergoing many combinations and dissociations during the course of development, by which combinations and dissociations they are transformed into the structures of the adult. Various names have been given to such units by different authors; they are the "physiological units" of Herbert Spencer, the "gemmules" of Darwin, the "plastidules" of Elsberg and Haeckel, the "pangenes" of de Vries, the "plasomes" of Wiesner, the "idioblasts" of Hertwig, the "biophores" and "determinants" of Weismann.

With the publication of Weismann's work on the germ-plasm in 1892 speculation with regard to these ultra-microscopic units of life and of heredity reached a climax and began to decline, owing to the highly speculative character of the evidence as to the existence, nature and activities of such units. But with the rediscovery of Mendel's principles of heredity the necessity of assuming the exist- 
ence of inheritance units of some kind once more became evident, and, without attempting to define what such units are or how they behave modern students of heredity invariably accept their existence. They are now called determiners or factors or genes, and are usually thought of as elements or units of the germ cells which condition the characters of the developed organism, and which are in a measure independent of one another; though of course neither they nor any other parts of a cell are really independent in the sense that they can exist apart from one another. They are to be thought of as we think of certain chemical radicals which exist only in combination with other chemical elements in the form of molecules, and yet may preserve their identity in many different combinations.

If there are inheritance units, such as determiners or genes, as practically all students of heredity maintain, they must be contained in the germ cells, and it becomes one of the fundamental problems of biology to find out where and what these units are. But whether we assume the existence of these units or not 
we know that the germ cells are exceedingly complex, that they contain many visible units such as chromosomes, chromomeres, plastosomes and microsomes, and that with every great improvement in the microscope and in microscopical technique other structures are made visible which were invisible before, and whether the particular hypothetical units just named are present or not seems to be a matter of no great importance, seeing that, so far as the analysis of the microscope is able to go, there are in all protoplasm differentiated units which are combined into a system; in short, there is organization.

5. Heredity and Development.-The germ cells are individual entities and after the fertilization of the egg the new individual thus formed remains distinct from every other individual. Furthermore, from its earliest to its latest stage of development it is one and the same organism; the egg is not one being and the embryo another and the adult a third, but the egg of a human being is a human being in the one-celled stage of development, and the characteristics of the adult develop out of the 
egg and are not in some mysterious way grafted upon it or transmitted to it.

Parents do not transmit their characters to their offspring but their germ cells in the course of long development give rise to adult characters similar to those of the parents. The thing which persists more or less completely from generation to generation is the organization of the germ cells which differentiate in similar ways in successive generations if the extrinsic factors of development remain similar.

In short, heredity may be defined as the appearance in offspring of characters whose differential causes are found in the germ cells. Heritage is the sum of all those qualities which are determined or caused by this germinal organization. Development is progressive and coordinated differentiation of this germinal organization, by which it is transformed into the adult organization. Differentiation is the formation and localization of many different kinds of substances out of the germinal substance, of many different structures and functions out of the relatively simple structures and functions of the oosperm. 
This germinal organization influences not merely adult characters but also the character of every stage from the egg to the adult condition. For every inherited character, whether embryonic or adult, there is some germinal basis. We receive from our parents germ cells of a particular kind and constitution, and under given conditions of environment these cells undergo regular transformations and differentiations in the course of development, differentiations which lead to particular adult characteristics. In the last analysis the causes of heredity and development are problems of cell structures and functions, problems of the formation of particular kinds of germ cells, of the fusion of these cells in fertilization, and of the subsequent formation of the various types of somatic cells from the fertilized egg cell.

\section{B. THE GERM CELLS}

Observations and experiments on developed animals and plants have furnished us with a knowledge of the finished products of inheritance, but the actual stages and causes of inheritance, the real mechanisms of heredity, are 
to be found only in a study of the germ cells and of their development. Although many phenomena of inheritance have been discovered in the absence of any definite knowledge of the mechanism of heredity, a scientific explanation of these phenomena must wait upon the knowledge of their causes. In the absence of such knowledge it has been necessary to formulate theories of heredity to account for the facts, but these theories are only temporary scaffolding to bridge the gaps in our knowledge, and if we knew all that could be known about the germ cells and their development we should have little need of theories. In the first lecture we looked at the germ cells and their development from the outside, as it were; let us now look inside these cells and study their minuter structures and functions.

Only a beginning has been made in this minute study of the germ cells and of their transformation into the developed animal, and it seems probable that it may engage the attention of many future generations of biologists, but nevertheless we have come far 

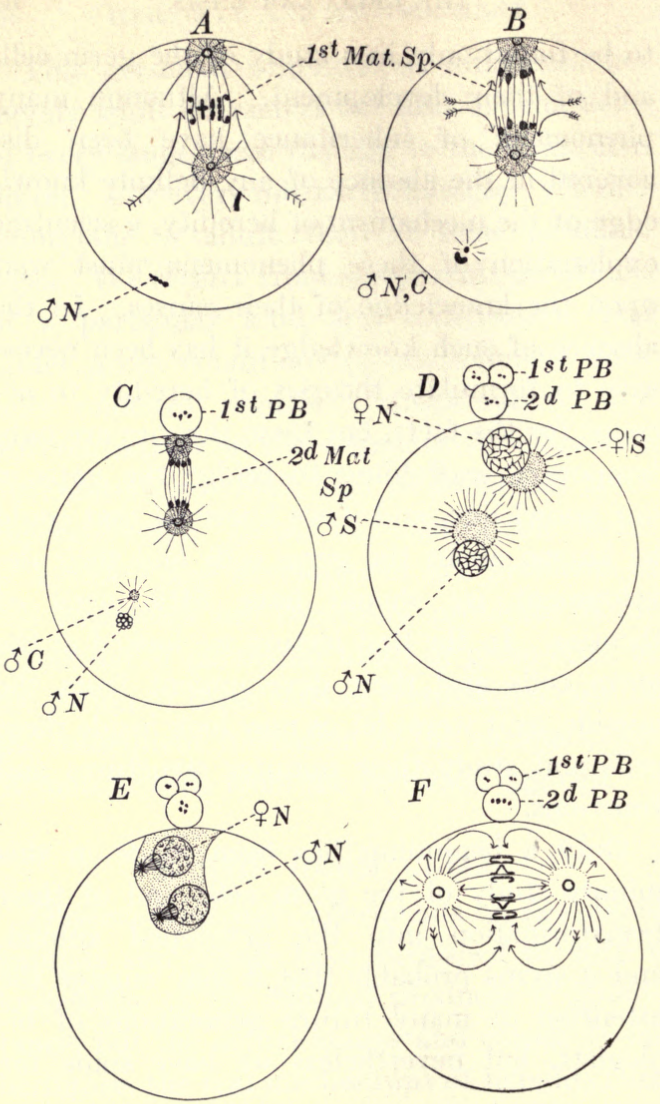

FIg. 23-For Description see page 107 
since that day, only about thirty-five years ago, when Oscar Hertwig first saw the approach and union of the egg and sperm nuclei within the fertilized egg. Indeed so rapid has been the advance of knowledge in this field that many of the pioneers in this work are still active in research.

1. Fertilization.-'The development of the individual may be said to begin with the fertilization of the egg, though it is evident that both egg and sperm must have had a more remote beginning, and that they also have undergone a process of development by which their peculiar characteristics of structure and function have arisen; a subject to which we shall return later. But the developmental processes which lead to the formation of fully

Fig. 23. Diagrams of the Maturation axd Fertilization of the Egg of a Mollusk (Crepidula). $A, B$. First maturation division (1st Mat. Sp.) C. Second maturation division (2d Mat. Sp.) and first polar body (1st $P B$ ) resulting from first division. $\delta^{A} N$, sperm nucleus, $\delta^{A} C$, sperm centrosome. $D$. Approach of sperm nucleus $(\delta N)$ and sphere $(\delta S)$ to egg nucleus $(q N)$ and sphere $(q S)$; the second polar body $(2 d P B)$ has been formed and the first has divided (1st $P B$ ). $E$. Meeting of egg and sperm nuclei and origin of cleavage centrosomes. $F$. First cleavage of egg showing direction of currents in the cell. 
developed ova and spermatozoa come to a full stop before fertilization and they do not usually begin again until a spermatozoon has entered an ovum, or until the latter has been stimulated by some other outside means. In some animals and plants eggs may develop regularly without fertilization, the stimulus to development being supplied by certain external or internal conditions; in other cases, as Loeb discovered, eggs which would never develop if left to themselves may be experimentally stimulated by physical or chemical changes in the environment, so that they undergo regular development. 'The development of an egg without previous fertilization is known as parthenogenesis or virgin reproduction; if it occurs in nature it is natural parthenogenesis, if in experiments it is artificial parthenogenesis. Natural parthenogenesis is relatively rare and in the vast majority of animals and plants the egg does not begin to develop until a spermatozoon has entered it.

But the spermatozoon not only stimulates the egg to develop, as environmental conditions may also do, but it carries into the egg 
living substances which are of great significance in heredity. Usually only the head of the spermatozoon enters the egg (Figs. 4-7) and this consists almost entirely of nuclear material which has a strong chemical affinity for certain dyes, and hence is called chromatin (Fig. $23 A$ and $B$ ) ; when the egg has matured and is ready to be fertilized its nucleus also consists of a small mass of chromatin (Fig. 23 C). Both of these condensed chromatic nuclei then grow in size and become less chromatic by absorbing from the egg a substance which is not easily stained by dyes and hence is called achromatin (Fig. $23 \boldsymbol{D}$ and $\boldsymbol{E}$ ). The chromatin then becomes scattered through each nucleus in the form of granules or threads which are embedded in the achromatin; this is the condition of a typical "resting" nucleus. The spermatozoon also brings into the egg a centrosome or division center, around which an aster appears consisting of radiating lines in the protoplasm of the egg (Fig. $23 \mathbf{B}$ ).

The moment that the spermatozoon touches the surface of the egg the latter throws out at the point touched a prominence, or reception 
cone (Fig. 4), and as soon as the head of the sperm has entered this cone some. of the superficial protoplasm of the egg flows to this point and then turns into the interior of the egg in a kind of vortex current. Probably as a result of this current the sperm nucleus and centrosome are carried deeper into the egg and finally are brought near to the egg nucleus (Fig. $23 D$ and $E$ ). In the movements of egg and sperm nuclei toward each other it is evident that they are passively carried about by currents in the cytoplasm; the entrance of the sperm serves as a stimulus to the egg cytoplasm which moves according to its preestablished organization.

2. Cleavage and Differentiation.-When the sperm nucleus has come close to the egg nucleus the sperm centrosome usually divides into two minute granules, the daughter centrosomes, which move apart forming a spindle with the centrosomes at its poles and with astral radiations running out from these into the cytoplasm (Fig. $23 \boldsymbol{F}$ ). At the same time the chromatin granules and threads in the egg and sperm nuclei run together into a smooth 
thick thread, the spireme, which is coiled within the nucleus. At this stage it is sometimes possible to see that the spireme is composed of a series of granules, like beads on a string; these granules are the chromomeres. The spireme then breaks up into a number of pieces in the form of short threads or rods (Fig. 24 $C$ and $D)$; these are the chromosomes. The number of these chromosomes is constant for every species and race, though the number may vary in different species. In the thread worm, Ascaris megalocephala, there are usually two chromosomes in the egg nucleus and two in the sperm nucleus (Fig. 24 D). In the gastropod, Crepidula, there are about thirty chromosomes in each germ nucleus and sixty in the two.

Then the spindle and asters grow larger and the nuclear membrane grows thinner and finally disappears altogether, leaving the chromosomes in the equator of the spindle (Figs. $23 \boldsymbol{F}, 24 \boldsymbol{E}$ and $\boldsymbol{F}, 25 I$ ). Each of the chromosomes then splits lengthwise into two equal parts, and in the splitting of the chromosomes 

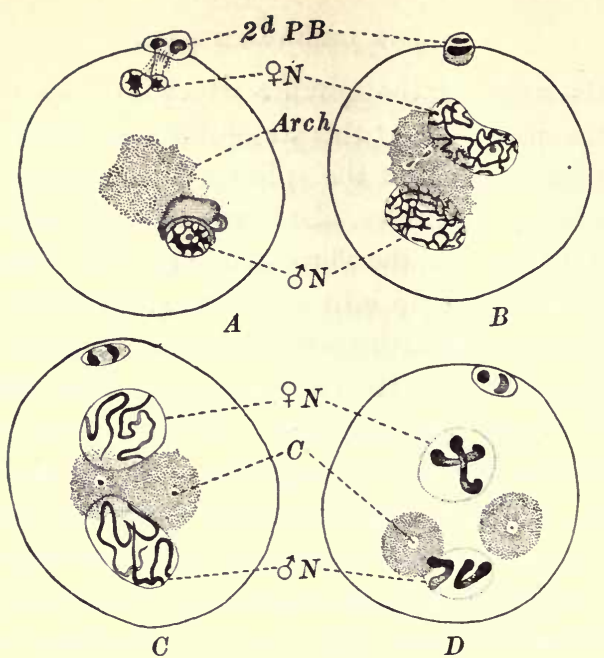

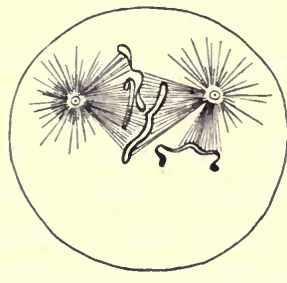

E

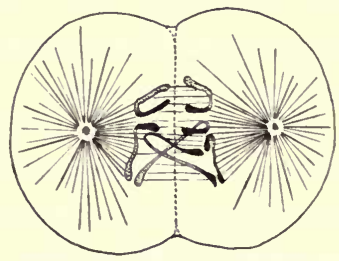

F

Fig. 24. Feiltilization of the Egg of the Nematode Wонм Ascaris megalocephala; $\$ N$, egg nucleus; $\delta N$, sperm nucleus; Arch, archiplasm; $C$, centrosome; $A, B$, approach of germ nuclei; $C, D$, formation of two chromosomes in each germ nucleus; $E, F$, stages in the division of the chromosomes which are split in $E$ and are separating in $F$; only three chromosomes are shown in $F$. (From Wilson after Boveri.) 
it is sometimes possible to see that each beadlike chromomere divides through its middle. 'The daughter chromosomes then separate and move to opposite poles of the spindle, where they form the daughter nuclei, and at the same time the cell body begins to divide by a constriction which pinches the cell in two in the plane which passes through the equator of the spindle (Figs. 24 $F, 26 B$ ). Finally the daughter nuclei grow in size by the absorption of achromatin from the cell body and the substance of the chromosomes is again scattered through the achromatin in the form of threads and granules and thus the daughter nuclei come back to a "resting" stage similar to that with which the division began, thus completing the "division cycle" of the cell.

During the whole division cycle it is possible in a few instances to distinguish the chromosomes of the egg from those of the sperm, and in every instance where this can be done it is perfectly clear that these chromosomes do not fuse together nor lose their identity, but that every chromosome splits lengthwise and its halves separate and go into the two daugh- 
A
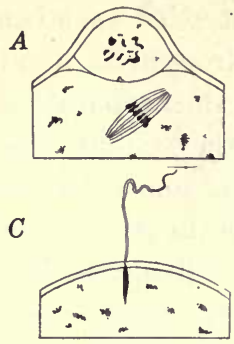

$D$

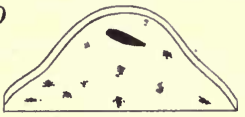

$E$

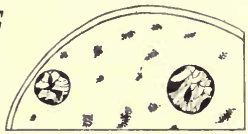

$H$

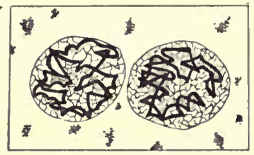

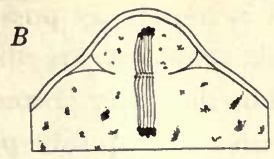

F

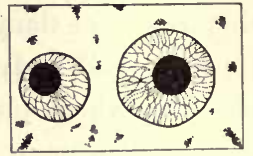

G
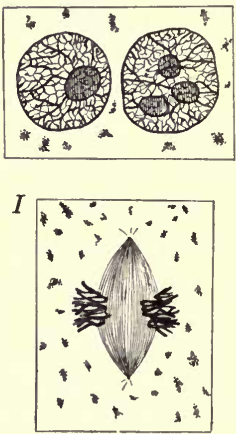

Fig. 25. Maturation and Fertilization of the Egg of THE Mouse. $A$, first polar body and second maturation spindle; $B$, second polar body and niaturation spindle; $C$, entrance of the spermatozoon into the egg; $D-G$, successive stages in the approach of egg and sperm nuclei; $H$, formation of chromosomes in each germ nucleus; $I$, first cleavage spindle showing chromosomes from egg and sperm on opposite sides of spindle. (After Sobotta.) 
ter cells where they form the daughter nuclei. Each of these cells therefore receives half of its chromosomes from the egg and half from the sperm. Even in cases where the individual chromosomes are lost to view in the daughter nuclei those nuclei may sometimes be clearly double, one-half of each having come from the egg chromosomes and the other half from the sperm chromosomes (Fig. 26).

At every subsequent cleavage of the egg the chromosomes divide in exactly the same way as has been described for the first cleavage. Every cell of the developing animal receives one-half of its chromosomes from the egg and the other half from the sperm, and if the chromosomes of the egg differ in shape or in size from those of the sperm, as is sometimes the case when different races or species are crossed, these two groups of chromosomes may still be distinguished at advanced stages of development. Where the egg and sperm chromosomes are not thus distinguishable it may still be possible to recognize the half of the nucleus which comes from the egg and the half which comes from the sperm even up to 

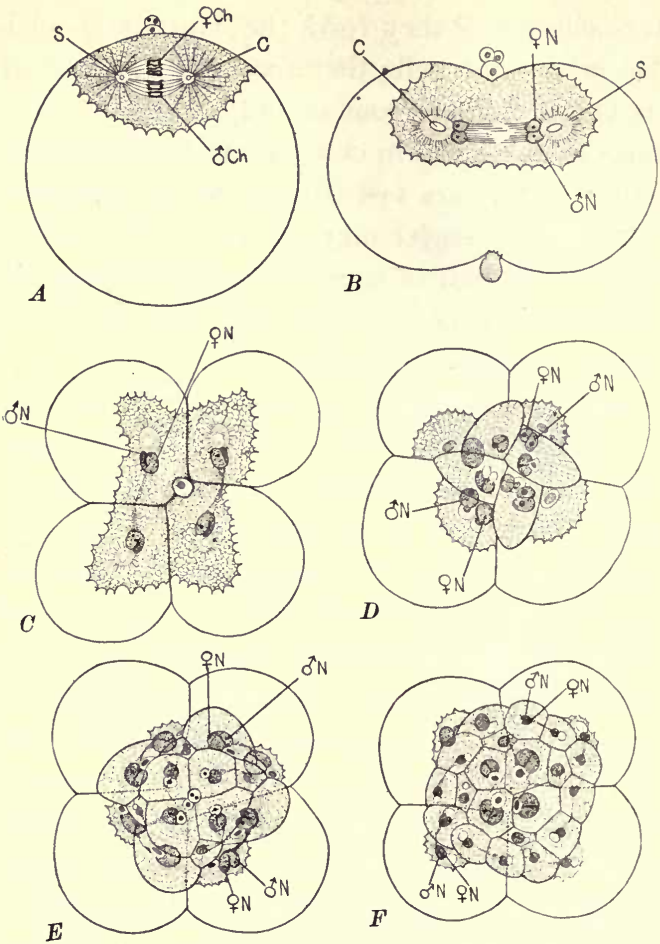

Fig. 26. Successive Stages in the Cleavage of the Ego of A Mollusk (Crepidula), showing the separateness of the male and female chromosomes $(\delta \mathrm{ch}, q \mathrm{ch}$ ) and of the male and female halves of each nucleus $(\delta N, q N)$. 
an advanced stage of the cleavage (Fig. 26). At the same time that the maternal and paternal chromosomes are being distributed with such precise equality to all the cells of the developing organism the different substances in the cell body outside of the nucleus may be distributed very unequally to the cleavage cells. The movements of the cytoplasm of the egg which began with the flowing of the surface layer to the point of entrance of the sperm lead to the segregation of different kinds of plasms in different parts of the egg and to the unequal distribution of these substances to different cells.

One of the most striking cases of this is found in the ascidian, Styela, in which there are four or five different kinds of substance in the egg which differ in color, so that their distribution to different regions of the egg and to different cleavage cells may be easily followed, and even photographed, while in the living condition. The peripheral layer of protoplasm is yellow and when it gathers at the lower pole of the egg where the sperm enters it forms a yellow cap (Fig. 27, 1). 
This yellow substance then moves, following the sperm nucleus, up to the equator of the egg on the posterior side and there forms a yellow crescent extending around the posterior side of the egg just below the equator (Fig. $27,3)$. On the anterior side of the egg a gray crescent is formed in a somewhat similar manner and at the lower pole between these two crescents is a slate blue substance, while at the upper pole is an area of colorless protoplasm. The yellow crescent goes into cleavage cells which become muscle and mesoderm, the gray crescent into cells which become nervous system and notochord, the slate blue substance into endoderm cells and the colorless substance into ectoderm cells.

Thus within a few minutes after the fertilization of the egg, and before or immediately after the first cleavage, the anterior and posterior, dorsal and ventral, right and left poles are clearly distinguishable, and the substances which will give rise to ectoderm, endoderm, mesoderm, muscles, notochord and nervous system are plainly visible in their characteristic positions. 
At the first cleavage of the egg each of these substances is divided into right and left halves (Fig. 27, 5). The second cleavage cuts off two anterior cells containing the gray crescent from two posterior ones containing the yellow crescent (Fig. 27, 6 and Fig. 28, 1). The third cleavage separates the colorless protoplasm in the upper hemisphere from the slate blue in the lower (Fig. 28, 2). And at every successive cleavage the cytoplasmic substances are segregated and isolated in particular cells, and in this way the cytoplasm of the different cells comes to be unlike (Figs. 28 and 29). When once partition walls have been formed between cells they permanently separate the substances in the different cells so that they can no longer commingle.

What is true of Styela in this regard is equally true of many other ascidians, as well as of Amphioxus and of the frog, though the segregation of substances and the differentiation of cells are not so evident in the last named animals because these substances are not so strikingly colored. Indeed the segregation and isolation of different protoplasmic sub- 

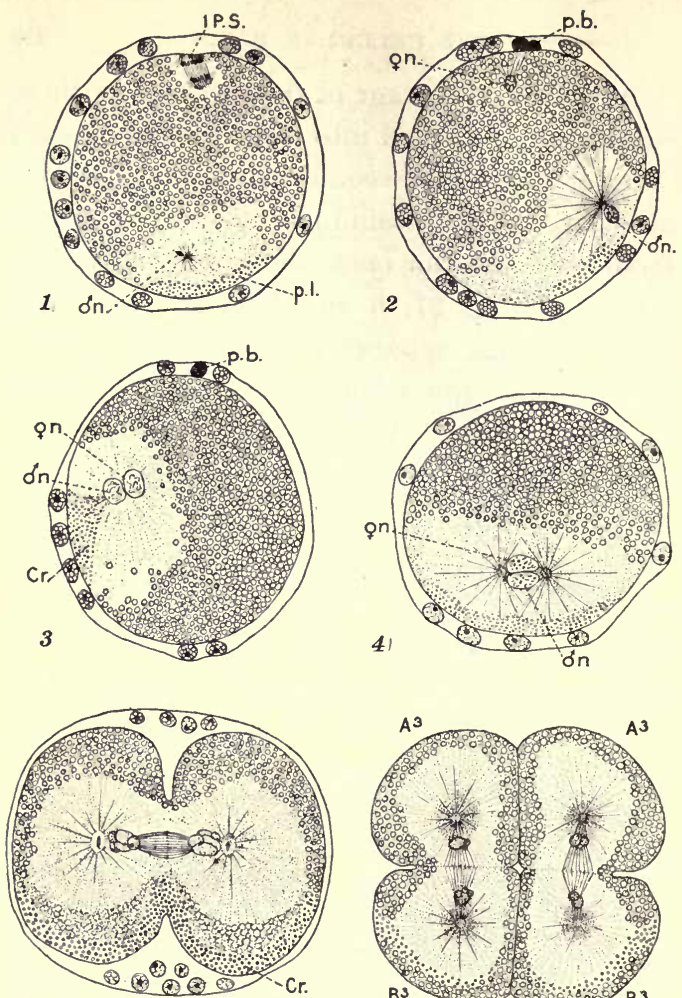

5

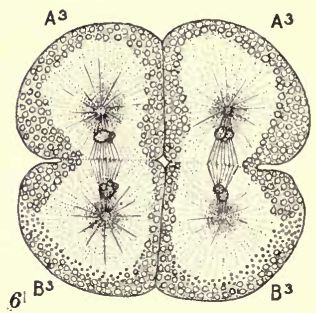

FIG. 27.

Fig. 27. Sections of the Egg of Styela, showing maturation, fertilization and early cleavage; $1 P$. S., first polar spindle, $p . b$. , polar bodies, $\delta N$, sperm nucleus, $\uparrow N$, egg nucleus, $p . l$., peripheral layer of yellow protoplasm, $C r$. crescent of yellow protoplasm, $A_{3}, A_{3}$, anterior cells, $B_{3}$, $B_{3}$, posterior cells of the 4-cell stage. In 1 the sperm nucleus and centrosome are at the lower pole near the point of 

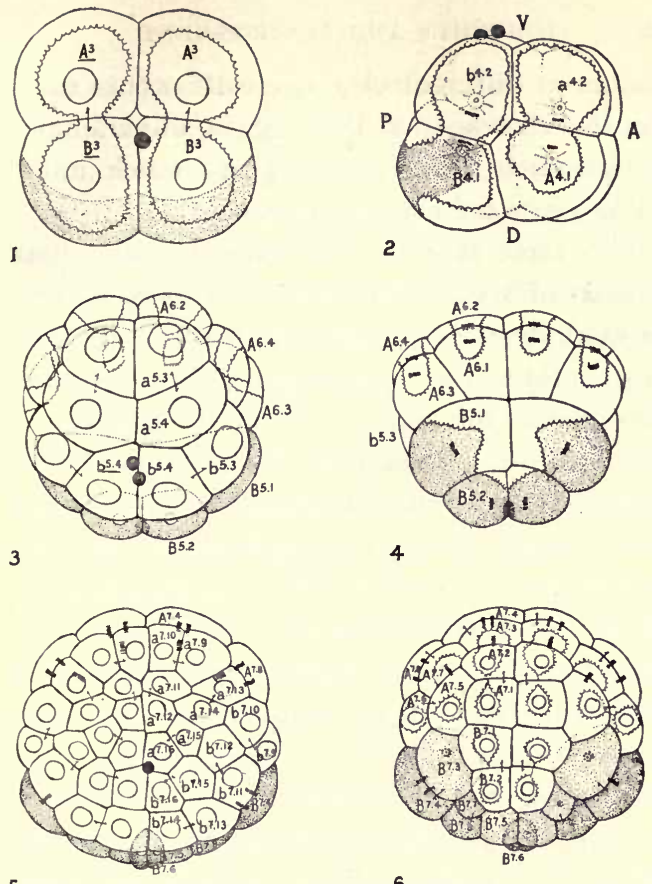

5

Frg. 28.

entrance; in 2 and 3 they have moved up to the equator on the posterior side of the egg; in 4 the egg and sperm nuclei have come together and the sperm centrosome has divided and formed the cleavage spindle; in 5 the egg is dividing into right and left halves; in 6 it is dividing into anterior and posterior halves.

Fig. 28. Cleavage of the Egg of Styela, showing distribution of the yellow protoplasm (stippled) and of the clear and gray protoplasm to the various cells, each of which bears a definite letter and number. 
stances in different cleavage cells occurs during the cleavage of the egg in all animals, though such differentiations are much more marked in some cases than in others.

This same type of cell division, with equal division of the chromosomes and more or less unequal division of the cell body, continues long after the cleavage stages, indeed throughout the entire period of embryonic development. Sometimes the division of the cell body is equal, the daughter cells being alike; sometimes it is unequal or differential, but always the division of the chromosomes is equal and non-differential. When once the various tissues have been differentiated the further divisions in these tissue cells are usually non-differential even in the case of the cell bodies.

There can be no doubt that this remarkably complicated process of cell division has some deep significance; why should a nucleus divide in this peculiarly indirect manner instead of merely pinching in two, as was once supposed to be the rule? What is the relation of cell division to embryonic differentiation? In this 
- process of mitosis, or indirect cell division, two important things take place: (1) Each chromosome, chromomere and centrosome is divided exactly into two equal parts so that each daughter structure is at the time of its formation quantitatively one-half the size and qualitatively precisely like its mother structure. (2) Accompanying the formation of radiations, which go out from the centrosomes into the cell body, diffusion currents are set up in the cytoplasm which lead to the localization of different parts of the cytoplasm in definite regions of the cell, and this cytoplasmic localization is sometimes of such a sort that one of the daughter cells may contain one kind of cell substance and the other another kind. 'Thus while mitosis brings about a scrupulously equal division of the elements of the nucleus, it may lead to a very unequal and dissimilar division of the cytoplasm. In this is found the significance of mitosis, and it suggests at once that the nucleus contains undifferentiating material, viz., the idioplasm or germ-plasm, which is characteristic of the race and is carried on from cell to cell and from 

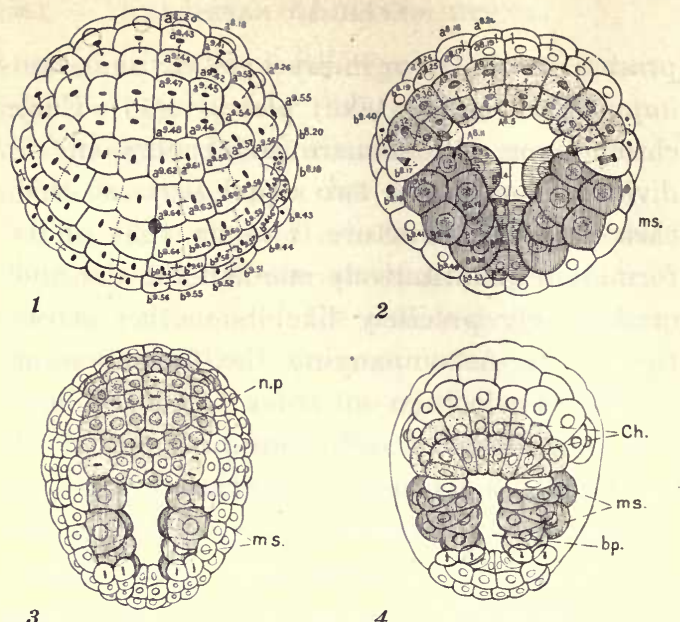

3

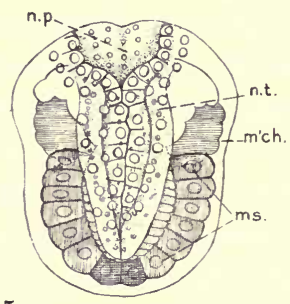

5
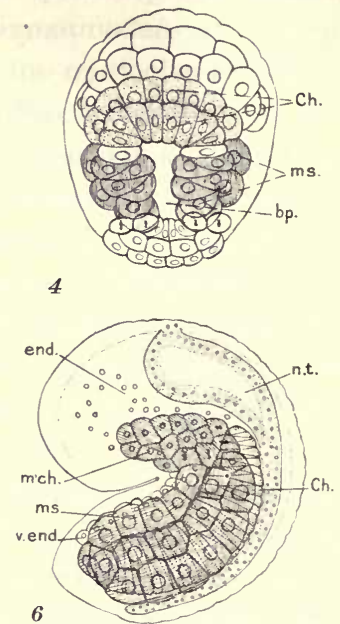

Fig. 29. Gastrula and Larva of Styela, showing the cell lineage of various organs, and the distribution of the different kinds of protoplasm to these organs. Muscle cells are shaded by vertical lines, mesenchyme by horizontal lines, nervous system and chorda by stipples. 
generation to generation; whereas the cell body contains the differentiating substance, the personal plasm or somatoplasm which gives rise to all the differentiations of cells, tissues and organs in the course of ontogeny.

Weismann supposed that the mitotic division of the chromosomes during development was of a differential character, the daughter chromosomes differing from each other at every differential division in some constant and characteristic way, and that these differentiations of the chromosomes produced the characteristic differentiations of the cytoplasm which occur during development. But there is not a particle of evidence that the division of chromosomes is ever differential; on the contrary, there is the most complete evidence that their division is always remarkably equal both quantitatively and qualitatively. If daughter chromosomes and nuclei ever become unlike, as they sometimes do, this unlikeness occurs long after division and is probably the result of the action of different kinds of cytoplasm upon the nuclei, as is true, for example, in the differentiation of the chromosomes in 
the somatic cells as contrasted with the germ cells of Ascaris (Fig. 30). But while the chromosomes invariably divide equally, other portions of the nucleus may not do so. Achromatin and oxychromatin, like the cytoplasm, may divide unequally and differentially, and this is probably a prime factor in development.

On the other hand, the differential division of the cytoplasm is a regular and characteristic feature of ontogeny; indeed, the segregation and isolation of different kinds of cytoplasm in different cells is the most important function of cell division during development. 'Thus we find in the division apparatus of the cell a mechanism for the preservation in unaltered form of the species plasm, or germ-plasm of the nucleus, and for the progressive differentiation of the personal plasm or somatoplasm of the cell body.

3. The Origin of the Sex Cells.-The sex cells are the latest of all cells of a developing organism to reach maturity, and yet they may be among the earliest to make their appearance. Every sex cell, like every other type of 
A.
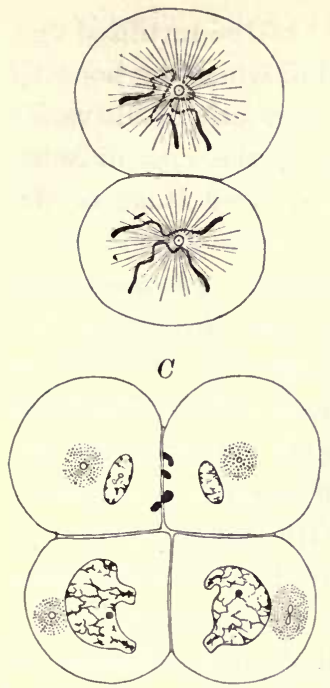

Fig. 30. Differentiation of Germ Cells and Somatic Celis in the Ege of Ascaris. $A$ and $B$, second cleavage division showing that the chromosomes remain entire in the lower cell, which is in the line of descent of the sex cells ("germ track"), but that they throw off their ends and break up into small granules in the upper cells, which become somatic cells. $C$, 4-cell stage, the nuclei in the upper (somatic) cells being small and the ends of the chromosomes remaining as chromatic masses in the cell body outside of the nuclei, while the nuclei in the lower cells are much larger and contain all the chromatin. $D$, third nuclear division, showing the somatic differentiation of the chromosomes in all the cells except the lower right one, which alone is in the germ track and will ultimately give rise to sex cells. (After Boveri.) 
cell, is a lineal descendant of the fertilized egg (Fig. 22), but the period at which the sex cells become visibly different from other cells varies from the first cleavage of the egg in some species to a relatively advanced stage of development in others.

(a) The Division Period. Oogonia and Spermatogonia.-When the primitive sex cells are first distinguishable they differ from other cells only in the fact that they are less differentiated; they have relatively larger nuclei and smaller cell bodies, a condition which is indicative of little differentiation of the cell body since the products of differentiation such as fibres, secretions, etc., swell the size of the cell body but do not contribute to the growth of the nucleus. These primitive sex cells or gonia divide repeatedly, but the oogonia grow more rapidly and divide less frequently than the spermatogonia. As a result of this difference in the rate of growth and division the spermatogonia become much smaller and immensely more numerous than the oogonia. This period in the genesis of the sex cells is known as the division period (Fig. 22). 
(b) The Growth Period. Oocytes and Spermatocytes.-This period of rapid cell division is followed by a period of growth without division during which the developing sex cells are called primary oocytes or spermatocytes. This growth period may be very long in the case of the oocytes, lasting, for example, in the human female from the time of birth to the end of the reproductive period; during this long time the oocytes in the ovary probably never divide, there are as many of them at birth as at any later time; during this period of growth the ovarian egg becomes relatively large, in some animals, e. g. birds, the largest of all cells. The growth period of a spermatocyte lasts for a briefer time than does that of an oocyte so that the former remains relatively small (Fig. 22).

All of the cell divisions which take place during the division period are of the usual kind, in which every chromosome splits lengthwise into two and the two halves then separate and move to opposite poles of the spindle where they break up into threads and granules and form the daughter nuclei, as is 
shown in Fig. 24. But during the growth period of the oocytes and spermatocytes the chromosomes form a closely wound coil of long chromatin threads (Fig. 31), and when
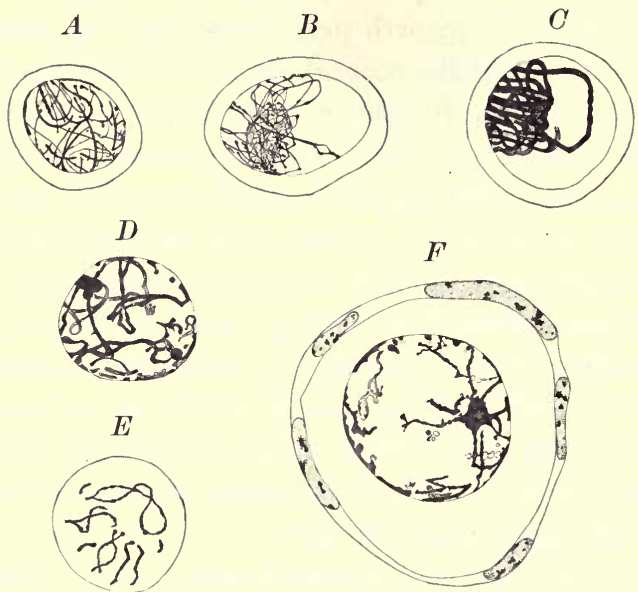

Fig. 31. Different Stages in the Development of the EgG of the Rabit. $A$, at the beginning of the growth period showing slender chromatic threads in the nucleus; $B$, later stage in which these threads ball up and parallel threads conjugate forming the shorter, thicker thread shown in $C$; $D$ and $E$, segmentation of the long thread into chromosomes each of which shows its double nature; $F$, later stage in which the distinctness of the chromosomes is temporarily lost. (After Winiwarter.) 
these threads uncoil later it is seen that the chromosomes have united in pairs (Figs. $31 D$ and $E, 32 B, 33 B$ ) ; this process is known as synapsis, or the conjugation of the chromosomes, and there is evidence that one member of each synaptic pair is derived from the father, and the other from the mother. The union of these chromosomes is probably not so close that they lose their identity, though there may possibly be some interchange of substance between them. By this union of the chromosomes into pairs the number of separate chromosomes is reduced to half the normal number; if there are usually 4 chromosomes, as in Ascaris, they are reduced to 2 pairs; if 48 chromosomes, as in man, there are 24 of these pairs.

In the conjugation of the chromosomes it is plain that, generally speaking, those chromosomes which are similar in shape and size unite; big chromosomes unite with big ones, little ones with little ones, and those of peculiar shape with others of similar shape (Figs. $32 B, 33 B$ ). It is probable that the two members of a pair of conjugating chromo- 

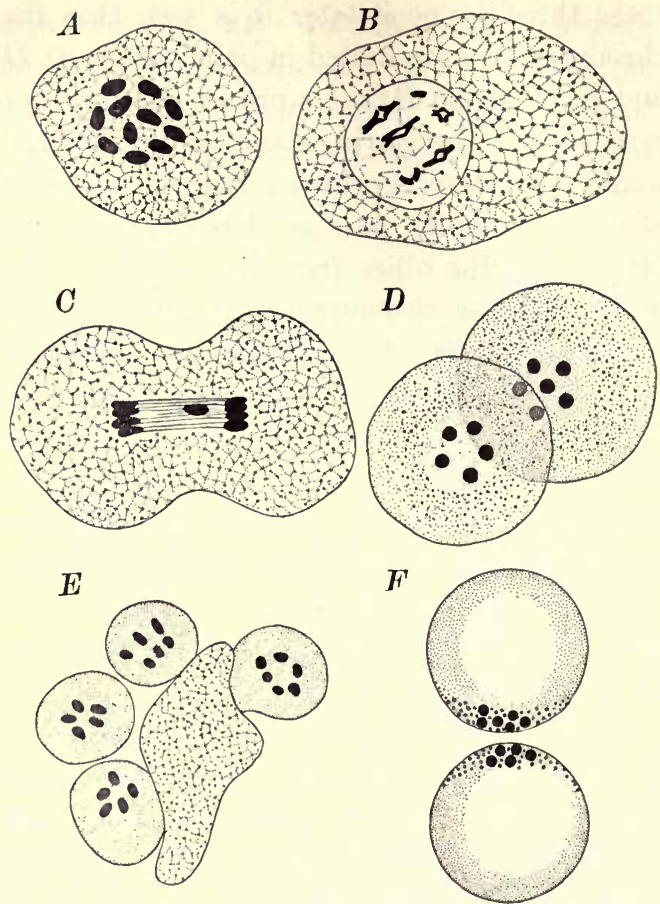

Fig. 32. Spermatogenesis of a Nematode Worm (Ancyracanthus). $A$, chromosomes of sperm mother cell, 11 in number, before their union into pairs. $B$, early stage of first division; 10 of the chromosomes have united into 5 pairs and each of these has split lengthwise; 1 chromosome remains un- 
somes are homologous not merely in shape and size but also in function, though this homology does not amount to identity.

In some instances it can be proved that one member of each conjugating pair of chromosomes comes from one parent and the other from the other parent, and it is probable that this is always true. In every cell of every individual which has developed from a fertilized egg there are two full sets of chromosomes, one of which came from the sperm and the other from the egg; but when this individual in its turn produces germ cells homologous chromosomes of each set unite in pairs, during the growth period.

These synaptic pairs are the bivalent chromosomes, and in addition to showing the line of junction by which they are united they fre-

paired. $C$, first maturation division after the 5 pairs of chromosomes have pulled apart; the unpaired chromosome is going entire to one pole of the spindle. $D$, two cells resulting from this division, one containing 5 and the other 6 chromosomes. $E$, four cells resulting from the division of two cells like $D$, in which each chromosome has split into two so that two of the cells contain 5 and two contain 6 chromosomes. $F$, two of these cells changing into spermatozoa, one containing 5 and the other 6 chromosomes. (After Mulsow.) 

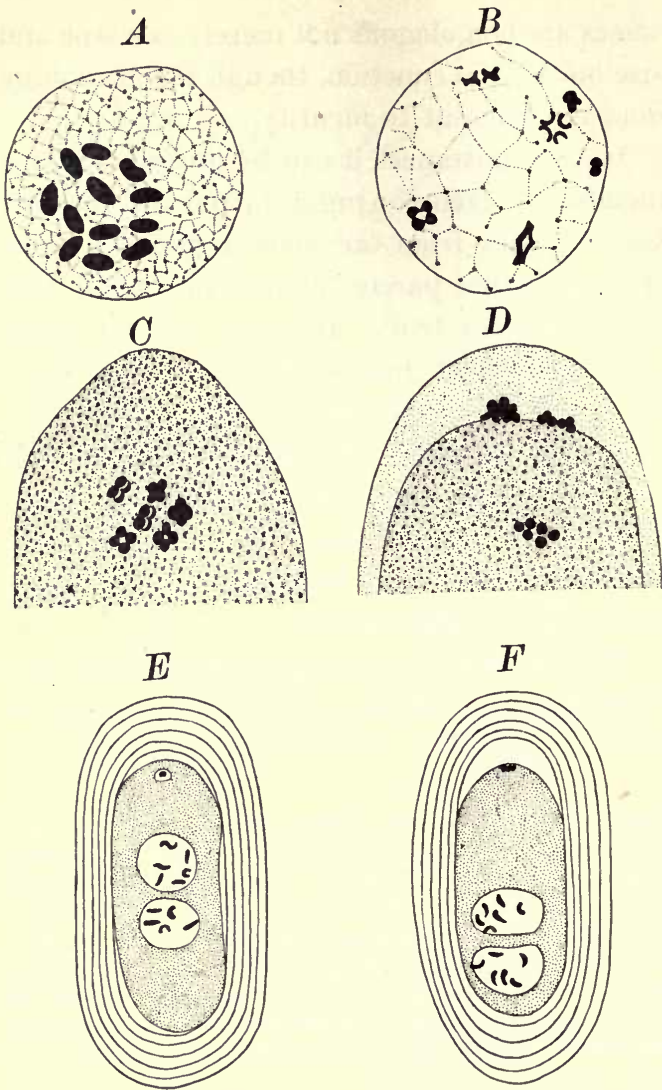

FIo. 33. For description see p. 135. 
quently show a longitudinal split through the middle of each chromosome and at right angles to the line of junction. It thus happens that these bivalent chromosomes are frequently four-parted and such four-parted chromosomes are known as tetrads (Figs. $32 \boldsymbol{B}$, $33 \mathrm{~B})$.

(c) The Maturation Period.-Finally at the close of the growth period both oocyte and spermatocyte undergo two peculiar divisions, one following immediately after the other, which are unlike any other cell divisions. These are known as the first and second maturation divisions and they are the last divisions which take place in the formation of the

Fig. 33. Oogenesis of a Nematode Worm (Ancyracanthus). $A$, egg mother cell containing 12 chromosomes before their union into pairs. $B$, early stage of first maturation division; all the chromosomes have united into 6 pairs, and all but one of these has split in two so that the pairs are really four-parted (tetrads). $C$, the six tetrads in the first maturation division. $D$, egg containing 6 chromosomes, after both first and second maturation divisions; the eliminated chromosomes are shown as the polar bodies at the margin of the eggs. $E$ and $F$, eggs after fertilization; the egg nucleus is above and contains 6 . chromosomes, the sperm nucleus is below and contains 5 chromosomes in one case and 6 in the other; the former becomes a male with 11 chromosomes, the latter a female with 12 chromosomes. (After Mulsow.) 
egg and sperm. In one or the other of these two maturation divisions the pairs of chromosomes separate along the line of junction, one member of each pair going to one pole of the spindle and the other to the other pole, so that in each of the daughter cells thus formed only a single set of chromosomes is present (Fig. $32 C$ and $D$ ) ; but since the position of the pairs of chromosomes in the spindle is a matter of chance it rarely happens that all the paternal chromosomes go to one pole and all the maternal ones to the other; thus each of the sex cells comes to contain a complete set of chromosomes, though particular individual chromosomes may have come from the father while others have come from the mother. There is reason to believe that homologous chromosomes show general resemblances but individual differences, and consequently when the members of each pair separate and go into the sex cells these cells differ among themselves because the individual chromosomes in different cells are not the same in hereditary value.

In this way the number of chromosomes in 
the mature egg or sperm comes to be one-half the number present in other kinds of cells, and when the egg and sperm unite in fertilization the whole number is again restored. 'The double set of chromosomes is known as the diploid number, the single set as the haploid number, and the maturation division in which this reduction from the double to the single set takes place is the reduction division. It is generally held that this reduction takes place in the first of the two maturation divisions (Fig. 32, C, D), and that the second of these divisions is like an ordinary mitosis in that each chromosome splits into two and the halves move apart, such a division being known as an equation division (Fig. $32 \boldsymbol{E}$ ), but it is possible that some chromosome pairs undergo an equation division in the first maturation mitosis and a reduction division in the second, while other chromosome pairs may reverse this order.

It is an interesting fact that long before the reduction of chromosomes had been actually seen Weismann maintained on theoretical grounds that such a reduction must occur, 
otherwise the number of chromosomes would double in every generation, and he held that this reduction must take place in one of the maturation divisions; this hypothesis of Weismann's is now an established fact.

As the result of these two maturation divisions four cells are formed from each cell (spermatocyte or oocyte) of the growth period. In the spermatogenesis each of these four cells is transformed into a functional spermatozoon (Fig. $32 E$ ), by the condensation of the nucleus into the sperm head and the outgrowth of the centrosome and cytoplasm to form the tail. In the oogenesis only one of these four cells becomes a functional egg while the other three are small rudimentary eggs which are called polar bodies and which take no further part in development (Fig. 23, $\boldsymbol{C}-\boldsymbol{F})$. The fertilization of the egg usually takes place coincidently with the formation of the polar bodies, and so we come back once more to the stage from which we started, thus completing the life cycle.

4. Sex Determination.-In the formation of the sex cells one can frequently distinguish 
at an early stage differences between the larger oogonia and the smaller and more numerous spermatogonia; this difference is the first visible distinction in the development of the two sexes. In the case of the human embryo this distinction can be made as early as the fifth week, and it is evident that the real causes of this difference must be found at a still earlier period of development.

The cause of sex has been a favorite subject of speculation for thousands of years. Hundreds of hypotheses have been advanced to explain this perennially interesting phenomenon. The causes of sex determination have been ascribed to almost every possible external or internal influence and the world is full of people who think they have discovered by personal experience just how sex is determined. Unfortunately these hypotheses and rules are generally founded upon a few observations of selected cases. Since there are only two sexes the chances are that any hypothesis will be right half the time, and if only one forgets the failures of a rule and remembers the times when it holds good it is possible to be- 
lieve in the influence of food or temperature or age, of war or peace or education on the relative numbers of the sexes, or on almost any other thing. By statistics it has been shown that each of these things influences the sex ratio, and by more extensive statistics it has been proved that they do not.

This was the condition regarding the causes of sex determination which prevailed up to the year 1902. Immediately preceding that year it had been found that two kinds of spermatozoa were formed in equal numbers in certain insects; one of these kinds contained a peculiar "accessory" chromosome, and the other lacked it. 'The manner in which these two types of spermatozoa were formed had been carefully worked out by several investigators without any suspicion of the real significance of the facts. It was shown that an uneven number of chromosomes might be present in the spermatogonia of certain insects and that when maternal and paternal chromosomes united in pairs in synapsis one "odd" chromosome was left without a mate (Fig. $32 B$ ). Later, in the reduction division, 
when the synaptic pairs separated, the odd chromosome went entire into one of the daughter cells, and the spermatozoa formed from this cell contained one chromosome more than those formed from the other daughter cell (Fig. $32 C$ and $D$ ).

Chiefly because these two kinds of spermatozoa occur in equal numbers McClung in 1902 concluded that this accessory chromosome was a sex-determinant. In 1905 Wilson discovered in a number of bugs that while there were two types of spermatozoa, one of which contained and the other lacked the accessory chromosome, there was only one type of egg, since every egg contained the accessory chromosome, and he pointed out that if an egg were fertilized by a sperm containing an accessory, two accessories would be present in the zygote, this being the condition of the female, while if it were fertilized by a sperm without an accessory there would be present in the zygote only the accessory derived from the egg (Fig. $33 \boldsymbol{E}$ and $\boldsymbol{F}$, Fig. 34).

In other cases Miss Stevens as well as Wilson discovered that two accessory chromo- 
somes, differing in size, might be present in the male whereas in the female they are of equal size (Fig. 35). In such cases two types of spermatozoa are produced in equal numbers, one containing a large and the other a small accessory chromosome, whereas every

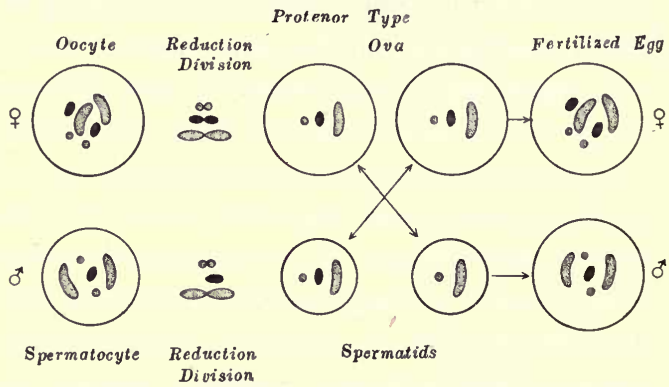

Fig. 34. Diagrams of Sex Differentiation in the Bug, Protenor. The oocyte contains 6 chromosomes and the spermatocyte 5 chromosomes which are not yet united into synaptic pairs; the "sex" chromosomes are shown in black, two are present in the oocyte, but only one in the spermatocyte. In the reduction division the synaptic pairs separate, giving rise to two types of spermatozoa, one of which has the sex chromosome and the other lacks it; all ova are alike in this regard. If an egg is fertilized by a sperm without the sex chromosome a male results; if fertilized by a sperm containing the sex chromosome a female results. (After Wilson with modifications.) 
egg contains one large accessory chromosome. If such an egg is fertilized by a sperm containing a large accessory (the $\boldsymbol{X}$ chromosome) it gives rise to a female, if by a sperm containing a small accessory (the $\boldsymbol{Y}$ chromosome) it gives rise to a male (Fig. 35).

In other animals one may not be able to distinguish separate $\boldsymbol{X}$ or $\boldsymbol{Y}$ chromosomes and yet such structures may be joined to one or two ordinary chromosomes. This is the case

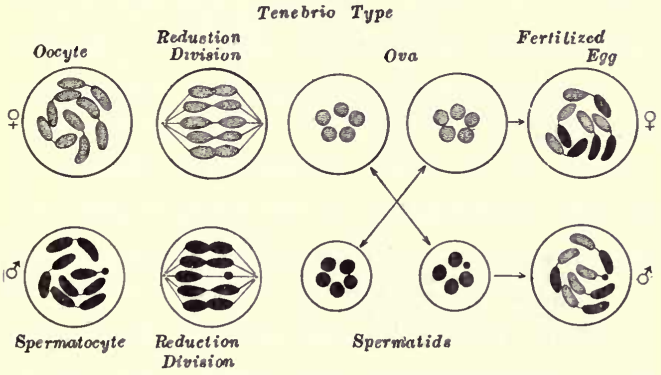

Fig. 35. Diagrams of Sex Differentiation in the Beetle, Tenebrio, showing 5 synaptic pairs of chromosomes (there are actually 10 pairs); in the oocyte the members of each pair are equal in size; in the spermatocyte the members of one pair are unequal. These pairs separate in the reduction division giving rise to two types of spermatozoa and one type of ova; eggs fertilized by one type of sperm give rise to females, those fertilized by the other type give rise to males. (After Stevens with modifications.) 
in the thread worm, Ascaris (Fig. 36), where two such accessory elements are present in the female, each being joined to the end of an ordinary chromosome, whereas in the male only one such element is present. Here also two classes of spermatozoa are found one with and the other without the accessory element, whereas all ova have this element, and in this case also sex is probably determined by the

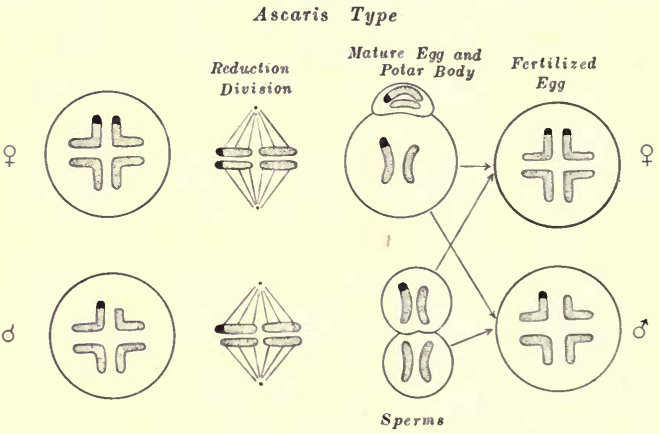

Fig. 36. Diagrans of Sex Differextiation in the Thread Wonv, Ascaris. The $\boldsymbol{X}$ chromosomes are here joined to ordinary chromosomes, there being two in the egg mother cell and one in the sperm mother cell. All eggs contain one of these $\boldsymbol{X}$ chromosomes, while half of the spermatozoa have it and half do not. Eggs fertilized by one type of sperm produce females, those fertilized by the other type produce males. (From Wilson.) 
type of spermatozoon which enters the egg (Fig. 36).

Even in man sex is determined in the same manner, according to several recent investigators. There are in the spermatogonia of man 47 chromosomes, according to Winiwarter, one of which is the $\boldsymbol{X}$ or accessory chromosome (Fig. $37 \boldsymbol{A}$ ). These unite in synapsis into 23 pairs, leaving the $\boldsymbol{X}$ chromosome unpaired (Fig. 37, B) and in the reduction division the pairs separate, while the $\boldsymbol{X}$ chromosome goes entire into one of the daughter cells, which consequently contains $23+\boldsymbol{X}$ chromosomes, whereas the other daughter cell contains 23 chromosomes (Fig. $37 C$ and $D$ ). The former gives rise to spermatozoa with 24 chromosomes, the latter to spermatozoa with 23 chromosomes. In the female there are probably 48 chromosomes, according to Winiwarter, there being two $\boldsymbol{X}$ chromosomes, one from each parent, and after the reduction divisions every egg contains 24 chromosomes. If an egg is fertilized by a sperm containing 24 chromosomes an individual with 48 chromosomes, or a female, is produced; if fertilized 
by a sperm with 23 chromosomes an individual with 47 chromosomes, or a male, results (Fig. 37).

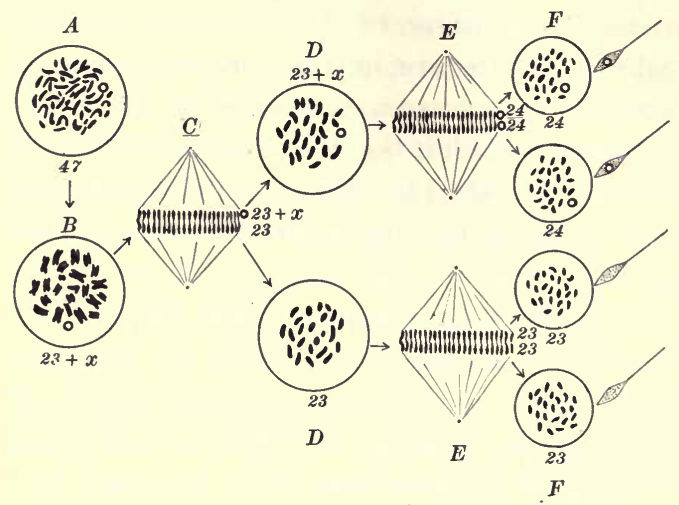

Fig. 37. Diagrams of Sex Differentiation in Man. $A$, spermatogonium with 47 chromosomes one of which (small circle) is the $X$ chromosome. $B$, spermatocyte showing 23 synaptic pairs and a single unpaired $X$ chromosome. $C$, reduction division in which the synaptic pairs separate while the $X$ chromosome does not divide, consequently the second spermatocytes $D$ and $D^{\prime}$ contain respectively $23+X$ and 23 chromosomes. $E$ and $E^{\prime}$, second maturation division in which every chromosome divides, giving rise to two equal classes of spermatids and spermatozoa, one of which has 24 chromosomes and the other 23. If an egg containing 24 chromosomes is fertilized by a sperm with 24 , a female with 48 chromosomes is produced; if an egg with 24 chromosomes is fertilized by a sperm with 23, a male with 47 chromosomes results. (From Morgan after Winiwarter.) 
It must be said that other investigators, notably Guyer and Montgomery, have not found 47 chromosomes in the spermatogonia of man, but 22. Since both the latter investigators worked on negroes whereas Winiwarter worked on white men it has been suggested quite recently by Morgan and Guyer that there may be twice as many chromosomes in the white race as in the black. A similar condition in which one race has twice as many chromosomes as another race of the same species is found in two races of the thread worm, Ascaris megalocephala, but it is still too soon to affirm that this is true of white and black races of man.

Similar correlations between chromosomes and sex have been observed in more than one hundred species of animals belonging to widely different phyla. In a few classes of animals, particularly echinoderms and birds, the evidence while not entirely convincing seems to point to the fact that two types of ova are produced and but one type of spermatozoa; but the general principle that sex is determined by the chance union of male-producing or fe- 
male-producing gametes is not changed by such cases.

On the other hand there are many observations which seem to indicate that the sex ratio may be changed by environmental conditions acting before or after fertilization and that therefore sex is determined by extrinsic rather than by intrinsic causes. Many of these observations, as already remarked, are now known to be erroneous or misleading, since they do not prove what they were once supposed to demonstrate. But there remain a few cases which can not at present be explained away in this manner. Perhaps the best attested of these are the observations of R. Hertwig and some of his pupils on the effects of the time of fertilization on the determination of sex. If frog's eggs, which are always fertilized after they are laid, are kept for some hours before spermatozoa are mixed with them, or if the female is prevented for two or three days from laying the eggs after they have entered the oviducts, the proportion of males to females is enormously increased. A wholly similar result has been reached by 
Pearl and Parshley in the case of cattle, where delayed fertilization of the egg leads to a great preponderance of males. Hertwig attempts to explain his extremely interesting and important observations as due to the relative size of nucleus and cytoplasm of the egg; but in general this nucleus-plasma ratio may vary greatly irrespective of sex and there is no clear evidence that it is a cause of sex determination.

Miss King, also working on toad's eggs, has increased the proportion of females by slightly drying the eggs or by withdrawing water from them by placing them in solutions of salts, acids, sugar, etc., but the manner in which drying increases the proportion of females is wholly unknown.

Extensive statistics show that in many animals including man more males are born than females whereas according to the chromosome theory of sex determination as many femaleproducing spermatozoa are formed as maleproducing ones. It is possible to explain such departure from the 1: 1 ratio of males and females in conformity with the chromosome 
theory if one class of spermatozoa are more active or have greater vitality than the other class, or if after fertilization one sex is more likely to live than the other. In the human species it is known that mortality is greater in male babies before and after birth than in female babies, and if before fertilization the activity or vitality of male-producing spermatozoa is greater than of female-producing ones it would offer a possible explanation of the greater number of males than of females at the time of birth. In certain insects it is known that only females develop from fertilized eggs, and in one of these cases, viz., Phylloxera, Morgan has discovered that this is due to the fact that all the male-producing spermatozoa degenerate and that only femaleproducing spermatozoa become functional. Possibly experimental alterations of the sex ratio, such as Hertwig, King and others have brought about may be explained in a similar way. At least the chromosomal theory of sex determination is so well supported in so many cases and has been found to apply in so many instances where at first it seemed impossible of 
application, that it ought not to be abandoned until unmistakable evidence can be adduced against it. For the present at least we are justified in concluding that sex is irrevocably determined at the time of fertilization.

\section{THE MECHANISM OF HEREDITY}

'The mechanism of heredity, as contrasted with the mechanism of development, consists in the formation of particular kinds of germ cells and in the union of certain of these cells in fertilization. We have briefly traced the origin, maturation and union of male and female sex cells in a number of animals, and in these phenomena we have the mechanism of the hereditary continuity between successive generations. But in addition to these specific facts there are certain general considerations which need to be emphasized.

\section{I. 'The Specificity of Germ Cells}

The conclusion is inevitable that the germ cells of different species and even those of different individuals are not all alike. Every individual difference between organisms must 
be due to one or more differentiating causes or factors. Specific results come only from specific causes. These causes may be found in the organization of the germ cells or in environmental stimuli, $i$. $e$., they may be intrinsic or extrinsic, but as a matter of fact experience has shown that they are generally intrinsic in the germ. In the same environment one egg becomes a chicken and another a duck; one becomes a frog, and another a fish, and another a snail; one becomes a black guinea-pig and another a white one; one becomes a male and another a female; one gives rise to a tall man and another to a short man, etc. Since these differences may occur in the same environment they must be due to differences in the germ cells concerned.

On the other hand different environmental conditions may be associated with similar developmental results. Loeb and others have found that artificial parthenogenesis may be induced by a great variety of environmental stimuli, viz., by salt solutions, by acids and alkalis, by fatty acids and fat solvents, by alkaloids and cyanides, by blood serum and 
sperm extract, by heat and cold, by agitation and electric current. There is certainly nothing specific in these different stimuli. Similarly Stockard has discovered that cyclopia, or one-eyed monsters, may be produced by magnesium salts, alcohol, chloretone, chloroform, and ether. In all such cases it is evident that the specific results of such treatment are due to a specific organization of the germ rather than to specific stimuli.

Why does one egg give rise to a chicken and another to a duck, or a fish, or a frog? Why does one egg give rise to a black guineapig and another to a white one, though both may be produced by the same parents? Why does one child differ from another in the same family? Why does one cell give rise to a gland and another to a nerve, one to an egg and another to a sperm? If these differences are not due to environmental causes, and the evidence shows that they are not, they must be due to differences in the structures and functions of the cells concerned.

Many differences in the material substances of cells are visible, and many more are invisi- 
ble though still demonstrable. These differences may not be detectable by chemical or physical tests, and yet they may be demonstrated physiologically and developmentally. The most delicate of all tests are physiological, as is shown by the Weidal test in typhoid fever, the Wassermann reaction in syphilis, the reactions of immunized animals to different toxins, etc. Lillie has recently shown that egg cells give off a substance which he calls fertilizin, which can be detected only by the way in which spermatozoa react to it. No chemical or physical test can distinguish between the different eggs or spermatozoa produced by the same individual, but the reactions of these cells in development prove that they are different. Undoubtedly chemical and physical differences are here present but no chemical methods at present available are sufficiently delicate to detect them. The developmental test proves that there must be as many kinds of germs as there are different kinds of individuals which come from germs. It is one of the marvellous facts of biology that every individual which has been produced 
sexually is unique, the first and last of its identical kind, and although some of these individual differences are due to varying environment, others are evidently due to germinal differences, so that we must conclude that every fertilized egg cell differs in some respects from every other one.

But are there molecules and atoms enough in a tiny germ cell, such as a spermatozoon, to allow for all these differences? Miescher has shown that a molecule of albumin with $\mathbf{4 0}$ carbon atoms may have as many as one billion stereoisomers, and in protoplasm there are many kinds of albumin and other proteins, some with probably more than 700 carbon atoms. In such a complex substance as protoplasm the possible variations in molecular constitution must be well nigh infinite, and it can not be objected on this ground that it is chemically and physically impossible to have as many varieties of germ cells as there are different kinds of individuals in the world.

Even with regard to morphological elements which may be seen with the microscope it can be shown that an enormous number of permu- 
tations is possible. It seems probable, as Boveri has shown, that different chromosomes of the fertilized egg differ in hereditary potencies, and where the number of chromosomes is fairly large the number of possible combinations of these chromosomes in the germ cells becomes very great. In woman, where there are probably 48 chromosomes, and, after synapsis, 24 pairs of maternal and paternal ones, the possible number of permutations in the distribution of these chromosomes to the different egg cells would be $2^{24}$, or $\mathbf{1 6 , 7 7 7 , 0 3 6}$, and the possible number of different types of fertilized eggs or oosperms which could be produced by a single pair of parents would be $(16,777,036)^{2}$, or approximately three hundred thousand billions. But probably other things than chromosomes differ in different germ cells, and it is by no means certain that individual chromosomes are always composed of the same chromomeres, or units of the next smaller order, and in view of these possibilities it may well be that every human germ cell differs morphologically and physiologically from every other one, in short 
that every oosperm and every individual which develops from it is absolutely unique.

Indeed the production of unique individuals seems to be the chief purpose and result of sexual reproduction. In asexual reproduction the individual variations which occur are chiefly if not entirely due to environment, but in sexual reproduction they are also due to new combinations of hereditary elements. 'The particular germinal organization transmitted from one generation to the next depends upon $(a)$ the ancestral organization, (b) the particular character of the cell divisions by which the germ cells are formed, (c) the particular kinds of egg and sperm cells which combine in fertilization. The ancestral organization determines all the general characteristics of race, species, genus, order, phylum. It determines the possibilities and limitations of individual variations. Given a certain ancestral organization, the individual peculiarities of the germ cells are determined by the particular character of cell division by which the germ cells are formed, and the peculiarities of the individuals or per- 
sons which develop from these cells are determined in large part by the particular kinds of germ cells which unite in fertilization.

The behavior of chromosomes in maturation and fertilization is like the shuffle and deal of cards in a game, and apparently with the same object, viz., never to deal the same hand twice. To make this comparison more complete suppose that kings be discarded from the pack, leaving 48 cards of two colors, red and black, which we will compare to the 48 chromosomes of maternal and paternal origin in the human oocyte; suppose that in the shuffling of these cards corresponding cards of the red and the black suits are temporarily stuck together so that the ace of diamonds is united with the ace of clubs, the queen of hearts with the queen of spades, etc., thus forming 24 redblack pairs of the same denominations. If these cards are then dealt into two hands, one card of each pair going to one hand and the other to the other hand, we will have two cards of each denomination in each hand, but if the cards are dealt indiscriminately some of them will be red and some black. This de- 
scription parallels what takes place in the maturation of the human ovum, except that there is no evidence that there are more than two suits of chromosomes, one of which is maternal and the other paternal.

To carry out this comparison in the case of the maturation of the human sperm where there are only 47 chromosomes it is necessary to take another pack and discard an additional card, say the queen of clubs; then in the union of corresponding red and black cards into pairs the queen of hearts unites with the queen of spades, but the queen of diamonds remains alone, and when the cards are dealt into two hands as before one hand will contain 24 cards and the other 23.

If now we complete this comparison by extending it to what takes place in fertilization we must take one hand from each of these deals and put them together into one pack; this pack would contain cards of every denomination from ace to queen but there would be varying numbers of red and black cards and a mixture of cards from two distinct packs. In no game of cards do corresponding cards 
from different packs have slightly different values nor are half of the cards taken from one pack and half from another at every game, but this is just what happens in the shuffle and deal of the chromosomes. Because of the mixture of chromosomes from distinct individuals in every generation, each of which has its own peculiar value, the game of heredity becomes vastly more complex than any game of cards.

This illustration may serve to make plain the fact that in the process of maturation and fertilization there is this shuffle and deal of the chromosomes, with the result that every oosperm and every individual which develops from it is different from every other one.

This conception of the specificity of every germ cell, as well as of every developed individual, sets the whole problem of heredity and development in a clear light. The visible peculiarities of an adult become invisible as development is traced back to the germ, but they do not wholly cease to exist. Similarly the multitudinous complexities of an adult fade out of view as development is traced to its earliest stages, but it is probable that they 
are not wholly lost. In short, the specificity of the germ applies not merely to those things in which it differs from other germs, but also to characters in which it resembles others; in short, to hereditary resemblances no less than to hereditary differences.

The mistake of the doctrine of preformation was in supposing that germinal parts were of the same kind as adult parts; the mistake of epigenesis was in maintaining the lack of specific parts in the germ. The development of every animal and plant consists in the transformation of the specific characters of the germ into those of the adult, but not in the formation of structures or characters de novo. From beginning to end development is a series of morphological and physiological changes but not of new formations or creations. It is only the incompleteness of our knowledge of development which allows us to say that the eye or ear or brain begins to form in this or that stage. They become visible at certain stages, but their real beginnings are indefinitely remote. 


\section{Correlations Between Germinal and Somatic Organization}

All the world knows that the organization of the germ is not the same as that of the developed animal which comes from it, and yet the specificity of the germ indicates that there must be some correlation between the germinal and the developed organization; in short, there is not identity of organization but correlation of organization between the germ and the adult. What correlations are known to exist between the oosperm and the developed animal?

1. Nuclear Correlations.-Many biologists maintain that the nucleus and more particularly the chromosomes are the exclusive seat of the "inheritance material" and that all the "determiners" of adult characters are located in them. Against the extreme form of this theory many general and specific objections may be urged. General objections are based upon the consideration that the entire cell, cytoplasm as well as nucleus, is concerned in 
differentiation and that neither is capable of embryonic development in the absence of the other. Differentiation is indeed the result of the interaction of nucleus and cytoplasm, and how then can it be said that the nucleus is the only seat of the inheritance material? If held rigidly, this theory involves the assumption that the cytoplasm and all other parts of the cell are the products of the chromosomes, and that therefore the chromosome and not the cell is the ultimate independent unit of structure and function; an assumption which is contrary to fact. Furthermore, since heredity includes a series of fundamental vital processes such as assimilation, growth, division and differentiation, there is something primitive and naïve in the view that this most general process can be localized in one specific part of the cell, something which recalls the long-past doctrine that the life was located in the heart or in the blood, or the ancient attempts to find the seat of the soul in the pineal gland or in the ventricles of the brain.

On the other hand it is objected by certain investigators, notably by Child, Foot and Stro- 
bell, that chromosomes are not the causes of anything, but that they are the "results of dynamic processes," "the expression rather than the cause of cell activities." 'This objection seems to confuse the idea of natural cause with that of final cause. Science knows nothing of the latter; any natural cause is only a link in the chain of cause and effect, it is itself the result of antecedent causes and the cause of subsequent results. Undoubtedly the chromosomes are the result of antecedent processes, and yet they may also be the causes of subsequent processes. No thoughtful person has ever maintained that chromosomes or any other things in nature are autonomous, absolute, uncaused causes.

There are certain general and a priori reasons for assuming that the chromosomes are important factors in heredity and differentiation: (1) they come in approximately equal numbers from the father and the mother, (2) one-half of each of the maternal and paternal chromosomes is distributed to each cell of the developing organism, (3) in the formation of 
the egg and sperm cells the normal number of chromosomes is reduced by one-half, and (4) in fertilization the normal number is restored by the union of the chromosomes of the egg and sperm. It is a remarkable fact that the determiners or factors of certain inherited characters come in equal numbers from both parents and that in spite of their ultimate association in an individual they may be separated or "segregated" in the formation of that individual's germ cells. Such inheritance is known as Mendelian and will be treated at length in the next chapter, but it may be said here that the association, distribution and segregation of Mendelian factors and of maternal and paternal chromosomes are exactly parallel. This is strong evidence that these factors are associated in some way with the chromosomes.

There are also certain special reasons for considering that the chromosomes are important factors in heredity and development: (5) Boveri has studied the abnormal distribution of chromosomes to different cleavage cells in doubly fertilized sea urchin eggs and has 
found evidence that the hereditary value of different chromosomes is different. (6) McClung, Stevens and Wilson have discovered that the determination of sex is associated with the presence or absence of a particular chromosome, the $\boldsymbol{X}$ chromosome, in the spermatozoon which fertilizes the egg. If an egg is fertilized by a sperm which lacks the $\boldsymbol{X}$ chromosome a male is produced, if fertilized by the other type a female results. (7) Finally Morgan has found that there is a linkage of certain somatic characters with sex in the fruit fly, Drosophila, which can be readily explained by assuming that the determiners for these characters are in some way associated with the sex chromosome.

We have in these facts a remarkable correlation between the distribution of the chromosomes and the occurrence of certain characters of the adult animal. The association of maternal and paternal chromosomes in fertilization and their segregation in the maturation of the germ cells is parallel to the association of Mendelian characters in the zygote and their segregation in the gametes; if the distribution 
of chromosomes in cleavage is abnormal the larva shows abnormal characters (Boveri); sex determination is associated with the distribution of a particular chromosome to one-half of the spermatozoa, and the fertilization of the egg by one type or the other of spermatozoa (Wilson); the linkage of certain characters with sex finds a ready explanation by assuming that the differential causes of these characters are associated with the sex chromosome (Morgan).

2. Cytoplasmic Correspondences.-On the other hand the most direct and the earliest recognized correlations between the oosperm and the developed animal are found in the polarity and symmetry of the fertilized egg and of the animal to which it gives rise.

(a) Polarity.-In all eggs there is a polar differentiation, one pole, at which the maturation divisions take place, being known as the animal pole, and the opposite one being known as the vegetative pole. The substance of the egg in the vicinity of the animal pole usually gives rise to the ectoderm, or outer cell layer of the embryo; the portion of the egg sur- 
rounding the vegetative pole usually becomes the endoderm or inner cell layer. The axis which connects these poles, the chief axis of the egg, becomes the gastrular axis of the embryo and in every great group of animals bears a constant relationship to the chief axis of the adult animal. The polarity of the developed animal is thus directly connected with the polarity of the egg from which it came (Figs. $23,26,27,28,38,39)$.

(b) Symmetry. - In many cases the symmetry of the developed animal is foreshadowed in the symmetry of the egg. The eggs of cephalopods (Fig. 38) and of insects (Fig. 39) are bilaterally symmetrical while they are still in the ovary; in other cases, such as ascidians, Amphioxus and the frog, bilateral symmetry appears immediately after fertilization (Fig. 27, 1, 2), though in some of these cases there is reason to believe that the eggs are bilateral even before fertilization; in still other cases bilaterality does not become visible until later in development and we do not now know whether it is present in earlier stages or not; but wherever it can be recognized in the earlier 


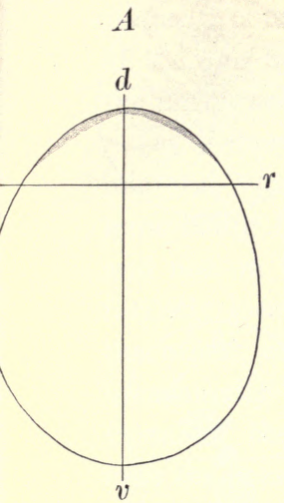

FIG. 38.
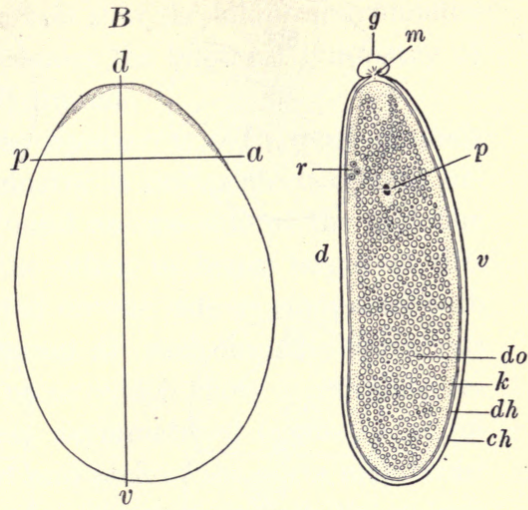

FIG. 39.

Fig. 38. Outhines of the Unfertilized Egg of a Squid, Loligo, showing the polarity and symmetry of the egg with reference to the axes of the developed animal; $d$, dorsal; $v$, ventral; $l$, left; $r$, right; $a$, anterior; $p$, posterior. (After Watase.)

Fig. 39. Median Section throdgh Egg of a Fly, Musca, just after fertilization, showing the relations of the polarity and symmetry of the egg to the axes of the developed animal; the long axis of the egg corresponds to the antero-posterior axis of the animal; $d$, dorsal; $v$, ventral; $m$, micropyle through which sperm enters the egg; $g$, glutinous cap over the micropyle; $r$, polar bodies; $p$, egg and sperm nuclei; $d o$, yolk; $k$, peripheral layer of protoplasm; $d h$, vitelline membrane of egg; ch, chorion. (After Korschelt and Heider.) 

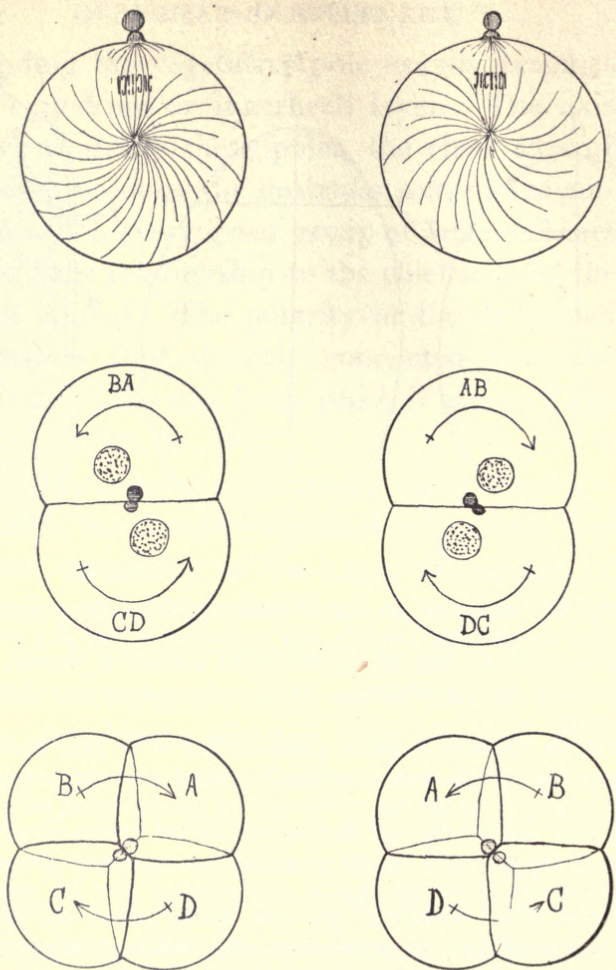

Figs. 40, 41, 42. The Cause of Inverse Symmetry in SNaILs. In each case the right-hand column represents dextral forms, the left-hand column sinistral ones.

Fig. 40. Normal and Inverse Symmetry in the UNsegmented Egg and in the First and Second Cleavages. 
stages it is certain that the bilateral symmetry of the egg becomes the bilateral symmetry of the developed animal.

(c) Inverse Symmetry. - In most animals bilateral symmetry is not perfect, certain organs being found on one side of the mid line and not on the other, or being larger or differently located on one side as compared with the other; among all such animals variations occasionally occur which show a complete reversal of these asymmetrical organs, $i$. e., in man the heart and arch of the aorta may occur on the right side instead of the left, the pyloris and chief portion of the liver on the left instead of the right, etc. Among certain snails this inversion of symmetry may occur regularly in certain species and not in others, the inverse form being known as sinistral and the ordinary form as dextral (Fig. 42). In these sinistral snails, and probably in all animals showing inverse symmetry, the embryo is inversely symmetrical and every cleavage of the egg from the first to the last is the inverse of that which occurs in dextral snails (Figs. 40, 41). 'There is good reason to believe that in 
such cases the unsegmented egg is also inversely symmetrical as compared with the more usual type (Fig. 40). In all of these cases there is a direct correspondence between the polarity and symmetry of the oosperm and the polarity and symmetry of the developed animal (Figs. 38-42).

(d) Localization Pattern.-In many animals the ectoderm, endoderm and mesoderm may be traced back to areas of peculiar protoplasm in the oosperm, but in addition to this one can recognize in the ascidian egg areas of peculiar protoplasm which will give rise to mesenchyme, muscles, nervous system and notochord, and these substances are present in the oosperm in the approximate positions and proportions which they will have in the embryo and larva (Figs. 27-29).

Indeed there are types of localization of these cytoplasmic materials in the egg which are characteristic of certain phyla; thus there are the ctenophore, the flat-worm, the echinoderm, the annelid-mollusk and the chordate types of cytoplasmic localization (Fig. 43). The polarity, symmetry and pattern of a 

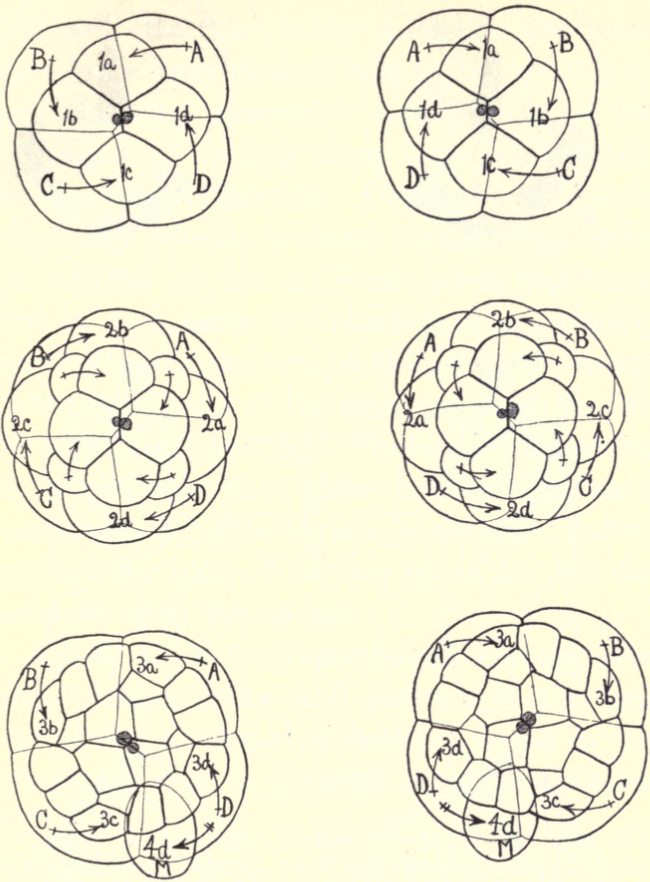

Fig. 41. Normal and Inverse Symmetry of the 3D, 4th, 5 th and 6 Th Cleavages. The cells $1 a-1 d, 2 a-2 d$ and $3 a-3 d$ give rise to all the ectoderm; $4 d$ or $M$ gives rise to mesoderm; $A, B, C, D$ to endoderm. 

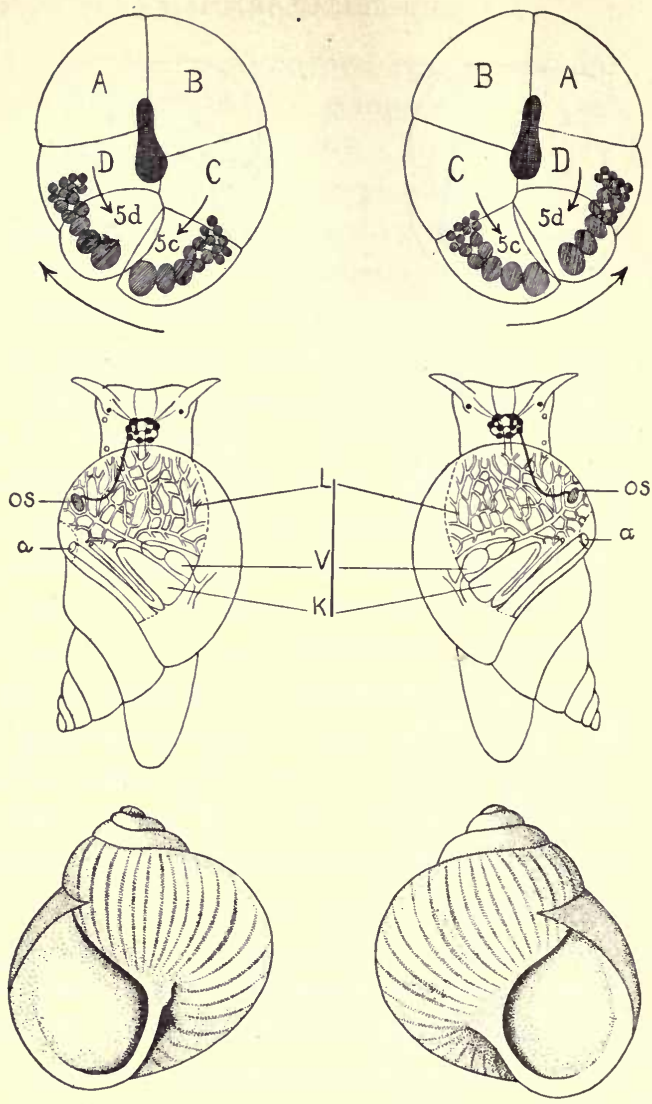

Fi6. 42. For description see p. 175. 
jellyfish, starfish, worm, mollusk, insect or vertebrate are foreshadowed by the characteristic polarity, symmetry and pattern of the cytoplasm of the egg either before or immediately after fertilization. In all of these phyla eggs may develop without fertilization, either by natural or by artificial parthenogenesis, and in such cases the characteristic polarity, symmetry and pattern of the adult are found in the cytoplasm of the egg just as if the latter had been fertilized. The conclusion seems to be justified that these earliest and most fundamental differentiations which distinguished the eggs of various phyla are not dependent upon the sperm.

All of these correspondences between the polarity, symmetry and pattern of the egg and of the developed animal are found in the cytoplasm. It is possible that the polarity

Fig. 42. Normal and Inverse Symmetry in Late Embryos and Adult Stages. In 1, cross-hatched area is blastopore; cells shaded hy lines, mesoderm, other cells, endoderm; the spiral twist of the snail begins in opposite directions in the two embryos. In 2 , the adult organization is shown with all organs inversely symmetrical; os, olfactory organ; $a$, anus; $L$, lung; $V$, ventricle; $K$, kidney. In 3 , sinistral and dextral shells of adult snails are shown. 
may be carried over from generation to generation through the egg cell, but the symmetry and localization pattern develop in the ovum before or just after maturation. In this differentiation and localization of the egg cytoplasm it is probable that certain influences have come from the nucleus of the egg, and perhaps from the egg chromosomes. There is no doubt that most of the differentiations of the egg cytoplasm have arisen during the ovarian history of the egg, and as a result of the interaction of nucleus and cytoplasm; but the fact remains that at the time of fertilization the hereditary potencies of the two germ cells are not equal, all the early stages of development, including the polarity, symmetry, type of cleavage, and the pattern, or relative positions and proportions of future organs, being foreshadowed in the cytoplasm of the egg cell, while only the differentiations of later development are influenced by the sperm. In short the egg cytoplasm fixes the general type of development and the sperm and egg nuclei supply only the details.

We are vertebrates because our mothers 
were vertebrates and produced eggs of the vertebrate pattern; but the color of our skin and hair and eyes, our sex, stature, and mental peculiarities were determined by the sperm as well as by the egg from which we came. There is evidence that the chromosomes of the egg and sperm are the seat of the differential factors or determiners for Mendelian characters, while the general polarity, symmetry and pattern of the embryo are determined by the cytoplasm of the egg (see p. 263).

It will be observed that the correlation between chromosomes and adult characters is different in kind from that between the cytoplasm of the egg and the adult characters; in the latter case polarity, symmetry and pattern are of the same kind in the egg and in the adult, and the correspondence is comparatively close; in the latter there is no correspondence in kind between the chromosomal peculiarities and the pecularities of the adult. This fact might suggest that the chromosomal organization may be more fundamental than that of the cytoplasm. There are reasons for believing that many substances of the cell are formed 



end.

ANRELID

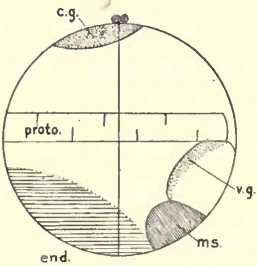

Fig. 43. 'Types of Egg Organization in Different Phyla; cross-hatched area, mesoderm or mesenchyme (mes); horizontal lines, endoderm (end); clear area, ectoderm (ect). In the first four figures the pattern of localization is that which is found at the close of the first cleavage; in Ascidian II the pattern is that which is found at the close of the second cleavage; in the annelid egg the localization of later stages is projected upon the egg; n.p., neural plate; ch., chorda; c.g., cerebral ganglion; v.g., ventral ganglion; proto., prototroch. 
by the interaction of nucleus and cytoplasm, and most probably the chromosomes are an important factor in this process. But in no case is the cytoplasm a neglible factor, in no case does it serve merely as food for the chromosomes. The entire cell, nucleus and cytoplasm, is concerned in heredity and differentiation.

\section{THE MECHANISM OF DEVELOPMENT}

Development consists in the transformation of the oosperm into the adult. What is the mechanism by which this transformation is effected? There is progressive differentiation of the germ into the developed organism but by what process is this differentiation accomplished?

Many different processes are concerned in embryonic differentiation. From the standpoint of the cell the most important of these are (1) the formation of different kinds of substances in cells, (2) the localization and isolation of these substances, (3) the transformation of these substances into the various 
structures which are characteristic of the different kinds of tissue cells. We shall here describe only the first and second of these processes which are of more general interest than the last.

1. The Formation of Different Substances in Cells.-Embryonic differentiation consists primarily in the formation of different kinds of protoplasm out of the protoplasm of the germ cells. It is plain that different kinds of protoplasm are present in the two germ cells before they unite in fertilization, but in the course of development the number of these substances and the degree of difference between them greatly increase.

Actual observation shows that by the interaction with one another of substances or parts originally present and by their reactions to external stimuli new substances and parts appear which had no previous existence just as new substances result from chemical reactions. This is "creative synthesis" in philosophy, epigenesis in development. Differentiations appear chiefly in the cytoplasm but only as the result of interaction between cytoplasm and 
nucleus. Similarly, it may be argued, smaller units of organization such as chromosomes or chromomeres do not in themselves give rise to any adult part, but only as they interact upon other units are new parts formed.

In many cases the first formation of such new substances appears in the immediate vicinity of the nucleus and, like assimilation itself, is evidently brought about by the interaction of nucleus and cytoplasm. In certain cases it can be seen that the achromatin and oxychromatin which escape from the nucleus during division take part in the formation of new substances in the cell body, and since the oxychromatin is derived from the chromosomes of the previous cell division, it is probable that the chromosomes are a factor in this process.

Weismann maintained that the chromosomes and the inheritance units contained in them undergo differentiation by a process of disintegration and that these disintegrated units escape into the cell body and there produce different kinds of cytoplasm in different cells. A somewhat similar view was advanced 
by deVries in his theory of intra-cellular pangenesis. However, as we have seen already, there is good evidence that the chromosomes do not undergo progressive differentiation in the course of development; they always divide with exact equality, and even in highly differentiated tissue cells their number and form usually remain as in embryonic cells.

On the other hand the cytoplasm undergoes progressive differentiation, and when by pressure or centrifugal force such differentiated cytoplasm is brought into relations with strange nuclei the differentiations of the cytoplasm are not always altered thereby, thus showing that the different nuclei are essentially alike and that differentiations are mainly limited to the cytoplasm. Thus the differentiations of cells are not due to the differentiations of their nuclei, but rather the reverse is true, such differentiations of nuclei as occur are due to differentiations of the cytoplasm in which they lie. Nevertheless differentiations do not take place in the absence of nuclear material, and it seems probable that the interaction of nucleus and cytoplasm is necessary to the formation of 
the new cytoplasmic substances which appear in the course of development.

2. Segregation and Isolation of Different Substances in Cells.-But differentiation consists not only in the formation of different kinds of substances in cells but also in the separation of these substances from one another. This separation is brought about to a great extent by flowing movements within cells which are associated especially with cell division.

In all these processes of heredity and development cell division plays a particularly important part. If cell divisions were always exactly alike there could be no initial difference between the daughter cells, and unless acted upon by different stimuli all cells would remain exactly alike. But there is much evidence that daughter cells are often unlike from the time of their formation, and that different stimuli act upon them to increase still further this initial difference.

(a) Differential and Non-differential Cell Division.-When each half of any dividing unit is like the other half the division is non- 
differential. So far as we know the divisions of all the smallest elements of the cell are of this sort; there is no good evidence that the plastosomes, the chromomeres, or the chromosomes ever divide into unlike halves, though in the maturation divisions the separation of whole chromosomes leads to the appearance of a differential division of the chromosomes. But while all of the cell elements may be supposed to grow and divide into equivalent halves there may be an unequal distribution of these halves in cell division, so that the two daughter cells are unlike. This is what is known as differential cell division and it plays a most important part in differentiation. While the chromosomes are equally distributed to the daughter cells, except in the case of the maturation divisions, the achromatin and the oxychromatin of the nucleus are not always distributed equally and this is probably an important factor in development. The divisions of the cytoplasm of the egg are frequently differential and such divisions are known to play a great part in the embryonic differentiation. 
In the differential divisions of the cytoplasm unlike substances become localized in certain parts of the cell body, chiefly by means of definite flowing movements of the cytoplasm, and when cell division occurs these substances become permanently separated by partition walls. In this way irreversible differentiations are formed. If the formation of partition walls is prevented the different substances within the cell body may freely commingle, especially during nuclear division when the cytoplasmic movements are especially active; in such cases differentiation may be arrested even though nuclear division continues. In the developing eggs of most animals partition walls between daughter cells are necessary to prevent the commingling of different kinds of substances, which are sorted by the movements within the cell and are isolated by the partition walls. In some cases, as for example in certain protozoa, the commingling of different kinds of protoplasm within a cell may be prevented by the viscosity of portions of the protoplasm, or by the formation of intracellular membranes, or by a reduction to a minimum of 
the mitotic movements within the cell by the persistence of the nuclear membrane during division. In general the degree of differentiation may be measured by the degree of unlikeness between different cells, and by the completeness with which the protoplasm of different cells is kept from intermingling.

\section{Summary}

All the phenomena of life, including heredity and development, are cellular phenomena in that they include only the activities of cells or of cell aggregates. 'The cell is the ultimate independent unit of organic structure and function. The only living bond between one generation and the next is found in the sex cells and all inheritance must take place through these cells. Inherited traits are not transmitted from parents to offspring but the germinal factors or causes are transmitted, and under proper conditions of environment these give rise to developed characters. Every oosperm as well as every developed organism differs more or less from every other one and this remarkable condition is brought about by 
extremely numerous permutations in the distribution of certain parts of the sex cells in maturation and fertilization. Sex is an inherited character dependent, probably, upon an alternative distribution of certain chromosomes of the nucleus. There is much evidence that the factors for all sorts of alternative characters are associated with the chromosomes. The differentiation of the oosperm into the developed organism is accomplished in part by the associations and dissociations of germinal units which lead to the formation of new materials, and in part by the segregation and localization of these in definite cells.

Germ cells and probably all other kinds of cells are almost incredibly complex. We know that former students of the cell greatly underestimated this complexity and there is no reason to suppose that we have fully comprehended it. What Darwin said of the entire organism may now be said of every cell: "An organic being is a microcosm - a little universe, formed of a host of self-propagating organisms, inconceivably minute and numerous as the stars in heaven." 



\section{CHAPTER III}

\section{PHENOMENA OF INHERITANCE}





\section{CHAPTER III}

\section{PHENOMENA OF INHERI'TANCE}

\section{A: OBSERVATIONS ON INHERITANCE}

The observations of men in all ages have established the fact that in general "like produces like," and that, in spite of many exceptions, children are in their main characteristics like their parents. And yet offspring are never exactly like their parents, and this has led to the saying that "like does not produce like but only somewhat like." What is meant is that there are general resemblances but particular differences between parents and offspring.

INDIVIDUALS AND THEIR CHARACTERS

In considering organic individuals one may think of them as wholes or as composed of parts, as indivisible unities or as constituent 
characters; either aspect is a true one and yet neither is complete in itself. Formerly in discussions on heredity the individual was regarded in its entirety and when all hereditary resemblances and differences were averaged it was said that one child resembled the father, another child the mother. This method of lumping together and averaging resemblances and differences led to endless confusion. In heredity no less than in anatomy it is necessary to deal with the constituents of organisms; in short, the organism must be analyzed and each part studied by itself. Francis Galton was one of the first to bring order out of chaos by dealing with traits or characters singly instead of treating all together. $\mathrm{He}$ made careful studies on the inheritance of weight and size in the seeds of sweet peas, and on the inheritance of stature, eye-color, intellectual capacity, artistic ability and certain diseases in man. At the same time that Galton was thus laying the foundations for a scientific study of heredity by dealing with characters separately, another and even greater student of heredity, Gregor Mendel, 
was doing the same thing in his experiments with garden peas, but inasmuch as Mendel's work remained practically unknown for many years, Galton has been rightly recognized as the founder of the scientific study of heredity.

Of course, neither Galton nor anyone else who has followed his method of dealing with the characters of organisms singly, ever supposed that such characters could exist independently of other characters and apart from the entire organism. This is such a self-evident fact that it may seem needless to mention it, and yet there have been critics who have believed, or have assumed to believe, that modern students of heredity attempt to analyze organisms into independently existing characters, whereas in most cases they have done only what the anatomist does in treating separately the various organs of the body.

HEREDITARY RESEMBLANCES AND DIFFERENCES

The various characters into which an organism may be analyzed show a greater or smaller degree of resemblance to the corresponding characters of its parents. Whenever the dif- 
ferential cause of a character is a germinal one the character is, by definition, inherited; on the other hand, whenever this differential cause is environmental the character is not inherited. While it is true that inheritance is most clearly recognized in those characters in which offspring resemble their parents, even characters in which they differ from their parents may be inherited, as is plainly seen when, in any character, a child resembles a grandparent or a more distant ancestor more than either parent. Sometimes actually new characters arise in descendants which were not present in ascendants, but which are thereafter inherited. Accordingly inherited characters may be classified as resemblances and differences, though both are determined by germinal organization, or heredity. There is therefore no fundamental difference between inherited similarities and dissimilarities. Heredity and variation are not opposing nor contrasting tendencies which make offspring like their parents in one case and unlike them in another; really inherited characters may be like or unlike those of the parents. 
On the other hand many resemblances and differences between parents and offspring art due not to heredity at all, but to environmental conditions. By means of experiment it is possible to distinguish between hereditary and environmental resemblances and differences, but among men where experiments are generally out of the question it is often difficult or impossible to make this distinction.

\section{Hereditary Resemblances}

\section{Racial Characters.-All peculiarities} which are characteristic of a race, species, genus, order, class and phylum are of course inherited, otherwise there would be no constant characteristics of these groups and no possibility of classifying organisms. The chief characters of every living thing are unalterably fixed by heredity. Men do not gather grapes of thorns nor figs of thistles. Every living thing produces offspring after its own kind. Men, horses, cattle; birds, reptiles, fishes; insects, mollusks, worms; polyps, sponges, micro-organisms, - all of the million 
known species of animals and plants differ from one another because of inherited peculiarities, because they have come from different kinds of germ cells.

2. Individual Characters.-Many characters which are peculiar to certain individuals are known to be inherited, and in general use the word "inheritance" refers to the repetition in successive generations of such individual peculiarities. Among such individual characters are the following:

(a) Morphological F'eatures.-Hereditary resemblances are especially recognizable in the gross and minute anatomy of every organism in the form, structure, location, size, color, etc., of each and every part. The number of such individual peculiarities which are inherited is innumerable and only a few of the more striking of these can be mentioned.

It is a matter of common knowledge that unusually great or small stature runs in certain families, and Galton developed a formula for determining the approximate stature of children from the known stature of the parents and from the mean stature of the race. How- 
ever, his statistical and mathematical formulæ give only general or average results, from which there are many individual departures and exceptions.

In the same way the color of the skin, the color and form of hair and the color of eyes are in general like those of one or more of the parents or grandparents. We all know that certain facial features such as the shape and size of eyes, nose, mouth and chin are generally characteristic of certain families.

But the inheritance of anatomical features extends to much more minute characters than those just mentioned. In certain families a few hairs in the eyebrows are longer than the others, or there may be patches of particolored hair over the scalp, or dimples in the cheek, chin, or other parts of the skin may occur, and these trifling peculiarities are inherited with all the tenacity shown in the transmission of more important characters. Johannsen has found races of beans in which the average weight of individual seeds differed only by .02 to .03 gram, and yet these minute differences in weight were characteristic of 
each race and were of course inherited. Jennings has found races of Paramecium which show hereditary differences of $.005 \mathrm{~mm}$. in length (Fig. 44). Nettleship says that the

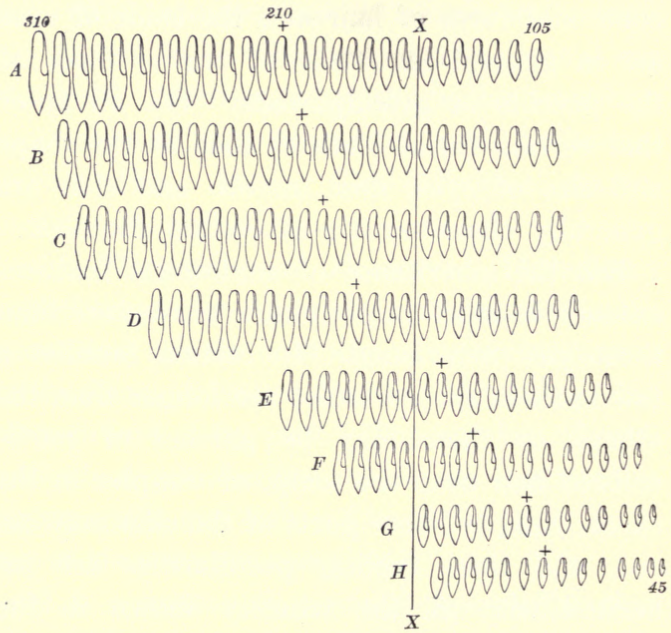

FIg. 44. Diagram of eight different races of Paramecium, each horizontal row $(\mathrm{A}-\mathrm{H})$ representing a single race. The individual showing the mean size in each race is indicated by + ; the mean of all the races is shown by the line $\mathrm{X}-\mathrm{X}$. The numbers are the lengths in micra (-thousandths of a millimeter), $\times$ 43. (After Jennings.) 
lens of the human eye weighs only about $\mathbf{1 7 5}$ milligrams, or about one three-millionth part of the body weight, and in hereditary cataract only about one twentieth part of the lens becomes opaque, and yet this minute fraction of the body weight shows the influence of heredity. Even the size, shape and number of the cells in certain organs, and in given embryonic stages, may be repeated generation after generation; and if our analysis were sufficiently complete we should doubtless find that even the minute parts of cells, such as nuclei, chromosomes and centrosomes, show individual peculiarities which are inherited.

(b) Teratological and Pathological Peculiarities are really only unusual or abnormal anatomical characters, but of such interest and importance as to deserve special mention. Many such abnormalities are undoubtedly inherited, among which are the following: poly. dactylism, in which more than the normal number of digits are present; syndactylism, or a condition of webbed fingers and toes; brachydactylism, in which the finger's are short and stumpy and usually contain less than the 
normal number of joints; acondroplasy, or short and crooked limbs, such as occur in certain breeds of dogs and sheep and in certain human dwarfs; myopia, in which the eyeball is elongated; glaucoma, or swelling of the eyeball; coloboma, or open suture of the iris; otosclerosis, or thickened tympanic membrane, causing "hardness of hearing"; some forms of deaf-mutism, due to certain defects of the inner ear; and many other characters too numerous to mention here. On the other hand many abnormal or monstrous conditions are due to abnormal environment and are not inherited.

The question of the inheritance of diseases may be briefly considered here. If a disease is due to some defect in the hereditary constitution, it is inherited; otherwise, according to our definition of heredity, it is not. Of course no disease develops without extrinsic causes but when one individual takes a disease while another under the same conditions does not, the differential cause may be an inherited one, or it may be due to differences in the previous conditions of life. There is no doubt that 
certain diseases run in families and have the appearance of being inherited, but in this case as in many others it is extremely difficult in the absence of experiments to distinguish between effects due to intrinsic causes and those due to extrinsic ones. Where the specific cause of a disease is some microörganism the individual must have been infected at some time or other, almost invariably after birth. In few instances is the oosperm itself infected, and even when it is, this is not, strictly speaking, a case of inheritance, but rather one of early infection. Pearson has found that there is a marked correlation (represented by the number .55 when complete correlation is 1.) between tuberculous parents and tuberculous children, but there is very little evidence that the child is ever infected before birth. What is inherited in this case is probably slight resistance to the tubercle bacillus. There is evidence that almost all adult persons have been infected at one time or another by this bacillus, but it has not developed far in all of them because some have superior powers of resistance. Such greater or smaller resistance, 
stronger or weaker build, is inherited, and while diminished resistance is not the direct cause of tuberculosis it is a predisposing cause. The same is probably true of many other diseases, the immediate causes of which are extrinsic, while only the more remote, or predisposing causes, are hereditary.

(c) Physiological peculiarities are inherited as well as morphological ones; indeed function and structure are only two aspects of one and the same thing, namely organization. For all morphological characters there are functional correlatives, for functional characters morphological expressions, and if the one is inherited so is the other. But there are certain characters in which the physiological aspect is more striking than the morphological one.

For example, longevity is a physiological character which is undoubtedly dependent upon many causes, but in the case of species which differ greatly in length of life there can be little doubt that we are dealing with an inherited character. The great differences in the length of life of an elephant and a mouse, of a parrot and a pigeon, of a cicada and a 
squash bug, are as surely the result of inherited causes as are the structural differences between those animals. Within the same species different races or lines show characteristic differences in length of life; in the case of man the average length of life is much greater in some families than in others, and life insurance companies take account of this fact. Even within the same organism certain organs or cells are short-lived, whereas others are long-lived; some cells and organs live only through the early embryonic period, while other's live as long as the general organism.

Obesity is another physiological characteristic which may be inherited; the members of certain families grow fat in spite of themselves, while members of other families remain thin however well fed they may be. Here also many factors enter into the result, but it seems probable that the differentiating factor is an hereditary one. Baldness affects the male members of certain families when they have reached a given age, while in others neither care, dissipation nor age can rob a man of his bushy top. Hæmophilia, or excessive bleed- 
ing after an injury, which is due to a deficiency in the clotting power of the blood, is strongly inherited in the male line in certain families. Fecundity and a tendency to bear twins or triplets, left-handedness, a peculiar lack of resistance to certain diseases, and many other physiological peculiarities are probably inherited.

(d) Psychological characters appear to be inherited in the same way that anatomical and physiological traits are; indeed all that has been said regarding the correlation of morphological and physiological characters applies also to psychological ones. No one doubts that particular instincts, aptitudes and capacities are inherited among both animals and men, nor that different races and species differ hereditarily in psychological characteristics.

Certain breeds of dogs such as the mastiff, the bull dog, the terrier, the collie and many others are characterized by peculiarities of temperament, affection, intelligence and disposition. No one who has much studied the subject can doubt that different human races and families show characteristic differences in 
these same respects. It is quite futile to argue that exceptional individuals may be found in one race with the mental characteristics of another race; the same could be said of different breeds of dogs, or of the sizes of different races of beans or of Paramecia (Fig. 44). The fact is that racial characteristics are not determined by exceptional and extreme individuals but by the average or mean qualities of the race; and measured in this way there is no doubt that certain types of mind and disposition are characteristic of certain families.

There is no longer any question that some kinds of feeble-mindedness, epilepsy and insanity are inherited, and that there is often an hereditary basis for nervous and phlegmatic temperaments, for emotional, judicial and calculating dispositions. Nor can it be denied that strength or weakness of will, a tendency to moral obliquity or rectitude, capacity or incapacity for the highest intellectual pursuits, occur frequently in certain families and appear to be inherited. In spite of certain noteworthy exceptions, which may perhaps be due to remarkable variations, statistics col- 
lected by Galton show that genius runs in certain families; while the work of certain recent investigators, particularly Goddard, Davenport and Weeks, proves that feeble-mindedness and epilepsy are also inherited; and the careful work of Mott and of Rosanoff leaves no room for doubt that certain types of insanity are hereditary. It frequently happens that families in which hereditary insanity occurs also have other members afflicted with epilepsy, hysteria, alcoholism, etc., which would indicate that the thing inherited is an unstable condition of the nervous system which may take various forms under slightly different conditions. Indeed there is a good deal of evidence that extraordinary ability, or genius, is frequently associated with an unstable nervous organization which may sometimes take the form of insanity or epilepsy or alcoholism. There is perhaps more truth than poetry in Dryden's lines:

"Great wits are sure to madness near allied, And thin partitions do their bounds divide." Woods has collected data concerning "Heredity in Royalty" which seem to show that 
very high or low grades of intellect and virtues may be traced through the royal families of Europe for several generations.

The general tendency of recent work on heredity is unmistakable, whether it concerns man or lower animals. The entire organism, consisting of structures and functions, body and mind, develops out of the germ, and the organization of the germ determines all the possibilities of development of the mind no less than of the body, though the actual realization of any possibility is dependent also upon environmental stimuli.

\section{Hereditary Differences}

There are many limitations or exceptions to the general rule that children resemble their parents. Sometimes these differences are due to new combinations of ancestral characters, sometimes they are actually new characters not present so far as known in any of the ancestors, though even such new characters must arise from new combinations of the elements of old characters, as we shall see later.

1. New Combinations of Characters.-In all cases of sexually produced organisms new 
combinations of ancestral characters are evident. Usually a child inherits some traits from one parent and other traits from the other parent, so that it is a kind of mosaic of ancestral traits. Such inheritance, bit by bit, of this character from one progenitor and that from another was described by Galton as "particulate" (Fig. 45). On the other hand Galton supposed that in some instances a child might inherit all or nearly all of his traits from one parent, a thing which is most improbable; such inheritance he called "alternative" (Fig. 45).
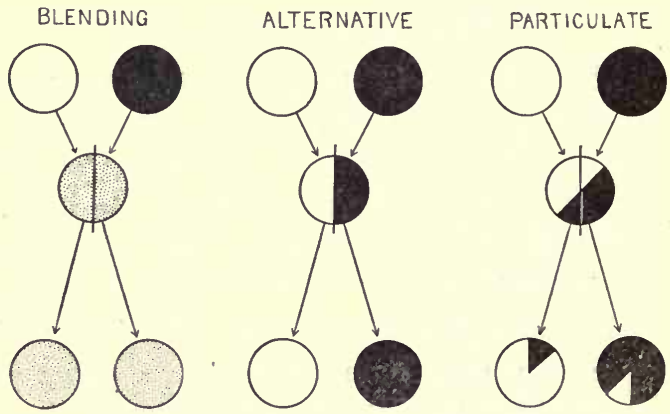

Fig. 45. Diagram to illustrate three kinds of inheritance described by Galton. (After Walter.) 
In other cases the traits of the parents appear to blend in the offspring, as for example, in the skin color of mulattoes; such cases were called by Galton "blending" inheritance (Fig. 45). Sometimes characters appear in offspring which were "latent" in the parents but were "patent" in one or more of the grandparents; such skipping of a generation, during which a character remains "latent," has long been known as "atavism." At other times characters which were present in distant ancestors, but which have since dropped out of sight or have remained "latent," reappear in descendants; such cases are known as "reversions."

In still other cases certain characters appear only in the male sex, others only in the female, this being called "sex-limited" inheritance; while in some instances characters are transmitted from fathers through daughters to grandsons or from mothers to sons, all such cases being known as "sex-linked" inheritance.

2. New Characters or Mutations.-But in addition to these permutations in the distribution and combination of ancestral characters 
- new and unexpected characters sometimes develop in the offspring, which were not present, so far as known, in any of the ascendants, but which, after they have once appeared, are passed on by heredity to descendants. Such inherited variations are usually of two kinds, continuous or slight, and discontinuous or sudden variations. The latter are especially noticeable when variations occur in the normal number of parts, as in four-leaved clover, or six-fingered men, and such numerical variations have been called by Bateson "meristic." However, sudden variations may include any marked departure from the normal type, in color, shape, size, chemical compositions, etc. Such sudden variations have long been known to breeders as "sports," and both Darwin and Galton pointed out the fact that such sports have sometimes given rise to new races or breeds, though Darwin was not inclined to assign much importance to them in the general process of evolution. Galton, on the other hand, maintained that variations, or what would now be called "continuous variations," cannot be of much significance in the process 
of evolution, but that the case is quite different with "sports."

More recently the entire biological world has been greatly influenced by the "Mutation 'Theory" of deVries, which has placed a new emphasis upon the importance of sudden variations in the process of evolution. At first deVries was inclined to emphasize the degree of difference between discontinuous and continuous variations, but in later works this distinction is given a minor place as compared with the distinction between inherited and non-inherited variations. Inherited variations, whether large or small, are called by deVries "mutations," whereas non-inherited variations are known as "fluctuations." The former are caused by changes in germinal constitution, the latter by alterations in environmental conditions; the former represent changes in heredity, the latter changes in development.

3. Mutations and Fluctuations.-This clear cut distinction between mutations and fluctuations marks one of the most important advances ever made in the study of development and evolution. Thousands of fluctuations oc- 
cur which are purely somatic in character and which do not affect the germ cells, for every single mutation or change in the hereditary constitution; and yet only the latter are of significance in heredity and evolution. This distinction between variations due to environment (fluctuations) and those due to hereditary causes (mutations) was recognized by Weismann and many of his followers, but the actual demonstration on a large scale of the importance of this distinction is due largely to deVries.

All hereditary variations, whether due to new combinations of old characters or to the appearance of actually new characters, whether small and continuous or large and discontinuous, have their causes in the organization of the germ cells, just as do inherited resemblances. Heredity is not to be contrasted with variation, nor are hereditary likeness and unlikeness due to conflicting principles; both are the results of germinal organization and both are phenomena of heredity.

4. Every Individual Unique.-As a result 
of the permutations of ancestral characters, the appearance of mutations, and the fluctuations of organisms due to environmental changes, it happens that in all cases offspring differ more or less from their parents and from one another. No two children of the same family are ever exactly alike (except in the case of identical twins which have come from the same oosperm). Every living being appears on careful examination to be the first and last of its identical kind. This is one of the most remarkable peculiarities of living things. The elements of chemistry are constant, and even the compounds fall into definite categories which have constant characteristics. But the individuals of biology are apparently never twice the same. This may be due to the immense complexity of living units as contrasted with chemical ones, indeed lack of constancy is evidence in itself of lack of analysis into real elements or of lack of uniform conditions; but whatever its cause the extraordinary fact remains that every living being appears to be unique. "Reproduction is the generation of unique beings that 
are, on the average, more like their kind than like anything else" (Brooks).

There seems to be no reason to doubt that all the extraordinary differences which organisms show, as well as all of their resemblances, are due to differences or resemblances in the hereditary and environmental factors which have been operative in their development. But in view of this universal variability of organisms it is not surprising that inheritance has seemed capricious and uncertain,-“"a sort of maze in which science loses itself."

\section{B. STATISTICAL STUDY OF INHERITANCE}

Francis Galton was one of the first who attempted to reduce the mass of conflicting observations on heredity and variation to some system and to establish certain principles as a result of statistical study. He was the real founder of the scientific study of inheritance; he studied characters singly and introduced quantitative measures. Galton's researches, which were published in several volumes, consisted chiefly in a study of certain families 
with regard to several selected traits, viz., genius or marked intellectual capacity, artistic faculty, stature, eye color and disease. As a result of his very extensive studies two main principles appeared to be established:

1. The Law of Ancestral Inheritance which he stated as follows:

The two parents contribute between them on the average one-half of each inherited faculty, each of them contributing one-quarter of it. The four grandparents contribute between them one-quarter, or each of them one-sixteenth; and so on, the sum of the series $1 / 2+1 / 4+1 / 8+1 / 16 \ldots$ being equal to 1 , as it should be. It is a property of this infinite series that each term is equal to the sum of all those that follow: thus $1 / 2=1 / 4+1 / 8+1 / 16$ $+\ldots, 1 / 4=1 / 8+1 / 16+\ldots$, and so on. The prepotencies of particular ancestors in any given pedigree are eliminated by a law which deals only with average contributions, and the various prepotencies of sex with respect to different qualities are also presumably eliminated.

The average contribution of each ancestor was thus stated definitely, the contribution diminishing with the remoteness of the ancestor. This Law of Ancestral Inheritance is represented graphically in the accompanying dia- 
gram (Fig. 46). Pearson has somewhat modified the figures given by Galton, holding that in horses and dogs the parents contribute $1 / 2$, the grandparents $1 / 3$, the great grandparents $\mathbf{2} / \mathbf{9}$, etc.

Theoretically the number of ancestors

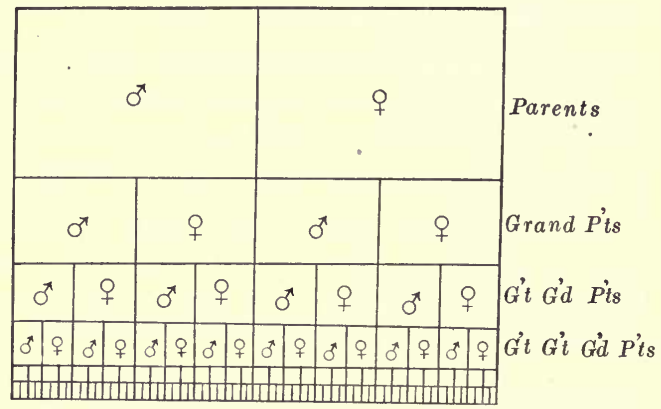

Fig. 46. Diagram of Galton's "Law of Ancestral Inheritance." The whole heritage is represented by the entire rectangle; that derived from each progenitor by the smaller squares; the number of the latter doubles in each ascending generation while its area is halved. (After Thompson.)

doubles in each ascending generation; there are two parents, four grandparents, eight great-grandparents, etc. If this continued to be true indefinitely the number of ancestors in any ascending generation would be $(2)^{n}$, in 
which $n$ represents the number of generations. 'There have been about $\mathbf{5 7}$ generations since the beginning of the Christian Era, and if this rule held true indefinitely each of us would have had at the time of the birth of Christ a number of ancestors represented by $(2)^{57}$ or about 120 quadrillions, - a number far greater than the entire human population of the globe since that time. As a matter of fact, owing to the intermarriage of cousins of various degrees the actual number of ancestors is much smaller than the theoretical number. For example, Plate says that the present Emperor of Germany had only 162 ancestors in the 10th ascending generation, instead of 512, the theoretical number. Nevertheless this calculation will serve to show how widespread our ancestral lines are, and how nearly related are all people of the same race.

Davenport concludes that no people of English descent are more distantly related than 30th cousins, while most people are much more closely related than that. If we allow three generations to a century, and calculate that the degree of cousinship is determined by 
the number of generations less two, since first cousins appear only in the third generation, the first being that of the parents and the second that of the sons and daughters, we find that 30 th cousins at the present time would have had a common ancestor about one thousand years ago or approximately at the time of William the Conqueror. As a matter of fact most persons of the same race are much more closely related than this, and certainly we need not go back to Adam nor even to Shem, Ham, or Japhet to find our common ancestor.

2. The second principle which Galton deduced from his statistical studies is known as the Law of Filial Regression, or what might be called the tendency to mediocrity. He found that, on the average, extreme peculiarities of parents were less extreme in children. Thus, "the stature of adult offspring must on the whole be more mediocre than the stature of their parents, that is to say more near to the mean or mid of the general population"; and again, "the more bountifully a parent is gifted by nature, the more rare will be his 
good fortune if he begets a son who is as richly endowed as himself." This so-called law of filial regression is represented graphically in Fig. 47 in. which the actual stature of individual parents is shown by the oblique line, the stature of children by the dotted curve, and the mean stature of the race in the horizontal dotted line.

One of the chief aims and results of statistical study is to eliminate individual peculiarities and to obtain general and average results. Such work may be of great importance in the study of heredity, especially where questions of the occurrence or distribution of particular phenomena are concerned; but the causes of heredity are individual and physiological, and averages are of less value in finding the causes of such phenomena than is the intensive study of individual cases.

By observation alone it is usually impossible to distinguish between inherited and environmental resemblances and differences, and yet this distinction is essential to any study of inheritance. If all sorts of likenesses and unlikenesses are lumped together, whether in- 


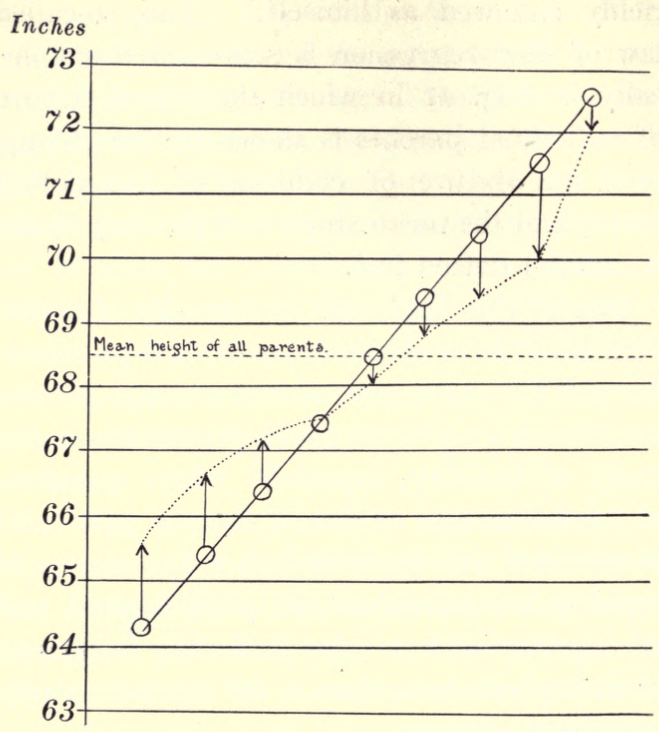

Fig. 47. Scheme to illustrate Galton's "Law of Filial Regression" as shown in the stature of parents and children. The mean height of all parents is shown by the dotted line between 68 and 69 inches. The circles through which the diagonal line runs represent the heights of graded groups of parents and the arrow heads indicate the average heights of their children. The offspring of undersized parents are taller and of oversized parents are shorter than their respective parents. (From Walter.) 
herited or not, our study of inheritance can only end in confusion. The value of statistics depends upon a proper classification of the things measured and enumerated, and if things which are not commensurable are grouped together the results may be quite misleading and worthless. Unfortunately Galton and Pearson, as well as some of their followers, have not carefully distinguished between hereditary and environmental characters. Furthermore much of their material was drawn from a general population in which were many different families and lines not closely related genetically. Consequently their statistical studies are of little value in dis-

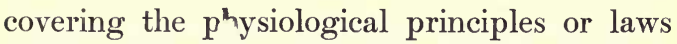
of heredity. rennings (1910) well says, "Galton's law: of regression and of ancestral inheritance are the product mainly of a lack of distinction between two absolutely diverse things, between non-inheritable fluctuations on the one hand, and permanent genotypic differentiations on the other." In the case of man we have few certain tests to determine whether the differential cause of any character 
is hereditary or environmental, but in the case of animals and plants, where experiments may be performed on a large scale, it is possible to make such tests by (1) experiments in which the environment is kept as uniform as possible while the hereditary factors differ, and (2) experiments in which, in a series of cases, the hereditary factors are fairly constant while the environment differs. In this way the differential cause or causes of any character may be located in heredity, in environment or in both.

The observational and statistical study of inheritance helped to outline the problem but did little to solve it. Certain phenomena of hereditary resemblance between ascendants and descendants were made intelligible, but there were many peculiar and apparently irregular or lawless phenomena which could not be predicted before they occurred nor explained afterward. For example when Darwin crossed different breeds of domestic pigeons, no one of which had a trace of blue in its plumage, he sometimes obtained offspring with more or less of the blue color and 
markings of the wild rock pigeon from which domestic pigeons are presumably descended. He described many cases of dogs, cattle and swine, as well as many cultivated plants, in which offspring resembled distant ancestors and differed from nearer ones; such cases had long been known and were spoken of as "reversions." He observed many cases in which certain characters of one parent prevailed over corresponding characters of the other parent in the offspring, this being known as "prepotency"; but there was no satisfactory explanation of these curious phenomena. They did not come under either of Galton's laws, and their occurrence was apparently so irregular that every such case seemed to be a law unto itself. 


\section{EXPERIMENTAL STUDY OF INHERI- TANCE \\ I. Mendelism}

The year 1900 marks the beginning of a new era in the study of inheritance. In the spring of that year three botanists, deVries, Correns, and Tschermak, discovered independently an important principle of heredity and at the same time brought to light a long neglected and forgotten work on "Experiments in Plant Hybridization" by Gregor Mendel, in which this same principle was set forth in detail. This principle is now generally known as "Mendel's Law." Mendel, who was a monk, and later abbot, of the Königskloster, an Augustinian monastery in Brünn, Austria, published the results of his experiments on hybridization in the Proceedings of the Natural History Society of Brünn in 1866. The paper attracted but little attention at the time although it contained some of the most important discoveries regarding inheritance which had ever been made, and it re- 
mained buried and practically unknown for thirty-five years. Plant hybridization had been studied extensively before Mendel began his work, but he carried on his observations of the hybrids and of their progeny for a longer time and with greater analytical ability than any previous investigator had done. The methods and results of his work are so well known through the writings of Bateson, Punnett, and many others that it is unnecessary to dwell at length upon them here. In brief . Mendel's method consisted in crossing two forms having distinct characters, and then in counting the number of offspring in successive generations showing one or the other of these characters.

During the eight years preceding the publication of his paper in 1866 Mendel hybridized some twenty-two varieties of garden peas. This group of plants was chosen because the different varieties could be cross-fertilized or self-fertilized and were easily protected from the influence of foreign pollen; because the hybrids and their offspring remained fertile through successive generations; and because 
the different varieties are distinguished by constant differentiating characters. Mendel devoted his attention to seven of these characters, which he followed through several generations of hybrids, viz.,

(1) Differences in the form of the ripe seeds, whether round or wrinkled.

(2) Differences in the color of the food material within the seeds, whether pale yellow, orange or green.

(3) Differences in the color of the seed coats (and in some cases of the flowers also), whether white, gray, gray brown, leather brown, with or without violet spots.

(4) Differences in the form of the ripe pods, whether simply inflated or constricted between the seeds.

(5) Differences in the color of the unripe pods, whether light to dark green, or vividly yellow.

(6) Differences in the positions of the flowers, whether axial, that is distributed along the stem, or terminal, that is bunched at the top of the stem. 
(7) Differences in the length of the stem, whether tall or short.

1. Results of Crossing Individuals with one Pair of Contrasting Characters.-Having determined that these characters were constant for certain varieties or species Mendel then proceeded to cross one variety with another, by carefully removing the unripe stamens, with their pollen, from the flowers of one variety and dusting upon the stigmas of such flowers the pollen of a different variety. In this way he crossed varieties of peas which differed from each other in some one of the characters mentioned above, and then studied the offspring of several successive generations with respect to this character.

In every case he discovered that the plants that developed from such a cross showed only one of the two contrasting characters of the parent plants, i.e. all were round-seeded, yellow-seeded, tall, etc., although one of the parents had wrinkled seeds, green seeds, or short stem, etc. "Those characters which are transmitted entire or almost unchanged in the hybridization are termed dominant, and those 
which become latent in the process, recessive." These hybrids ${ }^{1}$ when self-fertilized gave rise to a second filial generation of individuals some of which showed the dominant character and others the recessive, the relative numbers of the two being approximately three to one. Thus the hybrids produced by crossing yellowseeded and green-seeded peas yielded when self-fertilized 6,022 yellow seeds and 2,001 green seeds, or very nearly three yellow to one green (Fig. 48). The hybrids produced by crossing round and wrinkled seeded varieties yielded in the second filial generation $\mathbf{5 , 4 7 4}$ round and 1,850 wrinkled seeds, or approximately three round to one wrinkled (Fig. 52 ). 'The hybrids from tall-stemmed and shortstemmed parents produced in the second filial generation 787 long-stemmed and 277 shortstemmed plants, or again approximately three

"Bateson introduced the term "homozygote" for pure-bred individuals resulting from the union of gametes which are hereditarily similar, and heterozygote for hybrids resulting from the union of hereditarily dissimilar gametes. The gametes formed from a homozygote are all of the same hereditary type, those formed from a heterozygote are of two or more different types. 


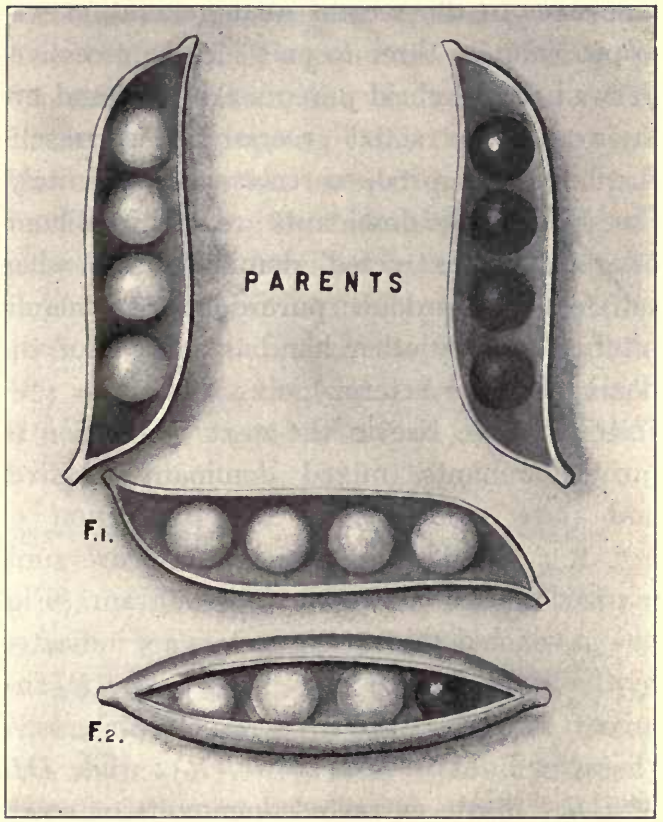

Fig. 48. Diagram showing the results of crossing yellowseeded (lighter colored) and green-seeded (darker colored) peas. (From Morgan after Thompson.) 
tall to one short. And in every other case Mendel found that the ratio of dominants to recessives in the second filial generation was approximately three to one. These recessives derived from hybrid parents are pure and are known as "extracted" recessives; when selffertilized they produce recessives indefinitely. One-third of the dominants are also pure homozygotes, or "extracted" dominants, and when self-fertilized produce pure dominants indefinitely. On the other hand two-thirds of the dominants are heterozygotes and when selffertilized give rise in the next generation to pure dominants, mixed dominant-recessives and pure recessives in the proportion of $1: 2: 1$. These general results are summarized in the accompanying diagram (Fig. 49 ) in which dominant characters are indicated by the letter $D$, recessive characters by $R$, and mixed dominant-recessives, with the recessive character unexpressed, by $D(R)$; while $D D$ or $R \boldsymbol{R}$ indicate extracted dominants or recessives, that is, pure dominants or recessives which have separated out from mixed dominant-recessives, $\boldsymbol{D}(\boldsymbol{R})$. The parental gener- 
ation is indicated by the letter $\boldsymbol{P}$, and the successive filial generations by $\boldsymbol{F}_{1}, \boldsymbol{F}_{2}, \boldsymbol{F}_{3}$, etc.

In the case of the peas studied by Mendel the hybrids of the $F_{1}$ generation show only the dominant character, the contrasted recessive character being present but not expressed. However in certain cases it has been found that the hybrids differ from either parent and in successive generations split up into both parental types and into the hybrid type; thus Correns found that when a white-flowered variety of Mirabilis, the four o'clock, was crossed with a red-flowered variety all of the hybrids

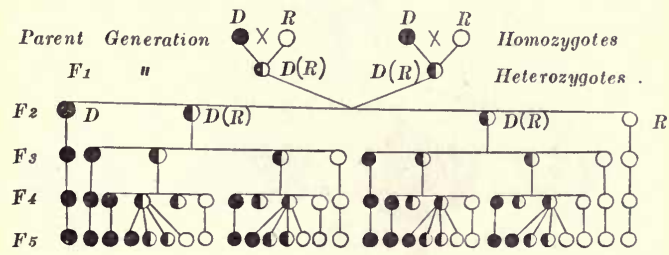

Frg. 49. Diagram showing results of Mendelian splitting where the parents are pure dominants and pure recessives (homozygotes). All pure dominants are represented by black circles, all pure recessives by white ones, while mixed dominant-recessives (heterozygotes) are represented by circles half white and half black. Successive generations are marked $F_{1}$, $\mathrm{F}_{2}, \mathrm{~F}_{3}$, etc. 
in the $\mathbf{F}_{1}$ generation had pink flowers and from these in the $F_{2}$ generation there came whiteflowered, pink-flowered and red-flowered forms in the proportion of 1 white : 2 pink : 1 red, as shown in Fig. 50. This is a better illustration of Mendel's principle of splitting than is

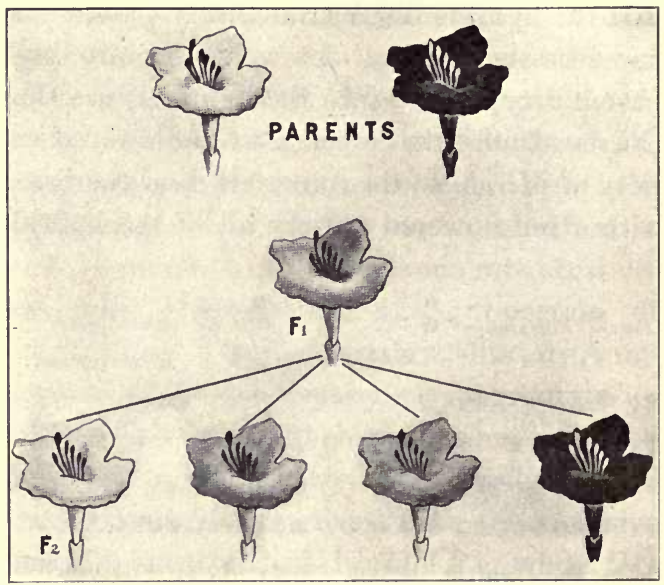

Fig. 50. Results of crossing white-flowered and red-flowered races of Mirabilis Jalapa (four o'clocks) giving a pink hybrid in $F_{1}$, which when inbred gives in $F_{2} 1$ white, 2 pink, 1 red. (Froin Morgan, after Correns.) 
offered by the peas, since in this case the mixed dominant-recessives $\boldsymbol{D}(\boldsymbol{R})$ are always distinguishable from the pure dominants $D D$.

In the $\mathbf{F}_{2}$ generation and in all subsequent ones the pure dominants and the pure recessives always breed true when self-fertilized, whereas the mixed dominant-recessives continue to split up in each successive generation into pure dominants, mixed dominant-recessives and pure recessives in the proportion $1: 2: 1$. The result of this is that the relative number of dominants and recessives increases in successive generations, whereas the relative number of mixed dominant-recessives decreases, and in a few generations a hybrid race will revert in large part to its parental types if continued hybridization is prevented. On the other hand there is no tendency for the relative number of dominants to increase and of recessives to decrease in successive generations; an equal number of pure dominants and pure recessives is produced in each generation.

With remarkable insight Mendel recognized that the real explanation of the splitting of pure recessives and pure dominants from 
hybrid parents must be found in the composition of the male and female sex cells. Since such extracted dominants and recessives breed true, just as pure species do, it must be that their germ cells are pure. In the cross between pure races of white-flowered and redflowered Mirabilis the germ cells which unite in fertilization must be pure with respect to white and red, though the individual which develops from this cross is a pink hybrid. But the fact that one-quarter of the progeny of this hybrid are pure white, and another quarter pure red, and that these thereafter breed true, proves that the hybrid produces germ cells which are pure with respect to red and white. Furthermore the fact that one-half the progeny of this hybrid are themselves hybrid may be explained by assuming that they were produced by the union of germ cells carrying pure white and pure red, as in the parental generation.

Mendel therefore concluded that individual germ cells are always pure with respect to any pair of contrasting characters, even though those germ cells have come from hybrids in which the contrasting characters are mixed. 
A single germ cell can carry the factors, or causes, for red flowers or white flowers, for green seeds or yellow seeds, for tall stem or short stem, etc., but not for both pairs of these contrasting characters. 'The hybrids formed by crossing white and red four o'clocks carry the factors for both white and red, but the individual germ cells formed by such a hybrid carry the factors for white or red, but not for both; these factors segregate or separate in the formation of the germ cells so that one-half of all the germ cells formed carry the factor for white and the other half that for red.

This is the most important part of Mendel's Law,-the central doctrine from which all. other conclusions of his radiate. It explains not only the segregation of dominant and recessive characters from a hybrid in which both are present, but also the relative numbers of pure dominants, pure recessives and mixed dominant-recessives in each generation. For if all germ cells are pure with respect to any particular character the hybrid offspring of any two parents with contrasting characters will produce in equal numbers two classes of 
germ cells, one bearing the dominant and the other the recessive factor, and the chance combination of these two classes of male and female gametes will yield on the average one union of dominant with dominant, two unions of dominant with recessive and one union of recessive with recessive, thus producing the typical Mendelian ratio, $1 D D: 2 D(R)$ :

$1 R R$, as shown in the accompanying diagram, (Fig. $51 \mathrm{a}, \mathrm{b}$ ).

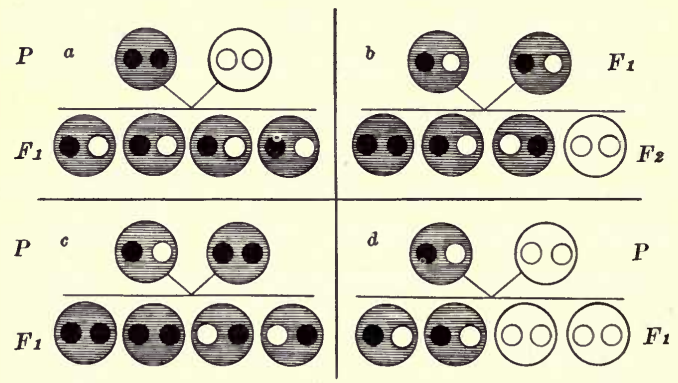

Fig. 51. Diagram of Mendelian inheritance, in which the individual is represented by the large circle, the germ cells by the small ones, dominants being shaded and recessives white. $a$, Pure dominant $\times$ pure recessive $=$ all dominantrecessives, $b$, Dominant-recessive $\times$ dominant-recessive $=1$ pure dominant : 2 dominant-recessives : 1 pure recessive, $c$, Dominant-recessive $\times$ pure dominant $=2$ pure dominant : 2 dominant $=$ recessive, $d$, Dominant-recessive $\times$ pure recessive $=2$ dominant-recessive $: 2$ pure recessive. 


\section{Other Mendelian Ratios}

When a pure dominant is crossed with a mixed dominant-recessive all the offspring show the dominant character, though one-half are pure dominants and the other half dominant-recessives. 'Thus if a pure round-seeded variety of pea is crossed with a hybrid between a round- and a wrinkled-seeded one, all the progeny are round-seeded, though one half of them carry the factor for wrinkled seed; this may be graphically represented as follows, $R$ representing the factor for round seed and $W$ that for wrinkled seed:

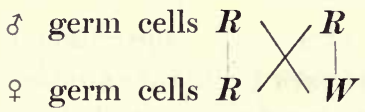

Possible combinations $2 R R: 2 R(W)$.

In subsequent generations the progeny of the pure round $(R R)$ breed true and produce only round-seeded peas, whereas the progeny of the hybrid round-wrinkled $(\boldsymbol{R W})$ split up into pure round, hybrid round-wrinkled, and pure wrinkled in the regular Mendelian ratio of $1 R R: 2 R(W): 1 W W$ (Fig. 52). 
When a pure recessive is crossed with a mixed dominant-recessive another typical ratio results. Thus if a wrinkled-seeded variety of pea is crossed with a hybrid between a roundand wrinkled-seeded one, round-seeded and wrinkled-seeded peas are produced in the proportion of $1: 1$. This is due to the fact that the hybrid produces two kinds of germ cells, the pure-bred but one, and the possible combinations of these are as follows:

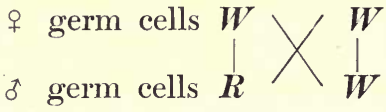

\section{Possible combinations $2 R W: 2 W W$.}

This ratio of $1: 1$ is approximately the ratio of the two sexes in many animals and plants, and there is good reason to believe that sex is a Mendelian character of this sort, in which one parent is heterozygous for sex and the other homozygous (Fig. 51, d).

2. Results of Crossings where there is more than one Pair of Contrasting Characters.-It rarely happens that two individuals differ in a single character only; more frequently they differ in many characters, and this leads to a 
great increase in the number of types of offspring in the $F_{2}$ generation. But however many pairs of contrasting characters the parents may show each pair may be considered by itself as if it were the only contrasting pair, and when this is done all the offspring may be classified according to the regular Mendelian formula given above.

But when two or more contrasting character's of the parents are followed to the $\mathbf{F}_{2}$ generation many permutations of these characters occur, thus giving rise to a larger number of types of individuals than when a single pair of characters is concerned. When there is only one pair of contrasting characters there are usually but two types of offspring apparent in the $\mathrm{F}_{2}$ generation, viz., dominants and recessives in the ratio of 3:1 (Fig. 52) ; where there are two pairs of contrasting characters in the parents there are four types of offspring in the $\mathrm{F}_{2}$ generation in the ratio of $(3: 1)^{2}=$ $9: 3: 3: 1$; when there are three pairs of contrasting characters in the parents there are eight types of offspring apparent in the $\mathrm{F}_{2}$ generation in the proportions of $(3: 1)^{3}=$ 
27:9:9:9:3:3:3:1, etc. Thus when Mendel crossed a variety of peas bearing round and yellow seeds with another variety having wrinkled and green seeds all the offspring of the $\mathbf{F}_{1}$ generation bore round and yellow seeds, round being dominant to wrinkled, and yellow to green. But the plants raised from these seeds, when self-fertilized, yielded seeds of

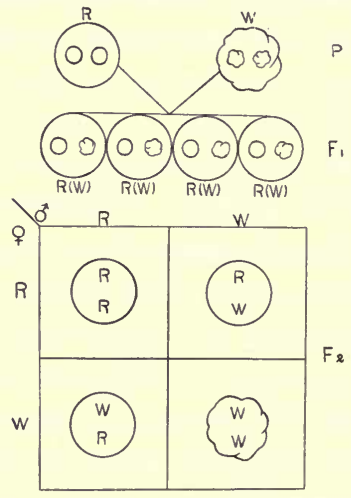

Fig. 52. Monohybrid Diagram showing results of crossing round $(R)$ seeded with wrinkled (W) seeded peas. Large circles represent zygotes, small ones, or single letters, gametes. In $F_{1}$ all individuals are round but contain round and wrinkled gametes. In $\mathrm{F}_{2}$ the $\delta$ gametes are placed above the square, the $q$ ones to the left, and the possible combinations of $\delta$ and $q$ gametes are shown in the small squares, the relative numbers of different types being $1 \quad R R: 2 R(W): 1$ WW. 
four types, round and yellow $(R Y)$, wrinkled and yellow $(\boldsymbol{W} Y)$, round and green $(R G)$, and wrinkled and green $(\boldsymbol{W G})$ in the proportion of $9: 3: 3: 1$ as shown in Fig. 53 .

In this case also this ratio may be explained

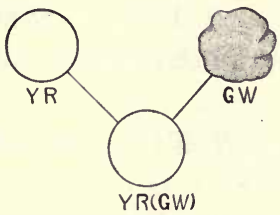

$p$

$F_{1}$

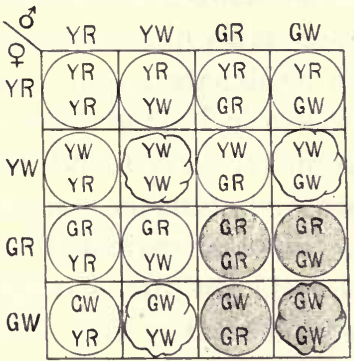

$F_{2}$

Fig. 53. Dihybrid Diagram showing results of crossing peas having yellow-round (YR) seeds with others having greenwrinkled (GR) ones. Four types of germ cells are formed by such a hybrid, viz. YR, YW, GR, GW, and the 16 possible combinations (genotypes) of these $\delta$ and $q$ gametes are shown in the small squares. Since recessive characters do not appear when mated with dominant ones these 16 genotypes produce 4 phenotypes in the following relative numbers: 9YR: 3YW:3GR:1GW. There is 1 pure dominant (upper left corner), 1 pure recessive (lower right corner), 4 homozygotes in diagonal line between these corners, and 12 heterozygotes. 
by assuming that the germ cells (ovules and pollen) are pure with respect to each of the contrasting characters, round-wrinkled, yellow-green, and therefore any combination of these may occur in a germ cell except the combinations $R W$ and $\boldsymbol{Y} G$. Accordingly there are four possible kinds of germ cells as follows:

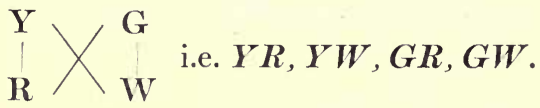

Each of these four kinds of pollen may fertilize any of the four kinds of ovules, thus giving rise to sixteen combinations, no two of which are alike, as shown in Fig. 53. The dominant characters are in this case round and yellow, and only when one of these is absent can its contrasting character, wrinkled or green, develop. Accordingly the sixteen possible combinations yield seeds of four different appearances and in the following proportions: 9RY:3RG:3WY:1WG. Only one individual in each of these four classes is pure (homozygous) and continues to breed true in successive generations; in Fig. 53 these are found in the diagonal from the upper left to the lower 
right corner. All other individuals are heterozygous and show Mendelian splitting in the next generation.

When parents differ in three contrasting characters a much larger number of combinations is possible in the $\mathrm{F}_{2}$ generation. Thus if a pea with round $(\boldsymbol{R})$ and yellow $(\boldsymbol{Y})$ seeds, and with tall $(T)$ stem is crossed with one having wrinkled $(W)$ and green $(G)$ seeds, and dwarf $(D)$ stem all the progeny of the $F_{1}$ generation have round and yellow seeds and tall stem, $R, Y$, and $\boldsymbol{T}$ being dominant to $W, G$, and $D$. But in the $\mathrm{F}_{2}$ generation there are sixty-four possible combinations (genotypes) of these six characters; but since a recessive character does not develop if its contrasting dominant character is present there are only eight types which come to expression (phenotypes) and in the following numbers: 27RYT : $9 R Y D$ : $9 R G T$ : 3RGD : $9 W Y T$ : $3 W Y D: 3 W G T$ : $1 W G D$. Of these sixtyfour genotypes only eight are homozygous and breed true (those lying in the diagonal between upper left and lower right corners in Fig. 54), while only one is pure dominant 
and one pure recessive (the ones in the upper left and lower right corners of Fig. 54).

When the parents differ in one character only, the offspring formed by their crossing are called monohybrids, when there are two contrasting characters in the parents the offspring are dihybrids, when three, trihybrids, and when the parents differ in more than three characters the offspring are called polyhybrids. There are certainly few cases in which parents actually differ in only a single character, but since each contrasting character may be dealt with separately, as if it were the only one, and since the number of types of offspring increases greatly when more than one or two characters are considered at the same time, it is customary to deal simultaneously with only one or two characters of hybrids, even though the parents may have differed in many characters.

3. Inheritance Formulae.-Mendel represented the hereditary constitution of the plants used in his experiments by letters employed as symbols, dominant characters being represented by capitals and recessives by small let- 


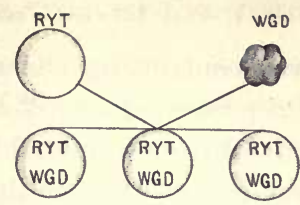

P

FI

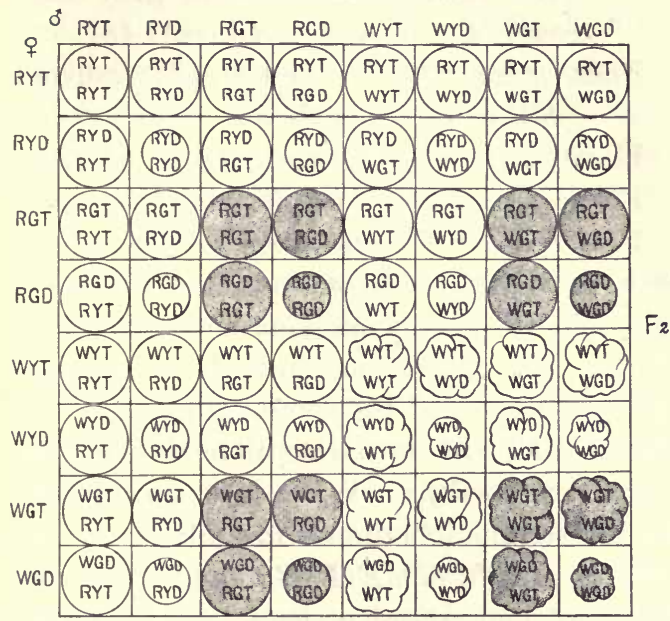

FIG. 54. 'Trihybrid Diagram showing results of crossing peas having round-yellow seeds and tall stem (RYT) with peas having wrinkled-green seeds and dwarf stem (WGD). Eight types of germ cells result from such a hybrid, as shown in the $\delta$ gametes above the square and the $q$ ones to the left of it, and the possible combinations (genotypes) of these $\delta$ and $q$ gametes are shown in the 64 small squares of which only 1 is pure dominant (upper left corner), 1 pure recessive (lower right corner) and 8 homozygotes (in diagonal line between these corners). The relative numbers of the different phenotypes are 27RY'T: 9RYD: 9RGT: 9WY'T: 3RGD: 3WYD: 3WG'T: 1WGD. 
ters. The seven contrasting characters of his peas could be represented as follows:

Seeds, round $(A)$, or wrinkled $(a)$; yellow $(B)$, or green $(b)$; with gray seed coats $(C)$, or white seed coats $(c)$.

Pods, green $(\boldsymbol{D})$, or yellow $(d)$; inflated $(\boldsymbol{E})$, or constricted $(e)$.

Habit, tall $(\boldsymbol{F})$, or dwarf $(f)$.

Flowers, axial $(G)$, or terminal $(g)$.

It is possible for one plant to have all of these dominant characters or all of the recessive ones, or part of one kind and part of the other. The inheritance formula of a plant having all seven of the dominant characters is ABCDEFG; of one having all of the recessive characters abcdefg. When two such plants are crossed the inheritance formula of the hy-

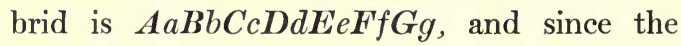
dominant and recessive characters (or rather determiners of characters) represented by these seven pairs of letters separate in the formation of the gametes, and since each separate determiner may be associated with either member of the six other pairs, the number of possible combinations of these determiners in the 
gametes is $(2)^{7}$ or 128 . That is, in this case 128 kinds of germ cells may be produced, each having a different inheritance formula; and since each of these 128 kinds of male germ cells may unite with any one of the 128 kinds of female germ cells, the number of possible combinations is $(128)^{2}$ or 16,384 , which represents the number of combinations of these characters which are possible in the $\mathrm{F}_{2}$ generation. Every one of these more than sixteen thousand genotypes may be represented by various combinations of the letters $A B C D E F G$ and abcdefg.

When many characters are concerned it is difficult to remember what each letter stands for, and consequently it is customary in such cases to designate characters by the initial letter in the name of that character. By this form of short hand one can show in a graphic way the possible segregations and combinations of hereditary units in gametes and zygotes through successive generations, and as a result many modern works on Mendelian inheritance look like pages of algebraic formulæ. 
Some progress has been made, as was pointed out in the last lecture, in identifying certain structures of the germ cells with certain hereditary units, but quite irrespective of what these units may be and where they may be located it is possible, by means of the Mendelian theory of segregation of units in the germ cells and of chance combinations of these in fertilization to predict the number of genotypes and phenotypes which may be expected as the result of a given cross.

4. Presence and Absence Hypothesis.Mendel spoke of the presence of contrasting or differentiating characters in the plants which he crossed, such as round or wrinkled seeds, tall or short stems, etc. Many other writers regard these contrasting characters as positive and negative expression of a single character, and consequently they speak of the presence or absence of single characters: thus round seeds are due to the presence of a factor for roundness $(\boldsymbol{A})$ while wrinkled seeds are characterized by the absence of that factor (a). Round seeds are wrinkled seeds plus the factor for roundness. Most of the phenomena 
of Mendelian inheritance are more simply stated in terms of presence or absence of single characters than in terms of contrasting characters.

When both gametes carry similar positive factors the zygote has a "double dose" of such factors and is said to be duplex; when only one of the gametes carries such a factor the zygote has a "single dose" and is simplex, when neither gamete carries a positive factor or factors, the zygote receives only negative factors and is said to be nulliplex. Thus the union of gametes $A B\left({ }^{\circ}\right)$ and $A B\left({ }^{*}\right)$ yields zygote $A A B B$, which is duplex in constitution; gametes $A b\left({ }^{\circ}\right)$ and $a B\left(\delta^{*}\right)$ yield zygote $A a B b$, which is simplex; gametes $a b\left({ }^{\circ}\right)$ and $a b\left(\delta^{*}\right)$ yield zygote $a a b b$, which is nulliplex.

In some instances a character comes to full expression only when it is derived from both parents, that is, when it is duplex; if derived from one parent only, that is, if simplex, it is diluted in appearance and is intermediate between the two parents. For example, when white-flowered four o'clocks which are nulliplex are crossed with red-flowered ones which 
are duplex the progeny, which are simplex, bear pink flowers; in this case red flowers are produced only when the factor for red is derived from both parents, pink flowers when it is derived from one parent, white flowers when it is derived from neither parent (Fig. 50).

5. Summary of Mendelian Principles.Since the rediscovery in 1900 of Mendel's work many investigators have carried out similar experiments on many species of animals and plants and have greatly extended our knowledge of the principles of inheritance discovered by Mendel, but in the main Mendel's conclusions have been confirmed again and again, so that there is no doubt that they constitute an. important rule of inheritance among all organisms.

In brief the "Mendelian Law of Alternative Inheritance" or of hereditary "splitting" consists of the following principles:

(a) The principle of unit characters.-The total heritage of an organism may be analyzed into number of characters which are inherited as a whole and are not further divisible; these are the so-called "unit characters" (deVries). 
(b) The principle of dominance.-When contrasting unit characters are present in the parents they do not as a rule blend in the offspring, but one is dominant and usually appears fully developed, while the other is recessive and temporarily drops out of sight.

(c) The principle of segregation.-Every individual germ cell is "pure" with respect to any given unit character, even though it come from an "impure" or hybrid parent. In the germ cells of hybrids there is a separation of the determiners of contrasting characters so that different kinds of germ cells are produced, each of which is pure with regard to any given unit character. This is the principle of segregation of unit characters, or of the "purity" of the germ cells. Every sexually produced individual is a double being, double in every cell, one-half having been derived from the male and the other half from the female sex cell. This double being, or zygote, again becomes single in the formation of the germ cells only once more to become double when the germ cells unite in fertilization. 


\section{Modifications and Extensions of Men- delian Principles}

It is a common experience that natural phenomena are found to be more complex the more thoroughly they are investigated. $\mathrm{Na}$ ture is always greater than our theories, and with few exceptions hypotheses which were satisfactory at one stage of knowledge have to be extended, modified or abandoned as knowledge increases. This observation is well illustrated in the case of the Mendelian theory. The principles proposed by Mendel were relatively simple, but in attempting to apply them to the many phenomena of inheritance now known it has become necessary to modify or extend them in many ways. And yet the general and fundamental truth of these principles has been established in a surprisingly large number of cases, and they have been extended to forms of inheritance where at first it was supposed that they could not apply.

1. The Principle of Unit Characters and of Inheritance $\boldsymbol{F}$ actors.-There has been much 
criticism on the part of some biologists of the principle of unit characters. It is said that unit characters cannot be independent and discrete things; the organism itself is a unity and every one of its parts, every one of its characters, must influence more or less every other part and every other character. Certainly unit characters cannot be absolutely independent of one another; the various parts and organs of the body, and even the organism as a whole, are not absolutely independent, and yet there are varying degrees of independence in organisms, organs, cells, parts of cells, hereditary units and characters which make it possible for purposes of analysis to deal with these things as if they were really independent though we know they are not.

Of course characters of adult individuals do not exist as such in germ cells, but there is no escape from the conclusion that in the case of inherited differences between mature organisms there must have been differences in the constitution of the germ cells from which they developed. For every inherited character there must have been a germinal cause in the 
fertilized egg. This germinal cause, whatever it may be, is often spoken of as a determiner of a character. But the character in question is not to be thought of as the result of a single cause nor as the product of the development of a single determiner; undoubtedly many causes are involved in the development of every character, but the differential cause or combination of causes is that which is peculiar to the development of each particular character.

Again it is not necessary to suppose that every developed character is represented in the germ by a distinct determiner, or inheritance unit, just as it is not necessary to suppose that every chemical compound contains a peculiar chemical element; but it is necessary to suppose that each hereditary character is caused by some particular combination of inheritance units and that each compound is produced by some particular combination of chemical elements. An enormous number of chemical compounds exists as the result of various combinations of some eighty different elements, and an almost endless number of words and 
combinations of words-indeed whole literatures-may be made with the twenty-six letters of the alphabet. It is quite probable that the kinds of inheritance units are few in number as compared with the multitudes of adult characters, and that different combinations of the units give rise to different adult characters; but it is certain that every inherited difference in adult organization must have had some differential cause or factor in germinal organization.

Mendel did not speculate about the nature of hereditary units though he evidently conceived that there was something in the germ which corresponded to each character of the plant. Weismann postulated a determinant in the germ for every character which is independently heritable, and many recent students of heredity hold a similar view.

But it is evident that there is not an exact one to one correspondence of inheritance units and adult characters. Many characters may be determined by a single unit or factor; for example, all the numerous secondary sexual characters which distinguish males from females 
may be determined by the original factor which determines whether the germ cells shall be ova or spermatozoa.

On the other hand two or more factors may be concerned in the production of a single character. In many cases among both plants and animals the development of color appears to depend upon the presence in the germ cells and the cooperation in development of at least two factors, viz. (1) a pigment factor for black $B$, for brown $B r$, for yellow $Y$, for red $\boldsymbol{R}$, etc., and (2) a color developer $C$. When both of these factors are present color develops, when either one is absent no color appears.

Such cases have been described for mice, guinea-pigs, and rabbits as well as for several species of plants. Bateson and Punnett found two varieties of white sweet peas which were apparently alike in every respect except the shapes of their pollen grains, one of them having long and the other round pollen. But when these were crossed a remarkable thing occurred for the progeny "instead of being white were purple like the wild Sicilian plant from which our cultivated sweet peas are de- 
scended." This is apparently a typical case of reversion and its cause was found in the fact that at least two factors are necessary in this case for the production of color, a pigment factor $R$ and a color developer $C$. One of these. was lacking in each of the white parents, their gametic formulæ being $\mathrm{Cr}$ and $c R$, but when these two factors came together in the offspring a purple-flowered type was produced with the gametic formula $C c R r$. These $\mathrm{F}_{2}$ plants produced colored and white $\mathrm{F}_{3}$ plants in the proportion of 9 colored to 7 white and the colored forms were of six different kinds (Fig. 55). For the production of these six colored forms five different factors must be present in the gametes, according to Punnett, viz.: (1) a color base $R,(2)$ a color developer $C$, (3) a purple factor $P$, (4) a light wing factor $L,(5)$ a factor for intense color I. When all of these factors are present the result is the purple wild form with blue wings, while the omission of one or more of these factors leads to the production of six forms of colored- and various types of whiteflowered plants of the $\mathbf{F}_{2}$ generation. 


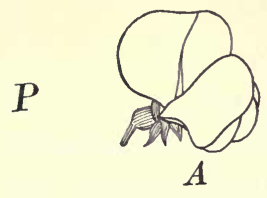

$F_{1}$
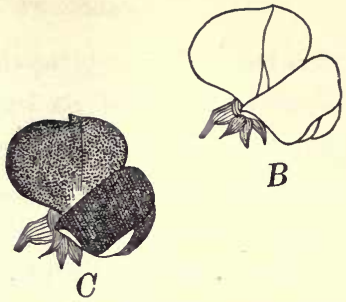

$B$
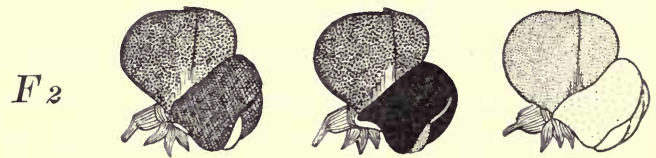

D

E

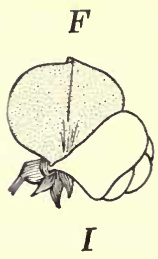

$\square$ WHITE
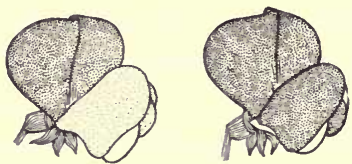

H

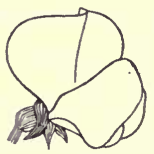

K

SRI PURPLE

BLUe

D DEEP PURPLE

Fig. 55. Results of crossing two different races (A and B) of white sweet peas; all the $F_{1}$ hybrids (C) are purple with blue wings like the wild ancestral stock; in $\mathrm{F}_{2}$ six colored varieties are formed ranging from purple with blue wings (D) to tinged white (I) and several kinds (genotypes) of white varieties (K). (After Punnett.) 
Castle found that eight different factors may be involved in producing the coat colors of rabbits; these are:

$C$ a common color factor necessary to produce any color.

$B$ a factor acting on $C$ to produce black. $B r$ a factor acting on $C$ to produce brown.

$\boldsymbol{Y}$ a factor acting on $\boldsymbol{C}$ to produce yellow.

$I$ a factor which determines intensity of color.

$U$ a factor which determines uniformity of color.

$A$ a factor for agouti, or wild gray pattern, in which the tip of every hair is black, below which is a band of yellow, while the basal part of the hair is gray.

$E$ a factor for the extension of black or brown but not of yellow.

Plate found that all of these factors except the last, $\boldsymbol{E}$, are also involved in the production of the coat colors of mice. Baur has recognized more than twenty different factors for the color and form of flowers in the snapdragon, Antirrhinum.

These factors are probably complex chemi- 
cal substances which preserve their individuality in various combinations, just as groups of atoms or radicals do in chemical reactions; they may be dropped out or added, substituted or transposed, just as chemical radicals may be in chemical compounds. To this extent they maintain continuity and independence, but they are not absolutely independent for they react upon one another as well as to environmental changes, so that the characters of the developed organism are the results of all these reactions and interactions.

\section{Inheritance Factors and Germinal Units}

If it is asked whether there are particular structures in germ cells which correspond to particular inheritance factors it must be admitted that we have no certain knowledge on this subject and that opinions differ greatly with respect to it. On the one hand it is maintained that the entire germ is concerned in the development of every character, and on the other hand that the differential cause of any character may be located in some differentiated structure or function of the germ. 
These views are not mutually exclusive and it may well be that both are true. We know that germ cells are composed of many parts which differ from one another in both structure and function, and it is highly probable that there are enough of these parts to provide a locus for every inheritance factor.

There was a time when the cell was the Ultima Thule of biological analysis and when the contents of cells were supposed to be "perfectly homogeneous, diaphanous, structureless slime." Then the nucleus was discovered within the cell, then the chromosomes within the nucleus, then the chromomeres within the chromosomes, and there is no reason to suppose that organization ceases with the powers of our present microscopes. With every improvement of the microscope and of microscopical technique, structures have been found in cells which were undreamed of before, and it is not probable that the end has been reached in this regard. We know that cells contain nuclei and chromosomes and chromomeres, centrosomes and plastosomes and microsomes, and we know that some of these parts differ in 
function as well as in structure. And there is no reason to doubt that if we had sufficiently powerful microscopes we should find still smaller and smaller units until we came at last to molecules and atoms.

The fact that inheritance units from the two parents unite in fertilization and later segregate in the formation of gametes, so that the latter are pure with respect to any character, is a familiar part of Mendelian inheritance (Fig. 56). Even if these units be re-

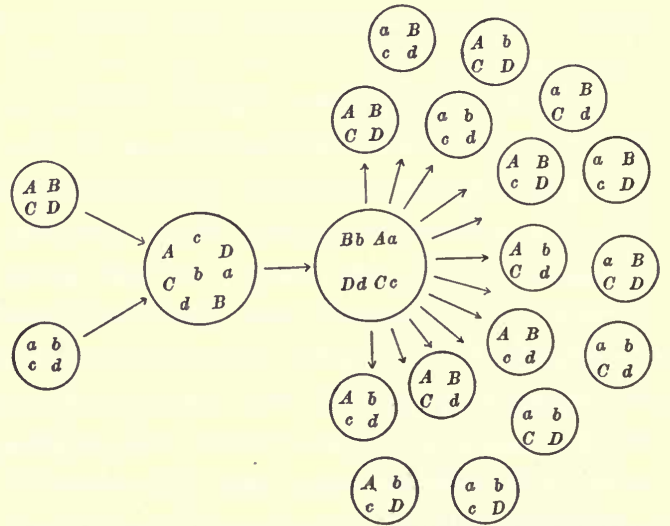

FIg. 56. Diagram showing union of factors in fertilization and their segregation in the formation of germ cells. With 4 pairs of factors ( $\mathrm{Aa}, \mathrm{Bb}, \mathrm{Cc}, \mathrm{Dd}) 16$ types of gametes are possible as shown in the two series of small circles at the right. (From Wilson.) 
garded as physiological processes they must be associated with particular structures, since function and structure are inseparable in life processes. What are these units in terms of cell structures and where are they located in the cell?

We have in the chromosomes, as Wilson especially has emphasized, an apparatus which fulfils all the requirements of carriers of Mendelian factors (Fig. 57). Both factors
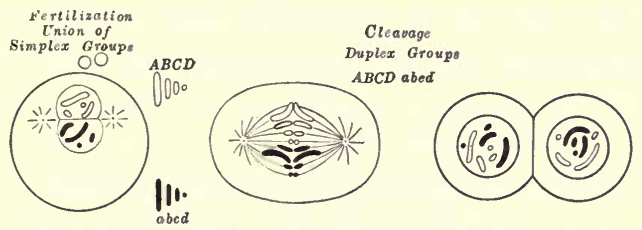

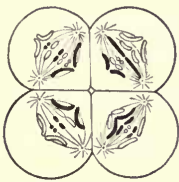

Somatic Divisions

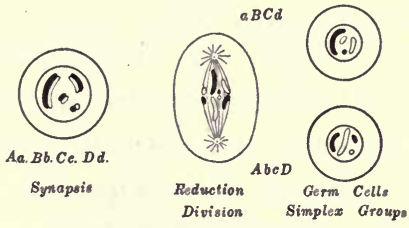

Duplex Grouns

FIg. 57. Diagram of germ cells corresponding to Fig. 56, showing the union of maternal chromosomes (ABCD) and paternal ones (abcd) in fertilization, their distribution in cleavage, their union into 4 pairs ( $\mathrm{Aa}, \mathrm{Bb}, \mathrm{Cc}, \mathrm{Dd}$,) in synapsis and the separation of the pairs in the reduction division. Only 2 of the 16 possible types of germ cells are shown at the lower right. (From Wilṣon.) 
and chromosomes come in equal numbers from both parents; both maternal and paternal factors and chromosomes pair in the zygote and separate in the gamete as shown in Fig. 56 and Fig. 57; and so far as is known the chromosomes are the only portions of the germ cells which fulfil these conditions. Furthermore there is much additional evidence that the chromosomes are especially concerned in heredity, as was pointed out in the last lecture, and it is not reasonable to suppose that this remarkable coincidence between the distribution of Mendelian factors and of chromosomes is without significance.

Of course Mendelian factors are not the only factors of development but merely the differential factors which cause, for example, one guinea-pig to be white and its brother to be black. Very many factors are involved in the production of white or black color but there is at least one differential factor for every unit character and this alone is the Mendelian factor. Of course there is no such thing as a "sex-producing chromosome," sex being the result of the interaction of many intrinsic and 
extrinsic causes. 'The $\boldsymbol{X}$ chromosome is only one factor in the determination of sex, but if it is a factor which differs in the case of the two sexes it is a "sex determining factor." There are many parts of a germ cell, all of which may be concerned in heredity and development, but the chromosomes appear to be the seat of the differential factors for Mendelian characters.

2. Modifications of the Principle of Dominance.-A great number of animal and plant hybrids show one contrasting character completely dominant over the other one as Mendel observed in the case of his peas. But in a considerable number of cases this dominance is incomplete or imperfect. When whiteflowered strains of four o'clocks are crossed with red-flowered ones the $F_{1}$ plants bear neither white nor red flowers but pink ones, and the $\mathrm{F}_{2}$ plants bear white, red and pink flowers. The whites and reds are always homozygous, the pinks heterozygous; pure white and pure red are produced only when their factors are duplex $(\boldsymbol{W} W),(R R)$; when they are simplex $(\boldsymbol{W} R)$ pink is produced. In 
this case red is not completely dominant over white, but the hybrid is more or less intermediate between the two parents (Fig. 50).

It has long been known that the breed of fowls called Blue Andalusian does not breed true, but in each generation produces a certain number of blacks and whites as well as blues. Bateson found that the blues are really hybrids between blacks and whites in which neither of the latter is completely dominant. Black and white appear only when they are pure (homozygous), blue only when both black and white are present (heterozygous).

Again a cross of red and white cattle produces roan offspring, but the latter when interbred give rise to reds, roans and whites in the proportion of $1: 2: 1$, showing that the roans are heterozygotes in which red is not completely dominant over white, while the reds and whites are homozygotes and consequently breed true.

Lang found that when snails with uniformly colored shells were crossed with snails having bands of color on the shells the hybrids were faintly banded, thus being more or less inter- 
mediate between the two parents; but when these hybrids were interbred they produced banded, faintly banded and uniformly colored snails in the ratio of $1: 2: 1$, thus proving that Mendelian segregation takes place in the $\mathbf{F}_{2}$ generation, and that dominance is incomplete in the heterozygotes. Many other similar cases of incomplete dominance are known.

Sometimes dominance is incomplete in early stages of development but becomes complete in adult stages. Davenport found that when pure white and pure black Leghorn fowls are crossed the chicks are speckled white and black, but in the adult fowl dominance is complete and the plumage is black. Similar conditions of delayed dominance are well known in the color of the hair and eyes of children, though dominance may become complete when they have reached adult life.

In a few instances a character may be dominant at one time and recessive at another. Thus Davenport found that an extra toe in fowls is dominant under certain circumstances and recessive under others. Tennent found that characters which are usually dominant in 
hybrid echinoderms may be made recessive if the chemical or physical nature of the sea water is changed. Such cases seem to show that dominance may depend sometimes upon environmental conditions, sometimes upon a particular combination of hereditary units.

\section{Sex and Sex-Limited Inheritance}

Sex and sex-limited inheritance may be considered here since they involve questions of dominance, certain characters remaining undeveloped in one sex which are fully developed in the other. 'There is good evidence, as was shown in the last lecture, that sex is a Mendelian character, in which the female has a double dose of the determiner for sex, whereas the male has only a single dose.' Consequently in the formation of the gametes every egg receives one sex-determiner, while only one-half of the spermatozoa receive such a determiner, the other half of them being without it. If then, an egg is fertilized by a sperm without one of these determiners, a male results; but if an egg is fertilized by a sperm with one of these determiners, a female is produced. This 
is graphically represented in Fig. 58 in which $\boldsymbol{X}$ represents the sex-determiner, which is duplex in the female and simplex in the male, and the chance unions of male and female gametes yield females $(\boldsymbol{X} \boldsymbol{X})$ and males $(X O)$ in equal numbers.

In either sex many secondary sexual charac-
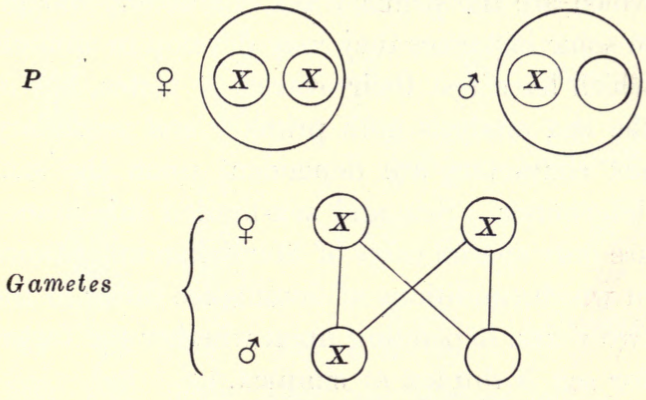

$F_{1}$

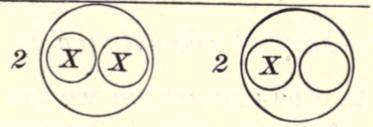

FIg. 58. Diagram showing sex as a Mendelian character, the female being homozygous, the male heterozygous for sex. The female forms gametes all of which contain the $\mathrm{X}$ chromosome; the male forms two sorts of gametes one-half of which contain the $\mathrm{X}$ chromosome and the other half lack it. All possible combinations of these gametes give a $2: 2$ or 1:1 ratio of females to males. 
ters of the other sex are present during development, and traces of these may persist in the adult; but one set of these characters develops in the male and another in the female, so that they may be called sex-limited. The development of the secondary sex characters is usually determined by the ovaries or testes, which are the primary sex characters, though in some instances they may develop in animals which have lost their ovaries or testes, but in the last analysis both primary and secondary sex characters are dependent upon the sexdeterminer. Sex and sex-limited inheritance are only special cases of Mendelian inheritance in which conditions of dominance differ in the two sexes, depending upon whether the factor for sex is duplex or simplex.

\section{Sex-Linked Inheritance}

In this connection we may consider another class of characters, which are linked with sex but are in no wise connected with sexual reproduction. Such characters are not necessarily limited to one sex or the other, as are many primary and secondary sexual characters, but 
they may appear in either sex though they are usually transmitted from fathers to daughters, or from mothers to sons ("criss-cross" inheritance) in exactly the way in which the sex chromosomes $(\boldsymbol{X})$ are transmitted. Morgan has therefore concluded that the factors for

Flies

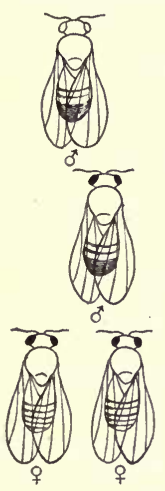

Chromosomes

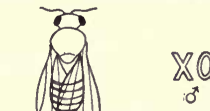

XO XX Parents

i

$\left.\begin{array}{rr}x & 0 \\ \mathbf{x} & 0 \\ \mathbf{X} & +\end{array}\right\}$ Gametes

$2 X(0): 2 X \times \quad F_{1}$

o

q

$\left.\begin{array}{lll}\mathbf{X} & 0 & 0 \\ 1 & 0 & 1 \\ \mathbf{X} & \mathbf{X} & q\end{array}\right\}$ Gametes

XX XX XO XO F2

\& +8 o

FIG. 59. Sex-linked inheritance of white and red eyes in Drosophila. Parents, white-eyed male and red-eyed female; $F_{1}$, red-eyed males and females; $F_{2}$, red-eyed females and equal numbers of red-eyed and white-eyed males. The distribution of sex chromosomes is shown to right of flies; $\mathbf{X}$ carries the factor for red eyes, $\mathbb{X}$ the factor for white eyes, $(0$ stands for absence of $\mathbf{X}$. (After Morgan.) 
these characters are carried by the sex chromosomes and has named them sex-linked characters. In the fruit fly, Drosophila, he has discovered more than twenty-five such characters, applying to the color of the eyes and of the body, to the length of the wings, etc. A typical case is shown in Figs. 59 and 60. The eye color of this fly is normally red, but muta-

Flies

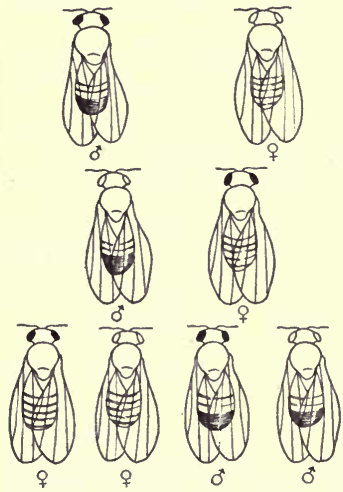

Chromosomes

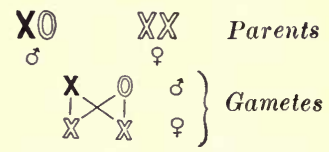

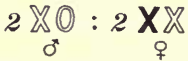

F1

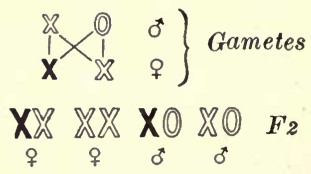

Fio. 60. Reciprocal cross of Fig. 61. Parents, white-eyed $\oint$ and red-eyed $\delta ; F_{1}$, red-eyed $q$ and white-eyed $\delta$ ("crisscross inheritance"); $F_{2}$, equal numbers of red-eyed $q$ and $\delta$ and white-eyed $q$ and $\delta$. The distribution of the sex chromosomes is shown on the right, as in Fig. 59. 
tions have arisen in which the eye is white. Such a mutation always appears in males, though it may later be transferred to females, as we shall see. If now a white-eyed male and a red-eyed female are crossed all the $F_{1} s$ are red-eyed, but if these $\mathrm{F}_{1} \mathrm{~s}$ are interbred all the females of $F_{2}$ have red eyes while half of the males have red eyes and the other half have white eyes (Fig. 59). On the other hand if one of the $F_{1}$ females of this cross is bred with a white-eyed male half of the females of $\mathrm{F}_{2}$ are red-eyed and half are white-eyed, and half of the males are red-eyed and half are white-eyed.

If now one of these white-eyed females is bred with a red-eyed male all the females of the $F_{1}$ generation are red-eyed and all the males white-eyed ("criss-cross" inheritance) and if these are interbred there are produced in the $\mathrm{F}_{2}$ generation equal numbers of redeyed and white-eyed males and females (Fig. 60).

The distribution of the maternal and paternal sex chromosomes $(X)$ exactly parallels this distribution of this sex-linked character, 
as is shown in the right half both of Fig. 59 and of Fig. 60, and this suggests that the differential factors for these characters are carried in these chromosomes.

By a series of ingenious experiments Foot and Strobell have shown recently that the differential factors for certain sex-limited characters in insects, that is characters which are limited to one sex, are not contained in the "sex chromosomes," and they argue that the differential factors for sex and for sex-linked characters cannot be located in these chromosomes. Morgan does not admit the validity of their conclusions, but it must be admitted that the evidence that particular determiners can be located in particular chromosomes is not entirely conclusive, and this question may for the present be regarded as an open one. However there is good evidence that the factors for the determination of sex and of sexlinked characters are distributed in the same way as the "sex chromosomes" are, and it would be a surprising thing if these two phenomena should be found not to be related causally. 
Another case of sex-linked inheritance is found in an abnormal condition in man known as haemophilia, which is characterized by a deficiency in the clotting power of the blood, and consequently by excessive bleeding after injury. "Bleeders" are almost always males, though the defect is always transmitted to a son from his mother who does not usually show the defect because it appears in females only when both parents were affected. The manner of inheritance of this character is exactly similar to the inheritance of white eyes in Drosophila and is in all probability due to similar causes.

One of the most striking cases of sex-linked inheritance is that form of color blindness known as Daltonism, in which the affected person is unable to distinguish between red and green. It is known that males are more frequently affected than females, and that color blindness is in some way associated with sex. It requires two determiners for color blindness, one from the father, the other from the mother, to produce a color blind female, whereas only a single determiner is necessary 
to produce a color blind male, just as is true of sex. The accompanying diagrams (Figs. 61,62 ) illustrate the method of inheritance of color blindness. As in the previous diagrams $\mathbb{X}$ represents the sex-determiner, (0) its absence, and $\mathbf{X}$ the sex-determiner which carries the factor for color blindness.

It will be seen that a color blind father and a

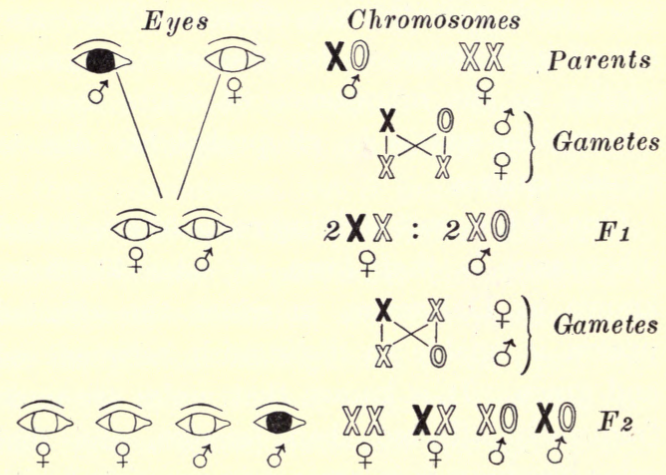

Fig. 61. Diagram of inheritance of color blindness through the male. A color blind male (here black) transmits his defect to his grandsons only. The corresponding distribution of the sex chromosomes is shown on the right, the one carrying the factor for color blindness being black. (After Morgan.) 
normal mother have only normal children, but the father transmits to his daughters and not to his sons the sex-determiner which carries the factor for color blindness. But since color blindness does not develop in females unless it is duplex (i.e. comes from both father and mother) whereas it develops in males if it is simplex (i.e. comes from either parent) all the daughters of a color blind

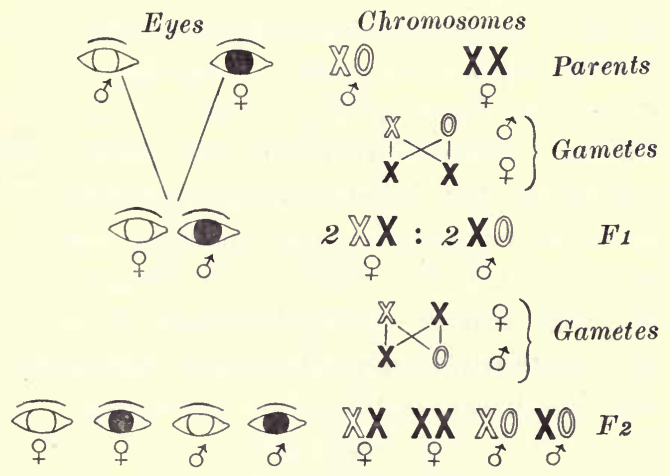

Fig. 62. Diagram of inheritance of color blindness through the female. A color blind female transmits her defect to all her sons, to half of her granddaughters and to half of her grandsons. Corresponding distribution of sex chromosomes on right. (After Morgan.) 
father and normal mother will appear normal although carrying one determiner for color blindness, while all the sons will be normal because they carry no determiner for color blindness. But these daughters transmit to one-half of their children the single determiner for color blindness and if any of those receiving this determiner are males they will be color blind. Consequently we have the curious phenomenon of simplex color blindness appearing only in males and being transmitted to them only through apparently normal females.

On the other hand if a female is color blind she has inherited it from both father and mother, i.e. the character in her is duplex, and in all of her children by a normal male the character will be simplex; accordingly all of her sons will be color blind and all of her daughters will be normal, though carrying the simplex determiner for color blindness.

In all cases dominance means merely the development in offspring of certain characters of one parent, while contrasting characters of 
the other parent remain undeveloped. The appearance of any developed character in an organism depends upon many complicated reactions of germinal units to one another and to the environment. Under certain conditions of the germ or of the environment some characters may develop in hybrids to the exclusion of their opposites whereas under other conditions these results may be reversed or the characters may be intermediate. The principle of dominance is not a fundamental part of Mendelian inheritance. Even when the characters of hybrids are intermediate between those of their parents, if the parental types reappear in the $F_{2}$ generation we may be certain that we are dealing with cases of Mendelian inheritance.

3. The Principle of Segregation.-The individuality of inheritance units, and their segregation or separation in the sex cells and recombination in the zygote are fundamental principles of the Mendelian doctrine. Indeed the evidence for the individuality and continuity of inheritance units is based entirely upon such segregation and recombination, so that 
the entire Mendelian theory may be said to rest upon the principle of segregation. If there are cases in which such segregation does not take place they belong to other forms of inheritance than the Mendelian; if segregation occurs in every instance there is no other type of inheritance than that discovered by Mendel. Are there cases which do not segregate according to Mendelian expectation?

When the Mendelian theory was new it was generally supposed that there were forms of inheritance which differed materially from the Mendelian type; indeed it was supposed that the latter was one of the less common forms of heredity and that blending of parental traits and not segregation was the rule. All cases in which the characters of the parents appeared to blend in the offspring or in which there was not a clear segregation of the parental types in the $\mathrm{F}_{2}$ generation or in which the ratio for a monohybrid differed from the well known 3 to 1 ratio were supposed to be non-Mendelian.

However further work has shown that some of these are really Mendelian. Sometimes 
offspring are intermediate between their parents owing to incompleteness of dominance, rather than to incompleteness of segregation; in such cases the parental types reappear in the $\mathbf{F}_{2}$ generation as in the cross between red and white four o'clocks. Sometimes departures from the 3 to 1 ratio are caused by the fact that two or more factors of the same sort are involved in the production of a single character. Nilsson-Ehle found that when oats with black glumes were crossed with varieties having white glumes the ratio of 3 white to 1 black was usually found in the second generation; but one variety of black oats when crossed with white gave in the second generation approximately 15 blacks to 1 white which is the dihybrid ratio. From this and other evidence he concludes that in this variety of oats two hereditarily separable factors are involved in the production of black. In crosses between red-grained and whitegrained wheat he usually got in the second generation the monohybrid ratio of 3 red to 1 white, but three strains gave the dihybrid ratio of 15 to 1 and two gave the trihybrid ratio of 
63 to 1. Consequently he concludes that while the red color of wheat grains is usually due to one factor for red, it may in some cases be due to two or even three factors; notable departures from expected ratios may thus be explained.

\section{Blending Inheritance}

But the most serious objections whicn can be presented against the universality of the Mendelian doctrine are found in phenomena of "blending" inheritance. In some instances contrasting characters of parents appear to blend in offspring and even in the $\mathrm{F}_{2}$ and in subsequent generations the descendants remain more or less intermediate between the parents. One of the best known illustrations of this is found in the skin color of the mulatto which is intermediate between the white parent and the black one, and even in the $\mathbf{F}_{2}$ and in subsequent generations mulattoes do not usually, if ever, produce pure white or pure black children, though the children of mulattoes show considerable variation in color. Here there is 
an apparent failure of the Mendelian principle of segregation.

But white skin is not really white nor is black skin ever perfectly black. Davenport has shown that there is a mixture of black, yellow and red pigment in both white and black skins, though the amount of each of these pigments varies greatly in negroes and whites. The relative amounts of these pigments in any given case may be determined by means of a rotating color disk. A white person may have a skin color composed of black $(b)$ 8 per cent., yellow $(y) 9$ per cent., red $(r) 50$ per cent., and absence of pigment or white $(w)$ 33 per cent. On the other hand a very black negro may have $b 68$ per cent., $y 2$ per cent., $r 26$ per cent., $w 4$ per cent. The nine children of two mulattoes, the father having 13 per cent. of black and the mother 45 per cent., ranged all the way from 46 per cent. to 6 per cent. of black, the latter so far as skin color is concerned being virtually white. On the other hand where both parents have about the same degree of pigmentation the children are more nearly uniform in color; thus seven children of 
two mulattoes, the father having 36 per cent. and the mother 30 per cent. of black, ranged only from 27 per cent. to 39 per cent. of black.

Such variations in color in the $\mathrm{F}_{2}$ and in subsequent generations are exactly what one would expect in a Mendelian character in which more than one factor is involved, as for example in the case of the color of the sweet peas shown in Fig. 55. Davenport, who has made an extensive study of this case, concludes that "there are two double factors $(\boldsymbol{A} A, B B)$ for black pigmentation in the full blooded negro of the west coast of Africa, and these are separably inheritable." These factors are lacking in white persons (this being indicated by the formula $a a, b b)$. Since the germ cells carry only single factors and not double ones the cross between negro and white would have only one set of these factors for black color, as shown by the formula $A B \times a b$ $=A B a b$; hence the color of the $\mathrm{F}_{1}$ generation is intermediate between that of the two parents. In the $\mathbf{F}_{2}$ generation there should be a variety of colors ranging all the way from white to black, though pure white or pure black 
would be expected in only a small proportion of the offspring. As a matter of fact it is known that the children of mulattoes vary considerably in color, and in some cases a child may be darker or lighter than either parent, which would indicate that segregation does actually occur. It is very probable that this classical case of "blending" inheritance is really Mendelian inheritance in which two or more factors for skin color are involved.

Similar "blending" inheritance is found in certain other cases where the parents differ in form or size. Thus Castle found that when long-eared rabbits were crossed with shorteared ones the offspring have ears of intermediate length, and in all subsequent generations the ear length remained intermediate between that of the parents. He found the same thing true of length and breadth of the skull (Fig. 63) and of the size of other portions of the skeleton, and he concluded that such quantitative characters are not inherited in Mendelian fashion.

Quite recently MacDowell, working on the inheritance of size in rabbits, concludes that 
this character, as well as other quantitative differences between parents which appear to blend in the offspring, such as Castle's case of ear length in rabbits, is not due to a single factor, as in the case of Mendel's tall and dwarf peas, but to several factors. Consequently in the formation of the germ cells there is not a clean segregation of all the factors for tallness

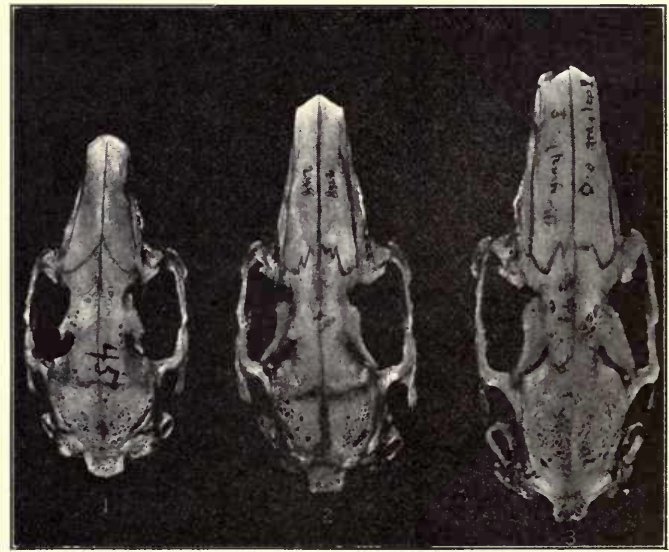

FIG. 63. Blending inheritance of size in rabbits; the skulls of two parents are shown in 1 and 3, of their intermediate offspring in 2. (From Castle.) 
or large size or long ears in half the germ cells and their total absence in the other half of those cells, but some of these factors go into certain cells and others into others, as in the case of dihybrids, trihybrids or polyhybrids. As a result offspring appear more or less intermediate in size between their parents.

Thus it is possible to explain even "blending" inheritance as due not to the real fusion or blending of inheritance factors but to varying combinations of numerous or multiple factors, according to the Mendelian rules. The Mendelian principle of segregation has been found to be of such general occurrence that there is a strong inclination among Mendelians of the stricter sort to make it universal, and to explain all cases of "blending" inheritance as due to incomplete dominance and to multiple factors. Whether or not such attempts may prove completely successful it is still too soon to say. 


\section{Mendelian Inheritance in Man}

The study of inheritance in man must always be less satisfactory and the results less secure than in the case of lower animals and for the following reasons: In the first place there are no "pure lines" but the most complicated intermixture of different lines. In the second place experiments are out of the question and one must rely upon observation and

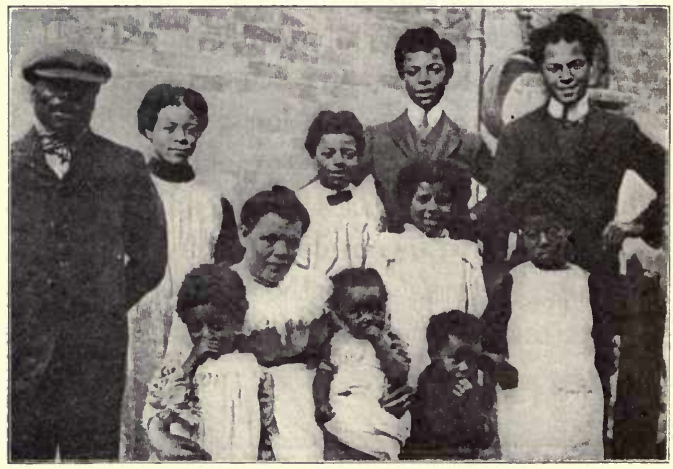

FIG. 64. Blending inheritance of skin color in negrowhite cross with dominance of kinky hair over straight hair. (From Bond.) 


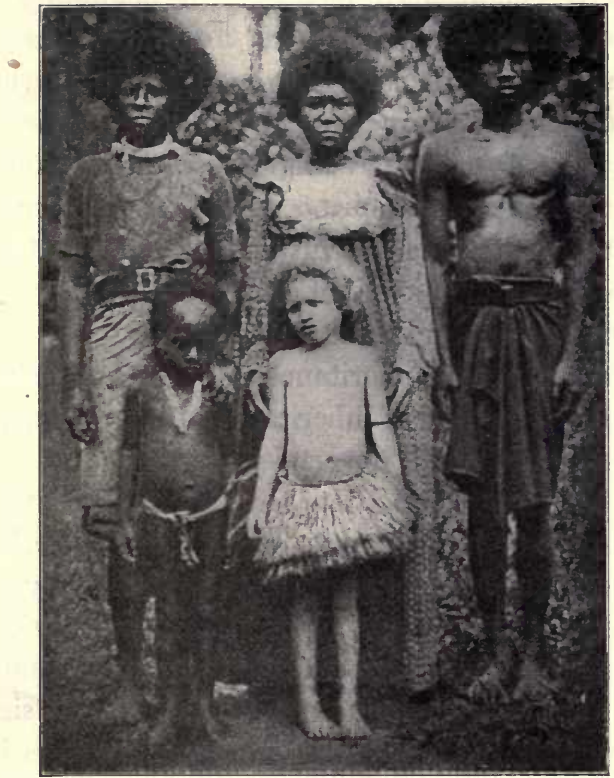

Fig. 65. Papuan family of New Guinea with one albino child. (From Pearson-Nettleship-Usher.) 
statistics. In the third place man is a slow breeding animal; there have been less than sixty generations of men since the beginning of the Christian era, whereas Jennings gets as many generations of Paramecium within two months and Morgan almost as many generations of Drosophila within two years. Finally the number of offspring are so few in human families that it is difficult to determine what all the hereditary possibilities of a family may be. Bearing in mind these serious handicaps to an exact study of inheritance it is not surprising that the method of inheritance of many human characters is still uncertain.

Davenport and Plate have catalogued more than sixty human traits which seem to be inherited in Mendelian fashion. About fifty of these represent pathological or teratological conditions while only a relatively small number are normal characters. This does not signify that the method of inheritance differs in the case of normal and abnormal characters, but rather that abnormal characters are more striking, more easily followed from generation to generation, and consequently statistics are 
more complete with regard to them than in the case of normal characters. In many cases statistics are not sufficiently complete to determine with certainty whether the character in question is dominant or recessive, and it must be understood that in some instances the classification in this respect is tentative. A partial list of these characters is given herewith:

\section{Mendelian Inheritance in Man \\ NORMAL CHARACTERS}

\section{Dominant}

\section{Recessive}

Hair:

Curly

Dark

Straight (Fig. 64)

Light to red

Eye Color:

Brown

Blue

Skin Color:

Dark

Normal Pigmentation

Light

Albinism (Figs. 65, 66)

Countenance:

Hapsburg Type (Thick Normal

lower lip and prominent chin)

German Type Jewish Type

Temperament :

Nervous

Phlegmatic

Intellectual Capacity:

Average

Very great

Average

Very small 


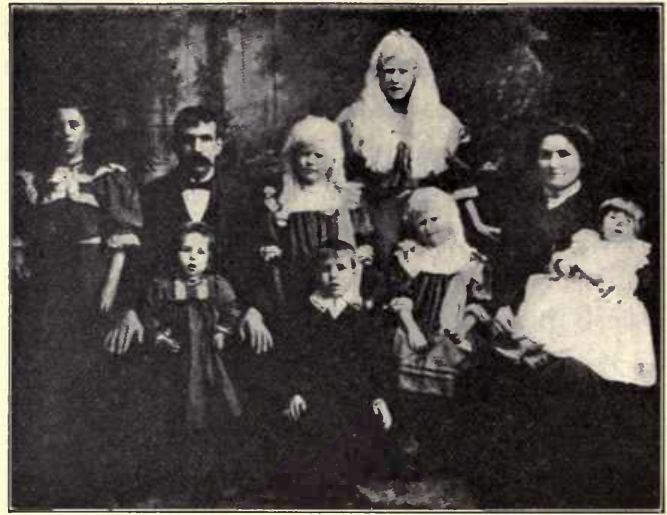

Fig. 66. European family with three albino and four normal children. (From Pearson-Nettleship-Usher.)

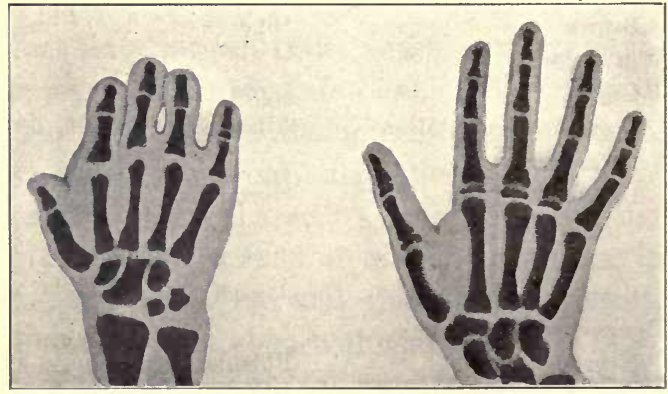

B

A

Fig. 67. X-ray picture, $\mathrm{A}$ of a normal, $\mathrm{B}$ of a short-fingered (brachydactyl) hand. (From Bateson.) 
Mendelian Inheritance in Man (Continued)

TERATOLOGICAL AND PATHOLOGICAL CHARACTERS

Dominant

Recessive

General Size:
Achondroplasy (Dwarfs
with short stout limbs
but with bodies and
heads of normal size)
Normal Size

Normal (Fig. 68)

Hands and Feet:
Brachydactyly (Short Normal (Fig. 67) fingers and toes)
Syndactyly (Webbed Normal fingers and toes)
Polydactyly (Supernu- Normal merary digits)

Skin:

Keratosis (Thickening Normal of Epidermis)

Epidermolysis (Exces- Normal sive formation of blisters)

Hypotrichosis (Hair- Normal lessness associated with lack of teeth)

Kidneys :

Diabetes insipidus

Normal

Diabetes mellitus Normal

Normal

Alkaptonuria (Urine dark after oxidation) 


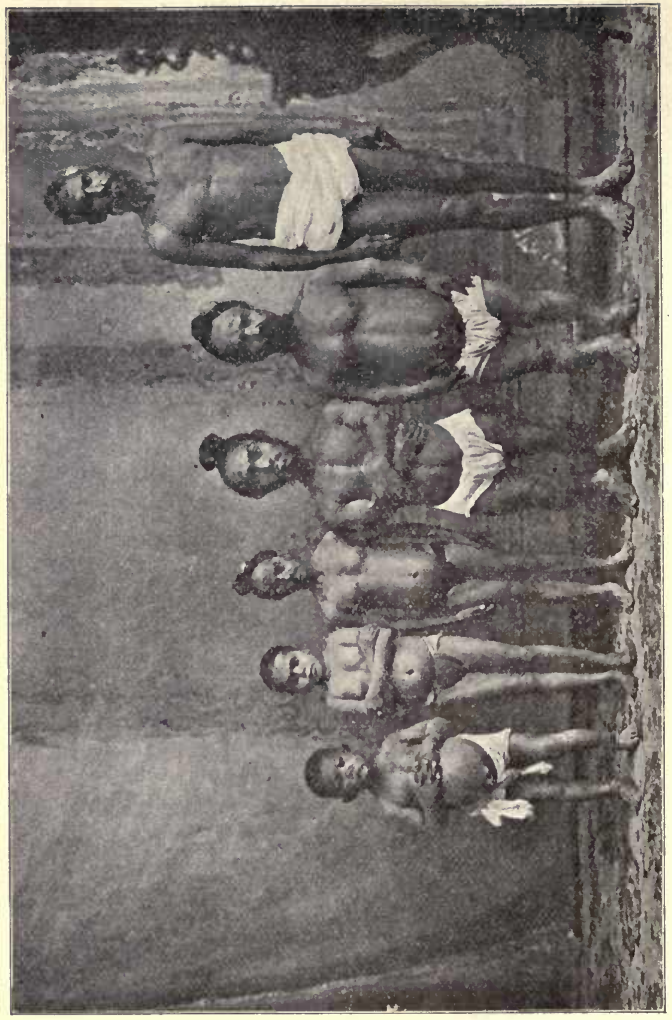

है ह 톨

0 든

당

告

स्रू०

近

$\pm$

일

[1

ผี

Z

है क्षे

$\Xi$

莫

पै

क्ष

포융

范

든

(4)

宓

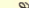

o륭

ड़

II फ़ Ф્ષ

는

핀

를 


\section{Mendelian Inheritance in Man (Contimued) TERATOLOGICAL AND PATHOLOGICAL CHARACTERS Dominant}

Nervous System:

Normal Condition

Normal

Normal

Normal

General Neuropathy, e.g. Hereditary Epilepsy

Hereditary Feeble-mindedness

Hereditary Insanity

Hereditary Alcoholism

Hereditary Criminality

Hereditary Hysteria

Multiple Sclerosis (Diffuse degeneration of nerve tissue)

Friedrich's Disease (Degeneration of upper part of spinal cord)

Meniere's Disease (Dizziness and roaring in ears)

Normal

Chorea (St. Vitus Dance)

Normal

Thomsen's Dis e a s e (Lack of muscular tone)

Huntington's Chorea

Normal

Muscular Atrophy

Normal

Eyes:

Hereditary Cataract

Normal

Pigmentary Degenera-

Normal tion of Retina 
Mendelian Inheritance in Man (Continued) TERATOLOGICAL AND PATHOLOGICAL CHARACTERS

Dominant

Glaucoma (Internal pres- Normal sure and swelling of eyeball)

Coloboma (Open suture Normal in iris)

Displaced Lens

Ears :

Normal

Normal
Recessive
Normal

Deaf-mutism

Otosclerosis (Thickened tympanum with hardness of hearing)

\section{SEX-LINKED CHARACTERS}

Recessive characters, appearing in male when simplex, in female only when duplex.

Normal

Normal

Normal

Normal

Normal
Gower's Muscular Atrophy

Hæmophilia (Slow clotting of blood)

Color Blindness (Daltonism; inability to distinguish red from green)

Night Blindness (Inability to see by faint light)

Neuritis Optica (Progressive atrophy of optic nerve) 


\section{Summary}

The principles of heredity established by Mendel are almost as important for biology as the atomic theory of Dalton is for chemistry. By means of these principles particular dissociations and recombinations of characters can be made with almost the same certainty as particular dissociations and recombinations of atoms can be made in chemical reactions. By means of these principles the hereditary constitution of organisms can be analyzed and the real resemblances and differences of various organisms determined. $\mathrm{By}$ means of these principles the once mysterious and apparently capricious phenomena of prepotency, atavism and reversion find a satisfactory explanation.

Before the establishment of Mendel's principles heredity was, as Balzac said, "a maze in which science loses itself." Much still remains to be discovered about inheritance, but the principles of Mendel have served as an Ariadne thread to guide science through this maze of apparent contradictions and exceptions in which it was formerly lost. 



\section{CHAPTER IV}

\section{INFLUENCE OF ENVIRONMENT}





\section{CHAPTER IV}

\section{INFLUENCE OF ENVIRONMENT}

The development of an individual or the evolution of a race is dependent upon the interaction of two sets of factors or causes, the intrinsic and the extrinsic. The former is represented by the organization of the germinal protoplasm, the latter by all other conditions; the former is known as heredity or constitution, the latter as environment or education; or in the words of Galton, these two sets of factors may be called "nature" and "nurture." The great problem of development is the unraveling of these two factors, the assignment of its true value to each, and the ultimate control of development so far as this may be possible through the knowledge thus gained. 


\section{A. RELATIVE IMPORTANCE OF HEREDITY AND ENVIRONMENT}

'The distinction between these two factors of development is generally recognized and the question of the relative importance of the two has been discussed for ages. Which is the more important, constitution or environment? What characteristics are due to nature and what to nurture? To what extent is man the creature of heredity, to what extent the product of education? The old question "Which of you by taking thought can add one cubit to his stature," is a vital question to-day. To what extent may nature be modified by nurture? To what extent may education make up for deficiencies of birth?

1. Formerly very great emphasis was placed upon influences of environment in phylogeny and ontogeny. From the earliest times it has been believed that species might be transmuted by environmental changes and that even life itself might arise from lifeless matter through the influence of favorable extrinsic conditions. If environment could exert 
so great an influence on the origin of species or even of life itself much more could it affect the process of development of the individual. It is still popularly supposed that complexion is dependent upon the intensity of light, and stature upon the quantity and quality of food, that sex is determined by food or temperature, mentality by education, and that in general individual peculiarities are due to environmental differences.

Many philosophers of the seventeenth and eighteenth centuries taught that man was the product of environment and education and that all men were born equal and later became unequal through unequal opportunities. Descartes begins his famous "Discourse on Method" with these words:

"Good sense is, of all things among men, the most equally distributed ... The diversity of our opinions does not arise from some being endowed with a larger share of Reason than others, but solely from this, that we conduct our thoughts along different ways, and do not fix our attention on the same objects."

The Declaration of Independence merely reflected the spirit of the age in which it was 
written when it held this truth to be self evident, "that all men are created free and equal." The equality of man has always been one of the foundation stones of democracy. Upon this belief in the natural equality of all men were founded systems of theology, education and government which hold the field to this day. Upon the belief that men are made by their environment and training rather than by heredity are founded most of our social institutions with their commands and prohibitions, their rewards and punishments, their charities and corrections, their care for the education and environment of the individual and their disregard of the inheritance of the race. Civilization itself means only good environmental conditions, and the advance of civilization means only improvement of environment.

2. On the other hand modern studies in genetics are emphasizing the immense, the overwhelming importance of heredity, in both phylogeny and ontogeny. No one now takes seriously the assertion that life can be experimentally produced at the present time from non-living matter. It is evident that the arti- 
ficial production of life is a much more difficult problem than was once supposed, and it may be an insoluble problem. The first flush of enthusiasm over experimental methods in biology led to the expectation that we would soon be making species and indeed whole faunas and floras by the process of experimental evolution, but the results of one or two decades of such experimental work have been somewhat disappointing. Inherited variations do appear, incipient species arise, but there is very little evidence to show that they appear in response to environmental changes only. Belief in the omnipotence of environment in the evolution of species has steadily waned in recent years, while a belief in the intrinsic causes of evolution, such as the mutation theory and orthogenesis, has increased.

In ontogeny also the environmental or extrinsic factors of development have been relegated to a subordinate place, while the intrinsic or hereditary factors appear more important than ever. The old view that men are chiefly the product of environment and training is completely reversed by recent studies 
of heredity. The modifications which may be produced by environment and education are small and temporary as compared with those which are determined by heredity.

3. These conclusions are, in the main, well founded. 'The evidence of the tremendous importance of heredity is so complete that we may rest assured that thinking men will never again return to the position which prevailed until a few years ago regarding the all-importance of environment. And yet there is danger of going too far in the opposite direction. Neither environment nor heredity is all-important, but both are necessary to development. The germ cells with all their inherent possibilities would forever remain germ cells were it not for environmental stimuli. The realization of germinal possibilities is dependent upon the responses of the germ to environmental stimuli, and although heredity is a relatively constant factor while environment is a more variable one, nevertheless the two are indispensable to development. Only by experiment can the relative importance of heredity and environment in development be 
determined. Extensive experiments have been made within recent years on developing animals and plants in order to discover the factors involved in development, and the modifications which may thus be produced are very striking.

\section{B. EXPERIMENTAL MODIFICATION OF DEVELOPMENT}

The study of development under experimental conditions has given rise to a new branch of biology, viz., experimental embryology or the physiology of development. By changes in environmental conditions notable modifications may be produced in adult organisms, but these modifications are much greater when the changed environment acts on the organism during the period of its development.

\section{Developmental Stimuli}

It is by no means easy to define such general terms as "environment," "stimulus," "response." In its common use "environment" 
means all that lies outside the individual, if it is defined from the standpoint of the entire organism; but from the standpoint of an organ or cell it is the surrounding organs, cells or fluids of the body-the latter may be defined as internal environment. If developmental stimuli arise outside the organism they are plainly extrinsic or environmental, but if they arise within the organism they are said to be intrinsic though they may be due to changes in the internal environment.

Stimuli are chiefly energy changes of a physical or chemical nature. A stimulus to which an adult organism responds by movements or other activities may call forth or inhibit developmental responses when applied to germ cells or embryos.

These developmental stimuli may be classed as:

1. Physical stimuli including the following, (a) mechanical, (b) thermal, (c) electrical, (d) radiant, (e) light, (f) density of medium, (g) gravity and centrifugal force, etc.

2. Chemical stimuli include the action of (a) substances found in normal development, 
such as oxygen, carbonic acid, water, food, secretions of ductless glands etc., and (b) substances not found in normal development, such as various salts, acids, alkalis, alcohol, ether, tobacco, etc.

3. In general the action of these stimuli during development does not call forth a perfectly specific and definite response of the organism; various stimuli may produce the same result. Thus artificial parthenogenesis has been produced by almost every stimulus named, and weakened or retarded development is produced by many different stimuli.

By the elimination of certain of these stimuli which are normally present or by introducing stimuli which are not usually present very important and even profound changes in development may be produced. In this way animals have been formed which are turned inside out, or side for side, or in which heads or nervous systems or muscles or backbones are lacking, or in which the various organs are not found in normal positions. In this way dwarfs and giants and one-eyed monsters as well as all sorts of double and par- 
tial embryos have been formed. In general monstrous and defective forms of development are due to alterations of the normal environmental stimuli rather than to defective hereditary constitution.

\section{Developmental Responses}

The character of developmental responses to stimuli depends primarily upon (a) the nature of the organism and (b) the stage of development at which the stimulus acts. Modifications are more easily produced and are more profound during cell division than during intervening periods and at early stages of development than at later ones.

1. Modifications of Germ Cells before Fertilization.-It has been found by many investigators that development may be profoundly changed by influences acting upon the germ cells before fertilization. In general environmental changes acting during the growth of eggs or spermatozoa and especially during their maturation may produce marked changes in development and even in heredity. Tower has found that unusual conditions of temperature and humidity during the later stages of 
oogenesis and spermatogenesis may lead to the production of new races in the case of the potato beetle (Fig. 94). I have found that a slight increase in temperature at the time of nuclear division may lead to abnormal separation of the chromosomes and presumably to a change in hereditary constitution; Gager has obtained similar results following the use of radium on plants. MacDougall's experiments on plants point to the conclusion that chemical substances may influence the ovules so as to change the hereditary character of the plant. Bardeen and the Hertwigs have shown that great monstrosities may be produced if $\mathbf{X}$-rays, radium or various chemical substances are allowed to act on spermatozoa before fertilization. Stockard subjected adult male and female guinea-pigs to the fumes of alcohol for some time before breeding them and then studied the effects of this drug on their offspring. He finds that the influence of alcohol on the spermatozoa is as deleterious as when acting on the ova and that it produces sterility, or greatly reduced fertility, a great excess of still-births, and weak and sickly off- 
spring (Fig. 69). Hoppe believes that a single drunken debauch may so injure the germ cells of man as to produce abnormal and defective
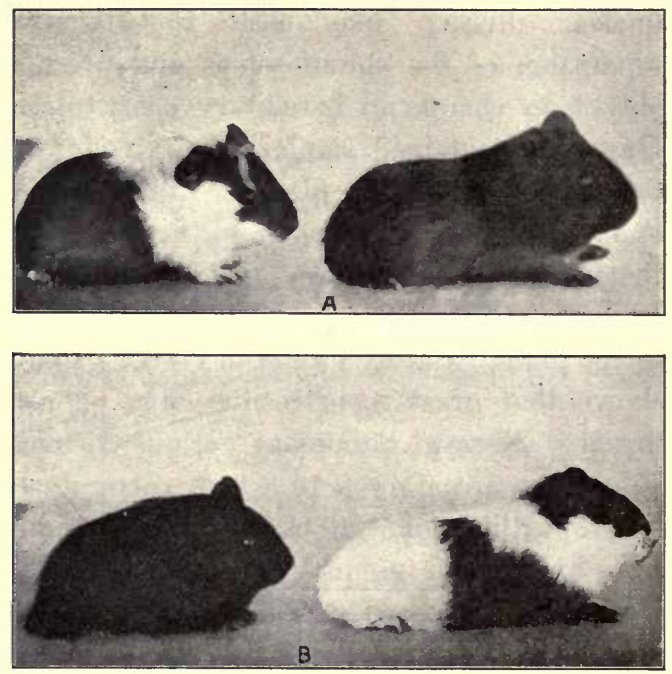

Fig. 69. Dwarfed guinea-pigs on the left and normal ones on the right. All are of approximately the same age though the normal ones are nearly twice the weight of the dwarfs. The normals came from normal parents, the dwarfs from a normal mother and an alcoholic father; the dwarfing has therefore been produced by the influence of alcohol on the spermatozoa. (From Stockard.) 
offspring, though this is by no means proved; while Hertwig concludes that the great prevalence of the drug habit may seriously affect the germ cells and their subsequent development. Forel has for many years maintained that one of the most serious causes of human malformations and degenerations is to be found in the effect of alcohol on the germ cells, especially at the time of conception.

2. Fertilization Stages. - Environmental changes acting during fertilization may cause more than one spermatozoon to enter the egg or may injure the egg or sperm; in either case the resulting development is abnormal. Where two or more spermatozoa enter the egg the nuclear divisions are usually abnormal, as Boveri has shown in the case of the sea urchin; the distribution of chromosomes to different cleavage cells is unequal and such cells do not undergo typical development, while the embryo or larva produced is not capable of continued life. In cases where an egg is fertilized by a spermatozoon belonging to a different phylum or class (heterogeneous fertilization) the foreign sperm, after 
stimulating the egg to begin development, may itself die or remain inactive, in which case the hereditary traits which develop are those of the mother only. In many animals unfertilized eggs may be stimulated to begin development by a great variety of changes in the medium, all such cases being known as "artificial parthenogenesis."

3. Modifications of Development after Fertilization.-Environmental changes, acting upon the oosperm after fertilization, or upon the embryo, may produce an almost infinite variety of abnormal types of development, but so far as known none of these modifications becomes hereditary. Changes in hereditary constitution take place in the main before fertilization and especially during the maturation divisions.

If the cleavage cells are separated from one another in the 2-cell or 4-cell stage each of them may give rise to an entire animal (Fig. $70)$; in this way four complete animals may be derived from a single egg of a star-fish or sea urchin, of an amphioxus, or of several other animal types. If the frog's egg is turned 
upside down in the 2-cell stage, double headed or double bodied embryos may result (Fig. 71). In such cases each cleavage cell is said to
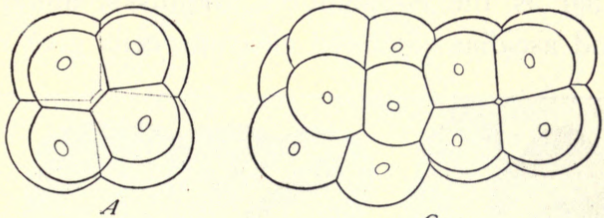

C
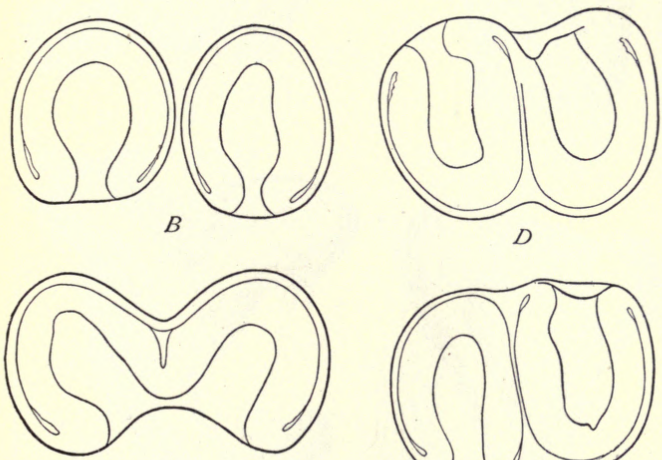

$E$

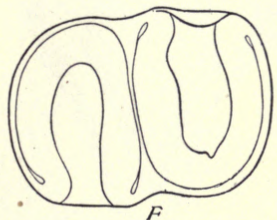

Fig. 70. Dwarf and double embryos of Amphioxus. A, isolated blastomeres of the 2-cell stage segmenting like an entire egg. B, twin gastrulæ from a single egg. C, double cleavage resulting from partial separation of the first two cleavage cells. D, E, F, double gastrulæ arising from such forms as the last. (From Wilson.) 
be totipotent, that is, it is capable of giving rise to an entire animal.

On the other hand in certain animal phyla such as the ctenophores, mollusks, annelids and ascidians isolated cleavage cells give rise

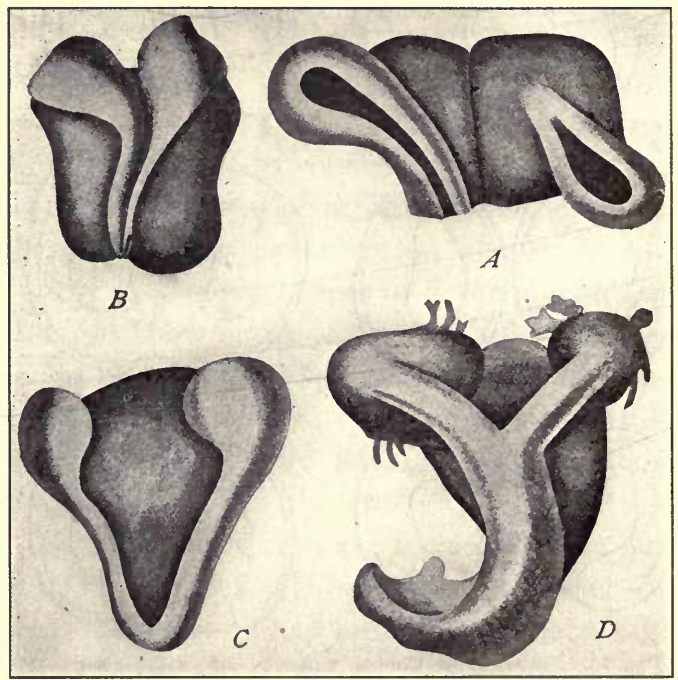

Fig. 71. Double embryos of frog developed from eggs inverted when in the 2-cell stage. $\Lambda$, twins with heads turned in opposite directions. B, twins united back to back. C, twins united by their ventral sides. D, double headed tadpole. (From Wilson after $O$. Schultze.) 

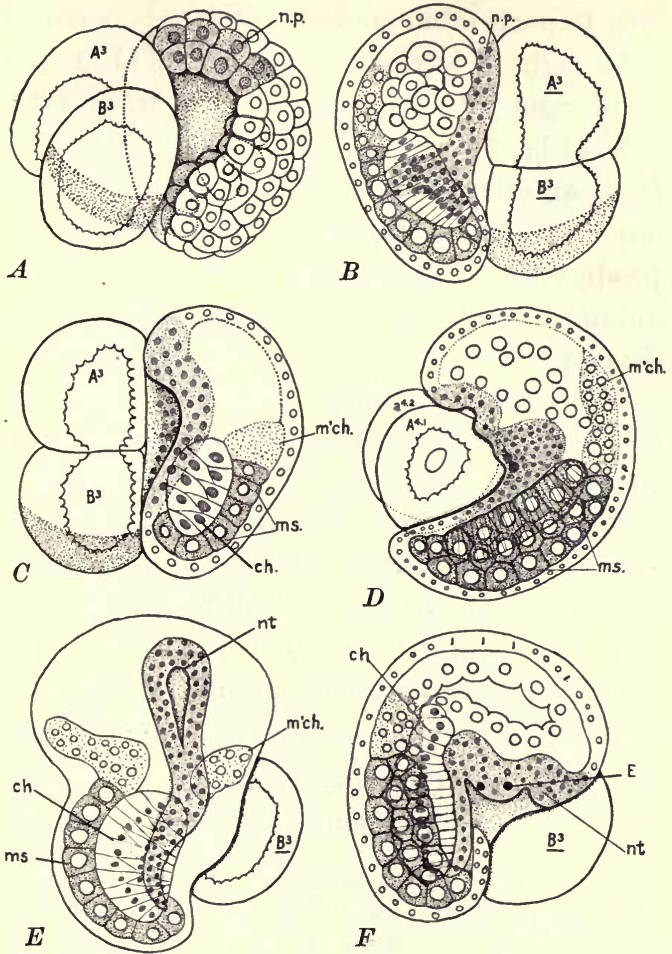

Fig. 72. Half and three-quarter embryos of Styela, $n p$ nerve plate, $n t$ nerve tube, $E$ eye, $m c h$ mesenchyme, $m s$ muscle, ch notochord. A, right half-gastrula which de- 
only to parts of an animal; in this way one may get a right or left half of an animal (Fig. 72) from right or left cleavage cells; an anterior half (Fig. 73), or a posterior half (Fig. 74) from anterior or posterior cleavage cells; or any one of the cells of the 4-cell stage may produce the corresponding quarter of an entire animal. Such cases are known as "mosaic development."

'There has been much discussion among biologists as to the meaning of these results. On the one hand it is said that the totipotence of any one of the first four cleavage cells proves that all of these cells are alike and that they have not yet begun to differentiate. On the other hand it is said that a part of an egg may give rise to a whole animal for the same reason that parts of certain adult animals may do the same thing, viz., because they have the power of regeneration. However there are

veloped after the left half of the egg, $A_{3} B_{3}$, had been killed. $B$, left half larva from the two left cells of the 4-cell stage, the right cells, $A_{3} B_{3}$, having been killed. The muscle cells (stippled) occur only on one side of the notochord. D, three-quarter larva, the left anterior cells having been killed. $\mathrm{E}, \mathrm{F}$, three-quarter larvæ, the right posterior cell $\mathrm{B}_{3}$ having been killed. 

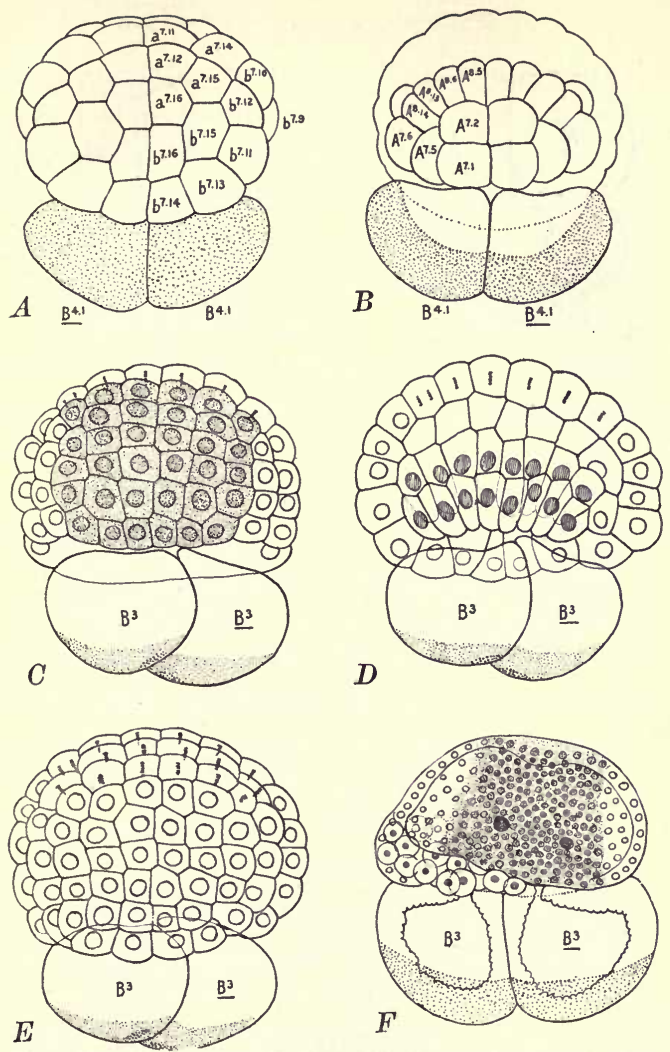

Fig. 73. Anterior half-embryos of Styela, the posterior cells having been killed by the 4-cell stage. 

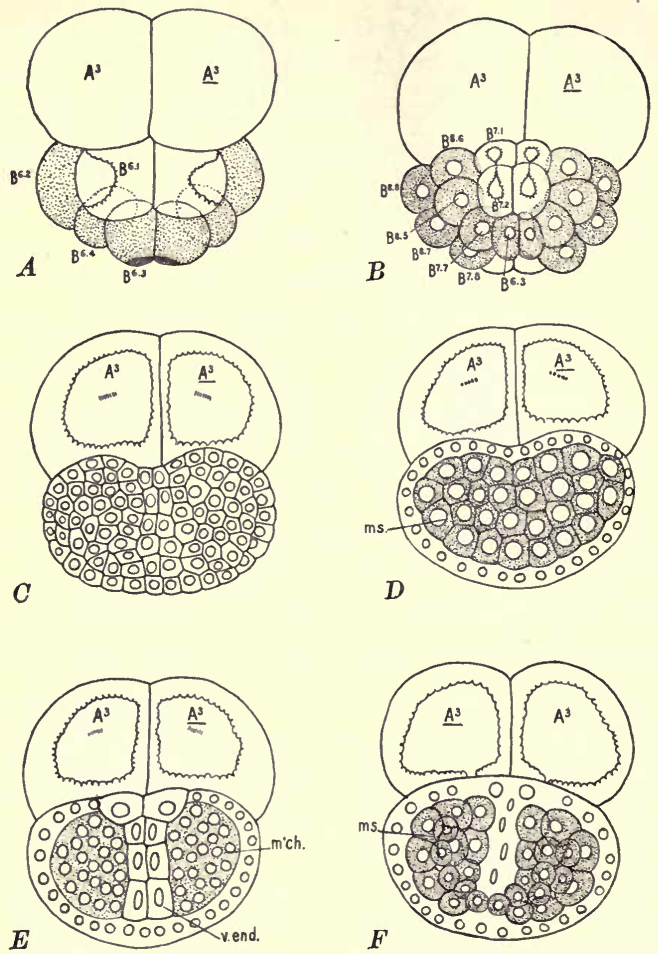

Fig. 74. Posterior half-embryos of Styela, the anterior cells having been killed in the 4-cell stage. 
many animals which are incapable of regenerating lost parts of their bodies, and similarly there are cases in which part of an egg cannot give rise to a whole animal. The evidence available at present favors the view that in cases where one of the cleavage cells is capable of giving rise to a whole animal there is a greater capacity of regeneration or regulation, and possibly also a lower degree of initial differentiation, than in those cases in which part of an egg is capable of producing only part of an animal.

If the fertilized egg is whirled rapidly on a centrifugal machine it may be subjected to a pressure several hundred times that of gravity. Under such conditions the heavier particles are thrown to one side of the egg and the entire substance of the egg becomes stratified into layers or zones. In the ascidian egg, where the different kinds of protoplasm give rise to different tissues and organs, this rearrangement of the egg substances may lead to a marked dislocation of organs; the animal may be turned inside out, having the endoderm on the outside and its skin and ectoderm on the inside, etc. (Fig. 75). 
If the cleavage cells are only partially separated they may produce animals which are partially separated, such as Siamese twins, two-headed forms, etc. (Fig. 71). Or these double monsters may be produced by division or budding of the embryo at a later stage of development. In the human species, no less than in other animals, all sorts of double monsters may be formed in this way by the partial division of a single egg or embryo (Fig. 76). If the division is slight the developed individual may show only the beginnings of a divi-
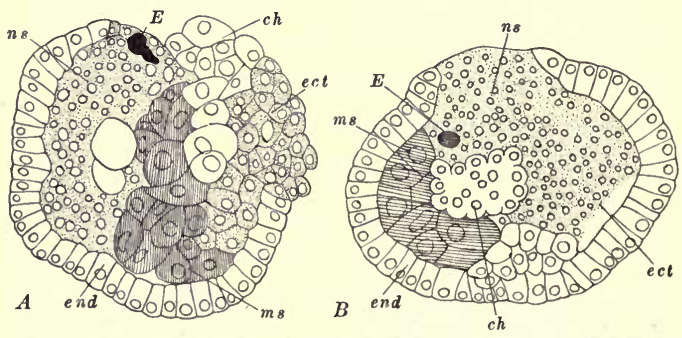

Fig. 75. Two larvæ of Styela which were centrifuged in the 4-celled stage thereby changing the position of various organ-forming substances. Nervous system (ns), eyes $(E)$, notochord $(\mathrm{ch})$ and muscles $(m s)$ have been displaced, and the larva has been turned inside out, the endoderm (end) being outside and the ectoderm (ect) inside. 
sion into two, as in two-headed forms; if the division of the egg or embryo is complete two separate and perfect individuals may be formed from an original single oosperm. When two individuals are formed from a single egg they have exactly the same heredity and accordingly they are always of the same sex and are so similar in appearance that they are known as "identical" or "duplicate" twins (Fig. 76). On the other hand twins which develop from different eggs do not have

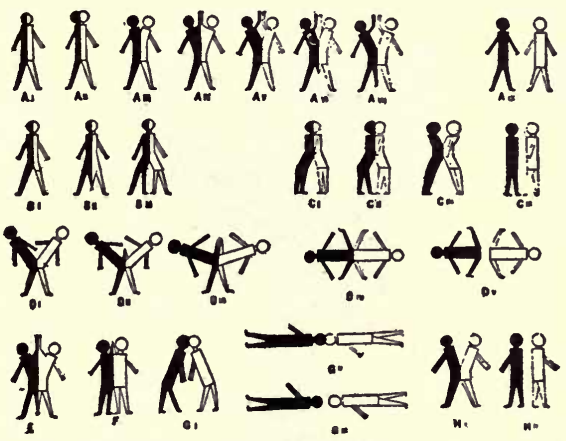

Fig. 76. Diagram showing the different types of union of double human monsters each being produced by a partial division of a single egg or embryo. If the division is a complete one, duplicate twins are formed, as shown on the right. (From Wilder.) 
the same heredity and may differ in sex as well as in other features; they are known as "fraternal" twins.

If the temperature or density of the surrounding medium is altered during the gastrula stages the endoderm may be caused to turn out instead of in (exogastrula), thus producing an animal which is turned inside out (Fig. 77). In other cases (vertebrates) the gastrula mouth may fail to close, thus producing animals in which the spinal cord and vertebral column are split in two (spina

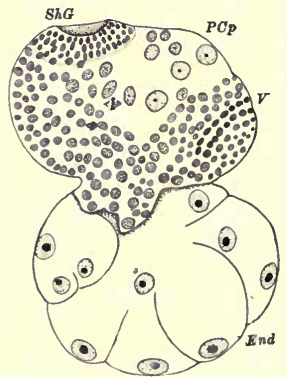

Fig. 77. Exogastrula of Crepidula. The endoderm (end) has been turned out instead of in, thus leaving the digestive layer of eells on the outside of the body; ShG, shell gland, $\checkmark$, velum. 
bifida); or the brain may be forced outside of the head or may be lacking altogether (anencephaly). In some cases eyes are wholly lacking, in others the two eyes fuse together into a single one as in the fabled Cyclops (Fig. 78). Practically all such cases of monstrous development are due to abnormal environmental conditions in early stages of development.

In addition to such monsters, which are incapable of long life, many peculiar if not abnormal types of animals are produced by the
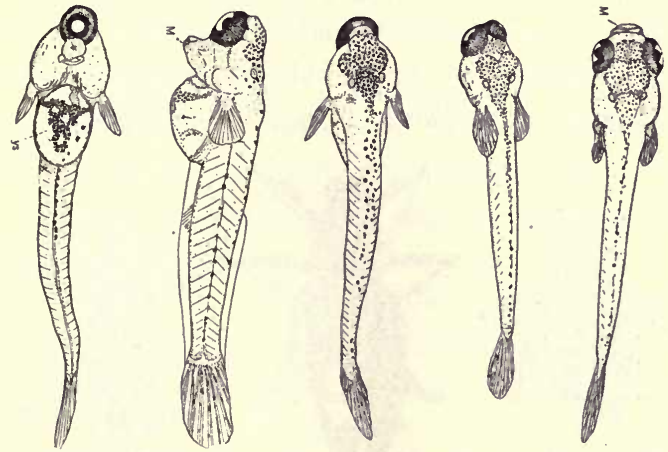

Fig. 78. Young fish; on the right a normal individual with two eyes; on the left cyclopean monsters with one eye; produced by treatment with magnesium solutions. (From Stockard.) 
action of unusual environmental stimuli during later stages of development. Gudernatsch found that if tadpoles of the frog were fed on the thyroid gland they transformed into minute frogs, scarcely larger than flies, but if fed on thymus gland they grew to be large, dark colored tadpoles but did not change into frogs; if fed on the adrenal gland they produced extremely light colored forms. If canary birds are fed on sweet red pepper they become red in color. If the larvæ of bees are fed.on "royal jelly," which is a bee food rich in fats, they become fertile females or queens; if fed on ordinary "bee bread" they become infertile females or workers (Fig. 79). There are
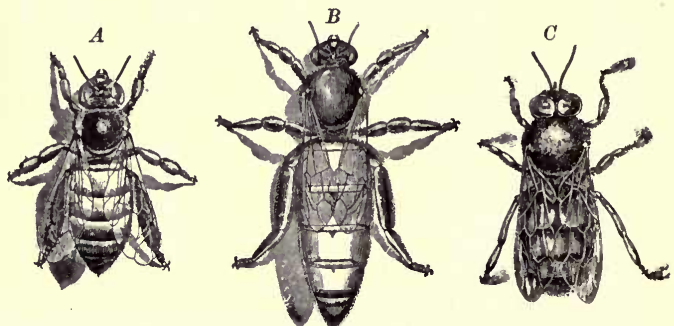

Fig. 79. The three castes of the honey bee. $\Lambda$, worker or imperfect female, B, queen or perfect female, C, drone or male. The differences bctween workers and queens are produced by the type of food supplied to the larvæ. 
marked structural differences between the workers and the queens but the differences in their habits and instincts are even more striking; all of these differences whether in bodily structure or in instincts are determined by the character of the food and not by heredity. Innumerable cases of a similar sort could be named which show the great effect of environmental stimuli on development.

\section{FUNCTIONAL ACTIVITY AS A FACTOR OF DEVELOPMENT}

Another factor of development which is partly intrinsic and partly extrinsic is functional activity or use. Functional activity is response to stimuli which may be external or internal in origin. 'The entire process of development may be regarded as a series of such responses on the part of the organism, whether germ cell, embryo or adult, to such stimuli. 'The nature of the response is determined by the nature and state of the organism at the time and by the character of the stimulus. By the normal or usual series of stimuli certain 
parts are kept active while other parts are kept inactive or are inhibited.

Normal development is dependent upon the correlated activity of many parts of the organism. If in any part stimuli and responses are lacking the development of that part is arrested or inhibited. For example in the cleavage stages different kinds of plasm are sorted and localized by protoplasmic movements within cells; these substances are isolated by cell divisions and by the formation of partition walls between cells, which are brought about by protoplasmic movements in response to stimuli; if these movements are stopped cleavage and differentiation are arrested. In later stages the infolding of the gastrula, the neural tube, the alimentary canal, and the folding of layers in general, which plays so important a part in development, are due to the movements of substances within cells and to the movements of cells in the layers in which they lie, and if these movements be inhibited normal development is prevented.

Another type of functional activity which is 
a potent factor in development is found in the trophic or nutritive relations which exist between different parts of the organism. Organs long unused undergo regressive changes and may become rudimentary, for example the muscles of a limb which has been paralyzed or placed in a cast shrivel; on the other hand use increases the size and strength of any organ. Inactivity or atrophy of one part usually leads to imperfect nourishment and development of related parts; for example, the optic nerve atrophies when the eye is lost, and muscles atrophy when the nerves leading to them are destroyed or paralyzed. In general the normal development of any part is dependent upon its proper nutrition and this is dependent upon the functional activity of this and of other related parts.

Still another phase of functional activity is found in the effects of certain secretions and chemical substances which are formed by different glands. In many cases the secondary sexual characters which distinguish the male and the female are due to chemical substances from the ovary or the testes, which stimulate or 
inhibit the formation of these characters. If the ovary is removed from a young hen she develops the larger size, the more brilliant plumage and the peculiar comb, wattles and spurs of the cock. 'These secondary sexual characters of the male are potential in the female but are kept from developing or are inhibited by the activity of the ovary. On the other hand the castration of the young cock does not prevent the development of most of the secondary sexual characters of the male. In the case of mammals removal of the ovaries of a young female or of the testes of a young male does not lead to the development of the secondary sexual characters of the other sex, but both sexes remain in a sexually undeveloped or infantile condition, that is, the presence of ovaries or testes serves as stimulus to call forth the development of the secondary sexual characters in mammals, and not as inhibitors to prevent the development of the secondary sexual characters of the opposite sex, as in the female fowl. If bits of the ovary of a guineapig are inserted under the skin of a young male which has been previously castrated, the 
latter develops mammary glands similar to those of a normal female; in short he is "feminized" by the stimulus of substances from the ovary.

Another gland whose secretions exercise a profound influence on development is the thyroid, which is found in the neck near the "Adam's apple." If this gland becomes enlarged it gives rise to goitre, protruding eyeballs, rapid heart beat; on the other hand if the thyroid is deficient in a young child it causes a peculiar type of idiotic dwarf known as "cretin" (Fig. 68). If the gland which lies between the roof of the mouth and the base of the brain and which is known as the hypophysis is deficient the child, or young animal, remains infantile; if the hypophysis is too large the individual's hands, feet and face become enlarged and he may grow to be a deformed giant, but with weak body and mind:

Many cases are known in which the development of a part is dependent upon the presence of another part; this is technically known as "correlative differentiation." Thus it has been found that the lens of the eye will develop 
from any portion of the ectoderm, or outer layer of the skin, if only the primitive retina, or optic cup, is brought near to this layer; if the optic cup is transplanted from the head to the thorax or abdomen a lens will form wherever the cup comes in contact with the ectoderm. If an embryonic limb is transplanted from its normal position to the middle of the back or belly, it will develop, and nerves and blood vessels will grow into it which would have had very different positions and distributions if the limb had not been there. If one of the first four cleavage cells is separated from the others it may develop into an entire animal though it would have formed only a quarter of an animal if it had remained in contact with the other three-quarters of the egg. All such cases are known as "correlative differentiation," implying that differentiation is dependent upon the stimuli which come from surrounding parts. On the other hand if the differentiation has already begun before the relation of a part to surrounding parts has been changed, it may continue to differentiate as if no change of position or relation had 
taken place. Thus if a right limb is transplanted to the left side of the body after it has begun to differentiate it remains a right limb and is not modified by its new relations (Harrison); if the cleavage cells are already differentiated in the four-celled stage, each cell when separated from the others will give rise to only one-quarter of an animal. In short the organ or cell is already set, or fixed, or differentiated to such an extent that it can not change its fate even though its environment should change. Such cases are known as "self differentiation."

Many students of the physiology of development have been led to the view that the fundamental causes of development are to be found not in the egg cell itself but in environmental stimuli and in the interaction of the various parts. Driesch in particular regards the egg, or any cleavage cell, as a "harmonic equipotential system," that is, any part is capable of any fate, and its actual fate is determined by its relation to other parts; in the striking phrase of Driesch, "The fate of a part is a function of its position." We now 
know that this expresses only a fraction of the truth. 'The fate of a part is primarily a function of its organization and only secondarily a function of its position.

These are only a few illustrations of the many kinds of abnormal development which may be caused by changed environment or by unusual functional activities. At all stages of ontogeny the course of development may be altered by extrinsic stimuli but earlier stages may be more profoundly influenced than later ones.

\section{INHERITANCE OR NON-INHERITANCE OF ACQUIRED CHARACTERS}

Few questions in biology have been discussed so fully and so fruitlessly as this. It is a problem of the greatest interest not only to students of biology but also to sociologists, educators and philanthropists and yet it is still to a great extent an unsolved problem. It is well known that Lamarck and his followers taught that characters due to the conditions of life, or to use and disuse, were inherited. Dar- 
win also held this view and proposed his hypothesis of pangenesis in order to explain the process of the transmission of such characters to the germ cells.

Weismann introduced a new era in biology by denying the inheritance of acquired characters, by showing the weakness of the evidence for such inheritance and by challenging the world to produce evidence that would stand a rigorous analysis. But Weismann's greatest service lay in his constructive theories rather than in destructive criticism; he forever disposed of theories of pangenesis and the like by showing that the germ cells are not built up by contributions from the body and that characters are not transmitted from generation to generation; but on the other hand that there is transmitted a germ plasm which is relatively independent of the body and which is relatively very stable in organization. This epoch-making theory of Weismann's has naturally undergone some changes, as the result of new discoveries. It is no longer believed that the germ plasm is really independent of the body, nor that it is absolutely stable, 
as Weismann at one time held. There is no doubt that the germ cells and the germ plasm are physiologically related to other cells and to other plasms, and similarly there is no doubt that the germ plasm although very stable can and does change its constitution under some, rare conditions. But in the main the germ plasm theory is accepted by the great majority of biologists to-day, and recent work in genetics and cytology has brought many confirmations of this theory.

As long as it was believed that the developed characters of an organism could be transmitted as such to its descendents it was customary to speak of developed characters as hereditary or acquired and to talk of the inheritance or non-inheritance of acquired characters. This distinction is not a logical one for all developed characters are invariably the result of the responses of the germinal organization to environmental stimuli; and of course no developed character can be purely hereditary or purely environmental. But when a given character arises in many individuals of the same genotype under different environ- 
mental conditions it is probable that heredity, which is the constant factor in this case, is also the determining factor for that character. On the other hand if a character develops in response to peculiar stimuli and does not appear in other individuals of the same genotype in which such stimuli are lacking it is said to be an environmental or acquired character.

But though environment and functional activity exercise a great influence on the course of development there is no sufficient evidence that they produce corresponding changes in heredity. Hereditary constitution is not generally changed by accidents of environment, but individual development is so changed.

Briefly stated the question of the inheritance of acquired characters is this: Can peculiarities of the environment which bring about the development of somatic characters so affect the germ cells that they will produce these somatic characters in the absence of the peculiar environment? Can the characteristics of a developed organism enter into its germ cells and be born again in the next generation? Considering the fact that germ cells are cells and 
contain no adult characteristics, it seems very improbable that any peculiarity of environment whether of nutrition, use, disuse or injury, which brings about certain peculiarities of developed characters in the adult, could so change the structure of the germ cells as to cause them to produce this same character in subsequent generations in the absence of its extrinsic cause. How, for example, could defective nutrition, which leads to the production of rickets, affect the germ cells, which contain no bones, so as to produce rickets in subsequent generations, although well nourished? Or, how could overexertion, leading to hypertrophy of the heart, so affect the future germ cells that they, in turn, would produce hypertrophied hearts in the absence of overexertion, seeing that germ cells have no hearts? Or how could the loss or injury of eyes or teeth or legs lead to the absence or weakened development of these organs in future generations, seeing that inheritance must be through germ cells which possess none of these structures?

But, apart from these general objections to 
the doctrine of the inheritance of acquired characters, there are many special difficulties. There is no conclusive and satisfactory evidence in favor of such inheritance. Almost all the evidence adduced serves to show only that characters are acquired, not that these characters are inherited.

It is a matter of common observation that mutilations are not inherited; wooden legs do not run in families, although wooden heads do. The evidence for the inheritance of peculiarities due to excessive use or disuse is wholly inconclusive, and in general the same may be said of any special character due to abnormal nutrition. 'That unusual conditions of food, temperature, moisture, etc., may affect the germs of future generations so as to produce general and indefinite variations is very probable, but this is a very different thing from the inheritance of acquired characters. The germ cells being a part of the parental organism may be modified by such changes in the environment as affect the body as a whole, they may be well nourished or starved, they may be modified by changed conditions of gravity, 
salinity, pressure, temperature, etc., and these modifications of the germ cells may and probably do lead to certain general modifications of the adult, which may be larger or smaller, stronger or weaker, according as the germ is well or poorly nourished, etc. It is further possible that these changed environmental conditions may bring about such changes in the structure of the germ cells as to produce great and remarkable peculiarities in the adult; but it is inconceivable that the environment which produces rickets, or hypertrophied heart, or loss of sight in one generation, should modify the germ cells of the next generation in such a peculiar and definite way that they should give rise to these particular peculiarities, in the absence of the extrinsic cause which first produced them. The inheritance of acquired characters is inconceivable, because the egg is a cell and not an adult organism; and in this case there is no sufficient evidence that the thing which is inconceivable really does happen.

If environmental conditions may alter hereditary constitution we should expect to find 
that where plants or animals are grafted together each would modify more or less the hereditary constitution of the other. But this does not occur. Everybody knows that when a branch of a particular kind of fruit tree is grafted upon a tree of a different variety the quality of the fruit borne by that branch is not altered by its close union with the new stock. The same is true of all forms of animal grafts. Harrison cut in two young tadpoles of two species of frog, Rana sylvatica and Rana palustris, and spliced the anterior half of one to the posterior half of the other. These frogs and their tadpoles differ in color as well as in other respects, $\boldsymbol{R}$. sylvatica being more deeply pigmented than $R$. palustris. In the grafted tadpoles each half preserved its own peculiarities even up to the adult condition (Fig. 80).

A still more striking case of the persistence of heredity in spite of environmental changes is found in experiments in which the ovaries are removed from one variety of animal and transplanted to another variety. Guthrie made such transplantations in the case of 
fowls and concluded that there was some influence of the foster mother upon the transplanted ovary, but Davenport, who repeated his experiments, was unable to confirm his results. Finally Castle and Phillips furnished the most conclusive demonstration that the
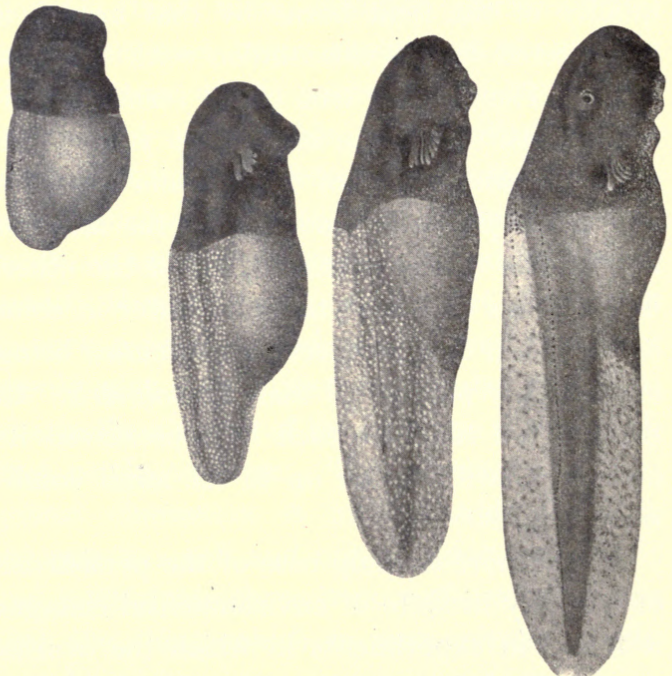

FIG. 80. Grafted frog embryos, anterior part, Rana sylvatica, posterior part, $R$. palustris. In later stages, and even in the adult condition, the two parts preserve their peculiarities. (From Harrison.) 
hereditary characteristics of the transplanted ova are in no wise changed by the foster mother. 'They removed the ovary from a pure black guinea-pig and put it in the place of the ovary of a pure white animal. After recovery from the operation this white female with the "black" ovary was bred to a pure white male (Fig. 81). Three litters of offspring from these parents were all pure black as shown in Figure 82. Although both parents were pure white all the offspring of the $F_{1}$ generation were black because they came from "black" eggs and black is dominant over white. 'The fact that these "black" eggs matured in the body of a white female did not in the least change their hereditary constitution.

A still more intimate union takes place when the dominant and recessive characters come together in any zygote. These characters, or rather the factors which determine them, may be intimately associated in every cell of the organism throughout an entire generation and yet we may get a clean separation of these characters in the next generation; in many cases neither the dominant nor the recessive 


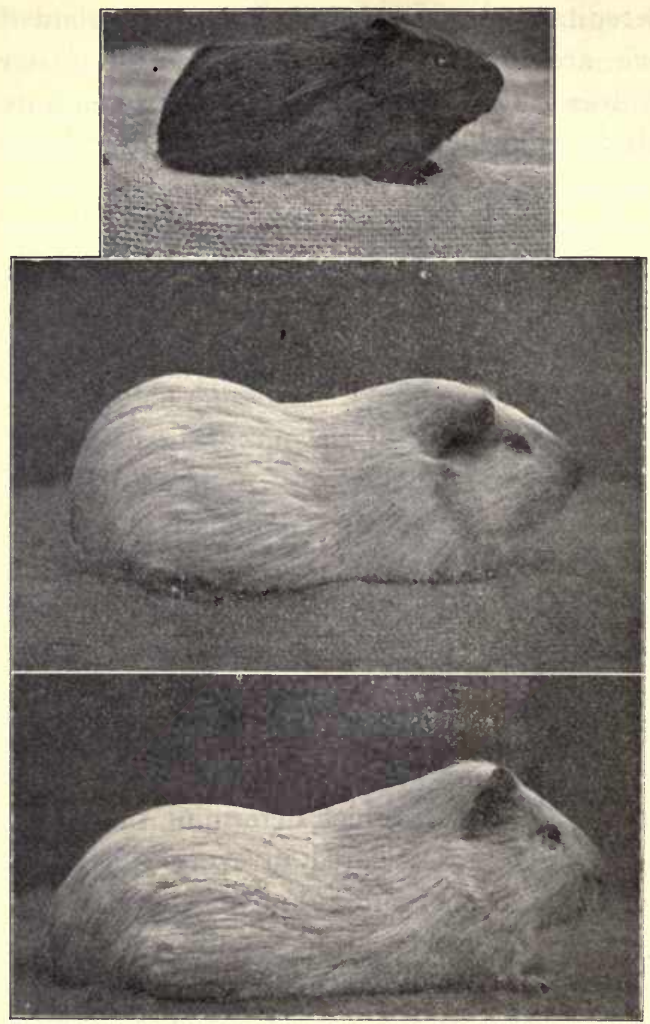

Fig. 81. Effect of transplanting ovaries in guinea-pigs. 
character has been at all modified by its most intimate association with the other.

A striking instance of the purely temporary effect of the environment and of the long persistence of hereditary constitution amidst new environmental conditions, which have greatly changed the appearance of the developed organism, is found in the case of alpine plants. Nägeli says that such plants, which have preserved the characters of high mountain plants since the ice age, lose these characters perfectly during their first summer in the lowlands.

If acquired characters were really inherited we should expect to find many positive evidences of this instead of a few sporadic and doubtful cases. In particular why do we not find in plant or animal grafting that the influence of the stock changes the hereditary potencies of the graft? Why do we not find that transplanted ovaries show the influence of

Above, young black female; in the middle, mature white female; below, mature white male. The white female's ovary was removed and in its place was put the ovary from the black female. The white female (with "black" ovary) was then bred to the white male. (From Castle.) 


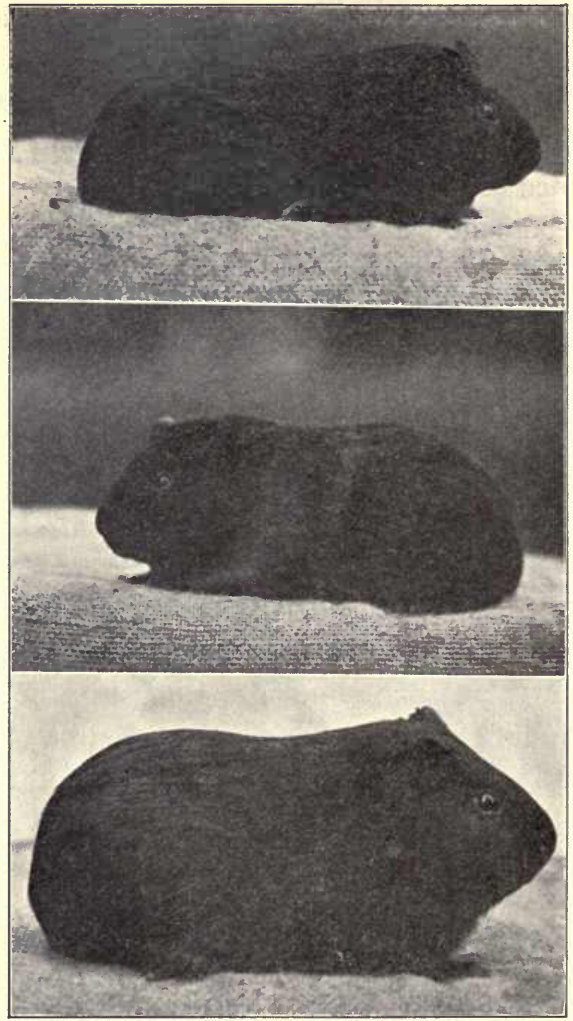

Fig. 82. Results of cross described in the preceding figure. 
the foster mother as Guthrie supposed-a thing which has been disproved by Castle (Figs. 81 and 82)? Why do dominant and recessive character's remain pure, even after their intimate union in a hybrid, so that pure dominants and pure recessives may be obtained in subsequent generations from this mixture? Why does every child have to learn anew what his parents learned so laboriously before him? Even the strongest defenders of the inheritance of acquired characters are constrained to admit that it occurs only sporadically and exceptionally.

Many modifications of the Lamarckian hypothesis of the inheritance of acquired characters have been proposed in recent years. Foremost among these are the "mneme" theory of Semon and the "centro-epigenesis" theory of Rignano. To Semon as to many other biologists the apparent ressemblance between memory and heredity has seemed sig-

All the offspring are pure black, though both parents are pure white, because the white female contains only "black" eggs and black is dominant over white. (From Castle.) 
nificant, and this furnishes the basis of his theory. Semon holds that every condition of life, every functional activity of an organism leaves a permanent record of itself in what he calls an "engramme." If these conditions or activities are long continued their engrammes are heaped up and affect heredity. Semon does not ask if "acquired characters" are inherited, but rather "Are the hereditary potencies of the germ cells altered by stimuli acting on the parental body?" This is a very different thing from the inheritance of a particular acquired character, and there is evidence that such stimuli may in some instances produce changes in the hereditary constitution of the germ cells, especially at or near their maturation stages. 'The observations and experiments of deVries on the evening primrose, of Hansen on yeast and of Fischer, Standfuss. 'Tower and Morgan on the production of mutations in insects favor such a belief.

On the other hand certain changes may be produced in germ cells or embryos which last only for a generation or two and then disappear. It is well known that plants grown in 
poor soil are smaller and produce smaller seeds than those grown in good soil, and deVries, Baur and Harris find that such seeds produce smaller plants with smaller seeds than do seeds of normal size. 'This is an after effect of poor nutrition which changes the amount of food material in the seeds and through this the size of the plant which develops from the seed, but it does not change the hereditary constitution. Woltereck found that in Daphnia there is an after effect of cold lasting for one or two generations, and this he calls "induction" when the effect lasts for one generation, or "preinduction" when it lasts for two or three generations. Whitney found that rotifers poisoned with alcohol were weaker in resistance to copper salts and were less fertile than others, and when brought back to normal conditions the first generation was weak but the second was normal. In man also alcohol may have an induction effect on offspring, but it does not seem to alter hereditary constitution. Probably of a similar character are Sumner's results; he found that mice raised in the cold have shorter tails than those raised at higher temperatures 
and this modified character appears in the next generation. If this is an after effect or "induction" it should disappear in the following generations.

Kammerer found that black- and yellowspotted salamanders reared on vellow soil gradually lose their black color becoming more yellow, and their young continue to grow more yellow until finally almost all black may disappear. 'The offspring of such salamanders are more yellow than normal; but this also may be an after effect or "induction" which would soon disappear under usual conditions.

Probably such cases are not instances of true inheritance; they do not signify a change in the hereditary constitution but an influence on the germ cells of a nutritive or chemical sort comparable with what takes place when fat stains are fed to animals; the eggs of such animals are stained and the young which develop from such eggs are also stained, though the germinal constitution remains unchanged. The very fact that the changed condition is reversible and that it disappears within a short time is evidence that it is not really inherited. 
In conclusion: (1) Developed characters, whether "acquired" or not, are never transmitted by heredity, and the hereditary constitution of the germ is not changed by changes in such characters. (2) Probably environmental stimuli acting upon germ cells at an early stage in their development may rarely cause changes in their hereditary constitution, but changes produced in somatic cells do not cause corresponding changes in the hereditary constitution of the germ cells. (3) Germ cells like somatic cells may undergo modifiations which are not hereditary; they may be stained with fat stains and the generation to which they give rise be similarly stained; they may be poisoned with alcohol or modified by temperature and such influence be carried over to the next generation without becoming hereditary. All such cases are known as "induction" and many instances of the supposed inheritance of acquired characters come under this category. 
E. APPLICATIONS TO HUMAN DEVELOPMENT: EUTHENICS

Man's environment is more extensive than that of any other animal, and its influence on his development is correspondingly greater. In addition to chemical and physical stimuli which are potent factors of development in the case of all organisms, man lives in a world of psychical, social and moral stimuli which exert a profound influence on him. He is stimulated not merely by present environment but also by memories of past experiences and anticipations of future ones. Through intelligence and social cooperation he is able to control environment for particular ends, in a manner quite impossible in other organisms. On the other hand heredity is no more powerful as a factor of development in the case of man than in any other organism. Consequently the relative importance of heredity and environment is not the same in the development of an intelligent and social being, like man of 
the present age, as it is in lower organisms. For man and for every other living creature heredity fixes the possibilities of development, it "sets bounds about us which we cannot pass"; but the more complex those possibilities become the more complex must be the environment which calls them forth and the more varied become the results of development under altered conditions of life.

Functional activity also plays a larger part in man's development than in that of any other animal, owing to the longer period of his development and to the more extensive and varied training which he is capable of undergoing. It is a notable fact that the period of immaturity in man is longer than in any other animal, and it is during this formative period that environment and education have their greatest influence. Other animals develop much more rapidly than man but that development sooner comes to an end. The children of lower races of man develop more rapidly than those of higher races but in such cases they also cease to develop at an earlier age. The prolongation of the period of infancy and of 
immaturity in the human race greatly increases the importance of environment and training as factors of development.

The possible training of human faculties is also more varied and extensive than in other animals, not only because those faculties are more numerous but also because they are more plastic and are capable of higher development, that is, are more educable. Human faculties are functions and methods of reaction, which are dependent in part upon the bodily mechanism and in part upon environment and training. Habits are the usual methods of responding to stimuli, and they may be classified as inherent or acquired. The latter are in a sense forced upon organisms by environmental conditions. All education is habit formation, and good education like good environment is such an experience as leads to the formation of good bodily, intellectual, social and moral habits; it consists in placing the individual in such an environment and bringing such stimuli to bear upon him as to call forth desirable responses and to suppress undesirable ones. 
Only that environment and training is good which leads to the development of good habits and traits and to the suppression of bad ones. What we commonly call "good environment" is frequently the worst possible, what is often called a bad environment may be the best possible. We are all strangely blind with regard to these matters. We know of many cases in which men began their careers on a farm, in the backwoods, on a flat-boat, amidst hardships and discomforts of every sort and yet who achieved great distinction. And we speak of such men as winning in spite of disadvantages, forgetting that often these very disadvantages, hardships, discomforts, have proved stimuli which have given them sturdy bodies, good judgments, good morals, and have called forth all their best qualities. On the other hand under different circumstances or with different men such conditions may prove to be too hard, too severe, and the result be disastrous. But environment may be too good as well as too hard. Food may be too rich and too abundant for good health, life may be too easy and luxurious for the develop- 
ment of character. Luxury, easy lives, refined surroundings have less of educational value than we commonly suppose and they may be a positive menace. That environment is bad, however cultured, refined or pleasant it may be, which leads to the development of bad traits of body or of mind. In general the best environment is one which avoids extremes, one which is neither too easy nor too hard,--one which produces maximum efficiency of body and of mind.

In education also we are strangely blind to proper aims and methods. Any education is bad which leads to the formation of habits of idleness, carelessness, failure, instead of habits of industry, thoroughness and success. Any religious or social institution is bad which leads to habits of pious make-believe, insincerity, slavish regard for authority and disregard for evidence, instead of habits of sincerity, open mindedness and independence.

Frequently the training of the human being, like the training of a star-fish, consists in limiting his activities to particular lines. Some physical defect which prevented a child from 
engaging in the usual activities of children has often turned his attention to scholarship. Galton says that great divines have usually had very poor health. Genius is frequently associated with physical defects. Great specialization is associated with corresponding limitations in other directions. Society needs the genius and the specialist, but for the general good of mankind the generalized type of man is needed even more than the specialized.

No given environment or training can be good for every individual, nor for the same individual at every stage of development. Every individual is unique and if the best results are to be had must have unique environment and training, which must be supplied by ommiscient intelligence. The impossibility of securing the absolutely best conditions of development need not prevent society from securing better conditions than those which now prevail.

It is plain that environment and education play a greater part in the development of man than in that of other animals, whereas heredity plays the same part; but it is difficult if not 
impossible to determine the relative importance of these three factors. So far as intellect and morals are concerned we are all inclined to place greater weight upon the extrinsic than upon the intrinsic factors, but this opinion is not based upon scientific evidence. So far as organisms below man are concerned there is general agreement that heredity is the most important factor, and this opinion is held also for man by those who have made a thorough study of heredity. Galton has made the best scientific study of this subject in the case of identical twins, in which as we know heredity is the same in the two, both individuals having come from the same oosperm (Fig. 76). In bodily and mental characters such twins are remarkably alike; the differences which exist are slight and may usually be traced to different environmental and educational influences, and particularly to different illnesses. Galton sums up his study with these words: "There is no escape from the conclusion that nature prevails enormously over nurture when the differences of nurture do not exceed what is commonly to be found among persons of 
the same rank of society and in the same country."

The part played by these different factors of development may be graphically illustrated by the accompanying diagram (Fig. 83), in which the base line represents heredity and the other lines represent the extrinsic factors of environment and education. For each individual heredity is a constant factor but environment and training are variables. With

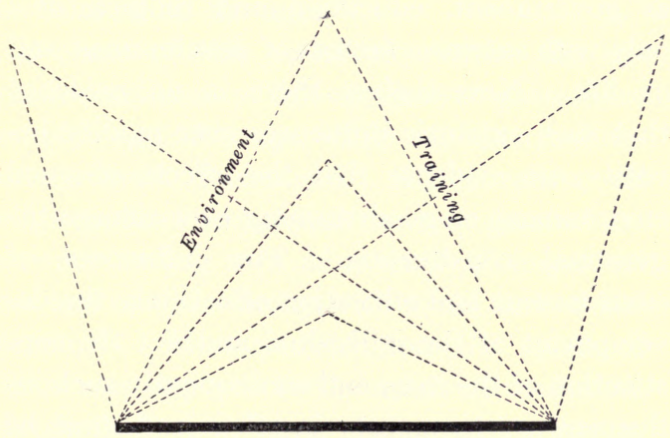

\section{Heredity}

Fig. 83. Diagram to show the influence of heredity, environment and training in the development of an individual. Various types of individuals (represented by the triangles) may be produced from the same germ cells (heredity) if the environment and training are variable. 
a given heredity the characteristics of the developed organism may vary enormously depending upon the extrinsic factors. Hereditary possibilities are not changed by accidents of environment but development is so changed. After the fertilization of the egg the hereditary potencies of every organism are unalterably fixed but the extrinsic factors remain variable and may be controlled.

All of our social and ethical institutions such as government, education and religion deal only with extrinsic factors of development and of life. Nevertheless there is no evidence that such extrinsic influences ever modify heredity, no evidence that the effects of good environment or good training ever change the germinal constitution. 'The influences of environment and education affect only the development of the individual and not the constitution of the race, and consequently such influences are temporary in effect and must be repeated generation after generation.

But though the effects of environment and training are not inherited, the environment and training and experience of former gener- 
ations are handed down to later generations through custom, tradition, history. We do not inherit through the germ cells the effects on our ancestors of their training and environment, but we do inherit, in the property sense of that word, their environment, customs, institutions. In short the experiences and accomplishments of past generations are not inherited through the germ cells but are inherited through society. In this sense "We are the heirs of all the ages."

Because of this social inheritance the extrinsic conditions of life continue to grow more complex age after age, while our inherited natures remain unchanged. All moralists, all religions, have recognized the very general experience among men of a sense of imperfection and of disharmony with social and ethical standards. Huxley held that the spirit of ethics was opposed to the spirit of evolution. Metchnikoff finds these disharmonies due to the survival of bestial instincts in man. Galton finds this sense of $\sin$ to be due to the fact that the development of our inherited nature has not kept pace with the development of our 
moral civilization. Our psychical, social and moral environment has come to us from the past with ever-increasing increments, every age standing on the shoulders of the preceding one. The aspirations, impulses, responsibilities of modern life have become enormous and our inherited natures and abilities have not essentially improved. Social heredity has outrun germinal heredity and the intellectual, social and moral responsibilities of our times are too great for many men. Civilization is a strenuous affair, with impulses and compulsions which are difficult for the primitive man to fulfil, and many of us are hereditarily primitive men. The frequent result is disharmony, poor adjustment, the struggle of the primitive instincts with high ideals, with a resulting sense of discouragement and defeat which often ends in abnormal states of mind. The great growth of alcoholism, depravity and insanity is an ever-increasing protest and menace of weak men against high civilization. We are approaching the time when one or the other must give way, either the responsibilities of life must be reduced and the march of civiliza- 
tion stayed, or a better race of men, with greater hereditary abilities, must be bred.

The present world-war, with its appeal to the primitive instincts of men and its destruction of the fairest and best fruits of civilization, points one way out of this disharmony between germinal and social inheritance; but it is a way from which all sane and sober minds recoil. Wars and revolutions shake off the burdens of social inheritance but they destroy the good along with the bad and afford only local and temporary relief. Mankind cannot return permanently to barbarism or savagery; civilization must be and will be preserved; but if society is to really advance from age to age the natures of men must improve as well as their environment. 



\section{CHAPTER V}

\section{CONTROL OF HEREDITY: EUGENICS}





\section{CHAPTER V}

CONTROL OF HEREDITY: EUGENICS

It is the aim of science to interpret phenomena and as far as possible to control them. To what extent is it possible to control heredity and thus to improve the race, as well as the individual?

\section{A. DOMESTIC ANIMALS AND CULTIVATED PLANTS}

The history of domesticated animals and cultivated plants shows that it is possible to control or rather guide phenomena of heredity and evolution. Very many species of wild animals have been tamed by man but cnly about 40 species may be classed as domesticated. In a number of instances the wild stocks from which these domestic forms came are known and it is possible to compare them with their modified descendants and thus 
to determine the degree of change which has been brought about under human guidance. In other cases where the original wild species are unknown it is possible to determine the amount of modification which has taken place within relatively recent times. DeCandolle recognizes 247 species of cultivated plants, 193 of which still exist in the wild state.

'The degree of change which has taken place under human guidance is very remarkable. In some cases dozens and even hundreds of races have been formed, showing the most remarkable differences in size, structure and proportions of parts, as well as in functions, instincts and behavior. The extent to which heredity may be guided by man is forcibly illustrated by our present races of domestic pigeons which Darwin said would be classed by any naturalist who did not know their origin in not less than twenty different species and three different genera, though all of them have descended from the wild rock pigeon (Figs. 84, 85); or by the numerous races of dogs varying in size from a toy dog to a Great Dane or St. Bernard and showing almost un- 


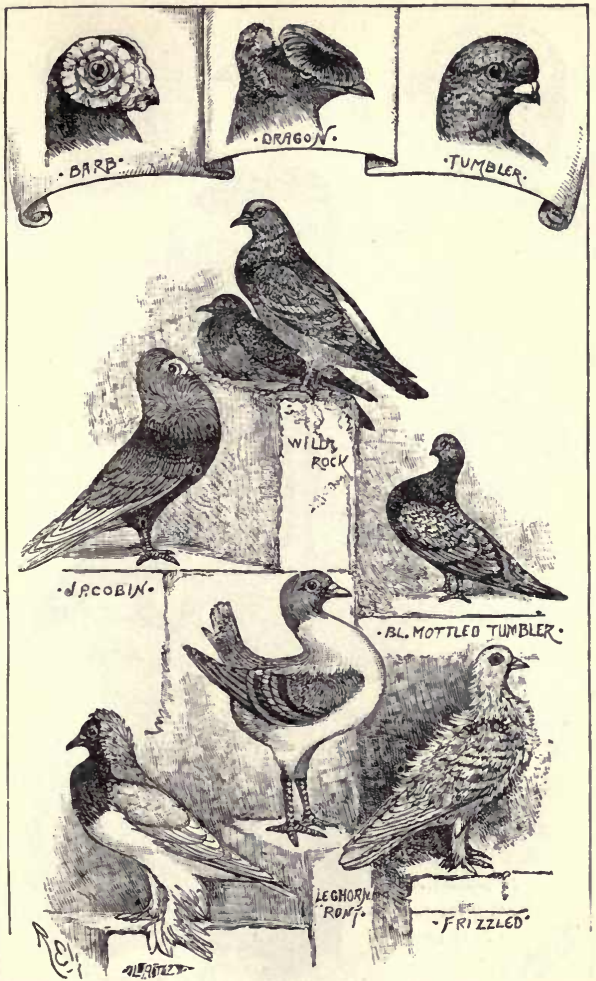

Fig. 84. Races of Domestic Pigeons, the wild rock pigeon being shown in the center. (From Romanes, "Darwin and After Darwin.") 


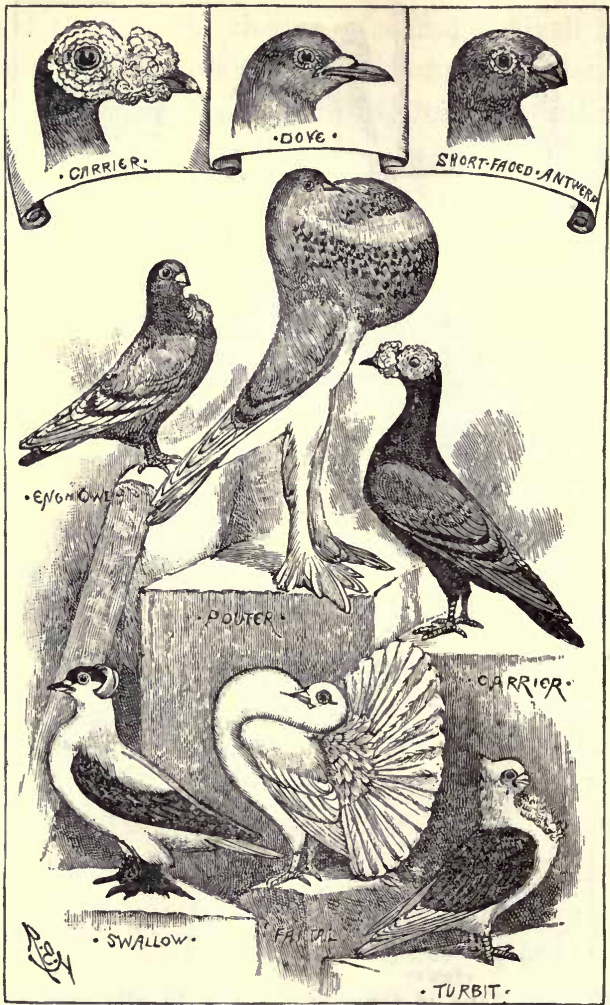

FIg. 85. Races of Domestic Pigeons, continued. (From Romanes.) 


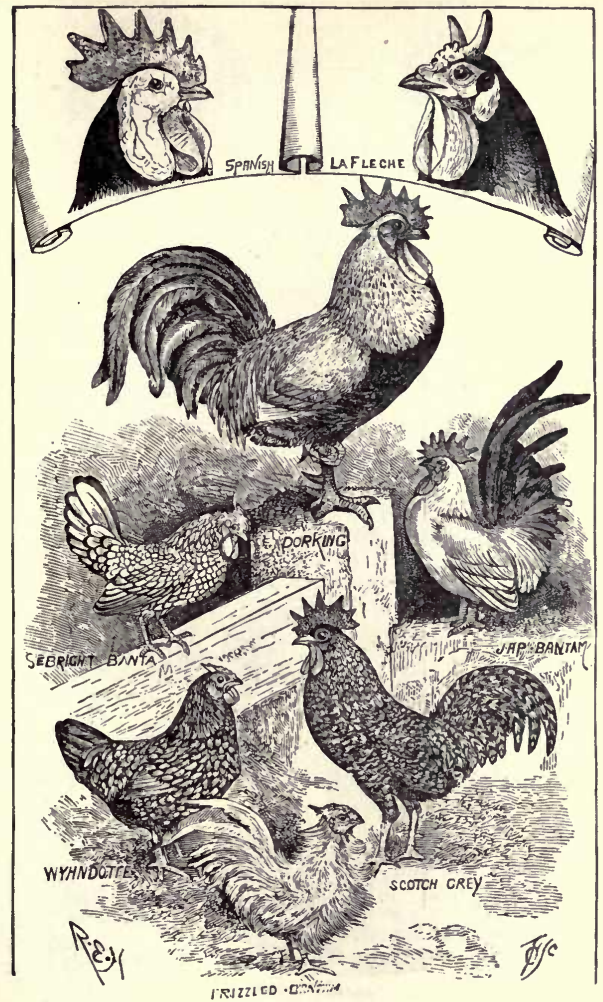

Fio. 86. Races of Fowls. (From Romanes.) 


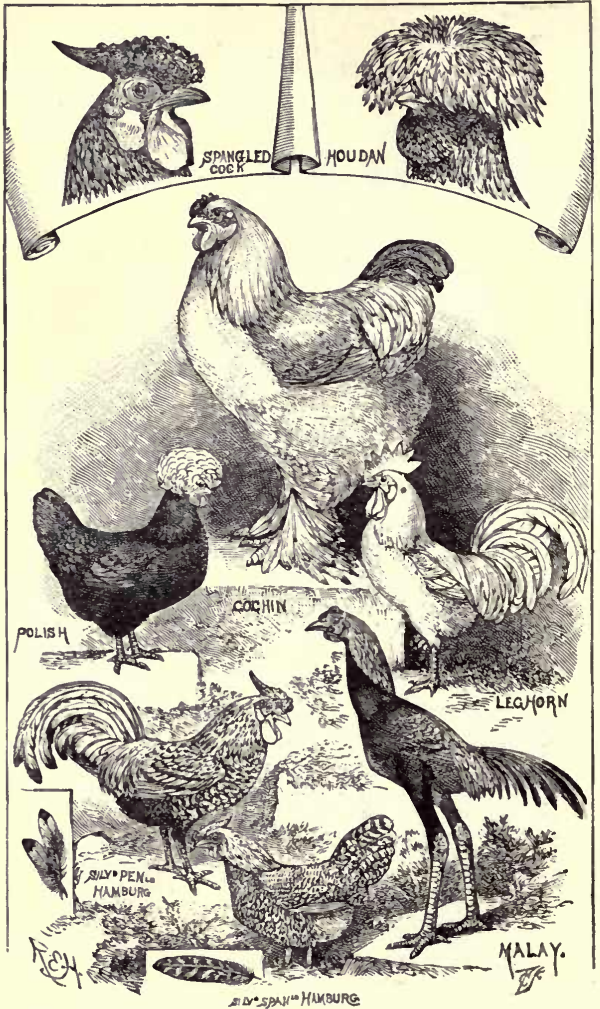

FIG. 87. Races of Fowls, continued. (From Romanes.) 
believable differences in structure and disposition; or by the great variety of domestic fowls, all of which have probably descended from the wild jungle-fowl; or by modern races of horses, cattle, sheep, or swine. These are only a few of the many illustrations which could be cited of the practical control of heredity and evolution for human purposes. How have the present races of domesticated animals and cultivated plants been produced?

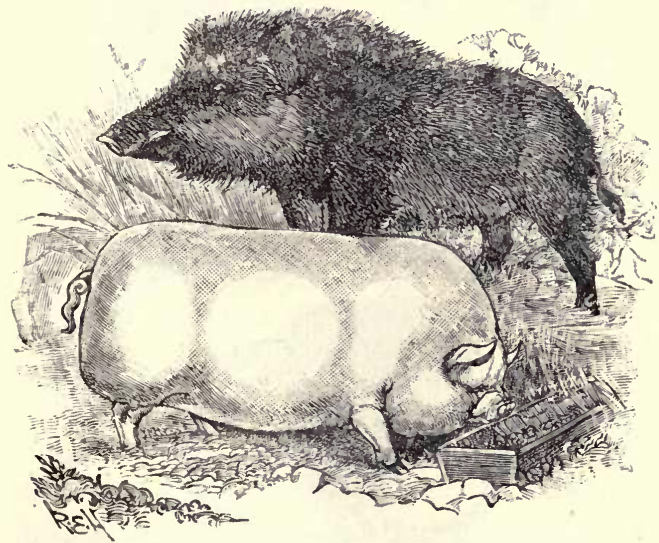

FIg. 88. Wild Boar contrasted with a modern domestic Pig. (From Romanes.) 


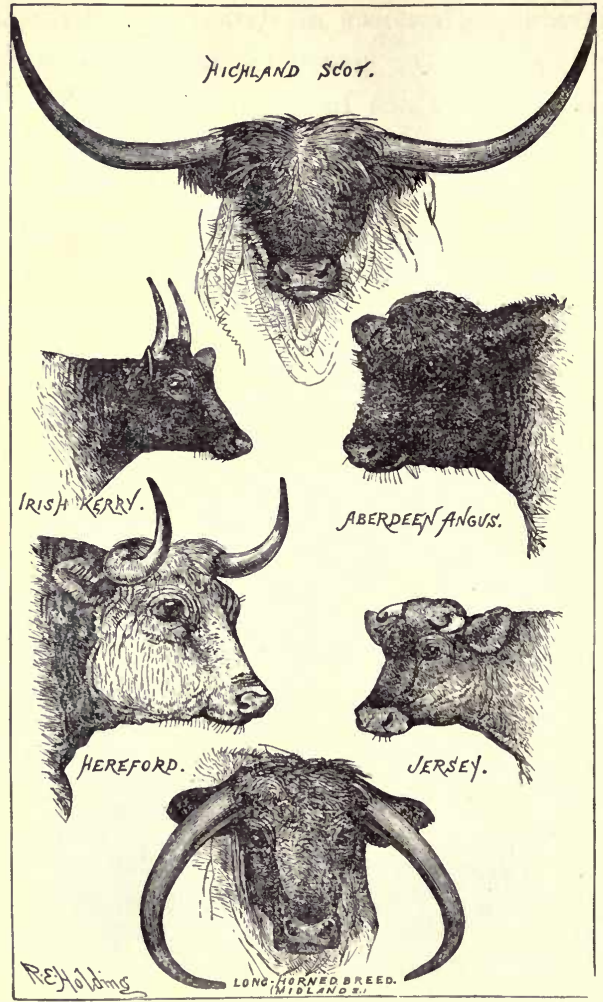

Fig. 89. Different Breeds of British Cattle. (From Romanes.) 
I. 'The Influence of Environ ment in Producing New Races

'There is a popular belief that the value of cultivated races is due to good environment, good food, good soil, protection from enemies, etc., and that if turned out to shift for themselves they revert at once to the original wild stock. There are two ways in which it is conceivable that new races might be produced by environmental influences:

1. By the direct inheritance of somatic or personal characters acquired under the stimulus of the environment. In spite of popular opinion in favor of this view there is no evidence that this ever occurs. There is no doubt that environment has much to do with individual development, but it does not usually modify the hereditary constitution of the race.

2. It is possible that environmental changes acting upon germ cells at a sensitive period of their development may produce germinal variations or mutations and thus give rise to new races. 'There is considerable evidence that en- 
vironment does sometimes act in this way, but there is no evidence that such changes in hereditary constitution are reversible and that the race reverts to its former state when the old environment is restored. Such reversible changes undoubtedly occur in somatic characters but they are not inherited; they are modifications of development, not of heredity; they are personal fluctuations, not racial mutations.

\section{Artificial Selection}

Since the beginning of historic times, and probably through long prehistoric ages, breeders have followed the method of selecting desirable individuals for propagating their stock. There can be no doubt that almost all that man has done in the production of domestic animals and cultivated plants has been accomplished by this process of selection.

1. The methods of selection have varied considerably with different breeders; sometimes they have selected:

(a) The best individuals grown in the best environment. 
(b) 'The best individuals grown in poor environment.

(c) Any individual of good pedigree, irrespective of the conditions of its environment. The fact that the good qualities of a race may be maintained by this last method as well as by either of the others shows how little good or bad environment has to do with hereditary or racial characters.

2. How has selection acted?

(a) Until very recently it was generally believed that continued selection of individuals which showed desirable characters gradually led to the improvement of those characters and thus to the production of new races; it was supposed that the character in question was "built up" by continued selection in one direction, and that the average development of the character in all the offspring was thus increased in successive generations. It was this view as to the supposed action of artificial selection which formed the basis of Darwin's theory of natural selection.

(b) The brilliant researches of deVries, Johannsen, Jennings, Tower and several oth- 
ers have shown that selection creates nothing new but merely isolates mutants or distinct hereditary lines which are already present in a mixed population. Johannsen found that from a single species of beans he was able, by keeping the progeny of each individual bean separate from the others, to get 19 different "pure lines" of beans, each differing in certain respects from every other line. He further found that when extremely large or small individuals from any pure line were selected and bred from, none of the progeny showed that character in a still more extreme degree but all merely fluctuated within the original extremes of that line. In short, he concludes that selection within a pure line is absolutely without effect in modifying any character in the offspring of that line.

Jennings found that different races or pure lines of Paramecium differ in size, structure and rate of division, and that these differences are "as rigid as iron." With respect to average length of body he was able to isolate eight pure lines which constantly differed more or less from one another. Within each of these 
lines there was considerable fluctuation in size, but he was unable by selecting extremes to increase these fluctuations, the progeny of any pure line always fluctuating about the mean of that line (Fig. 44).

Similarly Tower found in his studies on the potato beetle that he was unable to shift the mean or the extremes of any character by selection of extreme forms of an inbred line.

Pearl also made an extensive study of the records of breeding experiments extending over many years in which the attempt was made to increase the egg-laying capacity of hens by selecting in each generation for breeding only those which had a high record for egg production. It was found that certain "blood lines" produced a larger number of eggs than other lines, but by no amount of selection was it possible to increase the egg production within any line.

'These and other experiments seem to demonstrate the absolute inability of selection to produce anything new or to improve any character of a pure race. Nevertheless selection is of great service in separating good lines or 
races from poor ones, and this is the whole rationale of the artificial selection practiced by breeders.

'The elimination of certain races by natural selection may be an important factor in evolution though it has nothing to do with the formation of new characters or new races but serves merely as a sieve, as deVries has expressed it, to sort the individuals which are supplied to it. Selection has no power to make or change characters, but it may preserve certain lines and eliminate others and thus fix the type of a species. Finally the elimination of the unfit by natural selection is still the only natural explanation of fitness, or adaptation, in organisms.

\section{Methods of Modern Genetics}

1. Mendelian Association and Dissociation of Characters.-Breeders have long known that it is possible to get certain desirable characters of an organism from one race and other desirable characters from another race. But since the discovery of the Mendelian principles of heredity such new combinations of old char- 
acters have been made repeatedly, and with almost the same certainty of results as when the chemist makes combinations of elements or radicals.

In Fig. 90, $A$ and $B$, are shown two guinea-pigs, one having long $(L)$, rough and tumbled $(\boldsymbol{T})$, white $(\boldsymbol{W})$ hair, and the other having short $(S)$, smooth $(S m)$, red $(\boldsymbol{R})$ hair. When such animals are crossed one should get in the $\mathrm{F}_{2}$ generation 64 genotypes and 8 phenotypes, one of each of the latter being homozygous and breeding true, as is shown in Fig. 54 for trihybrid peas. These 8 phenotypes of this cross are $S T R, S T W, S S m R$, $S \boldsymbol{S} m \boldsymbol{W}, L T R, L T W, L S m R, L S m W$. In Figs. $90, C$ and $D$, and $91, A, B, C$, are shown 5 of these 8 phenotypes which were obtained by Castle from this cross. These figures well illustrate the new combinations of Mendelian characters which may be obtained by cross breeding.

This is the chief method employed by Burbank in producing his really wonderful "new creations in plant life." By extensive hybridization he brings about many new combinations 


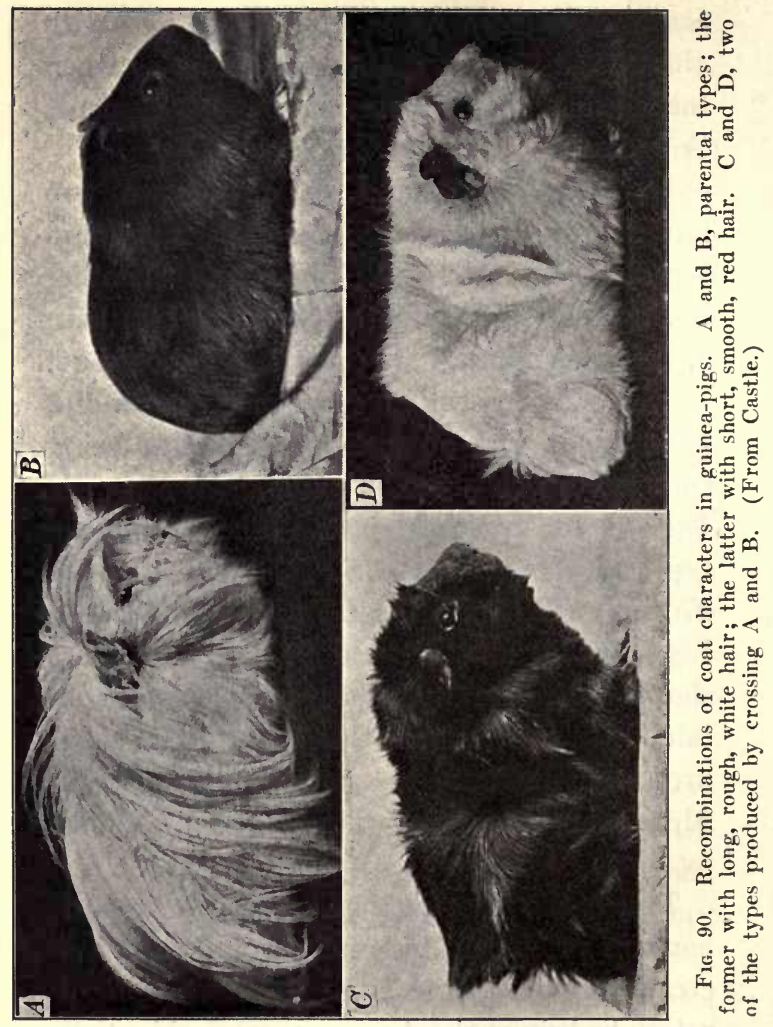




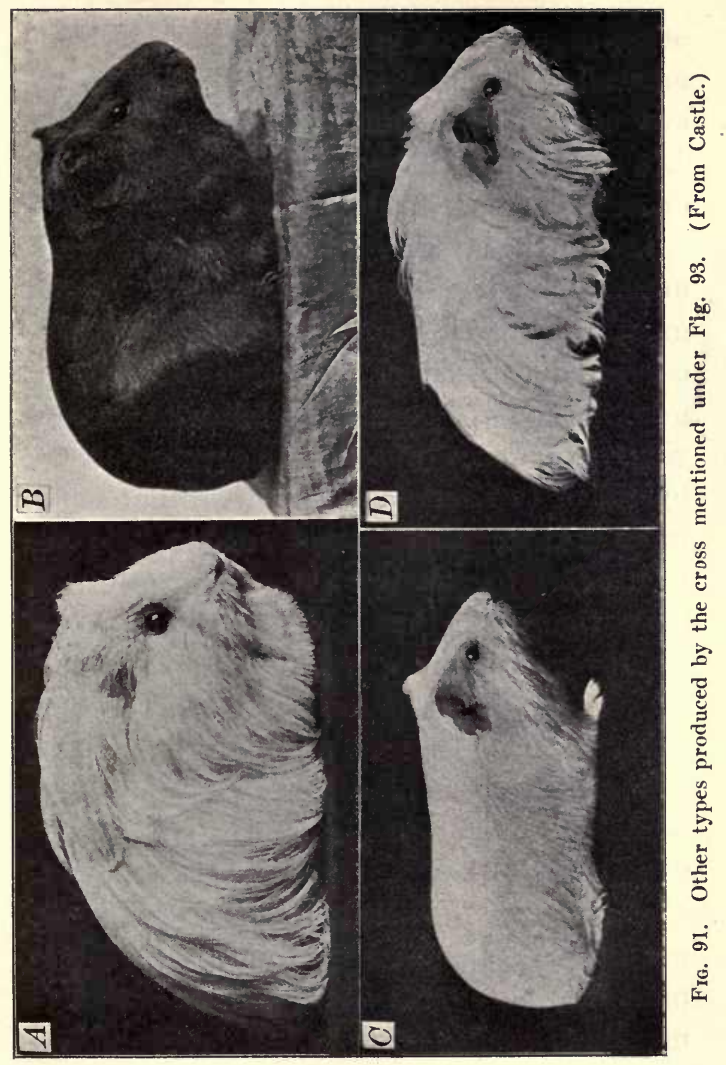


of old characters, a few of which may be commercially valuable, and sometimes actually new characters or mutations appear, possibly as a result of the interaction of old characters, or rather of their factors.

One of the striking results of modern work in plant-breeding has been the discovery of the greatly increased vigor of certain hybrids as compared with either pure-bred parent. In general it is not possible to tell without previous experience what the character of the hybrid of two races or "lines" will be; sometimes it is more and sometimes less vigorous than either parent, but not infrequently it is more vigorous. East and Shull have shown that hybrids between two races of corn may be very much larger and more fertile than either parent. In some instances the yield of corn per acre has been increased from 20-30 bushels to 80-90 bushels, and in one case to more than 250 bushels per acre (Figs. 92, 93). Unfortunately such hybrid races of corn do not continue to breed true and the crossing must be made anew in each generation if maximum results are to be had. Nevertheless 


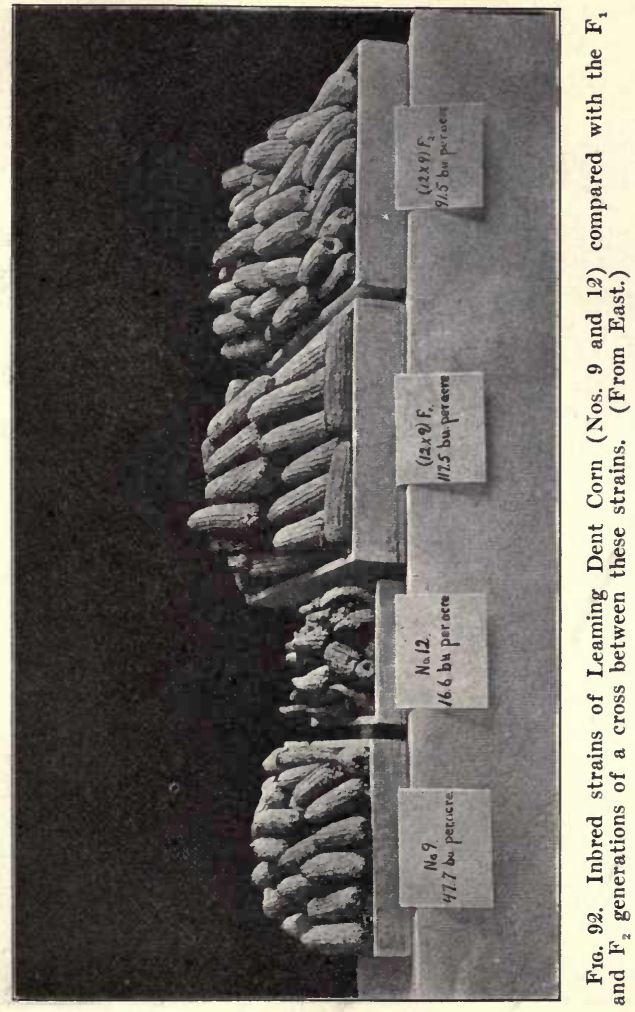




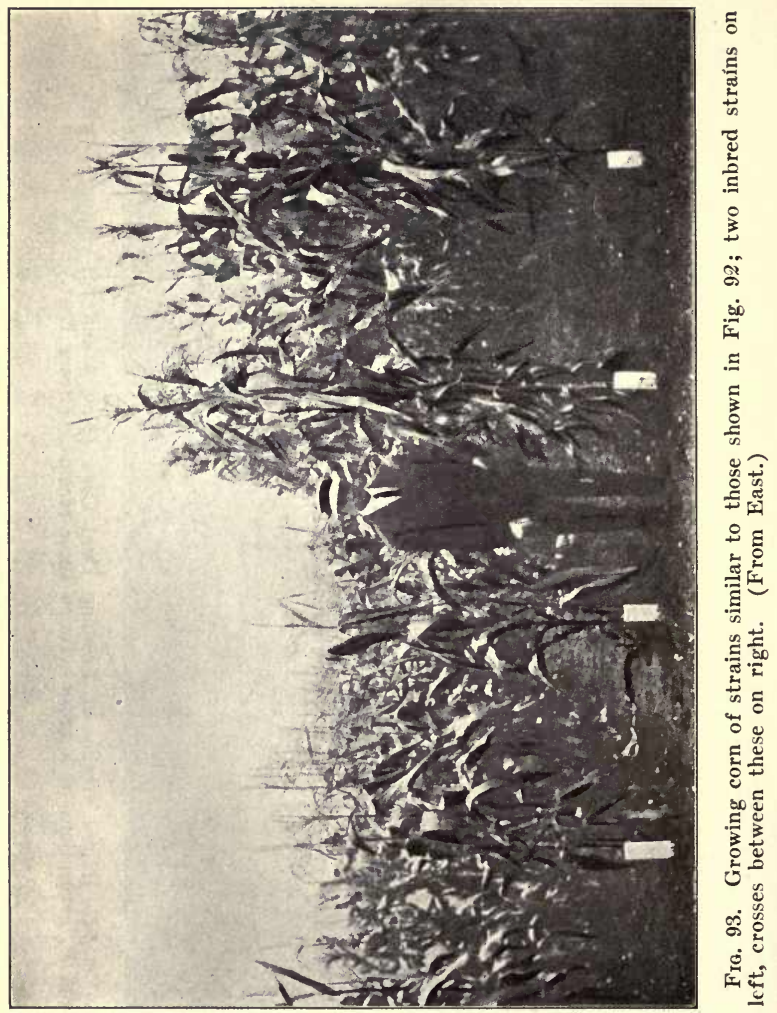


this method of hybridization or "heterozygosis," as it has been called, offers an extremely important means of quickly producing very vigorous and fruitful individuals, but not lines or races which breed true.

This is what is meant by the control of heredity, namely the possibility of preventing the reproduction of individuals with bad traits, and of making new and favorable combinations of old traits by means of selective breeding, and of seizing upon and perpetuating new and favorable mutations.

2. Origin of Mutations.-Mendelian association and dissociation of characters produces new forms of adult animals and plants but not new hereditary characters. Permutations of Mendelian characters we may have almost without number, of new combinations of these there may be no end, but no new unit characters are formed by such temporary combinations, no new inheritance factors are created or evolved. New combinations of factors may be compared to new combinations of chemical elements; you can always get out of the combination what went into it, whereas new 
factors are comparable to the changes which take place in certain atoms, for example radium, by which the element itself is changed in an irreversible manner. Evolution depends upon the appearance of new characters; the discoveries of Mendel show us how to follow old characters through many combinations and through many generations, but they do not show us how new characters arise. 'These discoveries have given us an invaluable method of sorting and combining hereditary qualities, but. Mendelian inheritance as such does not furnish the materials for evolution.

The actual origin of new hereditary characters or mutations is obscure. Practically all of the earlier workers and writers on evolution have found the principal causes of transmutation in the action of extrinsic or environmental forces on the organism. As the result of years of labor on this subject Darwin concluded that "variability of every. sort is due to changed conditions of life"; but in the light of modern genetics such a statement is too sweeping.

It is well known that environmental changes produce many kinds of modifications in organ- 
isms, and in general these modifications are the more profound the earlier they occur in ontogeny; it is known that slight alterations of the germ cells may produce great modifications of adult structure, and yet one of the most striking results of recent work is to show the small effect of environmental changes on racial characters. Marked individual modifications may be produced which do not become racial. Usually not one of thousands of variations which occur has any evolutionary value. These fluctuations come with changing environment and with changing environment they disappear. Very rarely a sudden variation or mutation arises which is perpetuated by heredity and which forms the basis of a new race (Figs. 94, 95). In most cases such mutations consist in the dropping out of some old character rather than in the addition of a new one, but at least they represent modifications of hereditary constitution and as such they furnish material for evolution. Whence and how they appear we rarely know, for like the kingdom of heaven they come without observation. Their infrequency 
amidst the multitude of fluctuations indicates the wonderful stability of racial types and teaches respect for Weismann's doctrine of a germ plasm relatively stable, independent and continuous.

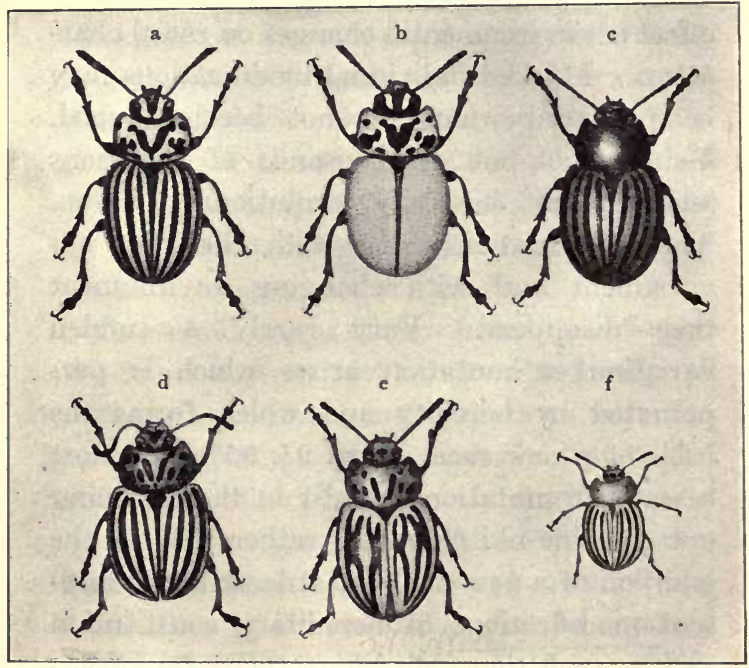

Fig. 94. Common Colorado Potato Beetle, Leptinotarsa. $a$, normal undecemlineata, $b$, the mutant augusto-vittata, $c$, the mutant melanothorax, d, normal decemlineata, e, the mutant tortuosa, f, the mutant defecto-punctata. (From Plate after Tower.) 
'This distinction between somatic and germinal variations, between those which concern only the individual and those which are inherited and furnish material for evolution, marks the greatest advance in the study of evolution since the work of Darwin. And just as these germinal variations are the only ones of importance in the process of evolution so the question of their origin is the greatest evolutionary problem of the present day. How are such germinal variations produced?

There is evidence, as was pointed out in the last lecture, that environmental changes of the right sort acting upon germ cells at the right stage may lead to permanent modification of the hereditary organization. The observations of Hensen on yeast and of Tower and Morgan on insects strongly support this conclusion.

It is probable that certain changes in environment acting upon germ cells at the time of their maturation divisions may lead to new distributions of chromosomes or even to changes in the composition of individual chromosomes, thus producing new hereditary 
types. Certain mutants of Oenothera (Fig. 95) seem to be of this sort; for example $O$. lamarckiana has $\mathbf{1 4}$ chromosomes, $O$. lata $\mathbf{1 5}$, O. semi-gigas $21, O$. gigas 28 , and these variations in the number of chromosomes are probably due to abnormalities in the maturation divisions. It is significant that the mutants lata and semi-gigas have occurred several times, whereas gigas appeared but once; this may be explained by the fact that the chances of the doubling of chromosomes in both germ cells (gigas) are very few compared with the chances of their doubling in one germ cell (semi-gigas) or of their increase by one in one germ cell (lata).

It is probable that mutations are not always nor even usually associated with changes in the number of chromosomes. Where the number of chromosomes remains constant the change may take place in the number or composition of the chromomeres or units of the next lower order, but it would be practically impossible to find such changes in bodies so small and so numerous. Whatever the cellular changes may be which accompany muta- 


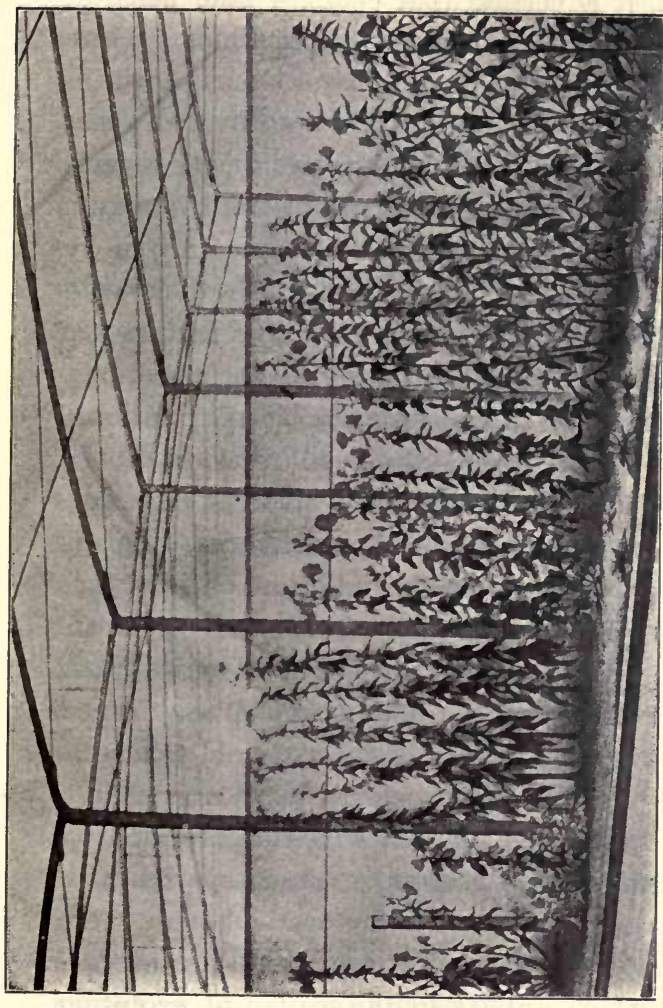

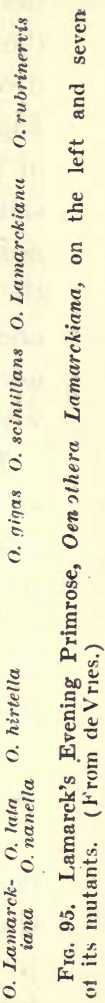


tions, it is certain that changes take place in the inheritance factors. Sometimes factors drop out, as in the white sweet peas shown in Fig. 57 and in many other cultivated races of plants and animals, thus producing regressive mutations. Indeed most of our domestic animals and cultivated plants have arisen by the omission of something which their wild ancestors had. Occasionally new factors are added thus producing progressive mutations, which are of special importance in evolution.

It is often said that evolution from the amoba to man necessarily involves the addition of many new inheritance factors. This is probably true, but the addition of new factors does not mean their creation. New hereditary factors are to be thought of as we think of new chemical compounds, which are formed by new combinations of the same old elements, or as we think of new elements, such as helium and radium emanation, which are formed by dissociation of radium. As compared with chemical elements the factors of heredity are probably very complex things and the new factors which appear in the course of evolution 
probably arise as new combinations of factors or parts of factors previously present. In short as modern science regards all types of organisms as having evolved by the transformation of previously existing organisms, so it must regard all types of hereditary factors as having existed from the beginning or as having evolved by transformations of preexisting factors; as it regards all types of chemical compounds as having arisen by various combinations of chemical elements, so it must regard all "new" elements as having existed from the beginning or as having evolved by the association or dissociation of still smaller particles, the negative and positive electrons. Nowhere in the entire process is there any evidence that factors or elements or electrons are created $d e$ novo. The whole process is one of evolution, that is of new combinations of existing units, having new qualities which are the result of these new combinations.

If these changes in the germ plasm may be induced by extrinsic conditions, then a real experimental evolution will be possible; if they cannot be so induced but are like the changes 
taking place in the radium atom we can only look on while the evolutionary processes proceed, selecting here and there a product which nature gives us but unable to initiate or control these processes.

\section{B. CONTROL OF HUMAN HEREDITY: EUGENICS}

\section{Past Evolution of Man}

There is every evidence that man also, no less than domesticated animals, has evolved from a natural or wild state. The most primitive types of men are known only from a few fossil remains, which indicate that these primitive men belonged to different species, and some of them even to different genera, from Homo sapiens (Fig. 96). Later stages in the evolution of man are known from many remains, implements and handiwork, as well as from certain primitive races or tribes which have persisted to the present time. 'The grades of culture represented by these extinct or persistent tribes and by modern men are usually classified as savagery, barbarism and civiliza- 

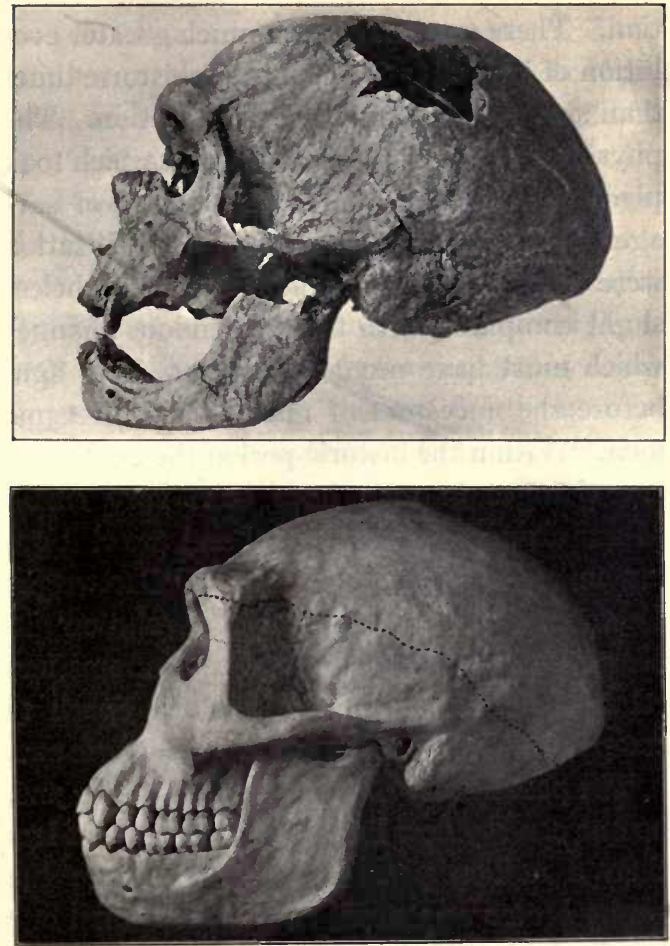

Fig. 96. Extinct Types of Man. A Skull of Homo neanderthalensis; from Chapelle-aux-Saints, France, 1908. (After Boule). B. Skull of Pithecanthropus erectus; found in Trinil, Java, 1895; parts below dotted line restored by $\mathrm{J} . \mathrm{H}$. McGregor. 
tion. There must have been much greater evolution of human types during prehistoric times than since the beginnings of civilization. The physical, mental and moral changes which took place in men from the earliest stages of savagery down to the beginnings of civilization were very great, but they were nevertheless slight compared with the tremendous changes which must have occurred in those long ages before the ancestors of man actually became men. Within the historic period the evolutionary changes in man have been very small. Minor changes have occurred and are still going on, as Osborn has shown in his "Cartwright Lectures on Contemporary Evolution in Man," but on the whole the race has remained relatively stable during the historic epoch as compared with the much longer prehistoric one.

The past history of man has been a long one, no one can say how long, but probably not less than a million years have passed since the genus Homo appeared, and not less than one hundred thousand years since the present species arose. There is every reason to believe that the future history of man will be even 
longer. Barring great secular changes, catastrophes or cataclysms, which cannot be foreseen or provided against, man controls his own destiny on this planet.

It is a curious fact that in prescientific times the instability of nature especially appealed to men. How often in the past have men looked forward to a "speedy end of the world"! It may well have seemed to our ancestors a useless thing to take any thought for the morrow if very soon the heavens are to be rolled up as a parchment and the elements dissolved in fervent heat; it would be folly to plan for future ages if the time is at hand when the angel shall stand with one foot on the sea and the other on land and declare that time shall be no more. But science has taught us something of the wonderful stability of nature, something of the immensity of past time and of future ages, something of the eternity of natural processes. Compared with this infinite stability and eternity of nature what are our little systems and customs! Our years and centuries fall like grains of sand into this abyss of time. Our individual lives are like drops of water in 
the great ocean of life. What intellectual development, what social institutions, what control of natural processes may come in the long ages of futurity it has not entered into the heart of man to conceive. And yet so far as we may judge by the small portion of the record of the past which we can read there has been no necessary progress. There has been "eternal process moving on," but not eternal progress. Stagnation, degeneration, elimination, as well as progression, have occurred all along the path of evolution. And yet on the whole evolution has been progressive and there is no reason to suppose that the elimination of the unfit and the preservation of the fit will cease to be the law of future evolution, as it has been of the past.

There are four principal types of the human species-white, yellow, brown, and black - and many subtypes and races. These races differ in many regards in physical, mental and social characteristics, and the comparative value of these races has frequently been discussed, It is difficult to take an impartial 
view of such a matter, though I suppose there would be little question on the part of any well informed person that the white and yellow types have contributed most to what we call civilization. Nevertheless every race probably has good qualities which could be made of service to society. The various races of cattle, horses, sheep, etc., are all useful to man, but in various ways and degrees, and the same is true of various races of men with respect to civilization. In general the dominant races are the most capable intellectually and socially, while those which have been left behind or have been eliminated have been the less capable races. And yet some very good types, possibly with capacities for high social and intellectual development, have been completely exterminated, as for instance the Lucayan Indians of the West Indies, and the aborigines of Tasmania.

Few animals have suffered such wholesale destruction as have the more primitive races of men in different parts of the earth. Several species of man have become entirely extinct, leaving only, as is generally believed, a single 
existing species, Homo sapiens. Race extermination has been witnessed in relatively recent times and on a large scale in the West Indies, North and South America, Africa, Australia, New Zealand and the Islands of the Pacific. But in the disappearance of native races extermination is usually supplemented by amalgamation. After the most warlike members of a race have been destroyed the more peaceful remnants are generally incorporated in the conquering race. Thus the Maoris of New Zealand, the finest native race with which the English have come in contact in their colonies, were estimated to number more than a quarter of a million at the end of the eighteenth century. Owing to destructive wars among the tribes and with the English there are not fifty thousand of them today, and these are being gradually absorbed into the white race.

From the way in which primitive races have gone down before more cultured ones there is reason to believe that in general the principle of the elimination of the unfit and the survival of the fit has characterized human evolu- 
tion no less than that of other organisms. Undoubtedly intelligence has played a great part in the evolution of man as is at once apparent when we consider the infinitely varied experiments by which he has worked his way from savagery to civilization. And yet he has not consciously set before himself an evolutionary goal to be attained by intelligent attention to principles of good breeding.

II. Can Human Evolution be Controlled?

All that man now is he has come to be without conscious human guidance. If evolution has progressed from the amœba to man without human interference, if the great progress from ape-like men to the most highly civilized races has taken place without conscious human control, the question may well be asked, Is it possible to improve on the natural method of evolution? It may not be possible to improve on the method of evolution and yet by intelligent action it may be possible to facilitate that method. Man cannot change a single law of nature but he can put himself 
into such relations to natural laws that he can profit by them.

1. Selective Breeding the only Method of Improving the Race.-It is surely not possible to improve on nature's method of eliminating the worst lines from reproduction. This has been the chief factor in the establishment of races of domesticated animals and cultivated plants, though as we have seen it has probably had nothing to do with the origin of mutations. 'The history of such races shows that evolution may be guided to human advantage by intelligent elimination and selection, and probably any hereditary improvement of the human race must be accomplished by this means, though of course such elimination and selection can apply only to the function of reproduction. The method of evolution by the elimination of persons, the destruction of the weak and cowardly and antisocial, which was the method practiced in ancient Sparta, is repugnant to the moral sense of enlightened men and cannot be allowed to act as in the past; but the worst types of mankind may be prevented from propagating, and the best types may be encour- 
aged to increase and multiply. This is apparently the only way in which we may hope to improve permanently the human breed.

2. No Improvement in Human Heredity within Historic Times.-The improvement of environment and opportunities for individual development enables men at the present day to get more out of their heredity than was possible in the past. "The advance of civilization" has meant only improvement of environment. But neither environment nor training have changed the hereditary capacities of man. There has been no perceptible improvement in human heredity within historic times, nothing comparable with the changes which have occurred in domesticated animals. Indeed no modern race of men is the equal of certain ancient ones. Galton has pointed out the fact that in the little country of Attica in the century between 530 and 430 B. C. there were produced fourteen illustrious men, one for every 4,300 of the free born, adult male population. In the two centuries from 500-300 B.C. this small, barren country with an area 
and total population about equal to that of the present State of Rhode Island but with less than one-fifth as many free persons produced at least twenty-five illustrious men. Among statesmen and commanders there were Miltiades, Themistocles, Aristides, Cimon, Pericles, Phocion; among poets Aschylus, Euripides, Sophocles, Aristophanes; among philosophers and men of science Socrates, Plato, Aristotle, Demetrius, Theophrastus; among architects and artists Ictinus, Phidias, Praxiteles, Polygnotus; among historians Thucydides and Xenophon; among orators Aschines, Demosthenes, Isocrates, Lysias. In this small country in the space of two centuries there appeared such a galaxy of illustrious men as has never been found on the whole earth in any two centuries since that time.

These illustrious men came from a remarkable race composed of individuals drawn together from all the shores of the Mediterranean by a process of unconscious but severe selection. Athens was the intellectual and social capital of the world and to it the most ambitious and most capable men were irresist- 
ibly drawn. It was good immigration as well as good heredity that made Athens famous. Galton concludes that the average ability of the Athenian race of that period was, on the lowest possible estimate, as much greater than that of the English race of the present day as the latter is above that of the African negro.

But this marvellously gifted race declined, as all such races have in time declined:

Social morality grew exceedingly lax, marriage became unfashionable and was avoided, many of the more ambitious and accomplished women were avowed courtesans and consequently infertile, and the mothers of the incoming population were of a heterogeneous class. . . . It can be therefore no surprise to us, though it has been a severe misfortune to humanity, that the high Athenian breed decayed and disappeared, for if it had maintained its excellence and had multiplied and spread over large countries, displacing inferior populations (which it well might have done, for it was naturally very prolific), it would assuredly have accomplished results advantageous to human civilization, to a degree that transcends our powers of imagination. (Galton, "Hereditary Genius," page 331.)

3. Why the Race has not Improved.-If the race has made no progress in hereditary 
characteristics since the time of the Greeks the cause is not far to seek. There have been gifted races and gifted families of men, doubtless many notable human mutations have occurred, but most of these have been diluted, squandered, lost. There has been persistent violation of all principles of good breeding among men. For example, there has been for ages a futile reliance upon good environment to improve heredity. Men do not so improve the races of animals and plants, and thousands of years of human history show that this method is of no avail in improving the human breed.

But the case is far worse than this; such efforts though futile are at least well intentioned, but on the part of most men and governments there has been complete disregard of the entire question of the improvement of the human stock. Natural selection which has through countless ages eliminated the worst and conserved the best and thus has led on the whole to the survival of the fit is so far as possible nullified by civilized man; the worst are preserved along with the best and 
all are given the same chance of reproduction. The mistake has been not in nullifying natural selection by preserving the weak and incompetent, for civilized men could not well do otherwise, but in failing to substitute intelligent artificial selection for natural selection in the propagation of the race. Instead of this there has been perpetuation of the worst lines through sentimental regard for personal rights, even when opposed to the welfare of society; and both church and state have cheerfully given consent and blessing to the marriage and propagation of idiots and of diseased, defective, insane and vicious persons. Finally there has been extinction of the world's most gifted lines by enforced celibacy in many religious orders and societies of scholars; by almost continuous wars which have taken the very best blood that was left outside of the monastic orders; by luxury and voluntary sterility; by vice, disease and consequent infertility.

Is it any wonder that the inheritance of the human race has not improved within historic times? Is it not rather an evidence of the 
broadcast distribution of good and wholesome qualities in the race that in spite of such serious violations of the principles of good breeding mankind remains as good as we find it to-day?

\section{Eugenics}

If a superior power should deal with man as man deals with domestic animals no doubt great improvement could be effected in the human breed. Society is in some respects such a power and can do what the individual, because of self-interest, short life or lack of ability, cannot accomplish. In matters of public health, comfort and security of life and property society is superior in power to the individual; in matters of the perpetuation of the race the individual is still supreme. In animal societies the race, the breed, is to the swift and strong and fit, and the same was probably true of primitive men. But it is impossible to return to the conditions of primitive society in this respect, and the social body itself must in some way control the breeding of men. 
There are millions of men in civilized countries whose mental equipment places them on a plane with barbarians or savages, and they have on the average more offspring than their civilized contemporaries. There are millions of others who are so seriously defective in body or mind, owing to hereditary causes, that they can never take care of themselves and must always be a charge upon the state, and yet in many civilized countries they are permitted to perpetuate their kind and produce an ever-increasing supply of mental and moral defectives, whose maintainance must seriously interfere with the proper education and development of the normal population and whose unrestrained existence constantly threatens to pollute purer streams of heredity. The practice of society regarding marriage and reproduction up to the present has been to allow all sorts, good, bad and indifferent, to propagate with the belief that good environment and training may make up for deficiencies of birth. But very recently the conviction has been growing that good environment is far less important than good heredity and that in 
some way society must influence the race of men at its source. This is the doctrine of eugenics, which Galton defines as follows:

The science of improving stock, which is by no means confined to questions of judicious mating but which, especially in the case of man, takes cognizance of all influences that tend in however remote a degree to give to the more suitable races or strains of blood a better chance of prevailing speedily over the less suitable than they otherwise would have had. ("Inquiries into Human Faculty.")

1. Possible and Impossible Ideals.-What the future evolution of the human race may lead to is an interesting speculation, but it is and can be only a speculation. There is no present evidence that there will ever be a higher animal than man on the earth, and the only evidence that there may be a higher species than Homo sapiens is to be found in the fact that there have been lower species of men in the past and that evolution has been on the whole progressive. The idea that by the aid of that infant industry eugenics a new race of supermen is shortly to be produced is an iridescent dream, and the fantastic demand of some enthusiasts for changes in racial fashions 
has served to bring this whole subject of eugenics into disrepute among thoughtful men.

To a considerable extent the ideals regarding individuals and society have differed in different ages and races in the past, but with the closer communications which have been established between all parts of the earth in modern times there has developed a greater uniformity of ideal. In a complex society all types of service are needed and many different types of individuals are socially useful. If the social good were the supreme end, as it is in a colony of ants or bees, the greatest differentiation of individuals for particular kinds of service would be desirable. There should be a hereditary class of laborers, of business men, of scholars, of artists, etc., and for the improvement of each class there should be inbreeding in that class. Such methods are now used by breeders of various races of domestic animals and cultivated plants with the best of results. No breeder would think of trying to improve draft horses by crossing with race horses, nor of improving milk cows by crossing with beef cattle. In other countries and ages 
the development of hereditary classes and castes in human society has been tried, and survivals of it persist to this day, but they are only vestigial remnants of an old order which is everywhere being replaced by a new ideal in which the good of the individual as well as that of society is the end desired.

The whole development of modern society is in the direction of racial solidarity and away from hereditary classes. Government, education and religion; socialism, syndicalism, anarchism all reflect the movement for individual liberty, fraternity and equality. 'The modern ideal individual is not the highly specialized unit in the social organism, as in the case of social insects, but rather the most general allround type of individual, the man who can when conditions demand combine within himself the functions of the laborer, business man, soldier and scholar. For such a generalized type the methods of inbreeding or close breeding used by the breeder of thoroughbreds are wholly inappropriate. On the other hand such a generalized type must include the best qualities of many types and races and Men- 
delian inheritance shows how it is possible to sort out the best qualities from the worst.

Nowadays one hears a lot of high sounding talk about "human thoroughbreds," which usually means that those who use this phrase desire to see certain narrow and exclusive social classes perpetuated by close inbreeding; it usually has no reference to good hereditary traits wherever found, indeed such traits would not be recognized if they appeared outside of "the four hundred." Such talk probably does neither harm nor good; the "social thoroughbreds" are so few in number and so nearly sterile that the mass of the population is not affected by these exclusive classes.

Galton advocated the segregation and intermarriage of the most highly intellectual members of society, such as the prize scholars in the colleges and universities; but if the human ideal is the generalized rather than the specialized type it would be better if the prize scholars married the prize athletes. A race of highly specialized scholars or athletes is not so desirable as a race in which these and other excellencies are well balanced. From this 
point of view the person who is voted the "best all round man in the class" is nearer the eugenical ideal than the prize scholar.

No man can trace his lineage back through many generations without realizing that it includes many hereditary lines differing greatly in value. The significance of sexual reproduction lies in this very fact that it brings about the commingling of distinct lines and thereby makes every individual different from every other one. The entire history of past evolution testifies to the value of this process, although it causes the gardener, the breeder, the eugenicist serious trouble. But the gardener can propagate his choice fruits by budding and grafting, the breeder can for a time preserve his choice stock by close inbreeding, but the eugenicist cannot shut out the influence of foreign blood, and it is well that he cannot for if he could do so the progress of the race would probably come to an end.

In the human species the only absolute barrier to the intermingling of races is geographical isolation. Every human race is fertile with every other one, and though races and nations 
and social groups may raise artificial barriers against interbreeding we know that these artificial restraints are frequently disregarded and that in the long run amalgamation does take place; and in general the farther amalgamation progresses the faster it goes. In Australia and New Zealand, after little more than a century's contact with white races, there are about as many "half castes" as there are full blooded aborigines. In the United States onequarter of all persons of African descent contain more or less white blood; there are about eight million full blooded negroes and two million mulattoes, and during the past twenty years the latter have increased at twice the rate of the former. In Jamaica, where there are about seven hundred thousand blacks and fifteen thousand whites, there are about fifty thousand mulattoes. A similar condition prevails wherever different races occupy the same country. Even the Jews, who were long supposed to be a peculiarly separate and distinct people, have received large admixtures of Gentile blood in every country in which they have lived. 
Whether we want it or not hybridization of human races is going on and will increase. Partition walls between classes and races are being broken down; complete isolation is no longer possible, and a gradual intermixture of human races is inevitable. We are in the grip of a great world movement and we cannot reverse the current, but we may to a certain extent direct that current into the more desirable channels.

There is a popular belief that hybrid races are always inferior to pure bred ones, but this is by no means the case. Some hybrids are undoubtedly inferior to either of the parents but on the other hand some are vastly superior; only experience can determine. whether a certain cross will yield inferior or superior types. Society may well attempt to prevent those crosses which produce inferior stock while encouraging those which produce superior types.

It is this fact which makes the problem of immigration so serious. In general immigration is regarded merely as an economic and political problem, but these aspects of it are 
temporary and insignificant as compared with its biological consequences. In welcoming the immigrant to our shores we not only share with him our country but we take him into our families and give to him our children or our children's children in marriage. Whatever the present antipathies may be to such racial mixtures we may rest assured that in a few hundred years these persons of foreign race and blood will be incorporated in our race and we in theirs. From the amalgamation of good races good results may be expected; but fusion with inferior races, while it may help to raise the lower race, is very apt to pull the higher race down. How insignificant are considerations of cheap labor and rapid development of natural resources when compared with these biological consequences!

2. Negative Eugenical Measures.-Galton said nothing about sterilization or elimination from reproduction of less valuable lines in his "Inquiries into Human Faculty" which was first published in 1883. He proposed no radical policy but rather one which he thought would be practical and might meet with general 
favor. He suggested a social policy which would delay the age of marriage among the weak and hasten it among the vigorous, whereas present social agencies act in the opposite direction. He showed by statistics that on the average marriage at the age of 22 would produce at the end of one century four times as many offspring as marriage at 33 and at the end of two centuries ten times as many. He particularly emphasized the great harm which would be done by an application of the theory of Malthus among the better classes. For the prudent to put off marriage and to limit offspring while the imprudent continue to reproduce at the present rate would be to give the world to the imprudent within a few centuries at most.

His suggestions, which were at first received with indifference or ridicule, were much less radical than the legal requirements in many of our States to-day. Public sentiment has been greatly aroused on this question; the alarming increase in the number of defectives and criminals has seemed to call for radical action and a flood of hasty but well intentioned 
legislation has been the result. We may confidently expect that in a very short time the marriage of the feeble-minded, hopelessly epileptic or insane, the congenitally blind, deaf and dumb, and those suffering from many other inherited defects which unfit them for useful citizenship will be prohibited by law in all the States. Our immigration laws already exclude such aliens, and the number of persons of the types named who seek legal consent to marry is not large so that it need not be expected that such laws will quickly improve the general population. If in addition such persons are either segregated or sterilized the danger of their leaving illegitimate offspring will be removed; such precautions have been taken in certain of our. States and will probably become general, though at present few of the laws on this subject are strictly enforced.

The study of heredity shows that the normal brothers and sisters, and even more distant relatives, of affected persons may carry a recessive defect in their germ plasm and may transmit it to their descendants though not 
showing it themselves. It will be more difficult, perhaps an impossible thing, to apply rigidly the principles of good breeding to such persons and to exclude them from reproduction; but if in each generation those persons in whom this recessive trait appears are prevented from leaving offspring the number of persons affected will gradually grow less, other conditions being equal.

But while such negative eugenical measures are wholly commendable when applied to such defects as those named, which are certainly inherited and which render those affected unfit for citizenship, the wholesale sterilization of all sorts of criminals, alcoholics and undesirables without determining whether their defects are due to heredity or to conditions of development would be like burning down a house to get rid of the rats; and the only justification which could be offered for the general sterilization of the inmates of all public institutions, which is urged by some of our modern crusaders, would be the defense which some persons make for war, that there are too many people anyway and anything which 
will prevent the growth of population is to be welcomed.

Advocates of war never cease to point out its beneficial effects on the race,- - how it makes men strong, courageous, unselfish, how it makes nations great, powerful, progressive. There is no doubt that war like any other great crisis discovers great men and furnishes opportunities for the development of great qualities that might otherwise remain undeveloped and unknown. But there is also no doubt that it takes the very best blood of the nations. 'Those who go to war are the young, the strong, the capable, while the weak, incompetent and degenerate are left behind as unfit for military service. If conditions could be reversed and the bungled and botched, the feeble-minded and insane, the degenerate and debauched could be put in the fore front of battle some benefit to the race might result, but no increase of national greatness can compensate for the awful waste of the best thing which any nation possesses-its best blood.

3. Positive Eugenical Measures.-Positive eugenical measures are much more difficult to 
apply and are of more doubtful value. Of course compulsory measures are out of the question and encouragement and advice alone are feasible. Giving advice regarding matrimony is proverbially a hazardous performance, and it is not much safer for the biologist than for others. With much more complete knowledge regarding human inheritance than we now possess it may ultimately be possible to give such advice wisely, especially with respect to physical characteristics which are hereditarily simple and generally of minor significance. But where the character is an extremely complex one as in intellectual ability, moral rectitude, judgment and poise, which are the chief characteristics which distinguish the great man from his fellows, it will probably never be possible to predict the result before the event.

He would be a bold prophet who would undertake to predict the type of personality which might be expected in the children of a given union. Some very unpromising stocks have brought forth wonderful products. Could anyone have predicted Abraham Lincoln from a study of his ancestry? Observe I say "pre- 
dict," and not "explain" after his appearance. Can anyone now predict from what kind of ancestral combinations the great scholars, statesmen, men of affairs of the next generation will come? The time may come when it will be possible to predict what the chances are that the children of given parents will inherit more or less than average intellectual capacity, but since germinal potentiality is transformed into intellectual ability only as the result of . development such a prediction could not be extended to the latter unless the environment as well as the heredity were known.

Mankind is such a mongrel race, good and bad qualities are so mixed in us, marriage is such a lottery, the distribution of the germinal units to the different germ cells and the union of particular germ cells in fertilization is so much a matter of chance, the influence of even bad hereditary units on one another is so unpredictably good or bad as is shown in many hybrids, even the minor influences of environment and education which escape attention are so potent in development, that the chances were infinity to one against any one of us, with 
all his individual characteristics, ever coming into existence. If the Greeks or Romans had known of the real infinity of chances through which every human being is brought to the light of day not only would they have deified Chance but they would have made her the mother of gods and men.

But granting the impossibility of predicting the character of children it may well be asked if good general advice may not be given regarding the choosing of a mate. Many people have thought so, and if all that has been said or written on this subject were to be gathered together I suppose that there would not or should not be room for it in all the libraries of the world. It is generally admitted that no lines are wholly free from hereditary defects and the question has often been asked what the eugenical practice should be in such cases. Of course people with really serious hereditary defects should not have children. If the defects are slight Davenport has suggested that they may be either disregarded or weakness in any character may be mated with strength in that character. That people with only slight 
hereditary defects should not marry at all is a counsel of perfection.

On the other hand it would be a dangerous rule to propose that persons having really serious hereditary defects should be mated with those who are strong in those characters on the ground that in general strength in a character is dominant over weakness. It has been suggested that a normal man who marries a feeble-minded woman would have only normal children, since both genius and feeblemindedness seem to be recessive when mated with mediocrity or normality. But in all such cases the weakness is not neutralized or removed but merely concealed in the offspring and is therefore the more dangerous. If a man chooses to marry a feeble-minded woman he at least does so with his eyes open and he need not be deceived. But the normal and perhaps capable children of such a union carry the taint concealed in their germ plasm and if they should be mated with other normal persons carrying a similar taint some of their children would be feeble-minded, and thus the sins of the parents in mating weakness with strength 
would be visited upon the children of the $n$th generation. Such a policy of concealing weakness by mating it with strength is wholly comparable with the custom once prevalent of concealing cases of contagious diseases, and may be properly characterized as the "ostrich policy."

After all in the choosing of mates a combination of instinct and intelligence is probably the safest guide. Our instincts, built up through long ages, are generally adaptive and useful, and if they be guided by reason the result is apt to be better than if either instinct or reason act alone. More need not be said on this subject, since it is treated ad infinitum in works of fiction and in ladies' journals.

4. Contributory Eugenical Measures.-In addition to the negative and positive eugenical measures mentioned many conditions may be classed as contributary to eugenics. One of the most important of all contributary measures is the general education of the people regarding heredity. The general ignorance on this subject is profound and very many offenders against the principles of good breeding 
have sinned through ignorance. Any general reform must rest upon enlightened public opinion, and the schools, the churches and the press can do no more important work for mankind than to educate the people, after they have been educated themselves, on this important matter.

Society too may cultivate a proper pride in good inheritance. Much of value would be accomplished if the silly pride in ancestral wealth or position or environment which touched our forebears only superficially and never entered into their germ plasm or the still sillier claims of long descent, in which we are all equal, could be replaced by a proper pride in ancestral heredity, a pride in those inherited qualities of body, mind and character which have made some families illustrious. A proper pride in heredity would do much to insure the perpetuation of the line and to protect it from admixture with baser blood.

Among other contributory measures which serve to promote good breeding among men must be reckoned coeducation, as well as other means of promoting good and early marriages. 
The president of a large coeducational institution once said that if marriages were made in heaven he was sure that the Lord had a branch office in his university. I had occasion a year ago to investigate the eugenical record of a coeducational institution, which is not unknown in the world of scholarship, and found that about 33 per cent. of the recent graduates had married fellow students, that there had been no divorces and that there were many children. There is no doubt that coeducation promotes good and early marriages and that it is not necessarily inimical to good scholarship even though it violates the spirit of mediæval monasticism. There was a time when it was supposed that a scholar must live the monkish life of seclusion and contemplation, but the monasteries are disappearing the world over, and it is time that the monastic spirit should go out of the colleges and universities.

On the other hand the colleges exclusively for women appear to have a bad influence on the marriage rate and birth rate of their graduates. Johnson has shown that 90 per cent. of all the women of the United States marry be- 
fore the age of 40 , but that among college women only half that number have married at the same age. As a result of investigations at one of the leading women's colleges he finds that the marriage and birth rate of the most brilliant students, who have been elected members of Phi Beta Kappa, is lowest of all. Cattell says that a Harvard graduate has on the average three-fourths of a son, a Vassar graduate one-half of a daughter.

At present early and fruitful marriages among able and ambitious people are very unfashionable and are becoming increasingly impracticable. If society has any regard for its own welfare all this must be changed. As Galton has shown, the race that marries at $\mathbf{2 2}$ instead of 33 will possess the earth in two or three centuries.

The good of society demands that we reverse our methods of putting a premium upon celibacy among our most gifted and ambitious young men and women, and if monastic orders and institutions are to continue they should be open only to the eugenicially unfit.

5. The Declining Birth Rate and the Death 
of $\boldsymbol{F}$ amilies.-Among animals and plants in a state of nature the number of individuals in each species remains fairly constant from year to year; that is, only enough young are born and survive to take the places of mature individuals that die. But when a species is placed in new and favorable conditions it may for a while increase at an amazing rate until the pressure of population becomes sufficient to reestablish an equilibrium between the birth rate and the death rate. Thus when the English sparrow was introduced into the United States it increased at a phenomenal rate for a number of years, but now the number of individuals in any given locality remains about the same from year to year, the birth rate merely compensating for the death rate. This equilibrium is brought about in the main by increased mortality, especially among the young, though decreasing fecundity may play a minor part.

Essentially the same principles apply to human populations. Up to two or three centuries ago the populations of the older countries of the world were practically stationary. 
Fecundity was relatively high but the death rate was also very high, the excess of population in each generation being carried off in large numbers by war, pestilence and famine. 'Then owing to the developments of science and industry and to the opening up of new countries a period of remarkable expansion of population began. The population of Europe, which was about 175 millions in 1800, increased to 420 millions in 1900, and this in spite of the fact that about 35 millions migrated from Europe to new countries during this period. This great increase in the population of Europe was due primarily to reduction of the death rate since the birth rate also declined slightly during this period, while in the newer countries there was both an increase in the birth rate and a decrease in the death rate.

It is perhaps an open question how long the advances of science in rendering available the natural resources of the earth may be able to keep pace with increasing population, but it is evidently impossible for this great increase in the population of the world to go on indefinitely; sooner or later it must come to an 
end and the population again become stationary. Already the birth rate is decreasing more rapidly than the death rate in all the western countries of Europe and this movement must ultimately extend to all parts of the world and lead to a checking of the great increase in population which has characterized the last two hundred years. This approach to a stationary population is both a normal and a desirable thing, for no one could wish to see population increase more rapidly than the supply of food or other necessaries of life; and of the two possible methods of checking population few would hesitate to choose a decreasing birth rate as preferable to an increasing death rate.

It is not therefore the declining birth rate in the general population that should cause alarm but rather the declining birth rate in the best elements of a population, while it continues to increase or at the least remains stationary among the poorer elements, and there is abundant evidence that this is just what is taking place. The descendants of the Puritans and the Cavaliers who have raised the cry for "fewer and better children" are already 
disappearing and in a few centuries at most will have given place to more fertile races of mankind. Everybody knows that the old New England families are dying out and that their places are being taken by recent immigrants. The few exceptions are merely eddies in the current that is bearing them to doom. In Massachusetts the birth rate of the foreign born is twice that of the native population while the death rate is about the same. The same is true of the older families in many parts of the world.

Professor Cattell has recently made a statistical study of the families of 917 American men of science and he finds that the average size of family of the parents of these men was 4.66 children, whereas the average size of family of these men is 2.22 children. In one generation the fertility of these lines has been reduced by more than half. The causes of this decline are chiefly voluntary being assigned to health, expense and other causes.

But the causes of sterility are not only social and voluntary ones, which could be 
changed by custom and public opinion; there are also involuntary and biological causes of a deep-seated nature. Fahlenbeck has made a study of 433 noble families of Sweden which have become extinct in the male line, and he shows that the last male died unmarried in 45 per cent. of these families, and before the age of 21 in 39 per cent., while the line ended in infertile marriage in 11 per cent. and in daughters only in 5 per cent.

Broman points out that most noble families of Europe die out after 100 to 250 years and generally do not live beyond the third generation. The same is true of the families of great scholars, artists and statesmen. Possibly one cause of such declining fertility may be found in too great brain activity, but there is no doubt that in many instances it is due to luxurious living. On the other hand bodily fatigue and simple living favor fertility in both animals and men. Wild animals brought into captivity where they have comfortable quarters and an unwonted abundance of rich food are usually infertile. And the conditions of life of the upper classes of society are al- 
most as dangerous for fertility as is captivity for wild animals. It is evident that if we had fewer luxuries we could have, and could afford to have, more children.

But animals in captivity may gradually become adapted to their new conditions so as to become fertile, and there is evidence that a slow adaptation through several generations to conditions of high civilization is possible. Some royal families of Europe go back six or eight hundred years, and in general if a family survives the new conditions of affluence and luxury for more than three generations it may become more or less adapted to the new conditions.

What Bernard Shaw regards as the greatest discovery of the nineteenth century, viz., the means of artificially limiting the size of families, may prove to be the greatest menace to the human race. If it were applied only to those who should not have children or to those who should for various reasons have only a few children it would be a blessing to mankind. But applied to those who could and should have many children it is no gift of the gods. No 
one denies that the chief motive for limiting the size of families is personal comfort and pleasure rather than the welfare of the race. The argument that people should have no more children than they can rear in comfort or luxury assumes that environment is more important than heredity, which is contrary to all the biological evidence. In the breeding of horses or cattle or men heredity is more potent than environment; and it is more important for the welfare of the race that children with good inheritance should be brought into the world than that parents should live easy lives and have no more children than they can conveniently rear amid all the comforts of a luxuryloving age.

The method of evolution in the past has been the production of enormous numbers of individuals and the elimination of the least fit. The modern method of improving domestic races is to select for reproduction the best types from large numbers of individuals. One reason why human evolution has gone on so slowly is to be found in the slow breeding of men. Nature has provided an almost infinite wealth and 
variety of potential personalities in human germ cells but only an infinitesimal number ever come to development. If this number is still further reduced by artificial means the race will be made the poorer not merely in quantity but also in quality. The optimism of those who believe that supermen may be produced by artificially limiting the number of children is a foolish and fatal optimism.

No eugenical reform can fail to take account of the fact that the decreasing birth rate among intelligent people is a constant menace to the race. We need not "fewer and better children" but more children of the better sort and fewer of the worse variety. 'There is great enthusiasm to-day on the part of many childless reformers for negative eugenical measures. The race is to be regenerated by sterilization. But unfortunately this reform begins at home among those who because of good hereditary traits should not be sterile. Sterility is too easily acquired; what is not so easily brought about is the fertility of the better lines. Galton was far wiser than most of his followers for he realized the necessity of 
increasing the families of the better types as well as of decreasing those of the worse.

Finally for those who are denied the privilege of parenthood and upon whom sterility is forced by whatever circumstances there is a lesson of value among the social insects. The sterile members of a colony of ants or bees are forever denied the possibility of having offspring of their own, but they become foster mothers to the offspring of the queen. They tenderly nurse, care for and rear the young of the colony. There are many children in the worid who need foster mothers and fathers; there are many men and women in the world. both married and unmarried, who need adopted children. "Go to the ant, thou sluggard; consider her ways and be wise." 


\section{CHAPTER VI}

\section{GENETICS AND ETHICS}





\section{CHAPTER VI}

\section{GENETICS AND ETHICS ${ }^{1}$}

Modern studies of development are profoundly changing the opinions of men with respect to human personality. Observation of the relentless laws of heredity, of the inevitable influences for good or bad of environmental conditions over which the individual has no control, undoubtedly tends to produce a sense of helplessness and hopelessness. What light is thrown upon the great problems of freedom and determinism, of responsibility and irresponsibility, of duty and necessity by modern studies of development? Such questions cannot be dealt with quantitatively and experimentally, and they lie outside the field of exact science, but they are involved in all inquiries which have to do with rational and social be-

${ }^{1} \mathrm{~A}$ portion of this lecture was given as the presidential address before the American Society of Naturalists in January, 1913, and was published in Science under the title "Heredity and Responsibility." 
ings; they lie at the foundation of the application of science to human welfare; they occupy a large place in the thought and conduct of all men.

I. The Voluntaristic Conception of Nature and of Human Responsibility

Primitive men regarded their own activities and all phenomena of nature as the expression of will, and a similar view has been maintained by certain philosophers and theologians even in modern times. Nature was regarded as the immediate expression of a vast will which creates, rules, builds and destroys as it sees fit. The lightning is hurled from the hand of Jove, the sea is disturbed by angry deities, the winds are let loose or stilled, the earth trembles, the hills smoke, the sun and moon and stars travel in their appointed courses as the gods will.

In this primitive view of nature even inanimate objects were supposed to be endowed with wills of their own, and many modern men are sufficiently primitive to kick the chair over which they stumble, or to swear that the devil 
has gotten into the automobile. Of course the actions of all animate things were held to be the result of choice; the fly that dances on your head or gets into the soup is doing it to annoy you; the cats that yowl, the dogs that howl, the maniacs that screech are possessed of devils, evil wills, and should be punished. All good is the result of good will, all evil of evil will. Some being, some volition, is responsible for everything that happens. All nature is the expression of big or little wills, of good or bad wills, and the good should be rewarded and the bad punished.

This conception of nature finds its counterpart and probably its origin in similar views concerning human conduct and responsibility. According to this belief every man is the architect of his own character; the will is absolutely free; no taint of heredity or necessity rests on the mind or soul; character is a tabula rasa, upon which the self writes its own record as it chooses, and is responsible for the result. Conduct whether good or bad, benevolent or criminal, rational or irrational rests upon voluntary choice, and for such choices men must 
be held responsible. To a great extent this view of freedom and responsibility is the basis of present systems of government, education, ethics and religion.

\section{The Mechanistic Conception of Na- ture and of Personality}

As contrasted with this voluntaristic view of nature and of man consider the scientific conception of nature as a vast mechanism, an endless chain of causes and effects. Science deals with "the unfailing order of immortal nature," with the universality of cause and effect, with the eternal stability and inevitability of natural processes. Natural phenomena are not the result of volitions big or little, good or bad, but of all the events which have gone before. To the man of science nature is not the mere caprice of god or devil, to be lightly altered for a child's whim; nature is, as Bishop Berkeley said, "stated, fixed, settled," eternal process moving on, the same yesterday, to-day and forever.

From sands to stars, from the immensity of the universe to the minuteness of the electron, in living things no less than in lifeless ones, 
science recognizes everywhere the inevitable sequence of cause and effect, the universality of . natural processes, the reign of natural law. Man also is a part of nature, a part of the great mechanism of the universe, and all that he is and does is limited and prescribed by laws of nature. Every human being comes into existence by a process of development, every step of which is determined by antecedent causes.

1. The Determinism of Heredity.-There can be no doubt that the main characteristics of every living thing are unalterably fixed by heredity. Men differ from horses or turnips because of their inheritance. Our family traits were determined by the hereditary constitutions of our ancestors, our inherited personal traits by the hereditary constitutions of our fathers and mothers. By the shuffle and deal of the hereditary factors in the formation of the germ cells and by the chance union of two of these cells in fertilization our hereditary natures were forever sealed. Our anatomical, physiological, psychological possibilities were predetermined in the germ cells from which we came. All the main characteristics 
of our personalities were born with us and cannot be changed except within relatively narrow limits. "The leopard cannot change his spots nor the Ethiopian his skin," and "though thou shouldst bray a fool in a mortar with a pestle yet will not his foolishness depart from him." Race, sex, mental capacity are determined in the germ cells, perhaps in the chromosomes, and all the possibilities of our lives were there fixed, for who by taking thought can add one chromosome, or even one determiner to his organization?

The thought of this age has been profoundly influenced by such considerations. We formerly heard that "all men were created free and equal"; we now learn that "all men are created bound and unequal." We were once taught that acts, if oft repeated, become habits, and that habits determine character; hereditarians of the stricter sort now teach that acts, habits and character were foreordained from the foundation of the family. We once thought that men were free to do right and wrong, and that they were responsible for their deeds; now we learn that our reactions 
are predetermined by heredity, and that we can no more control them than we can control our heart beats. For ages men have believed in the influence of example, in the uplift of high ideals, in the power of an absorbing purpose; for ages men have lived and died for what they believed to be duty and truth, and have received the homage of mankind; or they have lived malevolent and criminal lives and have been despised by men and punished by society. But if our reactions, habits, characters are predetermined in the germ plasm such men have deserved neither praise nor blame. If personality is determined by heredity alone all teaching, preaching, government is useless; freedom, responsibility, duty are delusions; whether men are useful or useless members of society depends upon their inheritance, and the only hope for the race is in eugenicsalways supposing that enough freedom is left to men or to society to control the important function of choosing a mate.

Already a few enthusiastic persons have begun to apply these doctrines to practical affairs. We are told that children should never 
be admonished or punished, for they do only what their natures lead them to do; the nature of the child must be respected and must be allowed to manifest itself in its own way. Lying and stealing will cure themselves like the mumps, or they will remain incurable, in which case the germ plasm is to blame and nothing could have been done anyway. Laziness is due to inheritance or to hookworms; the latter kind may be cured, but not the former. Thriftlessness, alcoholism and uncleanness run in families and can be cured only by extermination. Men who prey upon society were born with wolfish instincts, and cannot help but eat the lambs. Villains, lawbreakers, murderers should be pitied but not punished; if blame attaches to their deeds it falls upon the marriage bureau and the parents. The world needs hospitals and sanatoria and sterilization institutes for the criminal and the vicious, but not courts and prisons, and all punishments should be visited only upon the parents to the third and fourth generations.

Do our studies of heredity lead us to any such radical conclusions? If they do we must 
accept them like brave men. "Truth is truth if it sears our eyeballs." But when theories lead to such revolutionary results it behooves us to examine carefully those theories to see if there is not somewhere a fundamental flaw in them.

One of the most difficult things in the world is to recognize a great truth, to feel its significance and yet not be carried away by it. Great scientific errors are frequently due not so much to faulty observations as to sweeping conclusions. In biology the search for universal laws is a peculiarly dangerous pursuit. In philosophy great errors are often due not so much to false premises as to supposed logical. necessities. As a test of truth logic is inferior to experience; its faults are not so much in its methods as in its premises and applications. For this reason a logical chain has led many a man into the bondage of error. Truth is not usually found in extremes, in "carrying out a process to its logical conclusions," but rather in some middle course which is less striking but more judicious.

Having observed that the main characteris- 
tics of our minds as well as of our bodies are inherited, it is easy and natural to go further and to conclude not only that all the possibilities of our lives are marked out in the germ but that all that will actually develop from the germ is there determined and cannot be altered. There are many similarities between such an extreme view and the old doctrine of preformation, and it contains a like absurdity. It practically denies development altogether. If the germ is a closed system and receives nothing from without, and if adult characteristics are predetermined in the germ, they are as irrevocably fixed as if they were predelineated.

At the opposite extreme is the old voluntaristic view of absolute freedom and absolute responsibility. This view, like the old epigenesis, virtually postulates a new creation for each individual. As far as the mind and soul are concerned there is no hereditary continuity with past generations and none with future ones. But while such a view may be logically complete and theologically satisfying, it is not scientific, for it also contradicts the evidence. 
'The truth then seems to lie somewhere between these two extremes. Our personalities were not absolutely predetermined in the germ cells from which we came, and yet they have arisen from those germ cells and have been conditioned by them. When it is said that any characteristic is predetermined in the germ cell, what does this mean? What but that the development of that characteristic is made possible?. Adult characteristics are potential and not actual in the germ, and their actual appearance depends upon many complicated reactions of the germinal units with one another and with the environment. In short, our actual personalities are not predetermined in the germ cells, but our possible personalities are.

2. The Determinism of Environment.This determinism of heredity is matched by a corresponding determinism of environment. Life is possible only within rather narrow limits of physical and chemical conditions and in the main these limits are fixed by the constitution of nature. But apart from these antecedent conditions of life in general there are many minor conditions of environment which 
exercise a profound influence upon organisms, especially in the course of their development. Very slight changes in food, temperature, moisture and atmospheric conditions may produce great changes in the developing organism, and these conditions are for the most part entirely beyond the control of the individual affected.

In all organisms the potentialities of development are much greater than the actualities. In many animals a small part of the body is capable, when separated from the remainder, of producing a whole body, though this potency would never have become an actuality except under the stimulus of separation. In like manner a part of an egg may, when separated from the remainder, give rise to an entire animal. By modifying the conditions of development animals may be produced which have one eye, many eyes or no eyes; animals in which the body is turned inside out, or side for side; animals in which all sorts of dislocation of organs have taken place; and the earlier the environmental forces act the more profound are the modifications. 
But leaving out of account all forms which are so monstrous that they are incapable of reaching maturity we find that there are left many variations in the size and vigor of the body as a whole, as well as of its parts; many variations in the more or less perfect correlation of these parts with one another, which were determined by the conditions of development rather than by heredity. In a given germ cell there is the potency of any kind of organism that could develop from that cell under any kind of conditions. The potencies of development are much greater than the actualities. Anything which could possibly appear in the course of development is potential in heredity and under given conditions of environment is predetermined. Since the environment cannot be all things at once many hereditary possibilities must remain latent or undeveloped. Consequently the results of development are not determined by heredity alone but also by extrinsic causes. Things cannot be predetermined in heredity which are not also predetermined in environment.

Of all animals I suppose that man enjoys 
the most extensive and the most varied environment, and its effect upon his personality is correspondingly great. Of all animals man has the longest period of immaturity and it is during this period that the play of environmental stimuli on the organism is effective in modifying development. In addition to the material environment he lives in the midst of intellectual, social and moral stimuli which are potent factors in his development. By means of his power to look before and after he lives in the future and past as well as in the present; through tradition and history he becomes an heir of all the ages. 'The modifying influences of all these environmental conditions on personality are very great. Each of us may say with Ulysses: "I am a part of all that I have met." So great is the power of environment on the development of personality that it may outweigh inheritance; a relatively poor inheritance with excellent environmental conditions often produces better results than a good inheritance with poor conditions. Of course no sort of environment can do more than bring out the hereditary possibilities, but on the 
other hand those possibilities must remain latent and undeveloped unless they are stimulated into activity by the environment.

Functional activity or use is one of the most important factors of development. Functional activity is response to stimuli, which may be external or internal in origin. The entire process of development may be regarded as an almost endless series of such responses on the part of the organism, whether germ cell, embryo or adult, to external and internal stimuli. It is a truism that use strengthens a part and disuse weakens it; it is likewise a truism that responses which are oft repeated become more rapid and more perfect, and in this way habits are formed. Practically all education, whether of man or of lower animals, consists in habit formation, in establishing constant relations between certain external or internal stimuli and certain responses of the organism. At first these stimuli are largely of external origin; later the external stimuli may be replaced more and more by internal ones; but whatever the source of the stimulus the response of the organism to these stimuli is 
one of the most important factors of development, whether of the body or of the mind.

The influence of environment upon the minds and morals of men is especially great. 'To a large extent our habits, words, thoughts; our aspirations, ideals, satisfactions; our responsibility, morality, religion are the results of the environment and education of our early years. It cannot be doubted that if we had been born in other countries or ages we should have been different from our present selves in many important respects; if we had been born and reared in the slums of great cities we should have been other than we are; indeed if the little illnesses, accidents and contingencies of our lives had been different we should have been different in our bodies and minds, as identical twins come to differ from each other under such circumstances. The conditions of early life and education have a great influence in shaping personality and are almost as much beyond the control of the individual as is heredity.

If personality in all of its main features is fixed by heredity and environment over which 
the individual has little or no control, and this is certainly true, personality is as inevitably determined by its antecedents as is any other natural phenomenon. This is, I believe, a conclusion from which there is no escape. How then is it possible to believe in freedom and responsibility? Is there not justification for the view so often expressed of late that man is never free and that responsibility and duty are mere delusions?

\section{Determinism and Responsibility}

Many persons who have thought upon these subjects have felt, apparently, that there was no tenable middle ground between extreme voluntarism and extreme mechanism; man has been regarded as a "free agent" or a mere "automaton," absolutely free or absolutely bound, wholly indeterminate or wholly predetermined. But these extreme views are unreal, unscientific and unjustifiable, for they contradict the facts of experience. We have the assurance of experience that we are not absolutely free nor absolutely bound, but that we 
are partly free and partly bound; the alternatives are not merely. freedom or determinism, but rather freedom and determinism.

1. Determinism not Fatalism.-Whatever the philosophical meaning of "determinism" may be, all that is meant by that term in science and in actual life is that every effect is the resultant of antecedent causes and that identical causes yield identical results. Determinism does not mean predeterminism: the one finds every effect to be due to a long chain of preceding causes, the other attributes every effect to a single original cause; the ore is scientific naturalism, the other is fatalism.

Applying this to personality actual experience teaches that constant conditions of heredity and environment give constant results in development and that different conditions give different results. Undoubtedly the entire personality, body and mind, undergoes development, and modifications of either heredity or environment modify personality. This is scientific determinism, but it is not fatalism and it is not incompatible with a certain amount of freedom and responsibility. 
2. Control of Phenomena and of Self.Even the most extreme mechanists, who maintain that we are mere automata and that we could never do otherwise than we do, admit the possibility of a certain amount of control over phenomena outside ourselves. They tell us that the aim of science is not merely to understand but also to control nature. But if man may to a limited extent control physical, chemical and biological processes in the world around him, if he may control to a limited extent the behavior of a star-fish or dog or child, on what ground is it possible to deny a similar control of his own behavior? Does it not come to this that all such control means intelligent action, or rather the introduction of intelligence as a factor in the chain of cause and effect? Before the appearance of intelligence, whether in ontogeny or in phylogeny, no such control of phenomena or of self is possible, but when intelligence becomes a factor in behavior a limited control of the world and of the self is made possible.

Of course man has no control over events which have already happened. Our heredity and early development are accomplished facts 
which nothing can change. Development is not a reversible process; a man cannot enter a second time into his mother's womb and be born again. Once the sex cells are formed their hereditary nature is determined; once the egg is fertilized the hereditary possibilities of the new individual are fixed; once any stage of development has passed that page in the book of life is closed and sealed.

And yet at every step in this long process of development there were one or more alternatives which might have been taken instead of the one which was taken. There were-innumerable possible alternatives in the matings of our ancestors, there were billions of possible alternatives in the union of the millions of types of germ cells which each of our parents produced; at every step in the development of the oosperm from which each of us came there were many possible alternative stimuli and responses. But in each case one of these innumerable alternatives was taken and the others left. In every instance there was some cause that determined which alternative was taken, but these causes are so local and indi- 
vidual that they cannot be generalized; one cause works in one instance, another in another, and so we say that chance determines which alternative is taken, meaning by chance only this that the causes involved cannot be generalized. At critical stages in this process of development the alternatives are so evenly balanced that minor considerations, which we call chance, determine which path shall be taken; but there are no backward steps in development and once a path has been taken that particular crisis or turning point does not occur again.

Thus each of us has wandered through the maze of life, chance usually determining which path shall be taken of the many which heredity and environment offer, until he has come to a stage where associative memory makes it possible to profit by experience and where intellect and will make possible intelligent choice. With the growth of intellect and will there comes to be a limited degree of freedom and responsibility, and with increasing complexity of organization the number of alternative paths is greatly increased. The possible reac- 
tions of germ cells are relatively few and fixed, the possible reactions of a complex animal are relatively many and behavior is more plastic; and thus this very complexity and plasticity allow adaptations to the minutest alterations of environment.

3. Birth and Growth of Freedom.-In animals below man and in the stages of human development one may trace the birth and growth of freedom. Even in some of the simplest organisms one can observe inhibitions of responses and modifications of behavior which seem to be due to conflicting stimuli or to changes in the physiological state. In higher organisms such inhibitions or modifications proceed particularly from internal stimuli, which in turn are probably conditioned by hereditary constitution and past experience. The factors which determine behavior are not merely the present stimulus and the hereditary constitution, but also the experiences through which the organism has passed and the habits which it has formed.

A moth cannot avoid the impulse to fly toward the light, and it does not learn by ex- 
perience to avoid the flame. Its reactions are relatively fixed and machine-like. Many other animals learn by experience to inhibit responses to certain stimuli; a tane fish or frog will take food from your hand, but if it is repeatedly frightened when it attempts to take food it will not come near you though it is starving,-it inhibits the strong impulse of a hungry animal to take food by the counter impulse of unpleasant memories or of fear. Here we have the beginnings of what we call freedom, the immediate response to a stimulus is suppressed, internal stimuli are balanced against external ones and final action is determined largely by past experience. Owing to his vastly greater power of memory, reflection and inhibition man is much freer than any other animal. Animals which learn little from experience have little freedom and the more they learn the freer they become.

In both ontogeny and phylogeny there has been development of freedom. The reactions of germ cells and of the lowest organisms are relatively fixed. In more complex organisms reactions become modifiable through conflict- 
ing stimuli, intelligence, inhibitions. Freedom is the more or less limited capacity of the highest organisms to inhibit instinctive and nonrational acts by. intellectual and rational stimuli and to regulate behavior in the light of past experience. Such freedom is not uncaused activity, but freedom from the mechanical responses to external or instinctive stimuli, through the intervention of internal stimuli due to experience and intelligence. To the person accustomed to think of will and choice as absolutely free this may seem to be a sort of freedom so limited as to be scarcely worth the having; and yet "it is the dawning grace of a new dispensation," the beginnings of rational life, social obligations, moral responsibility.

The only control over natural phenomena which is possible is in choosing between alternatives which are offered; and the only control which one who has reached the age of intelligence can have over his own development consists in choosing between the alternatives which are open to him. He may not choose his heredity or early development for the alternative paths which were once offered here have long 
since been passed; but to a limited extent he may choose his present environment and training, he may choose a path which leads to discipline and increased powers of self-control or the reverse, and to this extent only is he responsible for what he may become.

4. Responsibility and Will.-All organisms are capable of responding to chemical and physical stimuli but in addition normal men have the capacity of responding to stimuli of a higher order. By responsibility in this higher sense I understand the ability on the part of the organism to respond to rational, social and ethical stimuli or impulses and to inhibit responses to stimuli of an opposite nature, and the corresponding expectation on the part of others that the individual will so respond. The psychical stimuli which influence our behavior are not merely remembered experiences but the words, suggestions, admonitions, ideas which come to us from others, as well as the almost endless permutations of such memories and suggestions in our thoughts. The social and ethical stimuli are not merely such as arise from love of reward 
and fear of punishment or the desire for praise and the fear of blame but also from the deep seated social instinct to do good, which may reach the highest levels of altruism and self sacrifice.

The higher the type of organization the larger is the range of stimuli to which it will respond and the larger the number and kind of responses which may be called forth; and at the same time the larger becomes the power of inhibition of responses whether through the balancing of one stimulus against another or from whatever cause. Human responsibility varies with the complexity of the stimuli involved as well as with the capacity of individuals to respond to those stimuli. A man might be quite responsible in savage society who would be quite irresponsible in civilized communities. In an infant there is no capacity to respond to rational, social or ethical stimuli but with increasing capacity in this respect comes increasing responsibility. Mental and ethical imbeciles, insane and mentally defective persons have a low capacity for such responses and inhibitions and consequently less is ex- 
pected of them. 'There are in different men all degrees of responsibility, as there are all degrees of capacity. In one and the same individual responsibility varies at different times and under different circumstances; it rises and falls, like the tides, in every life. Varying capacity to respond to rational, social and ethical stimuli and to inhibit responses of an opposite nature depends not merely upon inheritance but also upon training, habits, physiological states. The common opinion that all normal men are equally responsible is not correct; in the eyes of the law this may be true, because legal obligations are so far below the capacities of normal men that all may be held equally responsible before the law, though in reality their responsibilities are as varied as their inheritance or their training.

Conversely the responsibility of society to the individual is universally recognized. Irresponsible persons must be cared for by older or wiser persons who become responsible for them; and in general the responsibility rests upon society to provide as favorable environment as possible for all its members. Ex- 
perienced persons can to a certain extent choose their own environment and thus indirectly control their responses and habits but young children are almost if not quite as incapable of choosing their environment as of choosing their heredity, and it becomes the duty of society to see to it that the environmental stimuli are such as to develop rational, social and ethical habits rather than the reverse.

We need not think of the will as a deus ex machina, nor even as "a little deity encapsuled in the brain," but rather as the sum of all those psychical processes, such as memory and reason, which regulate behavior. In this sense the will is as free as the mind, and no freer. Indeed the will is the mind acting as internal stimulus, inhibition, regulation; in this sense the existence and power of will is no more to be doubted than the existence of those other mental conditions which we call intellect or memory.

Just as intellect or memory may be trained to accomplish results which would have been impossible to the untrained mind, so will may 
be trained to initiate, inhibit or regulate behavior in a manner quite impossible to one who has not had this training. It is one of the most serious indictments against modern systems of education that they devote so much attention to training memory and intellect and so little attention to the training of will, upon the proper development of which so much depends.

5. Our Unused Talents.-Will is indeed the supreme human faculty, the whole mind in action, the internal stimulus which may call forth all the capacities and powers. And yet the will does not directly create nor even discover these powers; they are produced by the factors of development, by heredity, environment and training; and they are usually discovered by accident or under the stress of necessity. How often have we surprised ourselves by doing some unusual or prodigious task! What we have once done we feel that we can do again. We realize more or less clearly, depending upon our experience, that what we habitually do is far less than we could do. It is this reserve, upon which we can 
draw on special occasions, that gives us the sense of freedom.

In his inspiring address on "The Energies of Men" William James showed that we have reservoirs of power which we rarely tap, great energies upon which we seldom draw, and that we habitually live upon a level which is far below that which we might occupy. Darwin held the opinion, as the result of a lifetime of observation, that men differ less in capacity than in zeal and determination to utilize the powers which they have. In playful comment on the variety and extent of his own life work he said in modest and homely phrase, "It's dogged as does it." It may be objected that the zeal and determination were inherited, but here also the hereditary possibilities become actualities only as the result of use, training, the formation of habits.

It is generally admitted that no constant distinction can be recognized between the brain of a philosopher and that of many a peasant. Neither size nor weight of brain nor complexity of convolutions bears any constant relation to ignorance or intelligence, though 
doubtless an "unlimited microscopist" could find differences between the trained and the untrained brain. The brains of Beethoven, Gauss and Cuvier, although unusually large, have been matched in size and visible complexity by the brains of. unknown and unlearned persons-persons who were richly endowed by nature but who had never learned to use their talents. In all men the capacity for intellectual development is probably much greater than the actuality. 'The parable of the talents expresses a profound biological truth, men differ in hereditary endowments, one receives ten talents and another receives but one; but the used talent increases many fold, the unused remains unchanged and undeveloped. Happy is he who is compelled to use his talents; thrice happy he who has learned how to compel himself! We shall not live to see the day when human inheritance is greatly improved, though that time will doubtless come, but in the meantime we may console ourselves by the thought that we have many half-used talents, many latent capacities, and although we may not be able to add to our inheritance 
new territory we may greatly improve that which we have.

Jennings has pointed out as one of the great tragedies of life the almost infinite slaughter of potential personalities in the form of germ cells which never develop. A more dreadful though less universal tragedy is the loss of real personalities who have all the native endowments of genius and leadership but who for lack of proper environmental stimuli have remained undeveloped and unknown; the "mute, inglorious Miltons" of the world; the Cæsars, Napoleons, Washingtons who might have been; the Newtons, Darwins, Pasteurs who were ready formed by nature but who never discovered themselves. Onè shudders to think how narrowly Newton escaped being an unknown farmer, or Faraday an obscure bookbinder, or Pasteur a provincial tanner. In the history of the world there must have been many men of equal native endowments who missed the slender chance which came to these. We form the habit of thinking of great men as having appeared only at long intervals, and yet we know that great crises al- 
ways discover great men. What does this mean but that the men are ready formed and that it requires only this extra stimulus to call them forth? To most of us heredity has been kind-kinder than we. know. The possibilities within us are great but they rarely come to full epiphany.

What is needed in education more than anything else is some means or system which will train the powers of self discovery and self control. Easy lives and so-called "good environment" will not arouse the dormant powers. It usually takes the stress and strain of hard necessity to make us acquainted with our hidden selves, to rouse the sleeping giant within us. How often is it said that the worthless sons of worthy parents are mysteries; with the best of heredity and environment they amount to nothing, whereas the sons of poor and ignorant farmers, blacksmiths, tanners and backwoodsmen, with few opportunities and with many hardships and disadvantages, become world figures. Probably the inheritance in these last named cases was no better than in the former, but the environment 
was better. "Grood environment" usually means easy, pleasant, refined surroundings, "all the opportunities that money can buy," but little responsibility and none of that self discipline which reveals the hidden powers and which alone should be counted good environment. Many schools and colleges are making the same mistake as the fond parents; luxury, soft living, irresponsibility are not only allowed, but are encouraged and endowed-and by such means it is hoped to bring out that in men which can only be born in travail.

'The chief educational value of athletics is found in this that it teaches self control. But in great athletic contests the self control of the spectators is usually inversely proportional to that of the players, and while excess of stimuli may lead to wholesome and beneficial reactions in the players it frequently leads to excess of stimulants and to other injurious reactions in the spectators. But college athletics has this much at least in its favor, it trains men who take part in the contests to do their best, to subordinate pleasure, appetite, the desire for a good time, to one controlling purpose; it 
trains them to attempt what may often seem to them impossible, to crash into the line though it may seem a stone wall, to get out of their bodies every ounce of strength and endurance which they possess. Such training makes men acquainted with their powers and teaches courage, confidence and responsibility. If only we could make young persons acquainted in some similar way with their hidden mental and moral powers what a race of men and women might we not have without waiting for that uncertain day when the inheritance of the race will be improved! Whatever the stimulus required, whether pride or shame, fear or favor, ambition or loyalty, responsibility or necessity, education should utilize each and all of these to teach men self knowledge and self control.

But it will be said that self control depends upon inheritance, that strong wills and weak wills are such because of heredity. It is true that one man may be born with a potentiality for self control which another man lacks, but in all men this potentiality becomes actuality only through development, one of the princi- 
pal factors of which is use or functional activity. An amazing number of persons have but little self control. Is this always due to defective inheritance, or is it not frequently the result of bad habits, of arrested development? 'To charge defects at once to heredity removes them from any possible control, helps to make men irresponsible, excuses them for making the least of their endowments. To hold that everything has been predetermined, that nothing is self determined, that all our traits and acts are fixed beyond the possibility of change is an enervating philosophy and is not good science, for it does not accord with the evidence. It is amazing that men whose daily lives contradict this paralyzing philosophy still hold it, as it were in some watertight compartment of the brain, while in all the other parts of their being their acts proclaim that they believe in their powers of self control: they set themselves hard tasks, they overcome great difficulties, they work until it hurts, until they can say with Johannes Müller, Es klebt Blut an der Arbeit, and yet in the philosophical compartment of their minds 
they can say that it was all predetermined in heredity and from the foundations of the world.

Whether all the phenomena of life and of mind can be explained on the basis of a purely mechanistic hypothesis or not, that hypothesis must square with the facts and not the facts with the hypothesis. It has always been true of those who "sat apart and reasoned high of fate, free will, foreknowledge absolute" that they have "found no end in wandering mazes lost." Whatever the way out of these mazes may be,- whether it. be found in the varied responses of an organism to the same stimulus, to the introduction of memory, intelligence and reason as internal stimuli, or to some form of idealism which finds necessity not in nature but in the spectator, and freedom not in the spectator but in the agent,-it is true for those who do not "sit apart and reason high," but who deal merely with evident phenomena, that the way out of these mazes is not to be found in denying the reality of inhibition, attention and control. Because we can find no place in our philosophy and logic for self de- 
termination shall we cease to be scientists and close our eyes to the evidence? The first duty of science is to appeal to fact and to settle later with logic and philosophy. Is it not a fact that the possibilities of our inheritance depend for their realization upon development, one of the most important factors of which is use, functional activity in response to stimuli? Is it not a fact that in many animals behavior is modifiable and that impulses may be inhibited and controlled? Is it not a fact that experience, intelligence, will are factors in human behavior and that by means of these men are often able to choose between alternatives and so to control their own activities as well as external phenomena? Is it not a fact that our capacities are very much greater than our habitual demands upon them? Is it not a fact that belief in our responsibility energizes our lives and gives vigor to our mental and moral fiber? Is it not a fact that shifting all responsibility from men to their heredity or to that part of their environment which is beyond their control helps to make them irresponsible? 
This debilitating philosophy in which everything is predetermined, in which there is no possibility of change or control, in which there is hypertrophy of intellect and atrophy of will is a symptom of senility whether in men or nations. We need to return to the joys of a childhood age in which men believed themselves free to do, to think, to strive, in which life was full of high endeavor and the world was crowded with great emprise. We need to think of the possibilities of development as well as of the limitations of heredity. Chance, heredity, environment have settled many things for us; we are hedged about by bounds which we cannot pass, but those bounds are not so narrow as we are sometimes taught and within them we have a considerable degree of freedom and responsibility.

$$
\text { "That which we are we are, }
$$

One equal temper of heroic hearts

Made weak by time and fate, but strong in will

To strive, to seck, to find, and not to yield." 


\section{The Individual and the Race}

There is a larger freedom and a greater responsibility than that which characterizes the individual. What the individual cannot do because of weakness, ignorance, self interest, short life, society can accomplish with the strength, wisdom, and interest of all, and through long ages of time. There are many grades of organization from the bacterium to the vertebrate, from the germ cell to the man. Society is the last and highest grade of organization and its freedom and responsibility are to those of the individual very much as the freedom and responsibility of the developed man are to those of the germ cell from which he came. Out of the correlations, differentiations and integrations of persons has grown this higher type of organization which we call society.

1. The Conflict between the Freedom of the Individual and the Good of Society.-The freedom, power and responsibility of society are founded upon limitations of individual free- 
dom for the good of the race. Among social animals, such as ants and bees, there is so much instinct and so little reason and freedom that there is practically no conflict between the individual and the race, but with the increase of intelligence and freedom among men there has developed an increasing conflict between the individual and society. So far as social limitations are artificial, selfish, for the good of a few rather than of all, this conflict of the ages, this struggle to be free has been the crowning glory of mankind. The struggle for freedom from tyranny in thought and speech, in religion, government and industry, no less than for the freedom that comes by the conquest of nature, is one of the greatest achievements of the human race.

But social restrictions on individual freedom are not all artificial and selfish. Some of them are absolutely essential not only to the welfare but even to the continued existence of the race, and when demands for individual freedom go to the extent of fighting against these racial obligations they become a serious menace to mankind. 
2. Perpetuation and.Improvement of the Race the highest Ethical Obligation.-Among all organisms the race or species is of paramount importance. Race preservation, not self preservation, is the first law of nature. Among all organisms the perpetuation and welfare of the race are cared for by the strongest instincts. In very many species of animals reproduction means the death of the individual. The breeding instinct drives every male bee, every male and female salmon, to its certain death in order that the race may be perpetuated. Among the higher organisms the strongest of all the instincts are those connected with reproduction. But in the human species intellect and freedom come in to interfere with instinct. 'The reproductive instincts are not merely controlled by reason, as they should be, but to an alarming extent they are thwarted and perverted among intelligent people.

The struggle to be free is part of a great evolutionary movement, but the freedom must be a sane one which neither injures others nor eliminates posterity. The feminist movement 
in so far as it demands greater intellectual and political freedom for women may be a benefit to the race but in so far as it demands freedom from marriage and reproduction it is suicidal. The cry of Rachel, "Give me children or I die," has been turned by many modern women to, "I'd rather die than have children." If the demand for individual freedom blinds men and women to their racial obligations the inevitable decadence and extinction of their lines must follow. In every age and country where demands for personal freedom have been most insistent and extreme, where men and especially women have demanded freedom from the burdens of bearing and rearing children as well as from other natural social obligations, the end has been degeneration and extinction.

'This has been the history of many talented races and families of mankind. The decay of the most gifted races of the ancient world, especially those of Greece and Rome, was not due primarily to bad heredity nor to bad material environment but rather to the growth of luxury and selfishness and unrestricted freedom; marriage became unfashionable, immo- 
rality was widespread, and then came sterility and extinction or mixture with inferior stock and degeneracy. And then the barbarian, the immigrant, the natural man, unspoiled by too much freedom and true to his instincts, came in to take the place of the more gifted race. Truly "there is a power not ourselves that makes for righteousness."

In these days when we talk of our race and our civilization as if they were necessarily supreme and immortal it is well to remember that there have been other races and other civilizations that regarded themselves in the same way. "Assyria, Greece, Rome, Carthage, where are they?" And what assurance have we that our race and our civilization will not run a similar course and come to a similar end? May we not surely predict that if we continue to put individual freedom and luxury and selfishness above social obligations our race and civilization will also see the writing on the wall, "Thou are weighed in the balances and art found wanting"? In these days when individuals are demanding more and more freedom it is well to remember that "the 
best use that man has made of his freedom has been to place limitations upon it." Again and again, age after age, men and families and nations have gone up to a climax of greatness and then have declined, while other unknown men have taken their places. Greatness has not for long perpetuated itself. An epitome of human history is contained in the words, "He hath put down the mighty from their seats and hath exalted them of low degree."

It may well be asked by those who are interested in breeding a better race of men whether such a thing is possible, whether the better race may not be lacking in vitality or fertility or morality and thus be doomed to an early end. Although this has been the fate of many gifted races of the past I do not think that it was a necessary fate. The history of domesticated animals and of cultivated plants, and especially the recent notable advances in genetics, indicate what eugenics might do for the human race. In time, under intelligent guidance, the worst qualities of the race might be weeded out and the best qualities preserved. This is the goal toward which intelligent effort should be directed. This should be the su- 
preme duty of society and of all who love their fellow men.

But I think that notable human improvement can take place only upon two conditions: (1) The physical and intellectual improvement of the individual through environment and training must not interfere with his racial and ethical obligations. Individual freedom must be subordinated to racial welfare. (2) The promotion of human evolution must be undertaken by society as its greatest work. Not only has society greater freedom and greater power than the individual but it persists while men come and go.

Our hereditary lines are so interwoven with those of other races and will be so entangled with other lines in the future that any selfish or narrow policy of improving our family or class can have little permanent value. We shall rise only as the race rises. Indeed when we consider all the influences of our fellow men upon our development, when we consider our hereditary connections with multitudes of men and women of the past, when we think of the nexus of hereditary strands which are woven 
into our personalities and which will be continued through us to many future generations, we realize that after all the individual is not really a separate and independent being, but a minor unit in the great organism of humanity, and that his greatest duty is to transmit unimpaired and undefiled a noble heritage to generations yet unborn.

It is possible greatly to improve environment. Conditions of life are still hard and cruel for many. A vast amount of good human material is wasted in modern society. As civilization becomes more complex the quantity of human wreckage and garbage ever grows greater. Many useful lives and some great possibilities are blotted out by unfavorable environment. It is the duty of society as far as possible to conserve these lives and to develop these possibilities.

It is possible greatly to improve education, to make it a potent factor in development instead of a conventional veneer. In spite of innumerable educational reforms the essential reform has not yet been reached; mere refinements of bad methods are not real reforms. 
The essence of all education is self discovery and self control. When education helps an individual to discover his own powers and limitations and shows him how to get out of his heredity its largest and best possibilities it will fulfil its real function; when children are taught not merely to know things but particularly to know themselves, not merely how to do things but especially how to compel themselves to do things, they may be said to be really educated. For this sort of education there is demanded rigorous discipline of the powers of observation, of the reason, and especially of the will.

It is possible greatly to improve heredity: (a) By weeding out from the possibility of reproduction human stocks bearing serious defects. (b) By cultivating pride in good heredity and by discouraging voluntary infertility on the part of those who have a goodly heritage. (c) By increasing opportunities for early and favorable marriages. (d) By carefully conserving the best human mutations or inherited variations. In this way if in any way the better race will be produced. The 
possible improvements of heredity are great, the possible improvements of environment and training are great, but whether men of the future will be better than those of the past or present is a question not only of genetics but also of ethics.

How better can I close this course of lectures than with the words of Francis Galton, one 'of the greatest students of human heredity and the founder of the science of Eugenics?

"The chief result of these inquiries has been to elicit the religious significance of the doctrine of evolution. It suggests an alteration in our mental attitude and imposes a new moral duty. The new mental attitude is one of a greater sense of moral freedom, responsibility and opportunity; the new duty which is supposed to be exercised concurrently with, and not in opposition to the old ones upon which the social fabric depends, is an endeavor to further evolution, especially that of the human race." 



\section{REFERENCES TO LITERATURE}

The following list of books and publications includes only those works which are referred to most frequently in the preceding pages. Several of the books cited, particularly those by Plate and Morgan, contain extensive bibliographies. Those desiring to become more fully acquainted with books and articles dealing with the subjects of heredity and development are referred to the larger works which are listed here.

\section{Books and Larger Works}

Bateson, W. Materials for the Study of Variation, London, 1894:

Bateson, W. Problems in Genetics. Yale Univ. Press. 1913.

Bateson, W. Mendel's Principles of Heredity. 3rd Impression, Cambridge, 1913.

Baur, E. Einführung in die experimentelle Vererbungslehre. Berlin, 1911.

Castle, W. Heredity in Relation to Evolution and Animal Breeding. New York, 1912.

Castle, W. E.; Coulter, J. M.; Davenport, C. B.; East, E. M.; Tower, W. L. Heredity and Eugenics. Chicago, 1912.

Correns, C. Die Neuen Vererbungsgesetze. Berlin, 1912.

Darbishire, A. R. Breeding and Mendelian Discovery. London, 1911. 
Darwin, C. Animals and Plants under Domestication. New York, 1887.

Davenport, C. B. Heredity in Relation to Eugenics. New York, 1911.

De Vries, H. Intracellular Pangenesis. Chicago, 1910.

De Vries, H. Die Mutationstheorie. Leipzig, 1901. De Vries, H. Plant Breeding. Chicago, $190 \%$.

Doncaster, L. Heredity in the Light of Recent Research. Cambridge, 1911.

Driesch, H. The Science and Philosophy of the Organism. Gifford Lectures, London, 1908.

Ellis, H. The Task of Social Hygiene. London, 1912.

Ellis, H. The Problem of Race Regeneration. New York, 1911.

Forel, A. The Sexual Question. New York, 1908. Galton, F. Inquiries into Human Faculty. New York, 1883.

Galton, F. Natural Inheritance. London, 1889. Galton, F. Hereditary Genius. London, 1892. Galton, F. Essays in Eugenics. London, 1909. Goddard, H. H. The Kallikak Family. New York, 1912.

Goldschmidt, R. Einführung in die Vererbungswissenschaft. Leipzig, 1911.

Häcker, V. Allgemeine Vererbungslehre. Braunschweig, 1912.

Hertwig, O. Allgemeine Biologie. Jena, 1909. Johannsen, W. Elemente der exakten Erblichkeitslehre, 2d Auf. Jena, 1913.

Kellicott, W. E. The Social Direction of Human Evolution. New York, 1911.

Lock, R. H. Variation, Heredity and Evolution. New York, 1911. 
Loeb, J. Comparative Physiology of the Brain and Comparative Psychology. New York, 1900.

Loeb, J. The Dynamics of Living Matter. New York, 1906.

Loeb, J. The Mechanistic Conception of Life. Chicago, 1911.

Loeb, J. Artificial Parthenogenesis. Chicago, 1913. Metchnikoff, E. The Nature of Man. Chicago, 1903.

Morgan, T. H. Heredity and Sex. New York, 1913.

Mott, F. W. Heredity and Eugenics in Relation to Insanity. London, 1912.

Nägeli, C. Mechanische-Physiologische Theorie der Abstammungslehre. München, 1884.

Plate, L. Vererbungslehre. Leipzig, 1913.

Problems in Eugenics. Papers communicated to 1st International Eug. Cong. London, 1912.

Punnett, R. C. Mendelism. London, 1911.

Rignano, E. The Inheritance of Acquired Characters. Chicago, 1911.

Romanes, G. J. Darwin and After Darwin. Chicago, 1892.

Saleeby, C. W. Parenthood and Race Culture. New York, 1909.

Semon, R. Das Problem der Vererbungslehre erwörbener Eigenschaften. Leipzig, 1912.

Spencer, H. Principles of Biology. New York, 1883.

Thompson, J. A. Heredity. Edinburgh, 1908.

Thorndike, E. L. Animal Intelligence. New Y'ork, 1911.

Treasury of Human Inheritance. London, 1912.

Walter, H. E. Genetics. New York, 1913. 
Weismann, A. The Germ Plasm. New York, 1893. Weismann, A. Essays on Heredity. Oxford, 1889. Wilson, E. B. The Cell in Development and Inheritance. New York, 1900.

Woods, F. A. Heredity in Royalty. New York, 1906.

\section{Monographs and Papers}

Bardeen, C. R. Abnormal Development of Toad Ova fertilized by Spermatozoa exposed to the Roentgen Rays. Jour. Exp. Zool., 4, $190 \%$.

Baur, E. Vererbungs und Bastardierungsversuche mit Antirrhinum. Zeit. f. induk. Abstam. 3, 1910. Boveri, Th. Zellen Studien. Die Entwicklung dispermer Seeigel-Eier, etc. Jena, $190 \%$.

Broman, I. Ueber geschlechtliche Sterilität. Wiesbaden, 1912.

Brooks, W. K. Are Heredity and Variation Facts? Address before 7 th Internat. Zoological Congress, $190 \%$.

Castle, W. E. Studies of Inheritance in Rabbits. Carnegie Inst. Wash. Publ. 114, 1909.

Castle, W. E. and Phillips, J. C. On Germinal Transplantation in Vertebrates. Carnegie Inst. Wash. Pub. No. 144, 1911.

Cattell, J. McK. The Causes of the Declining Birth Rate. Proc. First National Conference on Race Betterment. Battle Creek, 1914.

Conklin, E. G. Embryology of Crepidula. Jour. Morph. 13, $189 \%$.

Conklin, E. G. The Cause of Inverse Symmetry. Anat. Anz., 1903.

Conklin, E. G. The Organization and Cell-Lineage 
of the Ascidian Egg. Jour. Acad. Nat. Sci. Phila., 1905.

Conklin, E. G. Experimental Studies on Nuclear and Cell Division. Ibid., 1912.

Conklin, E. G. The Mutation Theory from the Standpoint of Cytology. Science, 21, 1905.

Conklin, E. G. The Mechanism of Heredity. Science, 27, 1908.

Conklin, E. G. Heredity and Responsibility. Science, 37, 1913.

Correns, C. Zur Kenntnis der scheinbar neuen Merkmale der Bastarde. Ber. D. bot. Ges. 23, 1905.

Davenport, C. B. Inheritance in Poultry. Carnegie Inst. Wash. Publ. 53, 1906.

Davenport, C. B. Heredity of Skin Color in Negro-White Crosses. Carnegie Inst. Wash. Publ. 188, 1914.

Davenport, C. B. Inheritance of Characteristics in Domestic Fowl. Carnegie Inst. Wash. Publ. 121, 1909.

East, E. M., Hays, H. K. Heterozygosis in Evolution and Plant Breeding. Bureau Plant Industry, Bull. 243, 1912.

Fischer, E. Exper. Untersuchungen über der Vererbung erwörbener Eigenschaften. Allg. Z. f. Fntomol. 6, 1901; 7, 1902 .

Gudernatsch, J. F. Feeding Experiments on Tadpoles. II. Amer. Jour. Anat. 15, 1914.

Guthrie, C. C. Further Results of Transplantation of Ovaries in Chickens. Jour. Exp. Zool. 5, 1908. Guyer, M. F. Accessory Chromosomes in Man. Biol. Bull. 19, 1910.

Harrison, R. G. Experimentelle Untersuchungen, etc. Arch. f. Mik. Anat. 63, 1903. 
Harshberger, J. W. Maize; A Botanical and Economic Study. Cont. from Bot. Lab. Univ. of Penna., 1893.

Hering, E. On Memory and the Specific Energies of the Nervous System. Chicago, 1897.

Hertwig, O. Neue Untersuchungen über die Wirkung der Radiumstrahlung auf die Entwicklung tierischer Eier. Sitz. d. Kgl. Preuss. Akad. d. Wissenschaften, 29, 1910.

Hertwig, O. Keimesschädigung durch chemische Eingriffe. Ibid., 30, 1913.

Hertwig, R. Ueber den derzeitigen Stand des Sexualitätsproblems. Biol. Centralblatt 32, 1912.

Hoppe, H. Die Tatsachen über den Alkohol, 4 Aufl. München, 1912.

Huxley, T. H. Evolution and Ethics. Romanes Lecture, 1893.

James, W. The Energies of Men. Science, v. 25, $190 \%$.

Jennings, H. S. Behavior of the Lower Organisms. New York, 1906.

Jennings, H. S. Heredity, Variation and Evolution in Protozoa. Proc. Am. Philos. Soc. 47, 1908.

Jennings, H. S. Experimental Evidence of the Effectiveness of Selection. Amer. Nat. 44, 1910. Jennings, H. S. Heredity and Personality. Science, 34, 1911.

Johnson, R. Marriage Selection. Jour. Heredity, $5,1914$.

Jordan, D. S. The Human Harvest, Boston, 1907. Jordan, H. E. The Biological Status and Social Worth of the Mulatto. Pop. Sci. Monthly, 1913. Kammerer, P. Direkt induzierte Farbanpassungen und deren Vererbung. Zeit für Ind. Abstl. 4, 1911. 
King, H. D. Studies on Sex Determination in Amphibians. Biol. Bull. 16 and 20. Jour. Exp. Zool. 12. 1909, 1911, 1912.

Lang, A. Vorversuche zu Untersuchungen über die Varietätenbildung von Helix hortensis und nemoralis. Festschr. f. Häckel. Jena, 1904.

Lillie, F. R. The Mechanism of Fertilization in Arbacia. Jour. Exp. Zool. 1914.

MacDougall, D. T. Alterations in Heredity induced by Ovarial Treatment. Bot. Gaz. 51, 1911.

MacDowell, E. C. Size Inheritance in Rabbits. Carnegie Inst. Wash. Publ. 196, 1914.

MacDowell, E. C. Multiple Factors in Mendelian Inheritance. Jour. Exp. Zool., 1914.

Macfarlane, J. M. Contributions to the History of Dionaea muscipula. Contributions Bot. Lab. University Pennsylvania, 1, 1892.

McClung, C. E. The Accessory Chromosome, 'Sex Determinant? Biol. Bull. 3, 1902.

Mendel, G. Versuche über Pflanzenhybriden. Verh. naturf. Ver. Brünn, 4, 1866.

Montgomery, T. H. Human Spermatogenesis. Jour. Acad. Nat. Sci. Phila. 15, 1912.

Morgan, T. H. A Biological and Cytological Study of Sex Determination in Phylloxerans and Aphids. Jour. Exp. Zool., 7, 1909.

Mulsow, K. Der Chromosomencyclus bei Ancyracanthus cystidicola Rud. Arch. f. Zellf., 9, 1912.

Nettleship, E. Some Hereditary Diseases of the Eye. Trans. Ophthal. Soc. 29, 1909.

Nilsson-Ehle, H. Einige Ergebnisse von Kreuzungen bei Hafer und Weizen. Bot. Notiser für 1908.

Osborn, H. F. Cartwright Lectures on Contemporary Evolution in Man, Amer. Nat. 26, 1892. 
Pearl, R. The Mode of Inheritance of Fecundity in the Domestic Fowl. Jour. Exp. Zool. 13, 1912.

Pearson, K. Tuberculosis, Heredity and Environment. London, 1912.

Pearson, K., Nettleship, E., Usher, C. Monograph on Albinism in Man. London, 1911.

Plate, L. Bemerkungen über die Farbenrassen der Hausmaus und die Schreibweise der Erbformeln. Zeit. f. induk. Abstam. 6, 1912.

Rosanoff, A. J. The Inheritance of the Neuropathic Constitution. Jour. Am. Med. Assoc. $58,1912$.

Shull, G. H. Hybridization Methods in Corn Breeding. Am. Breeder's Mag. 1, 1910.

Stevens, N. M. Studies in Spermatogenesis with Especial Reference to the "Accessory Chromosome." Carnegie Inst. Wash. Publ. 36, 1905.

Stockard, C. R. An Experimental Study of Racial Degeneration in Mammals Treated with Alcohol. Arch. Internat. Med. 10, 1912.

Stockard, C. R. The Experimental Production of

Various Eye Abnormalities, etc. Arch. f. vergleich. Ophthal. 1, 1911.

Summer, F. B. An Experimental Study of Somatic Modifications and their Reappearance in the Offspring. Arch. Entw. Mech. 30, 1910.

Tennent, D. H. Studies in Cytology, I and II. Jour. Exp. Zool. 12, 1912.

Tennent, D. H. The Dominance of Maternal or of

Paternal Characters in Echinoderm Hybrids. Arch. Entw. Mech. 29, 1910.

Tower, W. L. An Investigation of Evolution in Chrysomelid Beetles of the Genus Leptinotarsa. Carnegie Inst. Wash. Publ. 48, 1906. 
Weeks, D. F. The Inheritance of Epilepsy. Problems in Eugenics, 1.

Whitman, C. O. Animal Behavior. Biol. Lectures. Woods Hole, 1899.

Whitney, D. D. The Effects of Alcohol not inherited in Hydatina senta. Amer. Nat. 46, 1912.

Wiesner, J. . Die Elementar-structur und das Wachstum der lebenden Substanz. Wien, 1892.

Wilder, H. H. Duplicate Twins and Double Monsters. Amer. Jour. Anat. 3, 1904.

Wilson, E. B. Some Aspects of Cytology in Relation to the Study of Genetics. Am. Nat., 1912.

Wilson, E. B. Studies on Chromosomes. I-VIII. Jour. Exp. Zool. 2, 3, 6, 9, 13. Jour. Morph. 22. Winiwarter, H. Etudes sur spermatogenèse humain. Archiv d. Biologie, 27, 1912.

Wolff, C. F. Theoria Generationis. 1759.

Woltereck, R. Beiträg zur Analyse der Vererbung erwörbener Eigenschaften; Transmutation und Präinduktion bei Daphnia. Verh. D. Zool. Ges., 1911. 



\section{GLOSSARY}

Accessori y CHRo'-mo-some. An odd chromosome which is found in only half of the spermatozoa of certain animals; see "sex-chromosome."

A-CHRo'-MA-TIN. The non-staining substance of the nucleus as contrasted with the chromatin.

A-chon'-Dro-pla-sy. A condition in which the long bones cease to grow in length at an early age thus producing a dwarf with large body and head but short limbs.

Acquired Character. A character, the differential cause of which is environmental.

Alternative Inheritance. Galton's term for a doubtful kind of inheritance in which all characters are derived from one parent. In present use, Mendelian inheritance.

An'-NI-ON. One of the embryonic membranes of higher vertebrates.

AM-pHi-ox'-us. One of the lowest and simplest animals having a notochord (backbone).

AN-EN-CEPH'-A-LY. The condition of a brainless monster.

Animal pole. That pole of an egg at which the polar bodies are formed.

AN'-LA-GE. The embryonic basis of any developed part. $A-\mathrm{OR}^{\prime}-\mathrm{TA}$. The great artery arising from the heart.

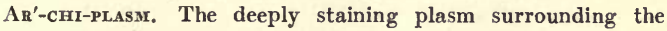
centrosome.

As'-CA-RIs. A genus of round worms which are intestinal parasites.

As'-ca-ris meg-a-lo-ceph'-a-la. A parasite in the intestine of the horse.

As-CrD'-I-AN. A "sea-squirt"; one of the lowest types having a notochord, or elementary backbone. 
As'-TER. The radiating figure surrounding the centrosome in a cell.

As-sim-I-LA'-tion. Conversion of food substances by an organism into its own living substance.

A-sYM'-ME-Try. 'The condition where opposite sides are unlike.

$\mathbf{A} \mathbf{T}^{\prime}$-A-VISM. The condition in which an individual resembles a grandparent, or a more distant ancestor, more than one of the parents.

BI'-o-phores. The ultimate units of life (Weismann).

BI'-VA-LENT CHRo'-Mo-somes. A pair of chromosomes, one maternal the other paternal, temporarily united.

Bras'-To-coel. 'The cavity within a blastula.

BI.As'-TO-DEa'-MIC VEs'-I-CLE. A hollow sphere, formed from the segmented egg of a mammal, which becomes attached to or embedded within the wall of the uterus.

Blas'-TO-PORE. 'I'he mouth of a gastrula.

BLAs'-TU-LA. A mass of cells, usually in the shape of a hollow sphere, formed by repeated divisions (cleavages) of an egg.

Blending Ixmeritance. Galton's term for that kind of inheritance in which the characters of the parents seem to blend in the offspring.

BRACH-Y-DAC'-TY-LISM. The condition of having abnormally short fingers or toes.

CenL. The fundamental unit of structure and function in all living things.

Cen'-Tro-some. The body at the center of radiations in a dividing cell.

CEPH'-A-LO-PoDs. A class of mollusks which includes the squid, cuttle-fish and devil-fish.

CER'E-baAl Gavg'ti-on. 'The brain of an' invertebrate animal.

Character. Any feature or property of an organism.

CHOR'-DA. A cellular rod in vertebrate embryos which forms the basis of the backbone.

Chor'-Date. A member of the highest phylum of the animal kingdom, including all animals having a chorda or backbone. 
Cho'-RI-ON. A tough membrane around an egg secreted by surrounding cells.

Chro'-Ma-tin. The deeply staining substance of the nucleus.

Chro'-mo-somes. Deeply staining bodies found in the nucleus at the time of indirect division.

CIL'-I-A. Minute protoplasmic threads on the surface of a cell which produce movements in the surrounding medium by waving back and forth.

Crass. The chief sub-division of a phylum.

Cleav'-Age. 'The division of the egg cell after fertilization into many cells.

Clep-st'-ne. A genus of leeches.

CoE'-Lom. 'The body cavity.

Continuous variation. A series of minute variations.

Correlative differestiation. Differentiation due chiefly to the interaction of different parts of an organism.

CRE-PID'-U-LA. A genus of marine gastropods.

"Criss-Cross" Ixheritance. Morgan's term for that kind of inheritance in whicn maternal characters are transmitted to sons and paternal ones to daughters.

CTEn'-o-phore. A jelly-sphere; a member of a phylum of marine animals standing above the jelly-fishes.

CY-CLo'-PI-A. A monstrosity in which both eyes have fused into a single one.

CY-TOL'-o-GY. The science which treats of cells.

$\mathrm{Cr}^{\prime}$-ro-plasm. The protoplasm of a cell outside of the nucleus.

DAL'-TON-ISM. That form of color-blindness in which one is unable to distinguish red and green; usually limited to males.

DAR'-WIN-ISM. The doctrine that evolution takes place through natural selection or the survival of the fittest.

Determinants. The units of heredity (Weismann).

Determiner. The differential cause or factor in a germ cell which determines the development of a character.

Dex'-Tral sNail. The usual type of snail in which the shell coils from base to apex in a clockwise direction.

Differentiation. The process of producing specific parts or substances from a general part or substance. 
DI-HX'-BrID. The offspring of parents differing in two characters.

DI-o-NAE'-A. An insect-catching plant, the "Venus Fly-trap." DiP'-Loid. The full number of chromosomes found in the fertilized egg and in all cells derived from this, except the mature germ cells.

Dominant character. A character inherited from one parent which develops to the exclusion of a contrasting character of the other parent.

Dros-OPH'-1-LA. A genus of fruit-flies.

Du'-plex factors or character. A condition where the determiners for a character are derived from both parents.

E-CHi'-No-DERMs. A phylum of marine animals which includes star-fishes and sea-urchins.

E-cor'-o-oY. 'The science which deals with the relations of organisms to one another and to environment.

Ec'-To-DERM. The outer layer of cells of an embryo which gives rise to epidermis, sense organs and nervous system.

EM-BRY-OG'-E-NY. Early development of an egg leading to the formation of an embryo.

EN'-DO-DERM. The inner layer of cells of an embryo, which gives rise to the digestive cells of the alimentary system.

EP-I-GEN'E-sis. The doctrine that the germ is simple and homogeneous and that development consists in the formation of complex parts from the simple germ.

Equation-Division. An ordinary nuclear division in which each chromosome divides equally.

EU-GEN'-ICs. The system of improving 'races by good breeding. EU-THEN'-ICs. The system of improving individuals by good environment.

Ex-0-GAs'-TRU-LA. A gastrula with the endoderm turned out instead of in.

FActor. A specific germinal cause of a developed character.

Fertilization. The union of male and female sex cells.

FLA-GEL'-LUM. A vibratile thread of protoplasm which serves as an organ of locomotion.

Fluctuations. Variations which are not inherited. 
Fol'-Li-cle Cells. Nutritive cells surrounding an ovarian egg. Fraternal Twins. Twins produced from different eggs and showing different hereditary characters.

Functional activity. Use.

GAM'ETE. The mature male or female sex cell.

GANG'-LI-ON. A group of nerve cells.

Gas'-Tro-coex. The digestive cavity of the gastrula.

G'As'-TRU-LA. A stage in development following the blastula, in which the embryo consists of an outer (ectoderm) and an inner (endoderm) layer of cells.

Genes. Factors, units, elements of germ cells which condition the characters of developed organisms (Johannsen).

GE-NET'-Ics. The science which deals with the origin of individuals and particularly with heredity.

GE'-No-TYPE. The germinal type with all its hereditary peculiarities. "The fundamental hereditary constitution of an organism" (Johannsen).

Germ-Plasm. The material basis of inheritance.

Germ-Track. The cell-lineage of the germ cells in a developing animal.

Germinal Units. Hypothetical parts of germ cells which are supposed to have certain specific functions in development. HAE-Mo-PHI'-I-A. An abnormal condition in which the blood clots slowly.

HAP'-Lord. The reduced number of chromosomes in the gametes.

HEREDITY. The appearance in offspring of characters whose differential causes are in the germ cells.

Heritage. The sum of those characters which are inherited by an individual.

HET-ER-O-ZX-Go'-sIs. Hybridization; cross-breeding.

HET-ER-O-ZY'-Gotes. Hybrids resulting from the union of gametes which are hereditarily dissimilar.

Ho-Mo-ZY'-Gotes. Pure-breds resulting form the union of gametes which are hereditarily similar.

Hy'-BRID. The offspring of parents which differ in one or more characters. 
IDentical twins. Twins which have come from a single egg and which show identical hereditary characters.

In'-I-0-PLASM. The germ-plasm or inheritance material.

Inducrion. A modification of the first filial generation caused by the action of environment on the germ cells of the parental generation.

In Herited Character. A character the differential cause of which is in the germ.

Instincts. Complex reflexes involving nerve centers.

Inverse SymMetry. Having the right half of one asymmetrical individual equivalent to the left half of another.

Irritability. Capacity of receiving and responding to stimuli. LA-MARCK'-ISM. The doctrine that evolution takes place through the inheritance of acquired characters.

Localization. The gathering together of particular substances in definite parts of an egg or embryo.

Lor'-I-Go. The squid, a genus of cephalopod mollusks.

MAR-SU'-PI-ALs. A primitive group of mammals, including opposums and kangaroos, which carry the young in a pouch.

MAT-U-RA'-Tion. The final stages in the formation of sex cells, characterized by two peculiar cell divisions.

Me-Ris'-Tic Variation. Variation in the number of parts. Mes'-EN-CHYMe. Loosely scattered cells of the mesoderm.

Mes'-o-Derm. A layer or group of embryonic cells lying between ectoderm and endoderm.

ME-TAB'-O-LISM. Transformations of matter and energy within a living thing.

Mr'-Cro-PYLE. The minute opening in an egg membrane through which the spermatozoon enters.

MI-To'-sis. Indirect nuclear division in which the nucleus is transformed into a spindle and chromosomes; the latter split and the halves move to the poles of the spindle where they form the daughter nuclei.

MoN-O-Hx'-BRID. The offspring of parents differing in one character.

Mon'-o-tremes. The lowest group of mammals, including the duck-bill and the spiny anteater. 
Mor-PHoL'-o-GY. The science which deals with structure and form.

Mus'-ca. A genus of flies including the house-fly.

MU'-TANT. A sudden variation or sport which breeds true.

MU-TA'-Trons. Inherited variations which are more or less striking.

NeC-TU'-RUs. A large salamander; the mud-puppy.

NEM'-A-TODE. A round-worm or thread-worm.

$\mathrm{NE}^{\prime}$-RE-IS. A marine annelid, or ringed worm.

Neural Groove. The groove on the dorsal surface of the embryo of a vertebrate which develops into the brain and spinal cord.

Neural Tube. A tube formed from the neural groove and giving rise to brain and spinal cord.

No'-ro-chond. The cellular rod which forms the basis of the backbone.

Nu'-cLE-Us. The central organ of a cell, composed of chromatin and achromatin.

Nulliplex Factors or Character. A condition in which a character is absent because its determiner is found in neither parent.

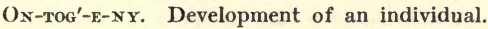

$\mathrm{O}^{\prime}$-o-cyTE. The ovarian egg before maturation (formation of polar bodies).

O-O-GEN'-E-SIS. The development of an ovum from a primitive sex-cell.

O-O-GO'-NI-A. The earliest generations of cells which produce ova; primordial egg cells.

$\mathrm{O}^{\prime}$-o-Sperur. The fertilized egg after union of egg and sperm.

Order. The chief sub-division of a class.

Organization. Differentiation and integration, i.e. different parts united into one whole.

$O_{R-G A N}-O^{\prime}-E-N Y$. The formation of various organs of the body.

OR-THo-GEN'-E-sIs. The doctrine that the course of evolution is definitely directed by intrinsic causes. 
O-VI-PAR'-I-TY. Young brought forth as eggs, i.e., in an early stage of development.

$\mathrm{O}^{\prime}$-vules. The female sex cells of flowering plants with the immediately surrounding parts.

$O^{\prime}$-vum. The female sex cell.

Ox-x-CHRo'-MA-TIN. That portion of the chromatin which does not form chromosomes.

PAN-GEN'-E-sIs. The hypothesis proposed by Darwin that every cell of the body gives off minute germs, "gemmules," which then collect in the sex cells.

PAR-A-ME'-CI-UM. A ciliated protozoan.

PAR-THE-NO-GEN'-E-SIs. Development of an egg without previous fertilization.

Particulate In heritance. Galton's term for that kind of inheritance in which certain characters are derived from one parent and others from the other parent, i.e. Mendelian Inheritance.

PA-THoL'-o-GY. The science which deals with disease.

Phe'-No-TYPe. The developed type in which some of the hereditary possibilities are realized while others remain undeveloped. "Developed, measurable realities" (Johannsen).

PHY-LOG'-E-NY. Evolution of a race or species.

PhyL-LOX'-E-RA. A genus of plant lice.

Phy'-Lum. One of the chief sub-divisions of the animal kingdom.

Pryys-I-or'-o-oy. The science which deals with function.

Plas'-To-somes. Threads or granules in the cytoplasm which are colored by certain dyes.

Polar Bodies. Two minute cells which are separated from the egg in its two maturations divisions.

Po-LAR'-I-TY. The condition where two poles of a body differ; in eggs the two poles are the animal (formative). and the vegetative (nutritive).

Pol'-Len. The male sex cells of flowering plants.

POL-Y-DAC'-TYL-ISM. The condition of having more than the normal number of digits on hands or feet.

PoL- $\mathbf{x}-\mathbf{H X}^{\prime}$-BrID. The offspring of parents differing in more than three characters. 
PRE-For-Ma'-Tion. The doctrine that the fully formed organism exists in the germ, and that development is merely its unfolding.

Pre-in-nuc'-tion. A modification of the second filial generation caused by the action of environment on the germ cells of the parental generation.

PRE-Po'-TEN-CY. The preponderance of one parent over the other in the transmission of hereditary characters.

PRI'-Mates. The highest order of mammals, including monkeys, apes, and man.

Primitre Sex Celis. The earliest recognizable progenitors of the sex cells in development.

$\mathrm{PRO}^{\prime}$-TE-IN. Complex organic substances containing nitrogen, e.g. white of egg.

Pro-TE'-xor. A genus of the true bugs.

Pro'-ro-PLASM. The living material of an organism.

Pro-To-zo'-A. The simplest animals, usually consisting of a single cell.

Py-Lo'-Rus. The narrow opening between stomach and intestine.

Recessive character. An inherited character which remains undeveloped when mated with a dominant character.

Reduction-Division. That maturation division in which the number of chromosomes is halved.

REFLEXes. Relatively simple, automatic responses.

Response. Any activity of an organism called forth by a stimulus.

Reversions. The sudden reappearance of long-lost racial characters.

Segregation. The separation of dominant and recessive characters in the offspring of hybrids.

Self Differentiation. Differentiation due chiefly to intrinsic causes.

Sensitrvity. Capacity of receiving and responding to stimuli.

Sex Chro'-мo-some. The "odd" or accessory chromosome which is supposed to determine sex.

Sex-Lmited. Any character which is found in one sex only. 
SEx-LIN Ked. Any character, the determiner of which is associated with the determiner of sex.

Simplex Factors or Character. A condition where the determiner for a character is derived from one parent only.

Sin'-Is-Tral sNatL. A type of snail in which the shell coils from base to apex in an anti-clockwise direction.

$\mathrm{So}^{\prime}$-MA. The body as contrasted with the germ cells.

So-MAT'-rc. Pertaining to the body, as contrasted with "germinal" pertaining to the germ cells.

So'-MA-To-PLASM. The body-plasm as contrasted with the germ-plasm.

So'-MrTE. $\Lambda$ segment of the body of a segmented animal.

SPER-MA'-TO-CYTES. The mother and grandmother cells of spermatozoa.

SPER-MIA-TO-GEN'-E-SIS. The development of a spermatozoon from a primitive sex cell.

SPER-Ma-To-Go'-NI-A. Primordial sperm cells.

SPER-Ma-To-Zo'-oN. The mature male sex cell.

SPINDLE. The nuclear division figure.

SPI'-REME. A coiled thread of chromatin which appears in the nucleus at the beginning of division.

SPI-RIL'-LA. A spiral type of bacteria.

STEN'-TOR. A ciliated protozoan.

STER-E-o-I'-so-meres. Molecules having different properties dependent upon varying spacial relations of their constituent atoms.

Strm'-U-Lus. Anything acting on an organism which calls forth a response.

STY-E'-LA. A genus of Ascidians.

SYM'-ME-TRY. The condition where opposite sides or poles are alike; bilateral, having equivalent right and left sides.

SYN-AP'-sis. The conjugation of maternal and paternal chromosomes preceding the maturation divisions.

- SYN-DAC'-TYL-ISM. The condition of having webbed fingers or toes.

TE-NEB'-RI-0. A genus of beetles, the larva of which is the common meal worm. 
TER-A-TOL'-o-GY. The science which deals with monstrous or abnormal forms.

TET'-RADs. Bivalent chromosomes which appear 4-parted in the maturation divisions.

To-TIP'-0-TENCE. The capacity of a cleavage cell to give rise to a whole animal.

Tox'-IN. A poisonous substance particularly such as is produced by bacteria.

TRI-HY'-BRID. The offspring of parents differing in three characters.

'Тrорн'-0-вLAst. The outer layer of the blastodermic vesicle of a mammal.

Tro'-PISMs. Automatic movements of organisms toward or away from a source of stimulus.

Unit Character. A character which is inherited as a whole and cannot be sub-divided.

Vegetative pole. The pole of an egg opposite the polar bodies.

VIL'-Lr. Processes which grow out from the embryonic membranes of a mammal and connect it to the walls of the uterus.

Vi-TeL'-Line Membrane. A delicate membrane around an egg secreted by the egg itself.

VIV-I-PAR'-I-TY. Young brought forth "alive," in an advanced stage of development.

$\mathrm{Zx}^{\prime}$-GOTE. The product of the union of male and female sex cells. 



\section{INDEX}

Proper names and titles of sections are in small capitals; page references to illustrations in italic numerals.

Aborigines of Australia 402

New Zealand 402

North America 402

Pacific Islands 402

South America 402

'Tasmania 4.01

West Indies 402

"Accessory" chromosome, 140, $141,143,144,145,166,167$, 271-277

Achondroplasy, 200, 293, 294

Achromatin, 109, 113

differential distribution, 184, in cell body, 181

Acquired Characters, I NheriTANCE OF, 334-351

Darwin on, 335

Lamarck on, 334

Weismann on, 335

definition of, 336, 337

general objections to, 338

specific objections to, 339347

Adaptive responses, 55, 78

Adrenal gland, fed to tadpoles, 326

African negro, 402, 407

in Jamaica, 4.17

in U. S., 417

Age of human race, 398

Albinism, 289, 291, 292

Alcoholism, 206, 295, 450

cause of sterility, still-

births, malformation, dwarfs, 311, 312, 313

induction effect on rotifers, 349 influence on germ cells, 311
Alkaptonuria, 293

Alpine plants, non inheritance of acquired characters, 345

"Alternative" inheritance, 208

Alternatives in development, 462,463

Amalgamation of races, 402, 416-419

American men of science, families of, 4.5

AmpHroxus, cleivage and differentiation, 119

cleavage and gastrulation, 25 , larvae, 27,29

isolated cleavage cells, 314 , $\$ 15$

Ancestors, number of, 216-218

Ancestry, pride of, 429

Ancrracanthus, oogenesis, 134, spermatogenesis, 132

Andalusian fowl, Blue, 266

Anencephaly, 325

Animal pole of egg, 167

Annelid type of egg, 178

Ants and bees, 440, 483

Artificial limitation of families, 437, 438

Artificial parthenogenesis, 314

Artificial Selection, 376 chief factor in production of domestic races, 376

creates nothing, 377-380

isolates pure lines, 378,379

lacking, 409, 411, 412

methods of, 376,377

results of, $377-380$

Ascaris, fertilization of, 112 
"germ track," 126, 127

sex differentiation in, 144

Ascidian egg, 119, 120, 124, 168, $31 \%, 319,320,322$

type, 178

Assheton, cleavage of egg of sheep, 23

Aster, 109, 111

Astral radiations, 110

Atavism, 209

Athens, 406, 407

Athletes, prize, 415

Athletics, educational value of, 4.76, 477

Atrica, illustrious men of, 405407

Automaton, 4.59, 461

Backbone, development of, 28, 29

"Back cross," ratios of, 237, 238

Bacteria, reactions to light, 49

Baldness, inherited, 203

BALZAC, heredity a maze, 297

Barbarism, 363, 396, 411, 486

BARDEEN, X-rays on spermatozoa, 311, 496

Bateson, Blue Andalusian, 266 brachydactyl hand, 292

"homozygote and heterozygote," 228

on Mendelism, 225, 493

Bateson and Punnetr, on sweet pea hybrids, 256, 257, 258

BAUR, factors for flowers of Antirrhinum, 259

induction effects of poor soil, $34.9,493,496$

Beans, pure lines of, 197, 205

Bees, and Ants, 440, 483 influence of food on development, 326 workers, queens, drones, 326

BeEthoven, 473

Behavior, dogs, cats, monkeys, 64

fish and frog, 4.65 lower organisms, 44

modifiability of, 68

Paramecium, 61-63, -66

plasticity of, 71,464

rigidity of, 71

test of psychical processes, 4.8

worms, star-fish, crustacea, vertebrates, 63, 64, 66, 70, 71

BeRKELEY, Bishop, 446

"Biophores" of Weismann, 100

Birthrate and deathrate, normally equal, 432

both decreasing, 433, 434

decreasing most in best families, 434

in Massachusetts, 435

Bivalent chromosomes, 133

Blastula, 25, 26

"Blending" in heritance, 208, 280, 282-287

in length of ears in rabbits, 285

in length of skull in rabbits, 285, 286

in skin color of mulatto, 282-285, 288

"Blood lines," 379

BoNd, negro $X$ white cross, 288

Boule, Chapelle - aux - Saints skull, 397

Boveri, chromosomes differ in value, 156,165

dispermic eggs, 313, 496

B rachydactylism, 199, 292, 293

Brain, development, 28

size and weight, 472,473

Breeder, methods of, 4.16

Broman, death of families, 436 496

Brooks, 214, 496

Buddhistic belief in transmigration, 40

BURBANK, new combinations of characters, 381

mutations, 384 
Canary birds, fed on red pepper, 326

Capacity, greater than realization, 471,472

Captivity, cause of infertility, 436,437

Castre, 493, 496

factors for coat colors of rabbits, 259

recombinations of characters, $381,382,383$

size in rabbits, 285-286

Caster and Primulps, transplanted ovaries of guineapigs, 342-344, 346

Cataract, hereditary, 199, 295

Catrell. birthrate of college graduates, 431, 496

families of scientists, 435

Cause and effect, universality of, 446,447

Causes, natural vs. final, 164

Celibacy, 409, 431

Cell characters inherited, 199

Cell division, 21, 24, 110, 112, $113,114,116,120,122$

differential, 119, 122, 183186

non-differential, 122, 183186

significance of, 122, 123, 125,126

Cell-Lineage, diagram of, 94

Cellular Basis of Heredity, 89

Centrifuged eggs, 321, 322

Centrosomes, 109

equal division of, 123, 184

Chances, definition of, 462,463 infinity of in development, 425,426

Characters, developed not transmitted, 351

individual, 196

inheritance of acquired, 334-351

inherited, definition of, 336 , 337 latent, 209

new in evolution, 388, 394, 395

not independent, 193

patent, 209

racial, 195

Chrud, on chromosomes, 163, 164

Choice of alternatives, 466

Chorea, 295

Chromatin, 24, 109

granules, 110

Chromomeres, equal division of, 184

Chromosomes, 24, 111, 113

abnormal distribution, 311, 313, 391, 392

accessory, 140

bivalent, 133

conjugation of, 131

daughter, 113

diploid, 137

distribution, 115

division, 111, 112, 123, 125, 184

haploid, 137

identity, 113

individuality, 115

maternal and paternal, 117

number of, 111, 145-147

"odd," 140

reduction of, 136

seat of factors, 164-167

shuffle and deal of, 158-160

tetrads, 135

$X$ and $Y, 143,166$

Civilization, means good environment, 304

vs. heredity, 362

will it endure, 396, 486, 401

Classes, hereditary, $4.13,414$ exclusive, 415

Cleavage, of egg, 24, 25, 26

AND DIFFERENTIATION, 110126

differential, 122

non-differential, 122

significance of, $122,123,126$ 
Cleavage cells, differentiation Culture, grades of, 396

$$
\text { of, } 26 \text { Cuvier, 473 }
$$

isolated, development of, Cyclopia, 325

$$
\text { 314-322 }
$$

Clepsine, behavior of, 68

Coeducation, 429, 430

Cold, induction effect on Daphnia, 349

induction effect on mice, 349,350

Coloboma, 200, 296

Color, of skin, hair, eyes, 197, $291,289,292$

Color-blindness, 275-278

Conscrousness, 73-76

continuity of, 74

loss of, 75

subconscious, 73

Control of, alternatives, 466

heredity and development, 5,367

HUMAN EVOLUTION, 403

meaning of, 461

nature, 6

phenomena, 367, 461

self, 461

Correlations of Germ and soma, 162-179

"Correlative differentiation," 331, 332

Correns, 493, 497

rediscovery of "Mendel's Law," 224,

on Mirabilis, 231, 232, 234, 249, 265

Creationism, 41

Creative Synthesis, 37, 84, 180

Crepidura, maturation and fertilization, 106, 107

individuality of germ nuclei, 116

exogastrula of, 324

Cretin, 294, 331

Criminality, 295, 445

CTENOPHORE, egg, 178

Cultivated plants, 367, 368 number of species, 368

Cytoplasmic Correlations, 167 differentiations, 180

inheritance, 175-177

localization, 123

movements, 117

Daltonism, sex-linked, 275, 276, $27 \%, 278$

DAPH NIA, effect of cold on, 349

Darbyshire, 493

DARWIN, hypothesis of pangenesis, 92

on domestic pigeons, 368, 369,370

inheritance of acquired characters, 335

prepotency, 223

reversion, 222, 223

"sports," 210

zeal, 472

organism a microsome, 187

theory of Natural Selection, 377,494

Daughter nuclei, 24, 113

Daven port, degrees of relationship, 217

extra toe in fowls, 267

inheritance of skin color, 283-285

Mendelian inheritance in man, 290

transplanted ovaries, 342

"weakness with strength," 426

white $\times$ black leghorns, 267 494, 497

Davenport and Weeks, epilepsy inherited, 206

Deaf-mutism, 200, 296

Death, of families, 434-439

Deathrate, declining, 4.32-435

Declaration of Independence, 303 
Decline of families and nations, 4.87

Defectives, growing burden of, 411

alarming increase of, 420

Defects, educational influence of, 356

Democracy and human equality, 304

Drscartes, 303

"Determinants" of Weismann, 100,255

Determiners, 101 combinations of, 255 differential causes, 254

DETERMINISM, and Responsibility, 443 definition of, 460

not FatalisM, 460 not predeterminism, 460 of ENviron MENT, 453-459

of HEREDITY, 447-4.53

of personality, 459 scientific, 460

Development, a series of responses, 327,457 alternatives in, 462 definition of, 103 is transformation not new formation, 161 mosaic, 333 not reversible, 462 of function, 36 of personality, 7, 77, 460 potentialities of, 454,455 physiology of, 307 various aspects of, 76, 77 viviparous, 18,19

Development of Body, 8 of Mind, 39-41

Developmental Responses, 310327

AFTER FERTILIZATION, 314 BEFORE FERTILIZATION, 310 DURING FERTILIZATION, 313

DE VRIEs, action of selection, 377,380 fluctuations, 211, 212 induction effects of poor soil, 349

intra-cellular pangenesis, 182

"mutation theory," 211

mutations, 211, 212

Oenothera mutants, 393 , 348

on nuclear control of differentiation, 182

pangenes, 100

rediscovery of "Mendel's Law," 224, 494

Diabetes, 293

Differential division, of Cytoplasm, 126

of cells, 119, 122, 183-187

Differentiation, 37

"correlative," 331, 332

definition of, 103

due to interaction of cell parts, 163, 180, 181, 182 measure of, 186 nuclear control of, 181, 182 "self," 332, 333

Dihybrid, 239, 241, 242, 244

Dimples, inheritance of, 197

DionaeA, reactions of, 56,58

Diploid number of chromosomes, 137

Disease, inheritance of, 200, 202

slight resistance to, 204

Dislocation of organs in centrifuged eggs, 321, 322

Dispermic eggs, 313

Divines, poor health, 357

Division period, 128

Dogs, different races, 368 psychological characters inherited, 204

Domestic Animals, 367-374. degree of change, 368 how produced, 375-377 number of species, 367 progenitors, 367,368 regressive mutants, 394 
Dominance, modifications of, Egg and sperm, hereditary in265

Blue Andalusian, 266 echinoderm hybrids, 268 extra toe in fowls, 267 in red $X$ white Mirabilis, 265

nature of, 278

not fund.rmental, 279

plain $\times$ banded snails, 266 red $X$ white cattle, 266

sex-limited characters, 270 sex-linked characters, 270278

white $\times$ black leghorns, 267

Dominant characters, 227

"extracted," 230

ratio to recessive, 233

Doncaster, 494

Double monsters, 315 , 316, 322, 323

Driesch, 333, 494

Drosophil. , rapid breeding of, 290

sex-linked characters, 166, 271, 272, 273, 275

Dryden, 206

Duplex Characters, 249

Duty, 443, 459

of science, 480

Dwarfs, true, 293, 294

caused by alcohol, 312

Dynamic equilibrium, 10

Ear, development, 28

EAST, heterozygosis, 384, 385, 386,497

Echinoderm type of egg, 178

Ectoderm, 25, 27, 28

Education, and heredity, 428 definition, 354

good and bad, 354, 356, 357 habit formation, 457

limiting activities, 356, 357 more potent in man, 354 needs of 475 possible improvements, 489

equality of, 176

Egg nucleus, 16, 24

Egg organization, types of, 178

Eur.Is, 494

Elsberg, plastidules, 100

Emboîtment, 81

EMBRYOGENY, 26

Embryology, experimental, 307

Embryonic differentiation, processes in, 179

Embryos, double, 315, 316, 322, 323

dwarf, 315

half and three quarter, $31 \%$, 319

Endoderm, 25, 27, 28

"Energies of Men," 472

ENGelmanN, 49

English sparrow in U. S. 432

Engrammes, 348

Environment, acting at sensitive period, 375

definition, 307

direct action on germ cells, 351,348

and education, 360

good and bad, 355, 356, 357, 475,476

influence in producing new races, 375,376

influence on ontogeny, 303, 305

influence on phylogeny, 302 , 305

possible improvements, 489 social institutions and, 304

Epidermolysis, 293

Epigenesis, 81, 83, 161, 180, 452

Epilepsy, 205, 206, 295

Equality of Man, 303, 448

Ethical Obligation, 484

Ethics, 491

Eugenicist, methods of, 416

Eugenical rules as to defects, recessive, 421,422 
serious, 426-428

slight, 426

Eugenics, 4:10-440

contributory, 428-431

declining birthrate, 431-440

definition of, 412

ideals, 412-419

negative, 4.19-423

only hope, 449

positive, $423-428$

Problems in, 495

Euthenics, 352

Evolution, control of, 403, 4.04

experimental, 305, 395

progressive, 400

promotion of, $403,488,491$

requires new characters,

$388,394,395$

retrogressive, 400

Evolution of MaN, 396-403

contemporary, 398

control of, 403, 4.04

future, 399, 400, 412

intelligence in, 403,

natural selection in, 402

prehistoric, 398

Exogastrula, 324

Experience, factor in behavior, 464

learning by, 65,465

Experimental medicine, 5

EXPERTMENTAL STUDY OF INHERTTANCE, 222, 224

Eyes, development, 28 color, 197, 291

lacking, 325

fused together, 325

Facial features, inheritance of, 197

German type, 291

Hapsburg type, 291

Jewish type, 291

Factors of DEVELOPMENT, 79-86

Factors, added in progressive mutations, 394 chemical comparisons, 394, 395

definition of, 101

differential, 264

distribution in maturation and fertilization, 262

dominant and recessive, not modified by union, 343

drop out in regressive mutations, 394

extrinsic and intrinsic, 85

for color developers, 256

of rabbits and mice, 259 , of sweet peas, 256, 257, 258

for pigment, 256

location in cell, 261, 262, 263, 264

Mendelian, 264, 265

multiple, 281-287

nature of, 260

no formation de novo, 395

origin of new, 394, 395

relations to characters, 255 , 256

sex determining, 265

FaHLENBEck, noble families of Sweden, 436

FaradaY, 474

Fat stains, effects on next generation, 350

"Fate of part function of position," 333

of organization, 334

Fecundity, inherited, 204.

Feeble-mindedness, 205, 206, 295

Feminist movement, 484

Fertility, of lower types, 4.11

Fertilization, 15, 16, 107-110 heterogeneous, 313

"Fewer and better children," 439

Fischer, mutations of insects, $348,4.97$

Fluctuations, 211, 212, 389

Food, influence on development in tadpoles, canaries, bees, 326,327 
Foot and Stronell, on chromosomes, 163, 164

on sex-limited characters, 274

Forel, 494

effect of alcohol on germ cells, 313

Formation of Substances in CELLS, 180

Formulae, inheritance, 244, 246,247

Fowls, races of, $371,372,373$ transplanted ovaries, 341, 342

Freedom, and determinism, 460 birth and growth of, 464

definition of, 466

development of, 465

from reproduction, 485

greatest in man, 465

not absolute, 459

not uncaused activity, 466

of action, 72

of individual, 414, 443, 483

of society, 482

Friedrich's Disease, 295

Frog, behavior of, 465

double embryos, 315, 316

Function and structure, correlated, 202

Functional Activity, 327

in human development, 353

Gager, radium on nuclear division, 311

Galton,

age of marriage, 420,431

"Ancestral Inheritance,"

215, 216, 223

artistic faculty, 192, 215

characters, 192

definition of eugenics, 412

diseases, 192, 215

eugenical policy, 419, 420

eye-color, 192, 215

"Filial Regression," 218220, 223 genius inherited, 206, 215

heredity $v s$. civilization, 361

intermarriage of scholars, 415

kinds of inheritance, 208

nature and nurture, 301

on Ancient Greeks, 405, 407

on identical twins, 358

pioneer in heredity, 193

poor health of divines, 357

religious significance of evolution, 491

on "sports," 210, 211

statistical study of inheritance, 214-223

stature, 192, 196, 215

weight of seeds, 192

Gamete, 13

Gardener, methods of, 416

Gastrula, 25, 27

Gates, Oenothera chromosomes, 392

GaUss, 473

"Gemmules," of Darwin, 92, 100

Generalized types, 413, 415

Generations, parental and filial, 228, 230

symbols of, 231

Genes, 101

Genius, and physical defects, 357

hereditary, 206

unstable nervous organization, 206

Genotype, 96, 241, 243, 245, 248, 337,381

Geographical isolation, 416

German Emperor, number of ancestors, 217

Germ cells, 8, 104

alive, 9

complexity of 187

possibilities determined in, 448

potential personalities in, 438

reactions of, 464 
Germ nuclei, 24

individuality of, 115, 116

Germ plasm, in nucleus, 123

Theory of Weismann, 96, 97, 335, 336

Germ vs. Soma, 96

"Germ track," diagram of, 94

Germinal Continuity, 92-97

Glandular secretions, effects of, 329-331

Glaucoma, 296

GodDard, feeble-mindedness inherited, 206, 494

GoLdschnidt, 494

Gonia, 128

Grafts, not modified by stock, 341, 342

Great men, in crises, 474

Greece, decay of, 485,486

Greeks, ancient, 405-408

Growth period, 128

Gudernatsch, effects of food on tadpoles, 326,497

Guinea-pigs, recombinations of characters, $381,382,383$

transplanted ovaries, 342344,346

Guthrie, transplanted ovaries, 341,497

GUYer, on chromosomes of man, 147, 497

Habits, definition, 354 good and bad, 354-356, 464

HÄCKER, 494

Haeckel, plastidules, 100

HAEMOPHILIA, 203, 275, 296

Hair, color, 291 form, 288,291

Half castes, of Australia, 417 of New Zealand, 417

HANSEN, mutations of yeast, 348,391

Haploid number of chromosomes, 137

Hardship, educational value of, 355,475
Harris, induction effects of poor soil, 349

HARRISON, on transplanted limbs, 333 graft of tadpoles, 341, 342, 497

Harsimberger, 498

Harvey, epigram, 9 epigenesis, 81

HATSCHEK, cleavage and gastrulation of Amphioxus, 25

larvae of AмpHioxus, 27, 29

Hereditary lines, interwoven, 488

Hereditary Resenblances axd Differences, 193, 194, 207214

Heredity, and memory, 347

and variation, 194, 212

control of, 387

definition of, 89, 90, 103

includes assimilation, etc., 163

mechanism of, 105 .

more potent than environment, 438

possible improvements, 490 theories of, 105

usually unchanged by environment, 437-447

Heredity and Developirent, 102-104

Heredity aNd ENviroNment, $85,86,302-306$

H E R E D I T Y, Evviron meNT, Training, 357-359

Hering, Organic memory, 59, 498

Heritage, definition of, 103

Hertwig, O., discovery of fertilization, 107

human ovum, 11

idioblasts, 100 .

influence on germ cells of $\mathrm{X}$-rays, radium, chemicals, drug habit, 311,313 , 498

Hertwig, R., inodification of sex ratio, 148-150, 498 
Heterozygosis, 384, 385, 386, 387 Heterozygotes, 228, 230, 241, 243,245

Hindu Dwarfs, 294

Hippocrates, 91

Homo sapiens, 396, 402, 412 NEAN DERTHALENSIS, 397

Homozygotes, 228, 230, 241, 242, 245

"Homunculus," 80

Hoppe, Effect of alcohol on germ cells, 312,498

Human embryo, development, 33,35

Human evolution, Control of, 403

slow, 438

Human faculties, definition, 354

Human Heredity, no improvement in, 405-410

Human oosperm, early development, 31

ovum, 11, 14

spermatozoa, 14

Humidity, influence on mutation, 310

Huntington's Chorea, 295

Huxuey, Evolution and Ethics, 361,498

Hybrid races, quality of, 418

Hybridization, human, 416, 417, 4.18

Hybrids, increased vigor, 384

Hypertrophied heart, not inherited, 338, 340

Hypophysis, effects on development, 331

Hypotrichosis, 293

Hysteria, 206295

Ideals, individual and social, 413,414

Identity, sense of, 75

"Idioblasts" of Hertwig, 100

Idioplasm, of Nägeli, 97

Immigration, 407, 418, 419 laws, 421

Impulses, conflicting, 465

Inbreeding, 414, 4.15, 4.16
INDividual, and Race, 482

minor unit, 488,489

In Dividual Characters, 196

Morphological, 196

Physiological, 202

Psychological, 204

Teratological, 199

Individuals and their characters, 191

"Induction," effect of colored soil, 350

poor, soil, cold, alcohol, 349 not inherited, 351

Inequality of all men, 448

Infancy, prolonged in man, 353, 456

Infertility, causes of, 436

Inheritance, “alternative," 208

"blending,"•"208

of baldness, 203

cell characters, 199

dimples, 197

facial features, 197

fecundity, 204

genius, 206

instincts, 204

intellectual capacity, 205

left-handedness, 204

longevity, 202, 203

moral tendency, 205

obesity, 203

"particulate," 208

pathological characters, 199-202

physiological characters, 202

psychological characters, 204-207

sex-limited and sex-linked, 209

stature, 196, 218, 219, 220 temperament, 205

teratological characters, 199

through cytoplasm, 175-177

tuberculosis, 201, 202

will, 205

INHERItANCE Factors, 252

Inheritance material, 97

seat of, 162 
Inheritance units, 99, 102

Inhibition, 68,464

Insanity, 205, 206, 295

INSTINCTS, 52-56, 78

altruistic, 467

inherited, 204

origin of, 56

reproductive, 484

INTELLECT, 59-66

Intellectual capacity, inherited, 205

genius, 291

mediocrity, 291

Intelligence, factor in control, 461

in evolution of man, 403

Interaction of parts, 328-334

Intra-cellular pangenesis, 182

INVERSE SyMmetry, 170-174,

Irritability, 12, 36

ISOLATION OF SURSTANCES IN

CELLS, 183, 185

in protozoa, 185

J AMes, William, 472, 498

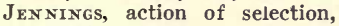
378

behavior of Paramecium, 62

behavior of Stentor, 68

inheritance of size in Paramecium, 198

on Galton's laws, 221

on potential personalities, 4,74

rapid breeding of Paramecium, 290

training of star-fish, 69, 498

JеRоMе, St., 41

Jews, mixture with Gentiles, 417

JoHANNSEN, action of selection, 377,378

genotype and phenotype, 96 inherited weight of seeds, 197

"pure lines," 378, 494

JoH NsON, marriages of college women, 430, 431, 498

JoRdAN, D. S., 498
JORDAN, H. E., 498

Kammerer, effects of colored soil on salamanders, 350 , 498

KeIBEL, development of human embryo, 31, 33, 35

KeLLicotT, 494

Keratosis, 293

KING, modification of sex ratio, $149,150,499$

Korschelt and Heider, Symmetry of egg of Musca, 169

LAMARCK, on inheritance of acquired characters, 334

LAMARCKIAN HYPOTHESIS, 347, 348

Lamarckism, 38

LANG, snail hybrids, 266, 267, 499

Laws on Eugenics, 420, 421

Learning by experience, 65,465

Left-handedness, inheritance of, 204

Lens, cataract, 199, 296

development of, 332

displaced, 296

weight of, 199

LEPTI NOTARSA, selection in 379

Life, artificial production of, 302,304

conditions limited, 453

definition of, 9

maze of, 463

Lillie, fertilization of Nereis, $17,20,21$

on fertilizin, 154, 499

Limbs, transplanted, 332, 333

LiNCOLN, 424

Localization Pattern, 172

in eggs of ctenophore, flatworm, echinoderm, annelid-mollusk, chordate, 172, 178

Localization of substances in cells, 185

Lock, 494.

LOEB, J. Artificial parthenogenesis, 108, 152, 495 
reflexes, 55

tropisms, 54

Logic, as test of truth, 4.51

Lourgo, symmetry of egg, 169

Longevity inherited, 202, 203

Luxury, cause of infertility, 436,437

in education, 475,476

Macfarlaxe, on Dionaea, 56, 499

Mc Clung, on sex determination, 141, 166, 499

Mac Dougali, influence of chemicals on ovules, 311, 499

Mac Dowel., size in rabbits, 285-287, 499

Mc Gregor, Restoration of Pithecanthropus skull, 397

Male babies, greater mortality, 150

Malthus, theory of, 420

Man, controls destiny, 399 dominant races of, 4.01 evolution of, 396-403 extermination of, 401,402 extinct types of, 396, 397 freer than animals, 465 mongrel race, 425 place in nature, 3 prehistoric, 398 races of, 4.00 species of, 396, $39 \tau$ value of races of, 400

Maoris of New Zealand, 402

Marriage, age of, 420, 431 selection, 426-428

Marsupials, 32

Massart, reactions of Spirilifa, 51

Materialism, 44

"Maternal impressions," 34

Matter and mind, 44

Maturation period, 135 divisions, 135, 137

Maze, of heredity, 214, 297 life, 463

Mechaxisy of Development, 179
Mechanism of Heredity, 151

Mechanistic hypothesis, 479

Mediocrity, tendency to, 218

Meischen, On stereoisomeres of albumin, 155

Memory, 56-59, 78

Mendel, abbot of Brünn, 224. dominant and recessive characters, 227-228

dominant: recessive ratios, 228-24.5

experiments on peas, 193, $224,226,499$

inheritance formulae, 246, 247

inheritance units, 255 .

method of work, 225

neglect of discoveries, 225

purity of germ cells, 234, $235^{\circ}$

Mendelian Association and Dissociation, 386-388

Mendelian factors and chromosomes, 165, 166, 262, $263,264,265$

Mendeliax INHeritaxce IN $\mathrm{M}_{\mathrm{AN}}, 288-296$

Table of, $291-296$

MeNDelian PRIXCIPLes, 250

Doninance, 251

Modifications and extensioxs, 252

Segregatiox, 251

UNIT CHARACTERS, 250

Mendelian ratios, simple, 228, 230, 231, 232-236

"back cross," 237, 238

monohybrid, 240, 244

dihybrid, 239, 241, 242, 244

trihybrid, 243, 244, 245

dominant-recessive, 233

departures from, 280, 281, 282

MeNDeisM, 224-251, 297

Mendelssohn, reactions of Paramecium, 53

Meniere's disease, 295

Mentality, influence of education, 303 
Mesoderm, 27, 28

Metabolism, 12, 36

Meтchinikoff, disharmonies in man, 361,495

Metempsychosis, 40

Microscopic particles, smallest visible, 99

Mind and body, 45

Mind, development of, 42, 43

Mirabilis, white-red cross, 231, 232, 234, 249, 265

Mitosis, 21, 24, 110, 112, 113, $114,115,116,120$ significance of, 122, 123, 125,126

"Mneme" theory, 347, 348

Modifiability of behavior, 68

Molecular constitution, stereoisomeres, 155

Molecules, largest known, 99

Monasticism, 409, 430, 431

Monohybrid, 228, 236, 240, 244

Monotremes, 32

Monstrous development, 309, 454,455

cause of, 310

Montgomery, on Chromosomes of man, 147, 499

Moral qualities inherited, 205

Morgan, mutations of insects, $348,391,495,499$

sex chromosome, 166, $167^{\circ}$

sex determination in Phylloxera, 150

sex-linked inheritance, $2 y 1$, 272, 274, 275, 276, 277, 278

rapid breeding of Drosophila, 290

Morphological characters, 196 tests, 39

Mosaic development, 333, 318

Moth and flame, 4.64

Мотт, insanity inherited, 206 495

Mouse, maturation and fertilization, 114
Movements, within eggs and cleavage cells, 50, 106, 110, 117, 183.

effects of stopping, 328 random, 55 of spermatozoa, 49,50

Mulattoes, skin color, 282-285 in Jamaica, 417 in U. S. 4.17

Müller, JohanNes, 478

Mulsow, 132-135, 499

Multiple factors, in oats and wheat, 281

skin color, 282-285

size, 285-287

Multiple sclerosis, 295

MúscA, symmetry of egg, 169

Muscular atrophy, 295

Mutation Theory, 305

Mutations, 209-211

and Fluctuations, 211, 212, 389

progressive and regressive, 394

origin of, 310-314, 348, 388392

Mutilations, not inherited, 339

Myopia, 200

NÄGELI, idioplasm, 97

non-inheritance of alpine habit, $\mathbf{3 4 5}, 495$

Natural selection, 377, 380, 402, 438

nullified, 408-411

Nature, definition of, 446

man part of, 447

mechanistic conception of, 44.6

vs. nurture, 301

stability of, 399

voluntaristic conception of, 444

Necturus, behavior of, 69

Neo-Darwinism, 45

Neo-Lamarckism, 45

NerEIs, spermatozoon of, 17 maturation and fertilization of, 20,21 
Netrueship, hereditary cataract, 198, 199, 499

Neural plate, groove, tube, 28, 29

Neuritis optica, sex-linked, 296

Neuropathy, 295

New England families dying out, 435

NewToN, 474

Night blindness, sex-linked, 296

Nilsson-Ehre, multiple factors, $281,282,499$

Notochord, 29

Nuclear correlations, 162

Nuclear division, indirect, 21, 24, $110,112,113,114,115,116$, $120,122,123,125,126$

Nuclear inheritance theory, 162167

Nucleus, 10, 109, 113 and cytoplasm concerned in heredity, 177,179

Nulliplex character, 249

Obesity inherited, 203

OBSERVATIONS ON IN HERITANCE, 191

"Odd" chromosome, 140

Oenothera, mutants, 392,393 chromosomes of, 392

Oneness of life, 5,47

Ontogeny and Phylogeny, 7, 302

Oocytes, 129 of rabbit, 130

Oogenesis of Ancyracanthus, 134

Oogonia, 128

Oosperm, 13, 16

double cell, 18

individuality of, 18, 19, 22

infection of, 201

Organ-forming substances, 84 in Styela, Amphioxus, frog, 118,119

Organism of humanity, 489

Organization, 10

OrGaNOGENY, 28

Origin of Sex Cells, 126-138 DIVISION PERIOD, 128
Primitive sex cells, 128

Oogonia, 128

Spermatogonia, 128

GROWTI PERIOD, 129

Oocytes, 129

Spermatocytes, 129

Maturation Period, 135

Orthogenesis, 305

Osborn, Cartwright Lectures, 398,499

Otosclerosis, 200, 296

Ovaries, transplanted, $343-346$

Oviparity, 30

Oviparous development, 18, 19

Ovules, 13

Oxychromatin, differential distribution, 184

in cell body, 181

"Pangenes" of deVries, 100

Pangenesis, hypothesis of, 92, 335

Paramecium, avoiding reaction, 62

behavior of, 61

reactions to heat and cold, 53

races differing in size, 198

races of, 205

rapid breeding of, 290

selection in, 378

trial and error, 63

Parthenogenesis, 108

"Particulate" inheritance, 208

Partition walls between cells, 185

Pasteur, 474

Pathological characters inHERITED, 199-202

PearL, action of selection, 379, 500

Pearl and Parshley, modification of sex ratio, 149

Penrsox, ancestral inheritance, 216

albinism in European family, 292

albinism in Papuan family, 289 
inheritance of tuberculosis, 201,500

statistics, fault of, 221

Pearson and Netrueship, 289, 292,500

Permutations in distribution of chromosomes, 156

Personality, determined by heredity, 4.49

development of, 7, 77, 460

infinity of chances in, 425 , 426

not predetermined, 453

potential, 474

prediction impossible, 424

Phenomesa of Development, 6

Phenotype, 241, 243, 245, 248, 381

vs. genotype, 96

Phylloxera, degeneration of male-producing spermatozoa, 150

Physiological characters, inheritance of, 202

division of labor, 37

processes, 10, 12

states, 68,464

tests, 39,54

units, 100

Pigeons, behavior of, 70, 71 numerous races, 368,369 , 370

Pineal gland, 163

Pithecanthropus erectus, skull, 397

"Plasomes" of Wiesner, 100

Plasticity of behavior, 71

"Plastidules" of Elsberg and Haeckel, 100

Plastosomes, equal division of, 184

Plate, ancestors of German Emperor, 217

factors for coat colors of mice, 259

Mendelian inheritance in man, 290-296, 495, 500

Plato, on transmigration, 40
Polar bodies, 23, 138

Polarity, 167-168

of Styela egg, 118, 120, 121

Pollen, 13

Polydactylism, 199, 293

Polyhybrid, 244

Population, normally stationary, 432-434

of Europe, 433

Poultry, selection for egg production, 379

Preformation, 79-81, 161，452

Preformation and Epigenesis, 83-85

"Preinduction," in Daphnia, 349

Prepotency, 223

Presence and Absence HyPOTHESIS, 248-250

Primitive sex cells, 128

Principles of good breeding, violation of, 4.08

Propagation of worst, 409

Protenor, sex differentiation in, 142

Protoplasm, 9

Psychical Anlagen, 47

Psychical development, table of, 78

Psychological characters inHERITED, 204-207

Punnett, 225, 258, 495

"Pure lines," 378

Puritans and Cavaliers disappearing, 434.

Purity of germ cells, 234, 235, 251

Pythagoras, on transmigration, 40

Race amalgamation, 402 extermination, 402

improvement, $6,487,488$ preservation, 484

Radium, disintegration of atom, $388,395,396$ influence on spermatozoa, 311 
RANa, grafted tadpoles of, 341, 342

Reactions, of germ cells, 43,49 machine-like, 465

Reason, 59-66

Reception cone, 109, 110

Recessive characters, 228 "extracted," 230 ratio to dominant, 233

Reduction of chromosomes, 136 RefleXes, 52-56

Regeneration, in eggs and adults, 318, 321

Reproduction, 12, 36

Responses, varied, 68

Responsibility, 443, 445, 459 definition of, 467

of society, $469,470,482$ varied, 468,469

Retinal degeneration, 295

Retzius, human spermatozoa, 11,14

Reversible changes not inherited, 350

Reversion, 209, 223

Rickets, not inherited, 338, 340 Rigidity of behavior, 71

Rigxayo, "Centro - epigenesis" theory, 347, 495

RoMaxes, $369,370,495$

cattle, $3 \% 4$

fowls, 371, 372

swine, $3 \% 3$

Roмe, decay of, 485,486

RosaxofF, insanity inherited, 206,500

Rotifers, induction effect of alcohol, 349

Salamanders, effects of colored soil on, 350

SALEeBY, 495

Savagery, 363, 396, 411

Scholars, prize, 415

Schultze, double frog embryos, 316

Science, duty of, 480
Segregation, apparent lack of, 280-287

fundamental to Mendelism, 279

of Mendelian factors, 234, 235, 251

of substances in cells, 183

Selective Breeding, only method of improving race, 404,405

Spartan method, 404

Self-control, 471, 475, 477, 478

"Self differentiation," 332, 333

Self discovery, 471,475

Semon, "Mneme" theory, 347, 348,495

Sensitive periods, 310

Sensitivity, 48

differential, 48,52

general, 52

of germ cells, 49

Sex, a Mendelian character, 238, 268, 269

influence of food and temperature, 303

Sex cells, fundamentally alike, 13

Sex Determanation, 138-150

in human embryo, 139

in man, 145, 146, 147

McClung on, 141

WiLson on, 141

Stevexs on, 141

Sex glands, effects on development, 329-331

SeX-linited in Heritance, 209, $268,270,274$

SEX-LINKED IN HERITANCE, 209, 270-278, 296

Sex ratio, modification of, 140 , 148-150

Sexual reproduction, value of, 157,416

Shaw, Bernard, 437

Sheep, cleavage of egg, 23

SHull, heterozygosis, 384 500 
Significance of cleavage, 122, 123,126 of mitosis, 122, 123, 126

Simplex character, 249

Skin color, 197, 289, 291, 292 mulatto, 282-285 influence of light on, 303

Slow breeding of man, 290, 438 Sовотта, fertilization of mouse, 114

Social inheritance vs. germinal, 360-363

Social institutions, deal only with environment, 360

Society, nighest grade of organization, 482

power of, 410

responsibility of, 482

supreme duty of, 487,488 , 491

Soil, poor, induction effect on plants, 349

Somatic Discontivuity, 92,97

Somatoplasm, in cell body, 125

Somites, 27, 29

Sparta, destruction of unfit, 404

Special senses, origin of, 52

Specializea types, 413,415

SPECificity of GeKM Cells, 151161

Spexcer, physiological units, $100,49.5$

Sperm centrosome, 16

Sperm nucleus, 16, 24

Spermatocytes, 129

Spermatogenesis of Ancyracanthus, 182

Spermatogonia, 128

Spermatozoon, 15, 17 formation of, 138

Spina bifida, 325

Spinal cord, development, 28

Spindle, mitotic, 110, 111

Spireme, 111

Sprrilla, reactions to chemicals, 51
“Sports," 210

SraNDFUss, mutations of insects, 348

Star-fish, isolated cleavage cells, 314

Statistical methods, strength and weakness of, 219, 221

Statistical Study of IxHeriTANCE, 214-223

Stature, inheritance of, 196, 218 , 219, 220

tendency to mediocrity, 218 , 220

influence of food on, 303

STENToR, modifiable behavior, 68

Sterile insects, 440

Sterility, 409, 435, 439

Sterilization, 419, 4.21, 422, 439

Stevess, on sex determination, $141,143,166,500$

Stimuli, chemical and physical, 467

conflicting, 68, 464

definition, 308

Detelopmental, 307, 310 chemical, 308 non-specific, 309 physical, 308

external and internal, 67, $457,464,465$

range of, 468

rational, social ethical, 467 summation of, 57

STockard, alcohol on spermatozoa, 311, 312, 500

experimental cyclopia, 153, 325

Structures and functions, reciprocal relations, 38,45

STrela, anterior half-embryos, 319

dislocated organs, 322

egg substances, 117-119 gastrulation and larva, 124 half and three-quarter embryos, $31 \%$ 
maturation, fertilization and cleavage, 119, 120, 121

posterior half-embryos, 320 Summation of Stimuli, 57

Sumare, effect of cold on mice, 349,500

Superman, 412, 439

SwEDEN, extinct noble families, 436

Swine, wild and domestic, 373 SYMMETRY, 168-170

Synapsis, 131

Syndactylism, 199, 293

Tadpoles, fed on thyroid, thymus, adrenal, 326

Talents, unused, 471

parable of, 473

Temperament, inheritance of, 205,291

Temperature, influence on $\mathrm{mu}-$ tation, 310

influence on cell division, 311

Texebrio, sex differentiation in, 143

Tennent, modified dominance in echinoderm hybrids, 267, 500

Teratological characters inherited, 199

Tertullian, 41

Tetrads, 135

Thompson, cross of yellow $X$ green peas, 229

diagram of Galton's 1st Law, 216, 495

'Thomsen's disease, 295

THORNDIKE, behavior of dogs, cats, monkeys, 64,495

"Thoroughbreds," 415

Thymus gland, fed to tadpoles, 326

Thyroid, effects on development, 331 gland, fed to tadpoles, 326
Totipotence, of cleavage cells, $316,318,332$

Tower, action of selection, 379 mutations in Leptinotarsa, $310,311,348,391$

Traducianism, 41

Training of animals, 69

Transmission hypothesis, 91, 92

Treasury of Human Inheritance, 294, 495

Trial and Error, 63

Trihybrid, 243, 244, 245, 381

Triplets, hereditary, 204

Trophic correlations, 329

TropisMs, 52-56

Tschermak, rediscovery of “Mendel's Law," 224

Tuberculosis, inheritance of, 201, 202

Turbellarian type of egg, 178

Twins, fraternal, .324 hereditary, 204 identical, 213, 323, 358, 457

Ultra-microscopic units, 100

Uniqueness of every individual, $155,212,213$

Unit Characters, 250, 252, 253

UNITS OF LIVING MATTER, 97-102 ultra microscopic, 100 units of growth and division, 98, 99

units of heredity, 99-102

Unity of organism, 46

Universal laws, 451

Use and disuse, effects of, 329 effects not inherited, 339

Uterus, attachment of oosperm to, 31

Variability, caused by environment, 388

Variations, continuous, 210 discontinuous, 210

fluctuations, 211, 212

meristic, 210

mutations, 211, 212

"sports," 210 
Varied responses, 68

Vegetative pole of egg, 167, 168

VIVIPARITY, 30

Viviparous development, 18, 19

WALTER, diagram of Galtonian inheritance, 208

filial regression, 220,495

Wars, effects of, 422, 423 shake off social heredity, 363

Wasserman test, 154

WATASE, symmetry of egg of Loligo, 169

WeEKs, 206, 501

Weidal test, 154

Weismans, determinants and biophores, 100, 255

germ plasm theory, 96, 100, 335

hereditary and environmental variations, 212

on differential division of chromosomes, 125

inheritance of acquired characters, 335

nuclear control of differentiation, 181

reduction of chromosomes, 137, 496

Whitman, behavior of clepsine, 68

Necturus, 69

pigeons, 70, 71

freedom and choice, 71, 72, 501

WHIrNEY, induction effects of alcohol, 349, 501
Wresser, plasomes, 100, 501

Wrlder, duplicate twins and double monsters, 323, 501

Wris, 67, 72, 459 absolutely free, 445

defined, 470

good and evil, 445

inherited, 205

nature, expression of, 444

supreme faculty, 471

training of, 470,471

WiLson, distribution of factors, 262

of chromosomes, 263

dwarf and double Amphioxus embryos, 315

on sex determination, 141, $142,144,166,167,496,501$

WINIWARTER, on chromosomes of man, 145-146 oocytes of rabbit, 130, 501

WoLFF, "Theoria Generationis," 82,501

WOLTERECK, induction effects of cold, 349 preinduction, 349,501

Women's Colleges, influence on marriage, 430, 431

Woons, "Heredity in Royalty," 206, 496

$\mathrm{X}$-rays, influence on spermatozoa, 311

$X$ and $Y$ chromosomes, 143, 166

Yolk, influence on size of egg, 13,14

Zygote, 13 



